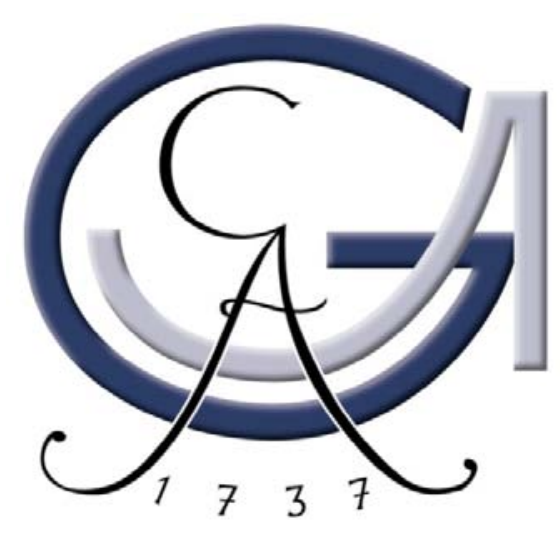

\title{
Analyse zur Rolle von pflanzlichen Wirkstoffen und Histondeacetylase-Inhibitoren auf Wachstumsfaktoren und deren Signalwege in Prostatakarzinomzellen
}

\author{
Dissertation \\ zur Erlangung des mathematisch-naturwissenschaftlichen Doktorgrades \\ "Doctor rerum naturalium" \\ der Georg-August-Universität Göttingen \\ im Grundprogramm Biologie \\ der Georg-August University School of Science (GAUSS)
}

vorgelegt von

Daria Witt

aus Varel

Göttingen, 2012 


\section{Betreuungsausschuss}

Prof. Dr. Dr. h.c. Wolfgang Engel, Abteilung Humangenetik, Universitätsmedizin Göttingen

Prof. Dr. Sigrid Hoyer-Fender, Abteilung Entwicklungsbiologie,

Johann-Friedrich-Blumenbach Institut für Zoologie und Anthropologie, Georg-August-Universität Göttingen

$\underline{\text { Anleiter }}$

Prof. Dr. Peter Burfeind, Abteilung Humangenetik, Universitätsmedizin Göttingen

Dr. Silke Kaulfuß, Abteilung Humangenetik, Universitätsmedizin Göttingen

\section{Mitglieder der Prüfungskommission}

Referent: Prof. Dr. Dr. h.c. Wolfgang Engel, Abteilung Humangenetik, Universitätsmedizin Göttingen

Korreferentin: Prof. Dr. Sigrid Hoyer-Fender, Abteilung Entwicklungsbiologie, Johann-Friedrich-Blumenbach Institut für Zoologie und Anthropologie, Georg-August-Universität Göttingen

Weitere Mitglieder der Prüfungskommission:

Prof. Dr. Peter Burfeind, Abteilung Humangenetik, Universitätsmedizin Göttingen

PD Dr. Michael Hoppert, Abteilung für Allgemeine Mikrobiologie, Institut für Mikrobiologie und Genetik, Georg-August-Universität Göttingen

Prof. Dr. Hubertus Jarry, Abteilung Klinische und Experimentelle Endokrinologie, Universitätsmedizin Göttingen

Prof. Dr. Dieter Kube, Abteilung Hämatologie und Onkologie, Universitätsmedizin Göttingen

Tag der mündlichen Prüfung: 23. Januar 2013 
Tutte le verità sono facili da capire una volta che sono state rivelate.

II difficile è scoprirle.

Alle Wahrheiten sind leicht verständlich, wenn sie aufgedeckt wurden.

Die Schwierigkeit ist es, sie zu entdecken.

Galileo Galilei (1564 - 1642) 


\section{Inhaltsverzeichnis}

Abkürzungsverzeichnis ............................................................. VIII

Fachwortverzeichnis...................................................................... XI

1 Einleitung.......................................................................................

1.1 Das Prostatakarzinom - Inzidenz, Risikofaktoren und Therapie.................... 1

1.2 Zukünftige Therapieansätze ....................................................................... 3

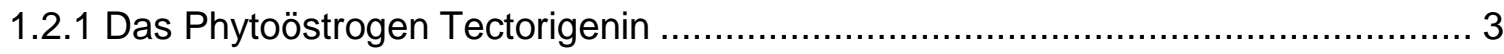

1.2.2 Der Histondeacetylase-Inhibitor Valproinsäure .............................................. 5

1.3 Ziele der Arbeit .......................................................................................... 9

2 Material und Methoden ..............................................................11

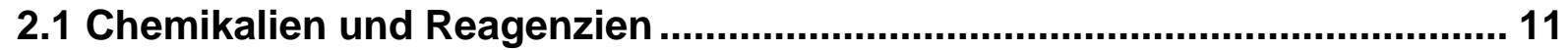

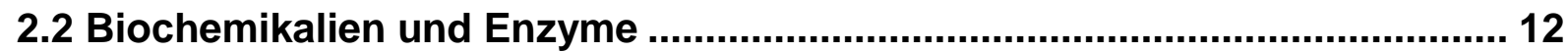

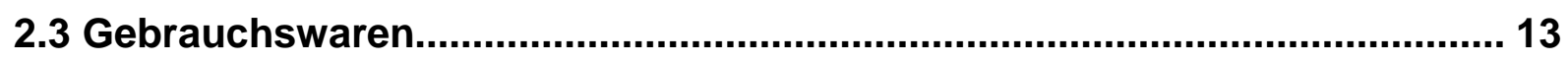

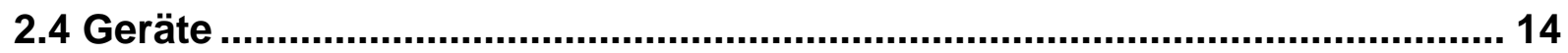

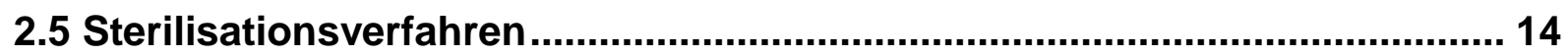

2.6 Gebrauchsfertige Reaktionssysteme.................................................... 14

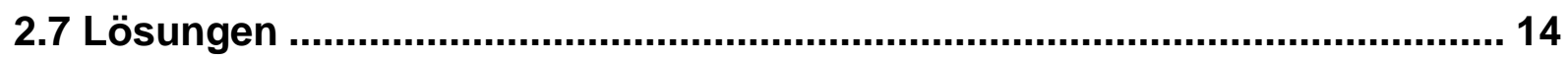

2.8 Medien, Antibiotika, Agraplatten ............................................................ 16

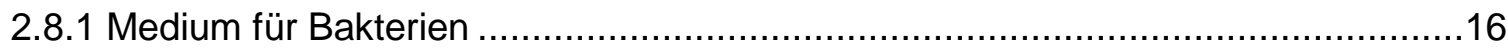

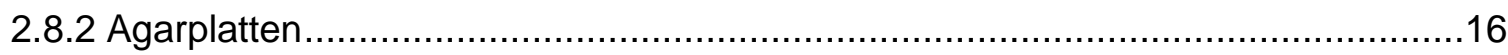

2.8.3 Medien für eukaryotische Zellkulturen ................................................16

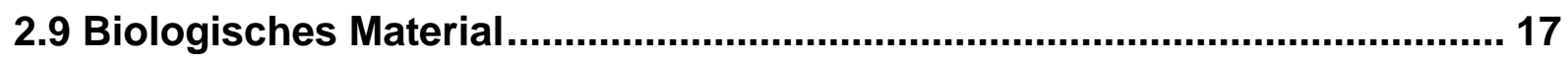

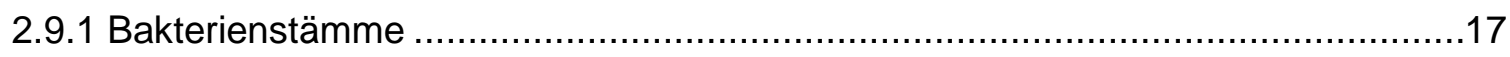

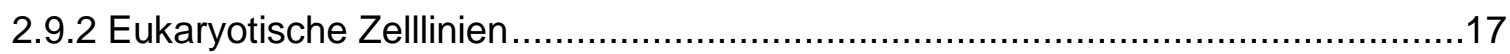

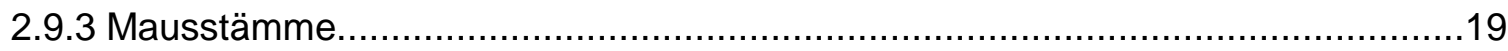

2.9.4 Synthetische DNA-Oligonukleotide...................................................

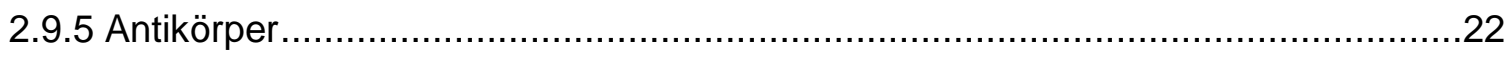


2.10 Datenbanken 23

2.11 Isolierung und Aufreinigung von Nukleinsäuren.

2.11.1 Isolierung von genomischer Gesamt-DNA sowie Gesamt-RNA aus Zellkulturen und anschließender Konzentrationsbestimmung .24

2.11.2 Aufreinigung von Nukleinsäuren aus einer PCR .24

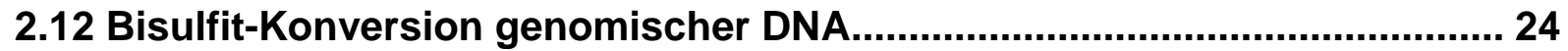

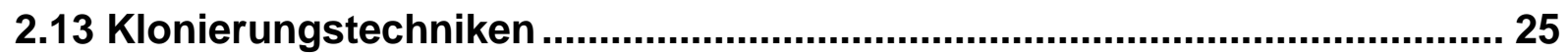

2.13.1 Herstellung von Bakterien-Glycerin-Stocks..........................................25

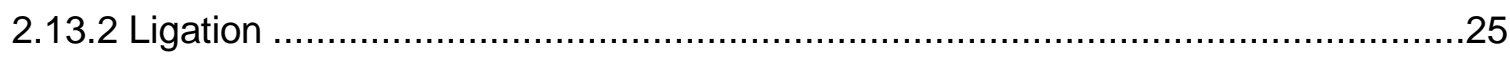

2.13.3 Transformation kompetenter Zellen mit Plasmid-DNA ...................................25

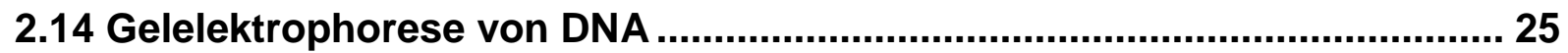

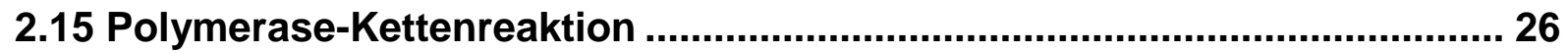

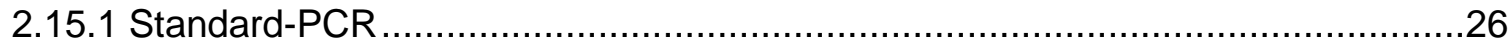

2.15.2 PCR zur Amplifikation einer CpG-Insel im Ccnd2-Promotorbereich....................26

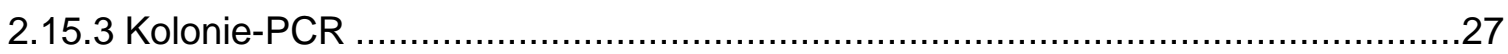

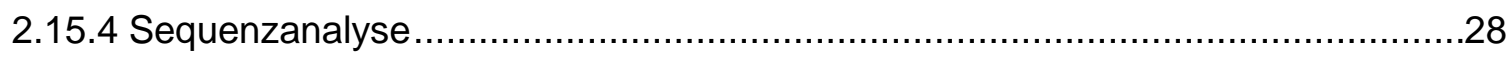

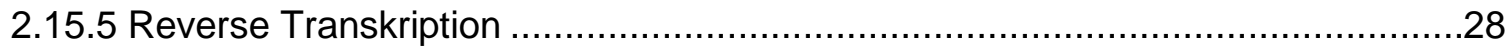

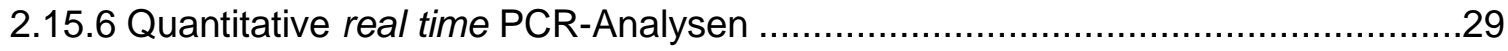

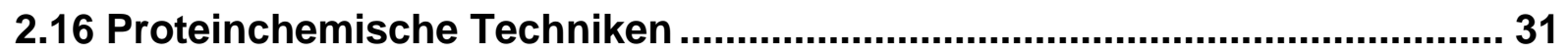

2.16.1 Isolierung von Gesamtprotein aus Zellkulturen.......................................

2.16.2 Konzentrationsbestimmung von Proteinen nach Bradford .............................31

2.16.3 Natriumdodecylsulfat-Polyacrylamidgelelektrophorese ...................................32

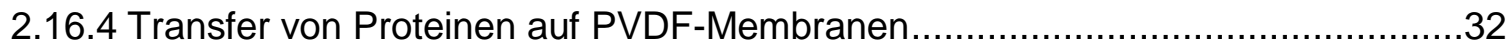

2.16.5 Inkubation von membrangebundenen Proteinen mit Antikörpern......................32

2.17 Chromatinimmunopräzipitation.................................................................. 33

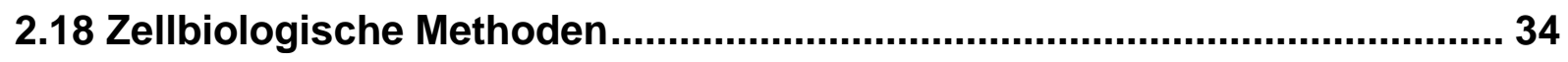

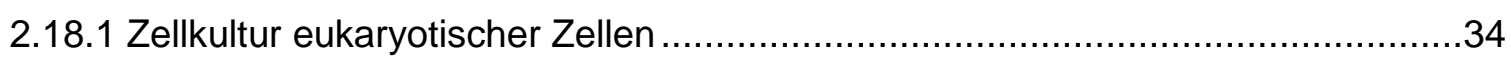

2.18.2 Kryokonservierung und Revitalisierung von eukaryotischen Zellen ...................35 


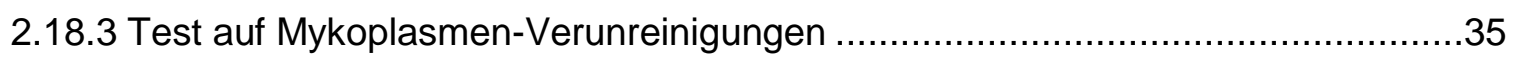

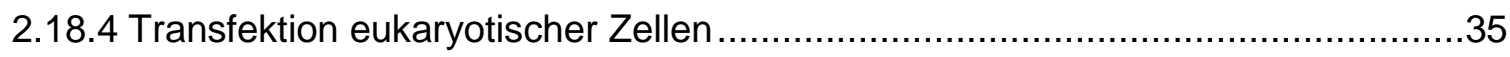

2.19 Funktionelle Analysen eukaryotischer Zellen ....................................... 36

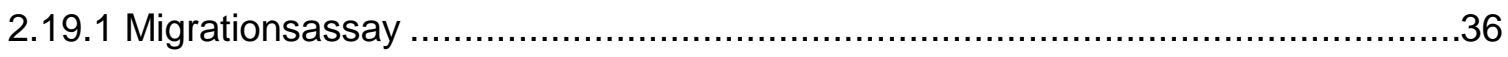

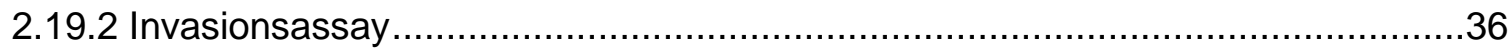

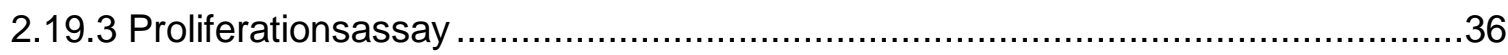

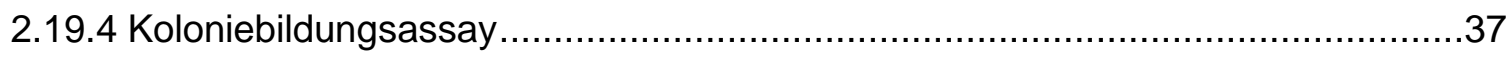

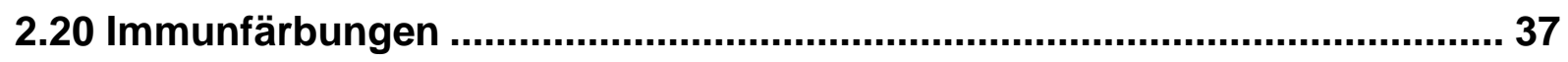

2.20.1 Immunfluoreszenz-Färbung eukaryotischer Zellen .....................................

2.20.2 Immunhistochemische Färbung von Patientengewebe ....................................38

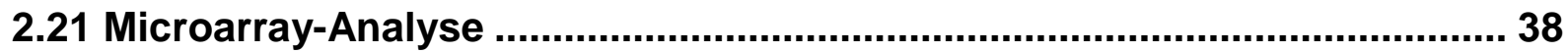

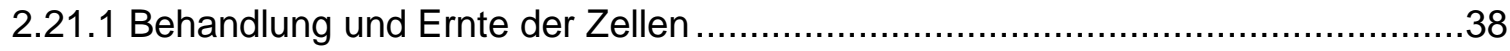

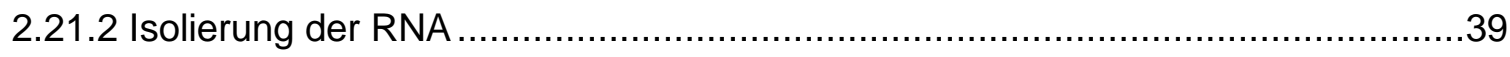

2.21.3 Labeling und Hybridisierung der Proben, Auswertung der Daten......................39

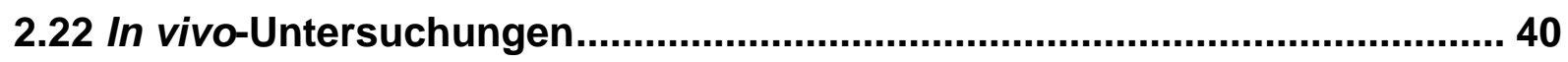

2.22.1 Subkutane Injektion von Zellen in Nacktmäuse .....................................40

2.22.2 Fütterung mit Tectorigenin-haltigem Futter ................................................41

2.22.3 Fütterung von TRAMP-Mäusen mit Valproinsäure über das Trinkwasser ...........41

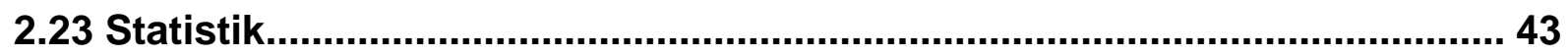

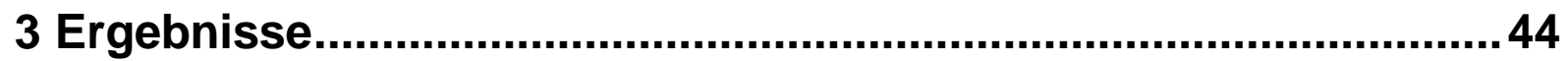

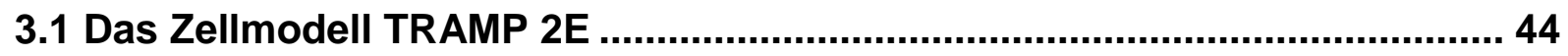

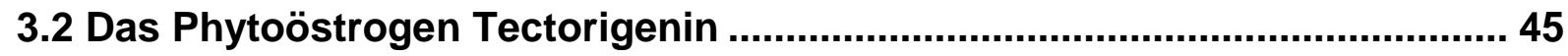

3.2.1 Untersuchungen zum Tectorigenin enthaltenden Gesamtextrakt aus Belamcanda chinensis . . .45

3.2.1.1 Analysen zur Proliferation nach Behandlung von Prostatakarzinomzellen mit Gesamtextrakten aus Belamcanda chinensis

3.2.1.2 Expressionsanalysen nach Behandlung mit Gesamtextrakten aus Belamcanda chinensis in Prostatakarzinomzellen 46 
3.2.1.3 Analysen mittels Immunfluoreszenz zur Veränderung der Expression und Lokalisation von Zielproteinen und der Zellmorphologie nach Behandlung von Prostatakarzinomzellen mit einem Gesamtextrakt aus Belamcanda chinensis

3.2.2 Expressionsanalysen nach Behandlung von Prostatakarzinomzellen mit Tectorigenin verschiedener Bezugsquellen

3.2.3 Microarray-Analyse nach der Behandlung von Prostatakarzinomzellen mit dem

Tectorigenin der Firma Shenzhen ....................................................................55

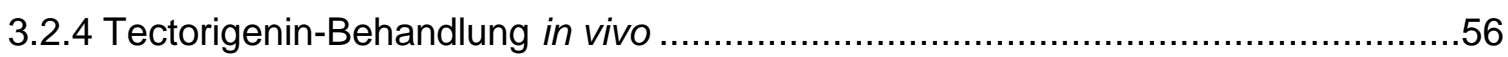

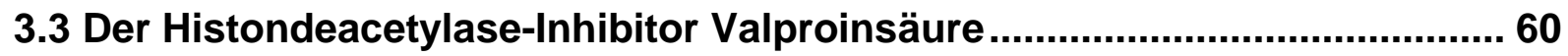

3.3.1 Funktionelle Effekte der Valproinsäure-Behandlung in Prostatakarzinomzellen....60

3.3.1.1 Analyse der Histonacetylierung nach Behandlung von Prostatakarzinomzellen mit Valproinsäure 60

3.3.1.2 Untersuchungen zur Proliferation nach Behandlung von Prostatakarzinomzellen mit Valproinsäure 60

3.3.1.3 Analysen zur Migrations- und Invasionsfähigkeit von primären Prostatakarzinomzellen nach Valproinsäure-Behandlung 63

3.3.2 Expressionsanalysen nach Valproinsäure-Behandlung von primären Prostatakarzinomzellen

3.3.2.1 Analyse der Expression des Androgenrezeptors nach Valproinsäure-

Behandlung von Prostatakarzinomzellen 65

3.3.2.2 Expressionsanalysen zu Apoptose-assoziierten Proteinen nach

Valproinsäure-Behandlung von Prostatakarzinomzellen .... 66

3.3.2.3 Expressionsanalysen zu Zellzyklus-assoziierten Proteinen nach Valproinsäure-Behandlung von Prostatakarzinomzellen 69

3.3.2.4 Expressionsanalysen zu Angiogenese-assoziierten Faktoren nach

Valproinsäure-Behandlung von Prostatakarzinomzellen ..... 70

3.3.3 Expressionsanalysen zu regulatorischen Faktoren nach ValproinsäureBehandlung von Prostatakarzinomzellen

3.3.3.1 Analyse differentiell exprimierter Gene nach Behandlung primärer Prostatakarzinomzellen mit Valproinsäure

3.3.3.2 Studien zur Acetylierung des Promotorbereichs der differentiell exprimierten Gene nach Valproinsäure-Behandlung der Prostatakarzinomzellen 2E ....... 74 
3.3.4 Untersuchungen zum Mechanismus der Re-Expression von Cyclin D2 nach

Valproinsäure-Behandlung von primären Prostatakarzinomzellen 2E

3.3.4.1 Untersuchungen zur spezifischen Re-Expression von Cyclin D2 nach

Valproinsäure-Behandlung der Prostatakarzinomzellen 2E

3.3.4.2 Untersuchung der Passagen-abhängigen Cyclin D2-Expression in den primären Prostatakarzinomzellen 2E

3.3.4.3 Analysen zum Einfluss weiterer Histondeacetylase-Inhibitoren auf die Cyclin D2-Expression in primären Prostatakarzinomzellen 2E

3.3.4.4 Untersuchungen zum Einfluss der Methylierung des Ccnd2-Promotors auf die Re-Expression von Cyclin D2 in den primären Prostatakarzinomzellen 2E ... 81

3.3.4.5 Analyse des Methylierungszustandes einer CpG-Insel im Promotorbereich des Ccnd2-Gens nach Valproinsäure-Behandlung der Prostatakarzinomzellen 2E

3.3.5 Untersuchungen zur Cyclin D2-Expression und Inhibition der Proliferation nach

Valproinsäure-Behandlung von verschiedenen Zelllinien. .88

3.3.5.1 Analyse der basalen Cyclin D1- und Cyclin D2-Expression von kolorektalen Karzinomzellen

3.3.5.2 Valproinsäure-Behandlung verschiedener maligner und nicht-maligner Zelllinien 89

3.3.5.3 siRNA-Studien zur Analyse der Rolle von Cyclin D2 bei der Inhibition der

Proliferation 93

3.3.6 Untersuchung der Cyclin D1- und Cyclin D2-Expression an humanen

Prostatakarzinom-Gewebeschnitten .96

3.3.7 Valproinsäure-Behandlung in vivo über das Trinkwasser .98

4 Diskussion 104

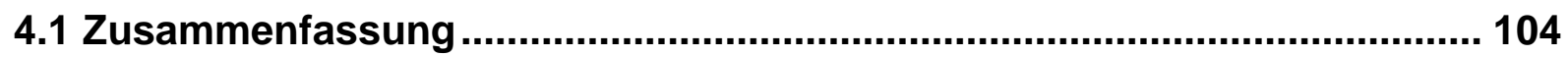

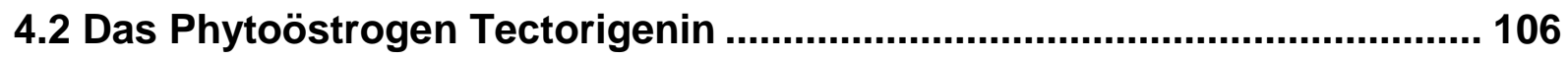

4.2.1 Auswahl einer geeigneten Substanz für weitere Analysen.............................106

4.2.2 Vesikelbildung nach Behandlung mit dem Gesamtextrakt aus Belamcanda chinensis.....

4.2.3 Tectorigenin als potentielles Mittel in der Prävention und Therapie des Prostatakarzinoms. 
4.3 Der Histondeacetylase-Inhibitor Valproinsäure

4.3.1 Einfluss von Valproinsäure auf Proliferation, Migration und Invasion von

Prostatakarzinomzellen

4.3.2 Molekulare Effekte von Valproinsäure auf Signalwege in Prostatakarzinomzellen

4.3.2.1 Der Einfluss von Valproinsäure auf den Androgenrezeptor-Signalweg ........124

4.3.2.2 Der Einfluss von Valproinsäure auf die Apoptose .................................125

4.3.2.3 Der Einfluss von Valproinsäure auf den Zellzyklus................................130

4.3.2.4 Der Einfluss von Valproinsäure auf die Angiogenese..............................136

4.3.2.5 Der Einfluss von Valproinsäure auf epigenetische Mechanismen ...............138

4.3.3 Cyclin D2 als Kandidatengen für die Wirksamkeit von Valproinsäure ................139

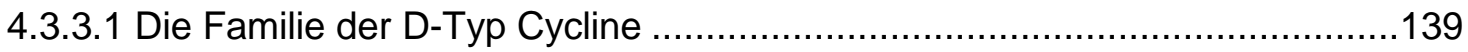

4.3.3.2 Ist Cyclin D2 ein Onkogen oder ein Tumorsuppressorgen? .......................141

4.3.3.3 Valproinsäure induziert die Re-Expression von Cyclin D2 .......................142

4.3.3.4 Ist die Re-Expression von Cyclin D2 in den Prostatakarzinomzellen 2E

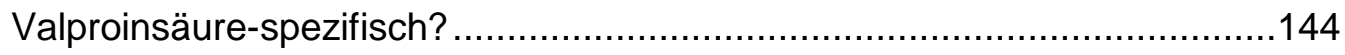

4.3.3.5 Ist die Re-Expression von Cyclin D2 nach Valproinsäure-Behandlung

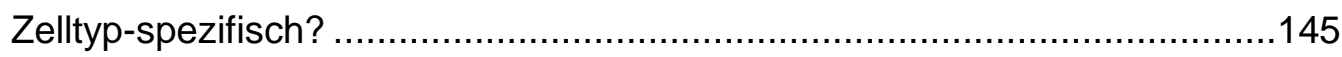

4.3.4 Valproinsäure als potentielles Mittel für die Therapie des Prostatakarzinoms .....148

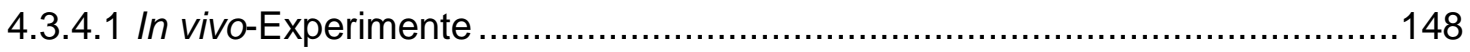

4.3.4.2 Klinische Studien zur Valproinsäure-Behandlung von Tumorerkrankungen 150

4.3.4.3 Tumorrisiko bei Patienten mit Valproinsäure-behandelter Epilepsie.............152

4.3.4.4 Fazit: Ist Valproinsäure ein potentielles Mittel für die Therapie des

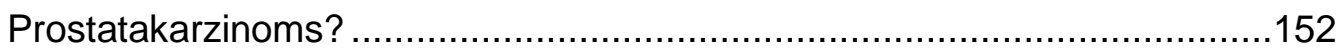

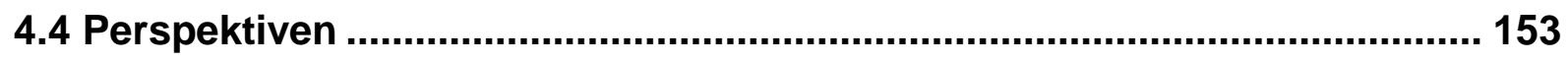

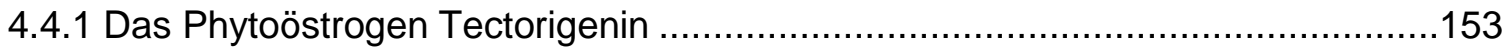

4.4.2 Der Histondeacetylase-Inhibitor Valproinsäure ............................................

5 Zusammenfassung ................................................................... 160

5.1 Das Phytoöstrogen Tectorigenin ............................................................. 160

5.2 Der Histondeacetylase-Inhibitor Valproinsäure ......................................... 161 
Literaturverzeichnis ................................................................ 166

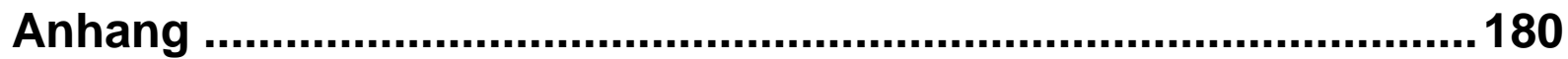




\section{Abkürzungsverzeichnis}

\section{A}

Abb.

$\mathrm{ad}$

ATP

AR

Bax

Bcl-2

Bim

Bok

bp

BSA

bzw.

C

${ }^{\circ} \mathrm{C}$

ca.

Cond

Cdk

cDNA

$\mathrm{Cp}$

$\mathrm{Ct}$

CTP

Cxcl15

DAPI

d.h.

DHT

DMSO

DNA

dNTP

DPBS

DTT

EDTA

ERa, ESR1

ERß, ESR2

ERK

et al.

FDR
Adenin

Abbildung

addiere: aus der Chemie: auffüllen auf... mit...

Adenosintriphosphat

Androgenrezeptor

BCL2-associated $X$ protein

$B$ cell leukemia/lymphoma 2

BCL2-like 11

$B C L 2$-related ovarian killer protein

Basenpaar

bovine serum albumin

beziehungsweise

Cytosin

Grad Celsius

circa (ungefähr)

Cyclin

cyclin-dependent kinase

komplementäre DNA

Ceruloplasmin

threshold cycle, Schwellenwertzyklus

Cytosintriphosphat

chemokine (C-X-C motif) ligand 15

4',6'-Diamidino-2-Phenylindol

das heißt

Dihydrotestosteron

Dimethylsulfoxid

Desoxyribonukleinsäure

Desoxynukleotidtriphosphat

Dulbecco's Phosphat-gepufferte Kochsalzlösung

1,4-Dithiothreitol

Ethylendiamintetraessigsäure

estrogen receptor $\alpha$, Östrogenrezeptor $\alpha$

estrogen receptor $\beta$, Östrogenrezeptor $\beta$

extracellular signal-regulated kinase

et alteri (und andere)

false discovery rate 


\begin{tabular}{|c|c|}
\hline FKS & Fetales Kälberserum \\
\hline Foxo & forkhead box, sub-group O \\
\hline G & Guanin \\
\hline GAPDH & Glycerinaldehyd-3-Phosphat-Dehydrogenase \\
\hline GEKID & Gesellschaft der epidemiologischen Krebsregister in \\
\hline & Deutschland e.V. \\
\hline Gsk3ß & glycogen synthase kinase 3 beta \\
\hline $\mathrm{h}$ & Stunde \\
\hline Hif1a & hypoxia inducible factor 1, alpha subunit \\
\hline HPRT & Hypoxanthin-Guanin-Phoshoribosyltransferase \\
\hline HRP & horse radish peroxidase \\
\hline IGF-BP-3 & insulin-like growth factor-I binding protein 3 \\
\hline IGF-I & insulin-like growth factor-I \\
\hline IGF-IR & insulin-like growth factor-I receptor \\
\hline $\mathrm{kb}$ & Kilobasenpaar \\
\hline $\mathrm{kDa}$ & Kilodalton \\
\hline Lif & leukemia inhibitory factor \\
\hline luc & Luciferase \\
\hline$\mu$ & micro $=10^{-6}$ \\
\hline$\mu l$ & Microliter \\
\hline$\mu \mathrm{m}$ & Micrometer \\
\hline $\mathrm{m}$ & milli $=10^{-3}$, murin \\
\hline M & Molar \\
\hline $\mathrm{mA}$ & Milliampere \\
\hline $\mathrm{mg}$ & Milligramm \\
\hline $\min$ & Minute \\
\hline $\mathrm{ml}$ & Milliliter \\
\hline $\mathrm{mM}$ & Millimolar \\
\hline mRNA & messenger RNA = Boten-RNA \\
\hline $\mathrm{n}$ & nano $=10^{-9}$ \\
\hline $\mathrm{nm}$ & Nanometer \\
\hline OD & Optische Dichte \\
\hline $\mathrm{p}$ & pico $=10^{-12}$ \\
\hline PAGE & Polyacrylamidgelelektrophorese \\
\hline Pak & p21 protein (Cdc42/Rac)-activated kinase 1 \\
\hline PBGD & Porphobilinogen deaminase \\
\hline PBS & Phosphat-gepufferte Kochsalzlösung \\
\hline
\end{tabular}


$\mathrm{PCa}$

PCR

PDEF

$\mathrm{pH}$

PIN

PSA

PTEN

Ptprn

qRT-PCR

$\mathrm{Rb}$

Rcbtb2

RKI

RNA

RNase

RT

SAPE

SDS

sec

sog.

SV

$T$

Tab.

TBP

TBS(-T)

TG

TRAMP

Uchl1

UTP

$\mathrm{V}$

Vegfa

vgl.

VPA

w/v

vs.

Z.T.

z.B. prostate carcinoma $=$ Prostatakarzinom

Polymerase-Kettenreaktion

prostate-derived Ets factor

Negativer dekadischer Logarithmus der Protonenkonzentration

prostatic intraepithelial neoplasia

prostate specific antigen

phosphatase and tensin homologue

protein tyrosine phosphatase, receptor type, $N$

quantitative real time PCR

retinoblastoma

regulator of chromosome condensation (RCC1) and BTB

(POZ) domain containing protein 2

Robert Koch-Institut

Ribonukleinsäure

Ribonuklease

Raumtemperatur; reverse Transkription

R-Phycoerythrin-markiertes Streptavidin

Natriumdodecylsulfat

Sekunde

sogenannt

similian virus

Thymin, Temperatur

Tabelle

TATA-Bindeprotein

Tris-gepufferte Kochsalzlösung (mit Tween)

Tectorigenin

transgenic adenocarcinoma of mouse prostate

ubiquitin carboxyl-terminal esterase $L 1$

Uridintriphosphat

Volt

vascular endothelial growth factor $A$

vergleiche

Valproinsäure

Massenprozent

versus (im Vergleich zu)

zum Teil

zum Beispiel 


\section{Fachwortverzeichnis}

In dieser Arbeit wurden sinnvolle englische Fachbegriffe der Molekularbiologie auch als solche verwendet und nicht ins Deutsche übersetzt. Deutsche Übersetzungen dieser Fachbegriffe sind häufig nur eine Umschreibung dessen, was im Englischen mit einem Wort ausgedrückt werden kann. Die Bedeutung dieser Fachbegriffe wird hier aufgeführt, sofern dies nicht im Text geschieht.

Annealing

Wörtlich übersetzt: ausglühen, härten

Hier: Primer-Anlagerung während der PCR

Assay

Wörtlich übersetzt: untersuchen, Untersuchung

Test, Versuchsreihe

housekeeping

Wörtlich übersetzt: Haushalt

Ein housekeeping-Gen ist ein konstitutiv exprimiertes Gen, das in allen Zellen essentiell ist.

Primer

Oligonukleotid von 20-35 Basenpaaren, welches von Polymerasen als Starthilfe zum Synthetisieren weiterer Nukleotide genutzt wird.

real time

Wörtlich übersetzt: Echtzeit

Während der PCR kann die Zunahme der Amplifikate in Echtzeit verfolgt werden

well

Wörtlich übersetzt: das Bohrloch

Hier: Vertiefung in einer Mikrotiterplatte 


\section{Einleitung}

\subsection{Das Prostatakarzinom - Inzidenz, Risikofaktoren und Therapie}

Das Prostatakarzinom (PCa) ist die am häufigsten diagnostizierte Krebsneuerkrankung bei Männern in Deutschland. Es liegt mit 25,7\% der Krebsneuerkrankungen 2008 deutlich vor dem Darmkrebs (14,3\%). An der dritten Stelle folgt mit 13,8\% das Lungenkarzinom. Allerdings ist das PCa nur die dritthäufigste Ursache (10,5\%) der krebsbedingten Sterbefälle nach dem Lungenkrebs (25,5\%) und dem Darmkrebs (11,8\%) (Robert Koch-Institut (RKI) und Gesellschaft der epidemiologischen Krebsregister in Deutschland e.V. (GEKID), 2012). Die Zahl der neu diagnostizierten PCa steigt stetig an, da heutzutage durch das Früherkennungsprogramm eine frühere Ersterkennung möglich ist. Dieses Programm sieht ab dem 45. Lebensjahr eine jährliche Untersuchung vor, welche die Untersuchung der äußeren Geschlechtsorgane sowie die digital-rektale Untersuchung der Prostata und das Abtasten der Lymphknoten beinhaltet (RKI, 2007; RKI und GEKID, 2012). Die Analyse des PSA-Spiegels (prostate specific antigen) im Blut ist nicht Teil der gesetzlichen Früherkennung, da der Zusammenhang von PSA-Spiegel und dem PCa bisher noch nicht eindeutig gesichert ist (Kilpeläinen et al., 2011). Es ist folglich unerlässlich, eine Früherkennung auf molekularer Ebene auch in Hinsicht auf Therapiemöglichkeiten zu verbessern.

Ein Risikofaktor für das Entstehen eines PCa ist vor allem das Alter des Patienten, allerdings spielen auch der Testosteronspiegel und z.T. die Familiengeschichte eine entscheidende Rolle. Bei ca. 9\% der Patienten mit einem PCa konnte eine familiäre Häufung festgestellt werden. Wenn bereits ein Verwandter ersten Grades erkrankt ist, steigt das PCa-Risiko um das doppelte im Vergleich zur Normalbevölkerung an (RKI, 2007). Umweltfaktoren konnten im Zusammenhang mit der Entstehung des PCa nicht hinlänglich bestätigt werden. Allerdings ist im internationalen Vergleich auffällig, dass die Inzidenz des PCa in Asien mit 0,5 Fällen pro 100.000 Männern deutlich unter der Inzidenz für Mittel- und Nordeuropa sowie Nordamerika liegt, welche bei 40 Fällen pro 100.000 Männer liegt. Zudem zeigten epidemiologische Studien zum PCa, dass Asiaten, die in die USA auswanderten, in der 2. Generation die gleiche Inzidenz für ein PCa aufweisen, wie sie in den USA besteht (Tominaga, 1985; Whittemore et al., 1995; Huber, 2000). Eine genetische Ursache kann diese Diskrepanz der gezeigten Inzidenzen im internationalen Vergleich nicht erklären. Die Änderung der Ernährungsgewohnheiten wird daher als ausschlaggebend für die erhöhte Inzidenz, an einem PCa zu erkranken, angesehen. Da die sojareiche Nahrung in Asien üblicherweise viele Phytoöstrogene enthält, ist die Untersuchung solcher Stoffe auf die 
präventive Wirkung oder sogar als Therapiemöglichkeit gegen das $\mathrm{PCa}$ dringend erforderlich.

Die Therapiemöglichkeiten für das $\mathrm{PCa}$ sind sehr beschränkt und sind abhängig vom Tumorstadium. Es ist zu unterscheiden, ob ein Karzinom auf das Organ beschränkt vorliegt oder bereits in das umliegende Gewebe gestreut hat. Sollte das PCa in das umliegendes Gewebe gestreut haben, so ist zwischen hormonsensitiver und hormonrefraktärer Phase zu differenzieren, wobei letzteres mit einer deutlich schlechteren Prognose, auch aufgrund fehlender Therapiemöglichkeiten, verknüpft ist. Tabelle 1.1 gibt einen Überblick über die Therapiemöglichkeiten in den verschiedenen Phasen der Erkrankung.

Tabelle 1.1: Übersicht zu den Therapiemöglichkeiten beim organbegrenzten und organüberschreitenden Prostatakarzinom (nach RKI, 2007)

\begin{tabular}{|l|l|l|}
\hline & Therapiemöglichkeit & Beschreibung \\
\hline E & & $\begin{array}{l}\text { Entfernung der Prostata mit Samenleiter und Samenblasen, } \\
\text { die Harnröhre wird wieder mit der Harnblase verbunden. } \\
\text { Voraussetzung ist eine mind. 10jährige Lebenserwartung }\end{array}$ \\
Mögliche Nebenwirkungen: Impotenz, Harninkontinenz, \\
Harnröhrenenge
\end{tabular}

Bei einem organbegrenzten Tumorwachstum wird vorwiegend die sogenannte „Watchful Waiting" -Methode eingesetzt, da sowohl die radikale Prostatektomie als auch die Bestrahlung des Tumors mit erheblichen Nebenwirkungen verbunden sein können. Beim organüberschreitenden PCa sind die Therapiemöglichkeiten sehr beschränkt. Es ist auch 
hier eine Bestrahlung möglich, die in Kombination mit einer Hormonablationstherapie oder allein angewendet wird. Die Hormonablationstherapie bewirkt durch den Entzug von Testosteron lediglich eine Verlangsamung der Tumorprogression um ca. 2-4 Jahre, es handelt sich daher nicht um eine kurative Therapie (RKI, 2007). Dabei ist zwischen chemischer oder chirurgischer Kastration und der Behandlung mit Anti-Androgenen zu unterscheiden. Bei der chemischen Kastration werden Analoga des Neurohormons Gonadotropin-Releasing-Hormon (GnRH) verwendet, die zu einer Senkung des Testosteronspiegels führen. Die chirurgische Kastration sieht eine operative Entfernung der Testes vor, so dass lediglich über die Nebenniere geringe Mengen an Testosteron produziert werden. Die Behandlung mit Anti-Androgen hemmt die Testosteron-Bildung nicht, lediglich die Wirkung von Testosteron wird unterbunden, z.B. durch eine Inaktivierung des Androgenrezeptors (Enders et al., 2009).

Schließlich ist auch eine Therapie mit Zytostatika möglich. Beim PCa ist hierfür lediglich das Medikament Docetaxel mit nachweislicher Wirksamkeit zugelassen. Es hemmt nicht nur die Zellproliferation der Tumorzellen, weshalb es zu den typischen Nebenwirkungen wie z.B. Haarausfall kommen kann (Enders et al., 2009). Aufgrund der starken Belastungen einer solchen Chemotherapie gilt es hier allerdings eingehend zu prüfen, ob es zu einer Verbesserung des Allgemeinzustandes, der Schmerzsituation und der Lebensqualität kommt (RKI, 2007). Die Übersicht macht deutlich, dass für die Therapie des PCa dringend neue Strategien entwickelt werden müssen, die zum einen nicht rein palliativ sondern kurativ wirken und zum anderen mit weniger ausgeprägten Nebenwirkungen beim Patienten verbunden sind.

\subsection{Zukünftige Therapieansätze}

In der vorliegenden Arbeit sollen pflanzliche Wirkstoffe und Histondeacetylase-Inhibitoren auf die jeweilige Wirksamkeit in PCa-Zellen untersucht werden.

\subsubsection{Das Phytoöstrogen Tectorigenin}

Als pflanzlicher Stoff für die Untersuchung der Wirksamkeit in PCa-Zellen wurde das Phytoöstrogen Tectorigenin ausgewählt. Wie bereits im oberen Abschnitt erläutert, gibt es deutliche Unterschiede zwischen der Inzidenz für das PCa im asiatischen Raum und der Inzidenz in Mittel- und Nordeuropa sowie den USA (Haenszel und Kurihara, 1968; Dunn, 1975; Tominaga, 1985; Matsuda und Saika, 2007). Ein Ansatz zur Erklärung dieser Diskrepanz der gezeigten Inzidenzen ist die unterschiedliche Ernährung in den Regionen. In Asien wird allgemein eine Ernährung bevorzugt, die z.B. durch hohe Zufuhr von Sojaprodukten wie Tofu oder Sojamilch reich an Phytoöstrogenen ist (Fukutake et al., 1996). 
Phytoöstrogene sind pflanzliche Stoffe, die funktional sowie strukturell dem Hormon Östrogen ähneln (Abb. 1.1). Es wird den Phytoöstrogenen daher auch die Eigenschaft eines selektiven Östrogenrezeptormodulators zugeschrieben (Vollmer und Zierau, 2004). Von dieser Eigenschaft wird in der Forschung zur Prävention sowie der Therapie des hormonabhängigen PCa profitiert.

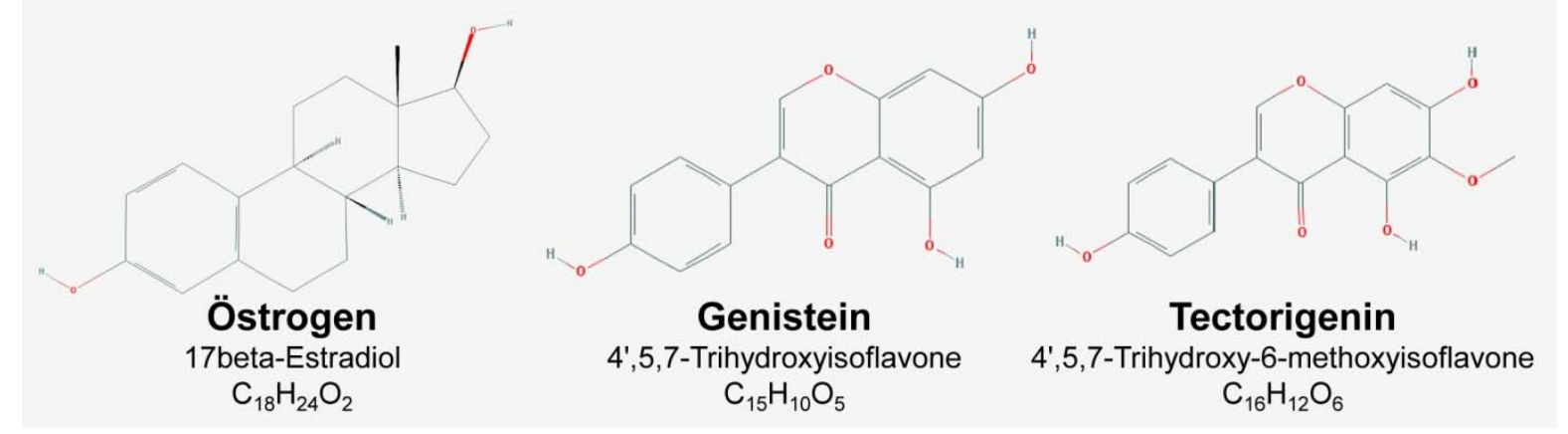

Abbildung 1.1: Strukturformeln von Östrogen und den beiden Phytoöstrogenen Genistein und Tectorigenin im Vergleich (modifiziert nach National Center for Biotechnology Information, 2012a, b, c).

Der bekannteste Vertreter der Phytoöstrogene ist das Genistein aus der Sojabohne. Es wurde ausführlich auf seine Effekte auf das Mammakarzinom und auch das PCa hin untersucht. Studien zur Wirkung von Genistein auf PCa-Zellen wurden bereits seit Anfang der 1990er Jahre durchgeführt. Es konnte gezeigt werden, dass eine Behandlung von PCa-Zellen mit Genistein das Wachstum sowie die Invasionsfähigkeit verringert (Peterson und Barnes, 1993; Santibanez et al., 1997). In einer weiteren Studie konnte die Inhibition der Proliferation mit einem G2/M-Arrest in PCa-Zellen verknüpft werden. Auf molekularer Ebene konnte dies mit einer Verringerung der Expression von Cyclin B1 sowie einer verstärkten Expression von p21 begründet werden (Davis et al., 1998). Auch eine Induktion von Apoptose in PCa-Zellen nach Genistein-Behandlung konnte gezeigt werden (Davis et al., 1998; Onozawa et al., 1998; Zhou et al., 1999). Die Wirksamkeit von Genistein in vivo wurde sowohl im TRAMP-Maus-Modell als auch im subkutanen PCa-Maus-Modell demonstriert (Wang et al., 2004; Zhou et al., 1999). Hierbei wurde vor allem ein reduziertes Tumorwachstum, aber auch eine Induktion der Apoptose in den Tumoren nachgewiesen.

Ein weiterer Vertreter der Phytoöstrogene ist das Tectorigenin. Es ist dem Genistein strukturell sehr ähnlich (Abb. 1.1). Tectorigenin wird aus dem Rhizom der Leopardenlilie (Belamcanda chinensis (L.) DC.) gewonnen. Der Gesamtextrakt aus Belamcanda chinensis wird in der traditionellen chinesischen Medizin bei zahlreichen Krankheitsbildern angewandt. Er soll eine schleimlösende und abschwellende Wirkung haben, daher wird der Extrakt häufig bei Erkrankungen der Atemwege eingesetzt (Zhou et al., 2011). 
Der Einsatz von Tectorigenin als mögliches Mittel in der Krebstherapie wurde von Jung et al. (2003) begründet. Sie zeigten in einem Hühnerembryo-Chorionallantoismembran-Assay, dass durch die Behandlung mit Tectorigenin die Angiogenese gehemmt wurde. In dieser Arbeit konnte auch gezeigt werden, dass das Tumorwachstum von subkutan injizierten Lungenkarzinomzellen in C57/BI6-Mäusen im Vergleich zu kontrollbehandelten Mäusen nach der Behandlung mit Tectorigenin verringert war.

Die Wirkung von Tectorigenin auf das PCa wurde zuerst durch Morrissey et al. (2004) beschrieben. Diese Arbeitsgruppe identifizierte den Bestandteil Tectorigenin aus dem Gesamtextrakt von Belamcanda chinensis als potenten Inhaltsstoff für die Therapie des PCa. Sie wiesen eine Inhibition der Proliferation von PCa-Zellen durch Zellzyklusarrest in der G1-Phase nach und konnten hierbei einige interessante Zielgene von Tectorigenin im PCa identifizieren, wie z.B. p21, p27, ER $\alpha$ und ER (Östrogenrezeptor $\alpha$ und $\beta$ ). In weiteren Studien wurde nach der Behandlung mit dem Gesamtextrakt aus Belamcanda chinensis von subkutanen PCa im Nacktmaus-Modell ein verzögertes und reduziertes Tumorwachstum in vivo gezeigt (Thelen et al., 2005). In in vitro-Analysen wurden einige Expressionsänderungen für Faktoren von im PCa deregulierten Signalwegen nachgewiesen. Es konnte eine Verminderung der AR (Androgenrezeptor)-, PDEF (prostate derived ets factor)-, PSA-, DD3 ${ }^{\text {PCA3 }}$ (prostate cancer antigen 3)-, IGF-IR (insulin-like growth factor I receptor)- sowie hTERT (human telomerase reverse transcriptase)-Expression nach Behandlung der humanen PCa-Zellen LNCaP mit Tectorigenin gezeigt werden. Die Expression des proapoptotischen Faktors TIMP-3 (tissue inhibitor of matrixmetalloproteinases 3) und des Tumorsuppressor-Gens ER $\beta$ hingegen nahm nach Behandlung mit Tectorigenin bzw. dem Gesamtextrakt aus Belamcanda chinensis zu (Thelen et al., 2005; Thelen et al., 2007). Anschließende Analysen konnten zeigen, dass die Herunterregulierung der Expression des ER $\beta$ mittels spezifischer siRNA in PCa-Zellen zu einer Umkehr der beobachteten Effekte nach der Tectorigenin-Behandlung von PCa-Zellen führte; diese waren: eine verstärkte Expression von PSA, PDEF, DD3 ${ }^{\text {PCA3 }}$, IGF-IR, hTERT und ERa (Stettner et al., 2007). Hiermit konnte gezeigt werden, dass der ERß ein Schlüsselprotein bei der Entstehung des PCa darstellt und die Behandlung des PCa mit Phytoöstrogenen ihre Wirksamkeit über die Östrogenrezeptoren vermitteln könnte.

Studien zur Wirksamkeit von Tectorigenin in vivo im PCa sowie Untersuchungen zur Identifizierung neuer Zielgene nach Tectorigenin-Behandlung von PCa-Zellen sind noch nicht durchgeführt worden und waren ein wesentliches Ziel der vorliegenden Arbeit.

\subsubsection{Der Histondeacetylase-Inhibitor Valproinsäure}

Die zweite Stoffklasse, die in dieser Arbeit untersucht wird, sind die HistondeacetylaseInhibitoren (HDIs). Die Gruppe der Histondeacetylase-Inhibitoren ist strukturell sehr 
heterogen. Es wird unterschieden zwischen Hydoxamsäuren (z.B. Trichostatin A (TSA) und Vorinostat (SAHA)), cyclischen Peptiden (z.B. Apicidin), Benzamiden (z.B. MS-275) und den aliphatischen Säuren (z.B. Natriumbutyrat (NaB) und Valproinsäure (VPA)) (Liu et al., 2006; Dokmanovic et al., 2007).

HDls hemmen die Aktivität der Histondeacetylasen (HDACs, vgl. Abb. 1.2). HDACs katalysieren die Deacetylierung der Histone im Chromatin. Deacetyliertes Chromatin liegt stark kondensiert vor und ist damit transkriptionell inaktiv (Gillet et al., 2007). Die Gegenspieler der HDACs sind die Histonacetyltransferasen (HATs). HATs katalysieren die Acetylierung der Histone, das Chromatin liegt stark dekondensiert vor und ist somit transkriptionell aktiv (Gillet et al., 2007). Wird nun durch eine Behandlung mit HDIs die Aktivität der HDACs inhibiert, so verschiebt sich das Gleichgewicht zwischen kondensiertem und dekondensiertem Chromatin in Richtung des dekondensierten, da die Aktivität der HATs unverändert bleibt. Eine Behandlung mit HDIs wird also allgemein eine Expressionsaktivierende Eigenschaft zugeschrieben.

\section{Deacetyliertes Chromatin}
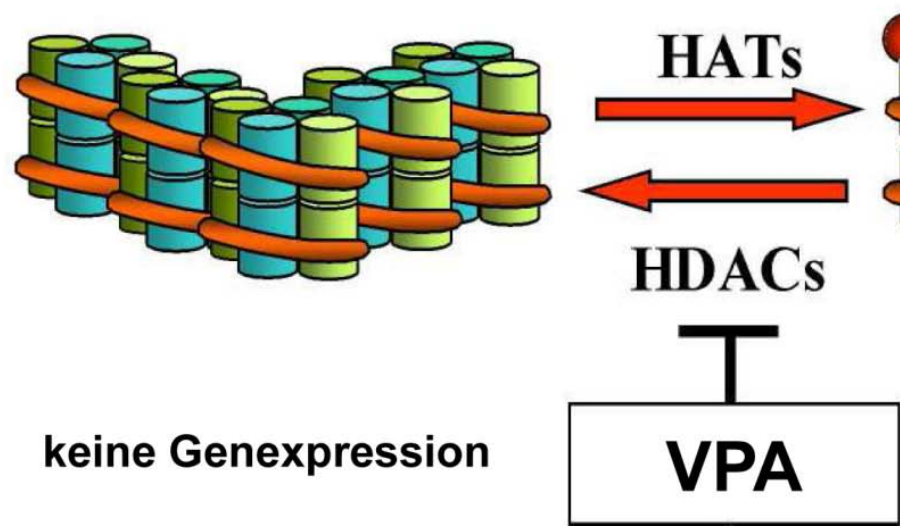

Acetyliertes Chromatin

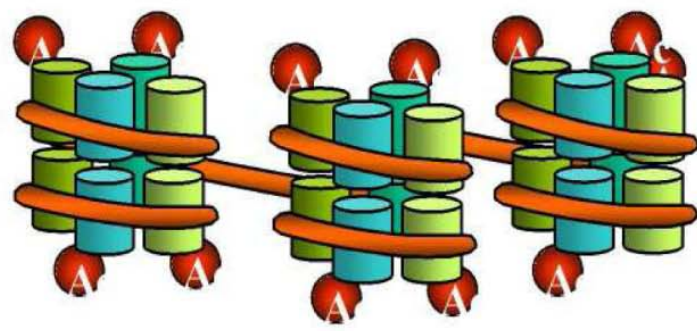

keine Genexpression

Abbildung 1.2: Schematische Darstellung der Katalyse der Histon(de)acetylierung.

Deacetyliertes Chromatin liegt stark kondensiert vor, so dass eine Genexpression nicht möglich ist. Durch Histonacetyltransferasen (HATs) wird das Chromatin an den Histonen acetyliert und dadurch wird die Struktur des Chromatins gelockert, so dass eine Genexpression stattfinden kann. Die umgekehrte Reaktion von acetyliertem zu deacetyliertem Chromatin katalysieren die Histondeacetylasen (HDACs). Die HDACs werden durch Valproinsäure (VPA) inhibiert, so dass das Gleichgewicht auf die Seite des acetylierten Chromatins verschoben wird und eine Genexpression stattfinden kann (modifiziert nach Gillet et al., 2007).

In den Studien zu der vorliegenden Arbeit wurde vorwiegend der HDI VPA verwendet. VPA ist bereits seit vielen Jahren ein erprobtes Antikonvulsivum mit einem bekannten Umfang an Nebenwirkungen. Eine der möglichen Nebenwirkungen ist das Risiko eines Neuralrohrdefekts beim Embryo, wenn die Mutter VPA im ersten Trimester der Schwangerschaft eingenommen hat (Robert und Guibaud, 1982; Wlodarczyk et al., 2012). Diese Nebenwirkung weist auf eine proliferationshemmende Wirkung von VPA hin. Diese Wirkung wurde von der Krebsforschung aufgegriffen und folgende Studien zur Proliferation 
von Neuroblastoma-, Glioma- sowie Promyelozytenleukämie-Zellen wiesen eine Inhibition der Proliferation der Zellen nach einer Behandlung mit VPA nach (Fischkoff und Walter, 1984; Regan, 1985). Untersuchungen zur Wirkung von VPA in hämatologischen Tumorerkrankungen sind heutzutage bis zu Phase 3-Studien bei Patienten fortgeschritten. Insgesamt konnte hierbei ein gutes Ansprechen auf die Therapie mit VPA verzeichnet werden, mit verzögerter Progression und teilweiser Remission, vor allem aber eine Verbesserung der Blutparameter (zusammengefasst in Wagner et al., 2010).

Aber auch bei soliden Tumoren konnten Effekte der VPA-Behandlung gezeigt werden. Die Inhibition der Proliferation ist hierbei als Kerneffekt der VPA-Behandlung in Krebszellen zu betrachten, da diese Inhibition für das Blasenkarzinom (Ozawa et al., 2010; Vallo et al., 2011; Byler et al., 2012), das Leberkarzinom (Machado et al., 2011), bei HNO-Tumoren (Gan et al., 2012), im kleinzelligen Lungenkarzinom (Hubaux et al., 2010), bei Pankreas- und Kolonkarzinomen (Jones et al., 2008a; Venkataramani et al., 2010), bei Nierenkarzinomen (Jones et al., 2009), im Gebärmutterhalskarzinom (Sami et al., 2008) sowie beim Mammakarzinom (Fortunati et al., 2008) nachgewiesen wurde. Molekular wurden einige Zielgene in den verschiedenen Krebsentitäten identifiziert (zusammengefasst in Blaheta et al., 2002; Blaheta et al., 2005; Michaelis et al., 2007). Klinische Studien zur Wirkung von VPA wurden bislang erfolgreich für das Mammakarzinom sowie für verschiedene solide Tumore (z.B. Cervix-, Ovarial-, Lungen- und Pankreaskarzinom) durchgeführt (Arce et al., 2006; Munster et al., 2009; Candelaria et al., 2007; Chateauvieux et al., 2010).

In dieser Arbeit sollte die Wirkung von VPA im PCa untersucht werden. Generell wird aufgrund der langjährigen Verwendung von VPA als Antikonvulsivum die Frage aufgeworfen, ob Patienten, die aufgrund ihrer Epilepsie mit VPA behandelt wurden, seltener Tumore entwickeln als Kontrollpersonen. Zu dieser Problematik gab es lange Zeit keine aussagekräftigen Studien (Singh et al., 2004). Allerdings konnte die 2012 von Stettner et al. veröffentlichte Studie zum Risiko von PCa bei Epilepsie-Patienten zeigen, dass eine Behandlung mit VPA das Risiko an einem PCa zu erkranken verringert. Daher ist es zwingend notwendig, die funktionellen und molekularen Mechanismen von VPA beim PCa zu erforschen.

Die funktionellen Effekte einer Behandlung von PCa-Zellen mit VPA wurden bereits durch einige Arbeitsgruppen in vitro und in vivo untersucht. So wurde die Inhibition der Proliferation in verschiedenen PCa-Zellen nachgewiesen (Annicotte et al., 2006; Gao et al., 2007; Shabbeer et al., 2007; lacopino et al., 2008; Chou et al., 2011). Teilweise konnte zusätzlich ein Zellzyklusarrest gezeigt werden (Shabbeer et al., 2007; Wedel et al., 2011d). Die molekularen Mechanismen dieser Proliferationsinhibition bleiben in den Studien allerdings weitgehend ungeklärt. Es wird unter anderem ein Anstieg der Expression von p21 beschrieben (Shabbeer et al., 2007), allerdings ist dies als allgemeiner Effekt auf alle Zellen, 
nicht-maligne und maligne, zu werten. Der Zusammenhang zwischen VPA-Behandlung und der Inhibition der Proliferation bleibt ungeklärt, da Brinkmann et al. (2001) zeigen konnten, dass durch den HDI SBHA (suberic bishydroxamate) in humanen Fibroblastenzellen zwar eine verstärkte Expression von p21 hervorgerufen wird, allerdings die Proliferation unverändert bleibt. Es ist daher Gegenstand der vorliegenden Arbeit, die Änderungen der Genexpressionen von PCa-Zellen nach VPA-Behandlung in einen Zusammenhang mit der Inhibition der Zellproliferation zu stellen und dabei den Fokus auf Kandidatengene zu setzen, die nur in Tumorzellen dereguliert sind.

Die Induktion von Apoptose in PCa-Zellen ist ein weiterer beschriebener zellulärer Effekt der VPA-Behandlung (Angelucci et al., 2006; Shabbeer et al., 2007; Chou et al., 2011; Fortson et al., 2011). Auch bei diesem VPA-Effekt sind die molekularen Mechanismen nicht vollständig aufgeklärt, Angelucci et al. (2006) zeigten einen Einfluss auf die Expression von Fas/FasL sowie eine Aktivierung von Caspase 3 und einen Anstieg der Bcl-2-Expression. Eine weitere Arbeitsgruppe assoziierte den Anstieg der Expression von TIMP-3, Caspase 3 und IGFBP-3 (insulin-like growth factor binding protein-3) mit der Induktion der Apoptose durch VPA in PCa-Zellen (Thelen et al., 2004).

Zusammenfassend kann gesagt werden, dass die vorhandenen Studien zur Wirkung von VPA auf PCa-Zellen in vielen Aspekten gute Ansätze für weitere Forschung bieten. Für einen umfassenderen Überblick über die Wirksamkeit von VPA im PCa sind in vivo-Studien allerdings unbedingt notwendig, da der Einfluss der umgebenden Zellen in vitro nicht ausreichend untersucht werden kann. Studien zur Wirkung von VPA im PCa in vivo wurden bislang vorwiegend in Xenograft-Modellen durchgeführt (Xia et al., 2006; Gao et al., 2007; Shabbeer et al., 2007; Kortenhorst et al., 2008; Hudak et al., 2012). Diese Modelle sind für viele Aspekte der Untersuchungen (z.B. Wachstum, Angiogenese und Apoptose) anwendbar, allerdings kann im Xenograft-Modell die Tumorinitiation und -progression sowie die Metastasenbildung nur unzureichend untersucht werden. Auch die Umgebung des Tumors entspricht nicht der natürlichen. Daher sollte in dieser Arbeit, als Grundlage für den Einsatz von VPA in der Therapie des PCa, der Einfluss von VPA in einem PCa-Modell analysiert werden, welches den gesamten Tumorverlauf vergleichbar zum Krankheitsverlauf beim PCa-Patienten nachvollzieht. Für die in vitro-Analysen sollten folglich vorwiegend primäre PCa-Zellen verwendet werden. Diese Zellen stammen aus dem TRAMP(transgenic adenocarcinoma of mouse prostate) Maus-Modell, welches in anschließenden Untersuchungen in vivo verwendet werden sollte. Das TRAMP-Maus-Modell wurde für diese Untersuchungen ausgewählt, da es den Krankheitsverlauf des PCa vollständig rekapituliert (Greenberg et al., 1995) und die Möglichkeit bietet, nicht nur das Tumorwachstum zu analysieren, wie z.B. in den häufig verwendeten Xenograft-Modellen, sondern auch Rückschlüsse auf den möglichen Krankheitsverlauf beim Patienten ziehen zu können. 


\subsection{Ziele der Arbeit}

In dieser Arbeit sollten das Phytoöstrogen Tectorigenin sowie der Histondeacetylase-Inhibitor VPA auf die jeweilige präventive bzw. kurative Wirkung gegen das PCa untersucht werden. Hierzu sollten vor allem die primären PCa-Zellen 2E analysiert werden, um eine Grundlage der Wirkungsmechanismen in vitro zu erstellen, damit diese auf folgende in vivo-Versuche angewendet werden können.

Für die Untersuchung der Wirksamkeit von Tectorigenin waren die Ziele:

- Untersuchung des Einflusses von Tectorigenin verschiedener Hersteller sowohl in den primären PCa-Zellen 2E als auch in den humanen PCa-Zellen LNCaP

- auf die Proliferation

- auf die Expression ausgewählter Zielgene (AR, PSA, PTEN, PDEF, IGF-IR, IGFBP-3, ER $\alpha, E R \beta)$

- Anschließende Bewertung der Ergebnisse und Auswahl eines Herstellers von Tectorigenin für die folgenden weiterführenden Versuche:

- Microarray-Analyse zur Identifizierung weiterer differentiell exprimierter Gene nach der Tectorigenin-Behandlung von PCa-Zellen

- in vivo-Versuche zur Behandlung mit Tectorigenin im Futter an subkutanen LNCaP-Tumoren im Nacktmaus-Modell

Die Analyse von VPA als mögliches Medikament gegen das PCa sah folgende Punkte vor:

- Funktionelle Analysen des Einflusses der VPA-Behandlung auf PCa-Zellen:

- Bestätigung der Wirksamkeit von VPA im verwendeten Zellmodell 2E anhand von aus der Literatur bekannten Parametern (erhöhte Histonacetylierung, Inhibition der Proliferation auch in den humanen PCa-Zellen PC-3)

- Untersuchung der Migrations- und Invasionsfähigkeit der PCa-Zellen 2E nach Behandlung mit VPA

- Expressionsanalysen nach der Behandlung von PCa-Zellen mit VPA

- des Androgenrezeptors

- von Apoptose-assoziierten Proteinen

- von Zellzyklus-assoziierten Proteinen

- von Angiogenese-assoziierten Faktoren

- von regulatorischen Faktoren

- von in der Microarray-Analyse (Witt, 2009) identifizierten, differentiell exprimierten Genen 
- Untersuchung der Promotor-Acetylierung der nach VPA-Behandlung von PCa-Zellen differentiell exprimierten Gene

- Eingehende Untersuchung des Kandidatengens Cyclin D2

- auf die Spezifität der Expressionsänderung innerhalb der Cyclin D-Genfamilie nach Behandlung von PCa-Zellen mit VPA

- auf Zellpassagen-abhängige Effekte nach VPA-Behandlung von PCa-Zellen

- auf die Expressionsänderung nach Behandlung von PCa-Zellen mit weiteren HDIs, sowie dem in vitro inaktiven Amid von VPA, Valpromid, als Negativkontrolle

- zum Einfluss der Methylierung auf die Genexpression

- auf eine Expressionsänderung nach der VPA-Behandlung von PCa-Zellen, kolorektalen Zellen, Fibroblasten-Zellen sowie Prostatastromazellen und embryonalen Nierenzellen

- mit Bezug der Expressionsänderung auf die Proliferationsrate von PCa-Zellen, kolorektalen Zellen, Fibroblasten-Zellen sowie Prostatastromazellen und embryonalen Nierenzellen nach der VPA-Behandlung

- mittels siRNA-Studien in den PCa-Zellen 2E und den Fibroblasten NIH/3T3

- auf die Expression an humanen PCa-Gewebeschnitten

- in vivo-Behandlung von TRAMP-Mäusen mit VPA über das Trinkwasser mit zugesetztem Süßstoff 


\section{Material und Methoden}

\subsection{Chemikalien und Reagenzien}

Alle nicht aufgeführten Substanzen wurden von den Firmen Roth (Karlsruhe) und SigmaAldrich (Deisenhofen) bezogen.

\begin{tabular}{|c|c|}
\hline Chemikalie & Hersteller \\
\hline Adenosintriphosphat (ATP) & Biomol GmbH, Hamburg \\
\hline Agar & Carl Roth GmbH, Karlsruhe \\
\hline Agarose & Life Technologies, Darmstadt \\
\hline Ampicillin & Carl Roth GmbH, Karlsruhe \\
\hline Ampuwa & Fresenius AG, Bad Homburg \\
\hline Apicidin & AppliChem GmbH, Darmstadt \\
\hline Dimethylsulfoxid (DMSO) & Carl Roth GmbH, Karlsruhe \\
\hline Dithiothreitol (DTT) & Biomol, Hamburg \\
\hline DNA Stain G & Serva GmbH, Heidelberg \\
\hline dNTPs (100 mM) & Life Technologies, Darmstadt \\
\hline Dulbecco's Phosphat-gepufferte & PAN Aidenharh \\
\hline Kochsalzlösung (DPBS) & PAIv, Aluetruacil \\
\hline Ethanol & Chemie Vertrieb Hannover, Hannover \\
\hline Ethidiumbromid & Sigma-Aldrich, Deisenhofen \\
\hline Formaldehyde & Carl Roth GmbH, Karlsruhe \\
\hline Fungizone & Life Technologies, Darmstadt \\
\hline Gesamtextrakt aus Belamcanda & Christoffel Scientific Consulting, Buchberg- \\
\hline chinensis (Extrakt R) & Sengenthal \\
\hline $\begin{array}{l}\text { Gesamtextrakt aus Belamcanda } \\
\text { chinensis (Extrakt O) }\end{array}$ & Orgentis Chemicals, Gatersleben \\
\hline Glycerol & Carl Roth GmbH, Karlsruhe \\
\hline Glycin & Carl Roth GmbH, Karlsruhe \\
\hline GlycoBlue & Applied Biosystems, Ambion, Austin, USA \\
\hline Hefeextrakt & Carl Roth GmbH, Karlsruhe \\
\hline Igepal CA-630 (NP-40) & Sigma-Aldrich, Deisenhofen \\
\hline Insulin & Sigma-Aldrich, Deisenhofen \\
\hline Isopropanol & Merck, Darmstadt \\
\hline Natriumbutyrat & Alfa Aesar, Karlsruhe \\
\hline NuPAGE TM MES Running buffer (20x) & Life Technologies, Darmstadt \\
\hline NUPAGE ${ }^{\mathrm{TM}}$ LDS Sample buffer (4x) & Life Technologies, Darmstadt \\
\hline
\end{tabular}


NuPAGE $^{\text {TM }}$ See Blue Plus2

Orange-G

RNase-Inhibitor

Penicillin/Streptomycin

Roti $^{\circledR}-$ Nanoquant

Simply Blue Safe Stain

Suberoylanilide hydroxamic acid (SAHA)

Tectorigenin

Tectorigenin

Tectorigenin

Tectorigenin

Tectorigenin

Trichostatin A

Tris

Triton X-100

TRIzol ${ }^{\circledR}$ Reagent

Tween 20

Valproinsäure

Valpromid

VectaShield mit DAPI

$X-G a l$

Zellkulturmedien
Life Technologies, Darmstadt

Sigma-Aldrich, Deisenhofen

$\mathrm{MBI}$, St. Leon-Rot

PAN, Aidenbach

Carl Roth $\mathrm{GmbH}$, Karlsruhe

Life Technologies, Darmstadt

Cayman Chemical Company, Ann Arbor, USA

Biopurify, Sichuan, China

Girindus, Bergisch Gladbach

Shenzhen Sungening Bio-Tech Co., Ltd,

Guangdong, China

PhytoLab, Vestenbergsgreuth

Orgentis Chemicals, Gatersleben

AppliChem $\mathrm{GmbH}$, Darmstadt

Carl Roth $\mathrm{GmbH}$, Karlsruhe

Fluka, Deisenhofen

Life Technologies, Darmstadt

Merck, Darmstadt

Sigma-Aldrich, Deisenhofen

Alfa Aesar, Karlsruhe

VectorLab, Burlingame, USA

Carl Roth $\mathrm{GmbH}$, Karlsruhe

PAN, Aidenbach; Life Technologies $\mathrm{GmbH}$,

Darmstadt

\subsection{Biochemikalien und Enzyme}

\begin{tabular}{l|l}
\hline Biochemikalie & Hersteller \\
\hline Albumin Fraktion V & Carl Roth GmbH, Karlsruhe \\
BigDye ${ }^{\circledR}$ & Life Technologies, Darmstadt \\
Fetales Kälberserum (SeraPlus) & PAN, Aidenbach \\
MangoTaq-DNA-Polymerase & Bioline, Luckenwalde \\
Matrigel $^{\text {TM }}$ & BD Bioscience, San Jose, USA \\
Nu-Serum $^{\text {TM }}$ & BD Bioscience, San Jose, USA \\
OneTaq ${ }^{\circledR}$ Hot Start & New England Biolabs, Ipswich, USA \\
Phalloidin, TRITC-markiert & Sigma-Aldrich, Deisenhofen \\
Proteinase K & Carl Roth GmbH, Karlsruhe
\end{tabular}


Reverse Transkriptase SuperScript II

RNase A

RNase ZAP

Platinum $^{\circledR} \quad$ SYBR $^{\circledR} \quad$ Green $\quad$ qPCR

SuperMix-UDG with Rox

T4 DNA Ligase
Life Technologies, Darmstadt AppliChem GmbH, Darmstadt

Sigma-Aldrich, Deisenhofen

Life Technologies, Darmstadt

Life Technologies, Darmstadt

\subsection{Gebrauchswaren}

Nicht aufgeführte Gebrauchswaren wurden von den Firmen Schütt (Göttingen) und OmnilabKrannich (Göttingen), sowie Sarstedt (Nümbrecht) bezogen.

\begin{tabular}{l|l}
\hline Gebrauchsware & Hersteller \\
\hline 6-, 24- oder 96well-Zellkultur-Platten & $\begin{array}{l}\text { Sarstedt, Nürnbrecht } \\
\text { Corning Inc., New York, USA }\end{array}$ \\
384well-Platten, weiß & ABgene, Hamburg \\
Blottingpapier GB 002, 003, 004 & Schleicher \& Schüll, Dassel \\
Deckgläser 24x60mm & Menzel Gläser, Braunschweig \\
FALCON culture slides & Becton Dickinson GmbH, Heidelberg \\
flachbödige 96well-Mikrotiterplatten & Thermo Scientific, Langenselbold \\
Membranfilter & Millipore, Billerica, USA \\
MultiScreen & Millipore, Billerica, USA \\
MycoZap ${ }^{\text {TM }}$ Spray & Lonza, Köln Filterplatten \\
Neubauer improved Zählkammer & Hartenstein, Würzburg \\
Sterilfilter & Sartorius, Göttingen \\
NuPAGE & Life Technologies, Darmstadt \\
Objektträger Superfrost ${ }^{\circledR}$ Plus & Schütt, Göttingen \\
Petrischalen & Greiner Nunc., Nürtingen \\
Pipettenspitzen & Sarstedt, Nürnbrecht \\
PVDF-Membran & GE Healthcare, München \\
Quarz-Küvetten & Hellma, Mühlheim \\
Reaktionsgefäße & Sarstedt, Nürnbrecht \\
Sterilfilter & Sartorius, Göttingen \\
Zellkulturflaschen & Sarstedt, Nürnbrecht \\
\hline
\end{tabular}




\subsection{Geräte}

Es sind lediglich Geräte für spezielle Anwendungen aus dem Institut für Humangenetik in Göttingen aufgeführt.

\begin{tabular}{l|l}
\hline Gerät & Hersteller \\
\hline FluorChem® Q & Alpha Innotech, Logan, Utah, USA \\
Konfokales Laser scanning Mikroskop IX81 & $\begin{array}{l}\text { Olympus, Hamburg } \\
\text { Bio Tek, Bad Friedrichshall } \\
\text { Synergy Mx }\end{array}$ \\
Ultraschallgenerator, Bioruptor plus UCD-300 & Diagenode, Liège, Belgien
\end{tabular}

\subsection{Sterilisationsverfahren}

Gebrauchswaren, Lösungen und Kulturmedien wurden bei $121^{\circ} \mathrm{C}$ und 1,5 bar autoklaviert oder über Nacht bei $220^{\circ} \mathrm{C}$ hitzesterilisiert. Hitzeempfindliche Lösungen wurden steril filtriert.

\subsection{Gebrauchsfertige Reaktionssysteme}

\begin{tabular}{l|l}
\hline Reaktionssystem & Hersteller \\
\hline CellTiter $96^{\circledR}$ AQuaous Non-Radioactive Proliferation Assay (MTS) & Promega, Mannheim \\
Complete Mini Protease Inhibitor Cocktail & Roche, Mannheim \\
DNeasy blood and tissue Kit & Qiagen, Hilden \\
ECL Plus & GE Healthcare, Freiburg \\
EpiTect Bisulfite Kit & Qiagen, Hilden \\
Myco Alert® Mycoplasma Detection Kit & Lonza, Köln \\
OneDay ChIP Kit & Diagenode, Liège, Belgien \\
peqGold Total RNA Kit & PeqLab, Erlangen \\
PhosSTOP Phosphatase Inhibitor & Roche, Mannheim \\
Shearing ChIP Kit & Diagenode, Liège, Belgien
\end{tabular}

\subsection{Lösungen}

Lösungen für den routinemäßigen Gebrauch wurden nach Sambrook et al. (1989) angesetzt. Die benötigten Chemikalien wurden den Erfordernissen gemäß in bidestilliertem Wasser angesetzt und nach Bedarf autoklaviert oder steril filtriert. 


\begin{tabular}{|c|c|}
\hline Lösung/ Puffer & Zusammensetzung \\
\hline Blockpuffer I (Western Blot) & $\begin{array}{l}\text { 1x TBS-Tween } \\
5 \% \text { Magermilchpulver }\end{array}$ \\
\hline Blockpuffer II (Immunhistochemie) & $\begin{array}{l}1 \times \text { PBS } \\
3 \% \text { BSA }\end{array}$ \\
\hline Lysispuffer I für Proteine (modified RIPA) & $\begin{array}{l}150 \mathrm{mM} \mathrm{NaCl} \\
1 \mathrm{mM} \text { EDTA } \\
50 \mathrm{mM} \text { Tris- } \mathrm{HCl}, \mathrm{pH} 7.4 \\
1 \% \mathrm{NP}-40 \\
0,25 \% \text { Natriumdeoxycholat }\end{array}$ \\
\hline $\begin{array}{l}\text { Lysispuffer II für Proteine (Venkataramani et al., } \\
\text { 2010) }\end{array}$ & $\begin{array}{l}50 \text { mM Tris } \\
150 \text { mM NaCl } \\
\text { 1\% Nonidet P-40 } \\
\text { 1\% Triton X-100 } \\
2 \text { mM EDTA } \\
\text { pH } 7.5\end{array}$ \\
\hline 10x PBS & $\begin{array}{l}1,37 \mathrm{M} \mathrm{NaCl} \\
81 \mathrm{mM} \mathrm{Na}_{2} \mathrm{HPO}_{4} \\
27 \mathrm{mM} \mathrm{KCl} \\
14,7 \mathrm{mM} \mathrm{KH}_{2} \mathrm{PO}_{4}\end{array}$ \\
\hline 10x TBS & $\begin{array}{l}1,37 \mathrm{M} \mathrm{NaCl} \\
100 \mathrm{mM} \text { Tris } \\
\text { mit } \mathrm{HCl} \text { auf } \mathrm{pH} 7.6\end{array}$ \\
\hline 1x TBS-Tween (TBS-T) & $\begin{array}{l}1 \times \text { TBS } \\
0,1 \% \text { Tween } 20\end{array}$ \\
\hline Transferpuffer Ila (Western Blot) & $\begin{array}{l}25 \text { mM Tris pH } 8.3 \\
150 \text { mM Glycin } \\
20 \% \text { Methanol }\end{array}$ \\
\hline 20x Turbo-Puffer & $\begin{array}{l}0,2 \mathrm{M} \mathrm{NaOH} \\
\text { mit festem } \mathrm{H}_{3} \mathrm{BO}_{3} \text { auf } \mathrm{pH} 8.0\end{array}$ \\
\hline Waschlösung I (Western Blot) & $\begin{array}{l}\text { 1x TBS-Tween } \\
\text { 2,5\% Magermilchpulver }\end{array}$ \\
\hline
\end{tabular}




\subsection{Medien, Antibiotika, Agraplatten}

\subsubsection{Medium für Bakterien}

Luria-Bertani-Medium (LB-Medium): 1\% Trypton

$0,5 \%$ Hefeextrakt

$1 \% \mathrm{NaCl}$

$\mathrm{pH} 7.0$

Das Medium wurde mit bidestilliertem Wasser angesetzt, autoklaviert und bei RT aufbewahrt. Für die Selektion wurde der Resistenz entsprechend Ampicillin (Endkonzentration $50 \mu \mathrm{g} / \mathrm{ml}$ ) zugegeben.

\subsubsection{Agarplatten}

Zur Herstellung von Agarplatten wurde dem LB-Medium vor dem Autoklavieren 1,5\% (w/v) Agar zugefügt. Nach dem Autoklavieren wurde der LB-Agar auf $55^{\circ} \mathrm{C}$ abgekühlt, mit Ampicillin (Endkonzentration $50 \mu \mathrm{g} / \mathrm{ml}$ ) versetzt und in Petrischalen gegossen. Nach dem Aushärten wurden die Agarplatten bei $4^{\circ} \mathrm{C}$ aufbewahrt.

\subsubsection{Medien für eukaryotische Zellkulturen}

Die verwendeten Medien zur Kultur eukaryotischer Zellen wurden käuflich erworben (PAN, Aidenbach; Life Technologies, Darmstadt), vor Gebrauch mit fetalem Kälberserum (FKS), Antibiotika (Penicillin/Streptomycin) und weiteren Zusätzen versetzt. Es wurden folgende Medien für die angegebenen Zelllinien verwendet:

\begin{tabular}{l|l}
\hline Zelllinie & Zusammensetzung des Mediums \\
\hline $2 \mathrm{E}$ & Advanced DMEM \\
& $8 \%$ NuSerum \\
& $10 \% \mathrm{FKS}$ \\
& $100 \mathrm{nM}$ Dihydrotestosteron (DHT) \\
& $80 \mu \mathrm{g} / \mathrm{ml}$ Gentamycin \\
& $1 \%$ Glutamin \\
\hline LNCaP, PC-3, DU145, DLD-1, HCT-116, & RPMI 1640 \\
SW480, SW620, SW837 & $10 \%$ FKS \\
& $1,2 \%$ Penicillin/Streptomycin \\
\hline Caco-2 & MEM \\
& $20 \%$ FKS \\
& $1,2 \%$ Penicillin/Streptomycin
\end{tabular}




\begin{tabular}{l|l}
\hline HEK293, L-Zellen, NIH/3T3, NxNx, WT & DMEM \\
& $10 \%$ FKS \\
& $1,2 \%$ Penicillin/Streptomycin \\
\hline MRC-5 & MEM \\
& $10 \%$ FKS \\
& $1,2 \%$ Penicillin/Streptomycin \\
\hline PrSC & DMEM \\
& $2,5 \%$ FKS \\
& $2,5 \%$ NuSerum \\
& $0,05 \%$ Insulin \\
& $1,2 \%$ Penicillin/Streptomycin \\
& $1 \%$ Fungizone
\end{tabular}

Für die Kryokonservierung der Zellen in flüssigem Stickstoff wurde das entsprechende Medium mit 10\% DMSO versetzt.

\subsection{Biologisches Material}

\subsubsection{Bakterienstämme}

Der Bakterienstamm Escherichia coli $\mathrm{DH} 5 \alpha$ wurde für die Transformation von Plasmiden (Hanahan, 1983) verwendet und von Invitrogen (Karlsruhe) bezogen.

\subsubsection{Eukaryotische Zelllinien}

2E Murine Prostataadenokarzinom-Zelllinie, generiert aus dem Prostatatumor einer TRAMP-Maus, Isolierung der Zellen wurde in der Arbeitsgruppe durchgeführt, reiner C57/BI6-Hintergrund

LNCaP Humane Prostataadenokarzinom-Zelllinie, generiert aus einer Lymphknotenmetastase, Androgen-sensitive Zellen, ATCC, Rockville, USA

PC-3 Humane Prostataadenokarzinom-Zellinie, generiert aus einer Knochenmetastase, kastrationsresistente Zellen, ATCC, Rockville, USA

DU145 Humane Prostataadenokarzinom-Zellinie, generiert aus einer Gehirnmetastase, kastrationsresistente Zellen, ATCC, Rockville, USA 
PrSC Humane Stromazellen der Prostata, Lonza, Basel, Schweiz

SW480 Humane, kolorektale Adenokarzinom-Zelllinie, generiert aus einer Lymphknotenmetastase, ATCC, Rockville, USA

SW620 Humane, kolorektale Adenokarzinom-Zelllinie, generiert aus einer Lymphknotenmetastase, ATCC, Rockville, USA

SW837 Humane, rektale Adenokarzinom-Zelllinie, ATCC, Rockville, USA

Caco-2 Humane, kolorektale Adenokarzinom-Zelllinie, ATCC, Rockville, USA

DLD-1 Humane, kolorektale Adenokarzinom-Zelllinie, ATCC, Rockville, USA

HCT 116 Humane, kolorektale Adenokarzinom-Zelllinie, ATCC, Rockville, USA

MRC5 Humane Lungenfibroblasten-Zelllinie, zur Verfügung gestellt von Frau M. Rave-Fränk, Abteilung für Strahlentherapie und Radioonkologie der Universitätsmedizin Göttingen

NIH/3T3 Murine embryonale Fibroblasten-Zellinie, ATCC, Rockville, USA

WT

Murine Hautfibroblasten-Zelllinie, generiert aus der Dermis von WildtypC57/BI6-Mäusen (Uhmann et al., 2011), zur Verfügung gestellt von Frau Dr. F. Nitzki, Abteilung Humangenetik, Arbeitsgruppe molekulare Entwicklungsgenetik, Universitätsmedizin Göttingen

NxNx Murine Hautfibroblasten-Zelllinie, generiert aus der Dermis von Ptch floxfllox C57/Bl6-Mäusen (Uhmann et al., 2011), zur Verfügung gestellt von Frau Dr. F. Nitzki, Abteilung Humangenetik, Arbeitsgruppe molekulare Entwicklungsgenetik, Universitätsmedizin Göttingen

L-Zellen Murine Bindegewebsfibroblastenzelllinie, zur Verfügung gestellt von der Arbeitsgruppe Prof. Dr. H. Hahn, Abteilung Humangenetik, Arbeitsgruppe molekulare Entwicklungsgenetik, Universitätsmedizin Göttingen 
HEK293 Humane embryonale Nierenzelllinie, zur Verfügung gestellt von der Arbeitsgruppe Prof. Dr. H. Hahn, Abteilung Humangenetik, Arbeitsgruppe molekulare Entwicklungsgenetik, Universitätsmedizin Göttingen

\subsubsection{Mausstämme}

Die immundefizienten Nacktmäuse des Stammes Nu/Nu stammten von der Arbeitsgruppe von Frau Prof. Dr. F. Alves (Abteilung Hämatologie und Onkologie der Universitätsmedizin Göttingen). Die TRAMP-Mäuse des Stammes C57/BI6 wurden von der Firma Jackson Lab. (Bar Harbor, USA) bezogen. Reine C57/Bl6-Mäuse stammten aus institutseigenen Beständen. Die Haltungsbedingungen bestanden aus einem zwölfstündigen Hell-DunkelRhythmus bei $22^{\circ} \mathrm{C}$ und $55 \pm 5 \%$ relativer Luftfeuchtigkeit. Das Tierfutter wurde von der Firma ssniff-Spezialdiäten (Soest) bezogen.

\subsubsection{Synthetische DNA-Oligonukleotide}

Für die Generierung von PCR-Produkten und für die quantitativen real time PCR-Analysen wurden synthetische Oligonukleotide von den Firmen Life Technologies (Darmstadt) und Eurofins MWG Operon (Ebersberg) verwendet. Die Sequenzen sind jeweils vom 5'- zum 3'Ende angegeben.

Human-spezifische Primer für Untersuchungen an cDNA.

\begin{tabular}{l|l}
\hline Primername & Sequenz \\
\hline AR-Fw & AGGAACTCGATCGTATCATTGC \\
AR-Rev & CTCTGCCATCATTTCCGGAA \\
\hline Cyclin D1-Q1-Fw & ATGTTCGTGGCCTCTAAGATGAAG \\
Cyclin D1-Q1-Rev & GTTTGCGGATGATCTGTTTGTTCT \\
\hline Cyclin D1-Q2-Fw & AAGCTGTGCATCTACACCGACAAC \\
Cyclin D1-Q2-Rev & GCATTTTGGAGAGGAAGTGTTCAA \\
\hline Cyclin D2-Q1-Fw & ATTGCTCTGTGTGCCACCGACTT \\
Cyclin D2-Q1-Rev & CCGTCACGTTGGTCCTGACGG \\
\hline GAPDH-Fw & CATCACCATCTTCCAGGAGC \\
GAPDH-Rev & ATGACCTTGCCCACAGCCTT \\
\hline IGF-BP-3-Fw & GCCGTAGAGAAATGGAAGACACAC \\
IGF-BP-3-Rev & CCATACTTATCCACACACCAGCAG \\
\hline IGF-IR-Fw & CCGAAGGTCTGTGAGGAAGA \\
IGF-IR-Rev & AATGGCGGATCTTCACGTAG \\
\hline PBGD-Fw & GCAATGCGGCTGCAACGGCGGAAG \\
PBGD-Rev & CCTGTGGTGGACATAGCAATGATT \\
\hline PDEF-Fw & CCTCGACCAGTGAGGAGAGCTG \\
PDEF-Rev & TCCGGATGATGCCCTTCTTGTA \\
\hline PSA-Fw & TGAACCAGAGGAGTTCTTGAC \\
PSA-Rev & CCCCAGAATCACCCGAGCAG \\
\hline TBP-Fw & AGCCTGCCACCTTACGCTCAG \\
TBP-Rev & TGCTGCCTTTGTTGCTCTTCCA
\end{tabular}


Maus-spezifische Primer für Untersuchungen an cDNA.

\begin{tabular}{|c|c|}
\hline Primername & Sequenz \\
\hline Ar-Q2-Fw & ATGACAACAACCAACCAGATTCCT \\
\hline Ar-Q2-Rev & ACCAAGTCAGGTGCAAAGTAGAGC \\
\hline Ccnd1-Q1-Fw & ACACCAGCTCCTGTGCTGCGAA \\
\hline Ccnd1-Q1-Rev & CCAGGTAGTTCATGGCCAGCGG \\
\hline Ccnd1-Q2-Fw & CCCTTGACTGCCGAGAAGTTGTGC \\
\hline Ccnd1-Q2-Rev & GTTCAGGCCTTGCATCGCAGC \\
\hline Ccnd2-Q1/2-Fw & GGAGCTGCTGGAGTGGGAACTGGT \\
\hline Ccnd2-Q1-Rev & GCGCATGCTTGCGGATCAGGGACA \\
\hline Ccnd2-Q2-Rev & TCGACGGCGGGTACATGGCAAACT \\
\hline Cdk4-Q1-Fw & GCTCGCGGCCTGTGTCTATGG \\
\hline Cdk4-Q1-Rev & TCTCGAAGCAGGGGATCTTACGC \\
\hline Cdk4-Q2-Fw & TCCCGGGCCCAGATAAAGGGC \\
\hline Cdk4-Q2-Rev & TCCATCAGCCGTACAACATTGGGAT \\
\hline Cdk6-Q1-Fw & AAGGTGTTCAAGGCCCGCGAC \\
\hline Cdk6-Q1-Rev & GCTTGGTTTCTCTGTCCGTCCGT \\
\hline Cdk6-Q2-Fw & CACGGACGGACAGAGAAACCAAGC \\
\hline Cdk6-Q2-Rev & GTACCACAGCGTGACGACCACC \\
\hline Cdkn1a-Q1-Fw & AGCCGAGAGGTGTGAGCCGCC \\
\hline Cdkn1a-Q1-Rev & СCCTCCAGCGGCGTCTCCGT \\
\hline Cdkn1a-Q2-Fw & AGCCGCCGCGGTGTCAGAGT \\
\hline Cdkn1a-Q2-Rev & GGGCCTCCTGGAGACAGCCCG \\
\hline Ceruloplasmin1-Q1-Fw & ACCAAGCAGGGCCTGGGAAAAGGA \\
\hline Ceruloplasmin1-Q1/2-Rev & CCCAAGTGCTCGTCTTCGGCTCGT \\
\hline Ceruloplasmin1-Q2-Fw & ACTCACCAAGCAGGGCCTGGGAAA \\
\hline Ceruloplasmin2-Q1-Fw & TACTCCACTGCCACGTGACTGACC \\
\hline Ceruloplasmin2-Q1/2-Rev & ACCAGGTCCCTCGCAAATGAACAGT \\
\hline Ceruloplasmin2-Q2-Fw & TGTCCATGCTGGGATGGCAACTACC \\
\hline Clusterin-Q2-Fw & ATGTCCAGCTCCACAGCCCAGCCTT \\
\hline Clusterin-Q2-Rev & AGTCGTTCAGCTCCTGGCGCAGGTT \\
\hline Cxcl15-Q1-Fw & GGCTGTCCTTAACCTAGGCATCTT \\
\hline Cxcl15-Q1-Rev & AGCATCAGGATCCAAACAAATCAT \\
\hline Cxcl15-Q2-Fw & GAAGGCTACTGTTGGCCCAATTAC \\
\hline Cxcl15-Q2-Rev & СTTGTTCTCAGGTCTCCCAAATGA \\
\hline Fox01-Q1-Fw & AAGGGCGACAGCAACAGCTCGG \\
\hline Foxo1-Q1-Rev & TCCAGGACCCTCTTGCCCAGACT \\
\hline Foxo1-Q2-Fw & CCGCGCAAGACCAGCTCGTCG \\
\hline Foxo1-Q2-Rev & TCCGCTCTTGCCTCCСTCTGGAT \\
\hline Gsk3ß-Q2-Fw & CGCTCGGCTTTTTCCGGCAGG \\
\hline Gsk3ß-Q2-Rev & CGACACAAGCCCGCATTCGGC \\
\hline Hif1a-Fw & GGTGCTTCACTGCACGGGCCA \\
\hline Hif1a-Rev & GCGGCCCAAAAGTTCTTCCGGC \\
\hline Hprt-Fw & AGCCCCAAAATGGTTAAGGTTGC \\
\hline Hprt-Rev & TTGCAGATTCAACTTGCGCTCAT \\
\hline $\operatorname{lgf} 1 r-F w$ & GTGGTCAAGGATGAACCCGAAAC \\
\hline Igf1r-Rev & TGGCCTCAGAGACCGGAGATAAC \\
\hline Lif1-Q1-Fw & AGACTGTGGAGGGCTGCGAGACCA \\
\hline Lif1-Q1/2-Rev & ATGGGTGGCGTATGGCACAGGTGG \\
\hline Lif1-Q2-Fw & GCTGCGAGACCACGGCTCCAGTAT \\
\hline Lif2-Q1/2/3-Fw & CGTTGTTGGGAAACGGCTCCССTT \\
\hline
\end{tabular}




\begin{tabular}{l|l}
\hline Lif2-Q1-Rev & GTGATTGGCGCGAGATGAGATGCAG \\
Lif2-Q2-Rev & GGAACGGCTCCCCTTGAGCTGTG \\
Lif2-Q3-Rev & GTTGGGAAACGGCTCCCCTTGAGC \\
\hline Pak3-Fw & CCTCCGCCTGTCATTGCACCAA \\
Pak3-Rev & AACAGTTCCTGATGCCCCTTGGC \\
\hline Pten-Fw & ATGGCTAAGTGAAGATGACAATCA \\
Pten-Rev & TTTTTGTCTCTGGTCCTTACTTCC \\
\hline Ptprn-Q1/2-Fw & TGCCCACGGCTGTCTGTTTGACCG \\
Ptprn-Q1-Rev & TGGGCACCAAACCAGACCTGTCCC \\
Ptprn-Q2-Rev & CCGGAGCACACCTTGTAGGCGCTG \\
\hline Rcbtb2-Q1-Fw & TCCAGCGGGTTGCCTGTGGCTACG \\
Rcbtb2-Q1-Rev & TGCCCACCTTGTGTCTTGGCAGCA \\
\hline Rcbtb2-Q2-Fw & AGCTGACCAAGGGACTGCACAGGA \\
Rcbtb2-Q2-Rev & GCCAGCACTGCCGAAGACACAAGC \\
\hline Tbp-Q-Fw & CACCAATGACTCCTATGACCCCTA \\
Tbp-Q-Rev & CAGTTGTCCGTGGCTCTCTTATTC \\
\hline Uchl1-Q1-Fw & GTACGAGCTCGATGGGCGAATGCC \\
Uchl1-Q1-Rev & GGGATCGGCTGGTTCTCTCTCCCC \\
\hline Uchl1-Q2-Fw & CTCCCCTGCTCAGGCTTTCCCAGT \\
Uchl1-Q2-Rev & CTCCTCCTCCAGCCCTAGCACGTC \\
\hline Vegfa-Q1-Fw & CCC CGG ACG GGC CTC CGA AA \\
Vegfa-Q1-Rev & TGC ACA GCG CAT CAG CGG CA
\end{tabular}

Maus-spezifische Primer für Untersuchungen an genomischer DNA.

\begin{tabular}{l|l}
\hline Primername & Sequenz \\
\hline Ccnd2-ChIP-Q4-Fw & TGCTCTCTAACTTCGGAGGCTTGCA \\
Ccnd2-ChIP-Q4-Rev & CCCTGGTTTGGCGAGGTTGCAATTT \\
\hline Ccnd2-ChIP-Q5-Fw & GCCTCGGATAGGGGAACCCACAA \\
Ccnd2-ChIP-Q5-Rev & GCAAGCCTCCGAAGTTAGAGAGCAC \\
\hline Ccnd2-ChIP-Q7-Fw & TGCAACCTCGCCAAACCAGGG \\
Ccnd2-ChIP-Q7-Rev & CTCTCCACGCACGTGGCTCG \\
\hline Ceruloplasmin-ChIP-Q1-Fw & TGCCCTCCTGGAATTTACAC \\
Ceruloplasmin-ChIP-Q1-Rev & CTTCATTTGCTTGGCTGACA \\
\hline Ceruloplasmin-ChIP-Q2-Fw & AGGTGTAGTGCCTGGGATTG \\
Ceruloplasmin-ChIP-Q2-Rev & AAACCACGAAGGGGAAAAAC \\
\hline Cxcl15-ChIP-Q1-Fw & CCCAAAGCAGGGTTTTGTTA \\
Cxcl15-ChIP-Q1-Rev & CTTCACAAGCCCAGAAGGAG \\
\hline Cxcl15-ChIP-Q1-Fw & ACGACAACAACAAGGGCCCCT \\
Cxcl15-ChIP-Q1-Rev & CTCCCAGCAGCCCCGGAGAT \\
\hline Lif-ChIP-Q1-Fw & GCGGCCCAGTCAGCTGTGAC \\
Lif-ChIP-Q1-Rev & GCACCCACACCACAGATGGAGC \\
\hline Ptprn-ChIP-Q1-Fw & CGGCGACGTTGGTGGGAGTC \\
Ptprn-ChIP-Q1-Rev & CCCCGGCTAAGAGGGGGCTC \\
\hline Ptprn-ChIP-Q2-Fw & GGCGGGGTCTAGTTGCCCCT \\
Ptprn-ChIP-Q2-Rev & AGCCAGGGAGACAGAGGCGG \\
\hline Rcbtb-ChIP-Q1-Fw & GGAGGAGGGATGGAGGCTACG \\
Rcbtb-ChIP-Q1-Rev & GGGAGCCTGTGGGGCTAGTGA \\
\hline Uchl1-ChIP-Q1-Fw & AGAGACCCTCGAGCTTTGGAGTGA \\
Uchl1-ChIP-Q1-Rev & TGCAGTCTCACTCGCCGGTG \\
\hline Uchl1-ChIP-Q2-Fw & CAGAGACCCTCGAGCTTTGGAGTG \\
Uchl1-ChIP-Q2-Rev & CCCCCATGCACCGCACAGAAT \\
\end{tabular}


Maus-spezifische Primer für methylierungsspezifische Untersuchungen an genomischer DNA.

\begin{tabular}{l|l}
\hline Primername & Sequenz \\
\hline Ccnd2-Seq-Q2-Fw & TTTGAGAGGGGGAGGAGATTTAATT \\
Ccnd2-Seq-Q2-Rev & AAATACTTCCCTTACCTCCTTCCTTTAACT
\end{tabular}

Verwendete siRNA-Nukleotide.

\begin{tabular}{l|l}
\hline Primername & Sequenz \\
\hline Cyclin D2 A & CAGCAGUUCCGUCAAGAGCAGCAUA \\
\hline Cyclin D2 B & UAUGCUGCUCUUGACGGAACUGCUG \\
\hline Cyclin D2 C & CCACACUGAUGUGGAUUGUCUCAAA \\
\hline Luciferase & CGUACGCGGAAUACUUTGATT
\end{tabular}

Vektorprimer für die Sequenzierung.

\begin{tabular}{l|l}
\hline Primername & Sequenz \\
\hline T7-new & AATACGACTCACTATAGGGCGAATTGG \\
\hline Sp6-new & TTAGGTGACACTATAGAATACTCAAGC
\end{tabular}

\subsubsection{Antikörper}

\begin{tabular}{l|l}
\hline Primärantikörper & Hersteller \\
\hline $\begin{array}{l}\text { Androgen Receptor Ab-2 } \\
\text { polyklonaler Antikörper, Kaninchen }\end{array}$ & NeoMarkers, Westinghouse, USA \\
\hline $\begin{array}{l}\text { acHiston 3, Lys9 } \\
\text { polyklonaler Antikörper, Kaninchen }\end{array}$ & Santa Cruz, Heidelberg \\
\hline $\begin{array}{l}\text { acHiston 3, Lys9 } \\
\text { polyklonaler Antikörper, Kaninchen }\end{array}$ & Millipore, Billerica, USA \\
\hline $\begin{array}{l}\text { a-Tubulin } \\
\text { monoklonaler Antikörper, Maus }\end{array}$ & Sigma-Aldrich, Deisenhofen \\
\hline $\begin{array}{l}\text { Bax } \\
\text { monoklonaler Antikörper, Kaninchen }\end{array}$ & Cell Signaling, Danvers, USA \\
\hline $\begin{array}{l}\text { Bcl-2 } \\
\text { monoklonaler Antikörper, Kaninchen }\end{array}$ & Cell Signaling, Danvers, USA \\
\hline $\begin{array}{l}\text { Bim } \\
\text { monoklonaler Antikörper, Kaninchen }\end{array}$ & Cell Signaling, Danvers, USA \\
\hline $\begin{array}{l}\text { Bok } \\
\text { polyklonaler Antikörper, Kaninchen }\end{array}$ & Cell Signaling, Danvers, USA \\
\hline $\begin{array}{l}\text { Caspase 3 } \\
\text { monoklonaler Antikörper, Kaninchen }\end{array}$ & Cell Signaling, Danvers, USA \\
\hline $\begin{array}{l}\text { Cyclin D1 } \\
\text { polyklonaler Antikörper, Kaninchen }\end{array}$ & NeoMarkers, Westinghouse, USA \\
\hline $\begin{array}{l}\text { Cyclin D2 } \\
\text { polyklonaler Antikörper, Kaninchen }\end{array}$ & Santa Cruz, Heidelberg \\
\hline $\begin{array}{l}\text { Cyclin D2 } \\
\text { monoklonaler Antikörper, Kaninchen }\end{array}$ & Cell Signaling, Danvers, USA \\
\hline $\begin{array}{l}\text { monclin D3 } \\
\text { monoklonaler Antikörper, Maus }\end{array}$ & Cell Signaling, Danvers, USA \\
\hline
\end{tabular}




\section{IGF-IR $\beta$}

polyklonaler Antikörper, Kaninchen

\section{Östrogenrezeptor $\alpha$}

polyklonaler Antikörper, Kaninchen

\section{Östrogenrezeptor $\boldsymbol{\beta}$}

polyklonaler Antikörper, Kaninchen

\section{p15}

polyklonaler Antikörper, Kaninchen

p27

Polyklonaler Antikörper, Kaninchen

pRb

Polyklonaler Antikörper, Kaninchen

SV-40

monoklonaler Antikörper, Maus
Santa Cruz, Heidelberg

Santa Cruz, Heidelberg

Cell Signaling, Danvers, USA

Cell Signaling, Danvers, USA

Cell Signaling, Danvers, USA

Cell Signaling, Danvers, USA

BD Bioscience, San Jose, USA

\begin{tabular}{l|l}
\hline Sekundärantikörper & Hersteller \\
\hline $\begin{array}{l}\text { anti-Kaninchen IgG } \\
\text { Cy3-konjugiert, Schaf }\end{array}$ & Sigma-Aldrich, Deisenhofen \\
\hline $\begin{array}{l}\text { anti-Kaninchen IgG (H+L) } \\
\text { HRP (horse radish peroxidase) konjugiert, Ziege }\end{array}$ & $\begin{array}{l}\text { Dianova, Hamburg, Jackson } \\
\text { ImmunoResearch }\end{array}$ \\
\hline $\begin{array}{l}\text { anti-Maus IgG } \\
\text { Cy3-konjugiert, Schaf }\end{array}$ & $\begin{array}{l}\text { Sigma-Aldrich, Deisenhofen } \\
\text { anti-Maus IgG (H+L) }\end{array}$ \\
$\begin{array}{l}\text { HRP konjugiert, Kaninchen } \\
\text { Dako REAL }{ }^{\mathrm{TM}} \text { Biotinylated Secondary Antibody Hamburg, Jackson } \\
\text { AP-konjugiert, biotinyliert, Gemisch, welches sowohl } \\
\text { gegen Kaninchen als auch Maus gerichtet ist, Ziege }\end{array}$ & ImmunoResearch \\
\hline
\end{tabular}

\subsubsection{Vektoren}

Es wurde das pGEM®-T Easy-Vektorsystem von Promega (Mannheim) verwendet.

\subsection{Datenbanken}

\begin{tabular}{l|l}
\hline Verwendung & Programm \\
\hline $\begin{array}{l}\text { Analyse von DNA- und } \\
\text { Protein-Sequenzen }\end{array}$ & BLAST-Programm (http://www.ncbi.nlm.nih.gov) \\
\hline Bioinformatik & $\begin{array}{l}\text { Ensembl v32 (http://www.ensembl.org/) } \\
\text { National Center for Biotechnology Information } \\
\text { (http://ncbi.nlm.nih.gov/) }\end{array}$ \\
\hline $\begin{array}{l}\text { Auswahl von } \\
\text { Oligonukleotiden }\end{array}$ & $\begin{array}{l}\text { Primer-BLAST } \\
\text { (http://Www.ncbi.nlm.nih.gov/tools/primer- } \\
\text { blast/index.cgi?LINK_LOC=BlastHome) }\end{array}$ \\
\hline $\begin{array}{l}\text { Auswahl von } \\
\text { Oligonukleotiden für } \\
\text { methylierungsspezifische } \\
\text { Analysen }\end{array}$ & $\begin{array}{l}\text { MethPrimer (Li und Dahiya, 2002) } \\
\text { (http://www.urogene.org/cgi-bin/methprimer/methprimer.cgi) }\end{array}$ \\
\hline
\end{tabular}


Auswertung der methylierungsspezifischen Sequenzierung
BISMA (Rohde et al., 2010)

(http://biochem.jacobsuniversity.de/BDPC/BISMA/manual_unique.php)

\subsection{Isolierung und Aufreinigung von Nukleinsäuren}

\subsubsection{Isolierung von genomischer Gesamt-DNA sowie Gesamt-RNA aus Zellkulturen und anschließender Konzentrationsbestimmung}

Die Isolierung von genomischer Gesamt-DNA aus Zellpellets erfolgte mit Hilfe des DNeasy blood and tissue Kit der Firma Qiagen (Hilden) nach dem Protokoll des Herstellers.

Die Isolierung von Gesamt-RNA aus Zellkulturen erfolgte mit Hilfe des peqGOLD Total RNA Kits der Firma peQLab (Erlangen) nach dem Protokoll des Herstellers.

Für die Bestimmung der Konzentration der isolierten Nukleinsäuren wurde ein Photometer (Eppendorf, Hamburg) verwendet. Das Absorptionsmaximum bei 260nm wurde bestimmt und gleichzeitig die Verunreinigung durch Proteine (bei 280nm) und Salzen (bei 320nm) ermittelt. Die Berechnung der Nukleinsäurekonzentration erfolgte über das Lambert'sche Gesetz.

\subsubsection{Aufreinigung von Nukleinsäuren aus einer PCR}

Für die Aufreinigung von PCR-Produkten in großem Maßstab nach der Kolonie-PCR (vgl. Kapitel 2.15.3) wurde die Vakuumeinheit MultiScreen $_{H T S}$ mit den dazugehörigen MultiScreen $_{\text {HTS }}$ 96well Filterplatten verwendet (Millipore, Billerica, USA). Hierfür wurden zunächst die Membranen der Filterplatten mit 100 $\mu$ TE-Puffer pro well für ca. $5 \mathrm{~min}$ bei RT äquilibriert. In der Zwischenzeit wurden jeweils 100 $\mu$ l TE-Puffer zu den zu aufreinigenden PCR-Produkten gegeben. Nach der Äquilibrierung wurden die Proben (ca. 120 $\mu$ ) in die Filterplatte gegeben und die Filterplatte auf der Vakuumeinheit plaziert. Die Proben passierten durch Anlegen eines Vakuums den Filter. Zum Eluieren der DNA wurden je nach PCR-Produkt bis zu $50 \mu \mathrm{H}_{2} \mathrm{O}$ auf die Membran gegeben und nach ca. 5 min Inkubation bei RT und leichtem Mischen der Proben wurde die aufgereinigte DNA in eine 96well PCR-Platte überführt und bis zur weiteren Verwendung der Probe bei $4^{\circ} \mathrm{C}$ aufbewahrt.

\subsection{Bisulfit-Konversion genomischer DNA}

Isolierte genomische DNA (vgl. Kapitel 2.11.1) wurde mit Hilfe des EpiTect Bisulfit Kits der Firma Qiagen (Hilden) nach den Angaben des Herstellers konvertiert. Hierbei bleiben methylierte Cytosine der DNA erhalten, unmethylierte Cyctosine jedoch werden in Uracil konvertiert. 


\subsection{Klonierungstechniken}

\subsubsection{Herstellung von Bakterien-Glycerin-Stocks}

Die Bakteriensuspension wurde mit 10\% sterilem Glycerin versetzt, gut vermischt und für spätere Analysen bei $-80^{\circ} \mathrm{C}$ aufbewahrt.

\subsubsection{Ligation}

In dieser Arbeit wurden lediglich PCR-Produkte mit einem A-Überhang in den pGEM®T Easy Vektor ligiert. Dieser Vektor besitzt einen T-Überhang. Es wurde folgender Ansatz verwendet:

$1 \mu \mathrm{l}$ pGEM®T Easy Vektor

$1 \mu \mathrm{l}$ Ligase

$5 \mu \mathrm{l} 2 \mathrm{x}$ Puffer

$1 \mu \mathrm{l}$ PCR-Produkt

$2 \mu \mathrm{H} 2 \mathrm{O}$

insgesamt $10 \mu \mathrm{l}$

Dieser Ansatz wurde über Nacht bei $4^{\circ} \mathrm{C}$ inkubiert und daraufhin eine Transformation (vgl. Kapitel 2.13.3) durchgeführt.

\subsubsection{Transformation kompetenter Zellen mit Plasmid-DNA}

Bei der Transformation wurden die kompetenten Zellen zunächst $5 \mathrm{~min}$ auf Eis aufgetaut. Anschließend wurde $2 \mu \mathrm{l}$ des Ligationsansatzes zu je $50 \mu \mathrm{l}$ der kompetenten Zellen gegeben und 30min auf Eis inkubiert. Anschließend wurden die Zellen für $1 \mathrm{~min}$ bei $42^{\circ} \mathrm{C}$ einem Hitzeschock unterzogen und schließlich erneut $5 \mathrm{~min}$ auf Eis inkubiert. Nach Zugabe von $200 \mu$ l LB-Medium wurde der Ansatz bei $37^{\circ} \mathrm{C}$ für $45 \mathrm{~min}$ auf einem Thermomixer bei 1000rpm inkubiert. Danach wurden 200 $\mu$ l des Ansatzes auf geeigneten Agarplatten ausgestrichen und über Nacht bei $37^{\circ} \mathrm{C}$ inkubiert.

\subsection{Gelelektrophorese von DNA}

In dieser Arbeit wurde die Agarose-Gelelektrophorese verwendet, um DNA-Fragmente nach ihrer Größe aufzutrennen. Der Anteil an Agarose im Gel lag zwischen 0,5-2,0\% (w/v) und die Agarose wurde in 1x Turbo-Puffer durch Kochen gelöst. Anschließend wurde der Lösung DNA Stain G (Serva, Heidelberg) zugesetzt um die DNA-Fragmente sichtbar zu machen. Es wurde neben den Proben ein Längenstandard mitgeführt (1kb DNA-ladder, Life Technologies, Darmstadt) und die Gele wurden bei 200V und 200mA laufen gelassen. 


\subsection{Polymerase-Kettenreaktion}

Die Polymerase-Kettenreaktion (PCR) ist eine in vitro-Methode, um spezifische DNAFragmente zu amplifizieren (Saiki et al., 1985). Hierbei wird doppelsträngige DNA mit Hilfe von hohen Temperaturen denaturiert, so dass Oligonukleotide (Primer) an die DNA binden können (sog. Annealing). Anschließend wird durch eine Polymerase das gebundene Oligonukeotid verlängert (sog. Elongation). Dieser Vorgang aus Denaturierung, Annealing und Elongation wird zyklisch wiederholt, so dass die Menge des DNA-Fragments exponentiell ansteigt.

\subsubsection{Standard-PCR}

Die Standard-PCR wurde in dieser Arbeit verwendet um die Effizienz der cDNA-Synthese nach Reverser Transkriptase-PCR zu kontrollieren (vgl. Kapitel 2.15.5). Hierfür wurde folgender Ansatz verwendet:

$$
\begin{aligned}
& 0,5 \mu \mathrm{l} \text { cDNA } \\
& 5 \mu l \text { 5x Puffer } \\
& \text { 2,5 } \mu \mathrm{l} \text { dNTP-Mix (2mM) } \\
& \text { 0,5 } \mu \mathrm{l} \text { Primer Fw (10pmol/ } \mu \mathrm{l}) \\
& \text { 0,5 } \mu \text { l Primer Rev (10pmol/ } \mu \mathrm{l}) \\
& 0,75 \mu \mathrm{MgCl}_{2}(50 \mathrm{mM})
\end{aligned}
$$

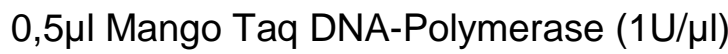

$$
\begin{aligned}
& 14,25 \mu \mathrm{l} \mathrm{H}_{2} \mathrm{O}
\end{aligned}
$$

Der Ansatz wurde anschließend mit folgendem Programm in einem Thermocycler inkubiert: $95^{\circ} \mathrm{C} 2 \mathrm{~min}$

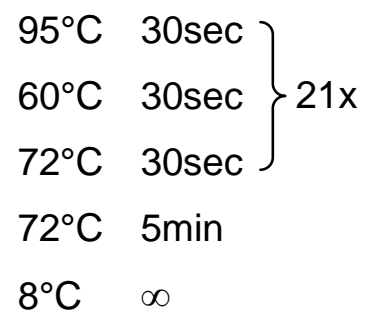

\subsubsection{PCR zur Amplifikation einer CpG-Insel im Ccnd2-Promotorbereich}

Diese spezielle PCR wurde verwendet um aus Bisulfit-konvertierter genomischer DNA (vgl. Kapitel 2.12) eine CpG-Insel im Promotorbereich des Ccnd2-Gens zu amplifizieren. Der Ansatz enthielt folgende Komponenten: 
$5 \mu \mathrm{l}$ Standard Puffer

$0,5 \mu \mathrm{l} 10 \mathrm{mM}$ dNTPs

0,5 $\mu$ l Primer Fw (10pmol/ $\mu \mathrm{l})$ (Ccnd2-Seq-Q2 fw)

0,5 $\mu$ l Primer Rev (10pmol/ $\mu$ l) (Ccnd2-Seq-Q2 rev)

$0,3 \mu$ l OneTaq ${ }^{\circledR}$ HotStart (NEB)

$1 \mu \mathrm{l}$ Bisulfit-konvertierte genomische DNA

$17,2 \mu \mathrm{l} \mathrm{H}_{2} \mathrm{O}$

insgesamt $25 \mu \mathrm{l}$

Der Ansatz wurde anschließend mit folgendem Programm in einem Thermocycler inkubiert:

$94^{\circ} \mathrm{C} \quad 30 \mathrm{sec}$

$94^{\circ} \mathrm{C} \quad 30 \mathrm{sec}$

$\left.\begin{array}{ll}55^{\circ} \mathrm{C} & 1 \min \\ 68^{\circ} \mathrm{C} & 1 \min \end{array}\right\} 40 \mathrm{x}$

$68^{\circ} \mathrm{C} 5 \mathrm{~min}$

$8^{\circ} \mathrm{C} \infty$

\subsubsection{Kolonie-PCR}

Die Kolonie-PCR stellt eine Methode dar, bei der in kurzer Zeit viele verschiedene Klone untersucht werden können. Sie wurde im Rahmen dieser Arbeit bei der methylierungsspezifischen Sequenzierung verwendet um jeweils 15 geeignete Klone zu identifizieren, die das PCR-Produkt integriert hatten.

Es wurde hierbei in 96well PCR-Platten gearbeitet. Es wurden 14,25 $\mu \mathrm{H}_{2} \mathrm{O}$ vorgelegt, der jeweilige Klon wurde mit Hilfe einer Pipettenspitze von der Agarplatte aufgenommen und in $\mathrm{H}_{2} \mathrm{O}$ angeimpft, der Rest des Klons wurde zur Sicherung auf einer neuen Agarplatte mit geeigneter Resistenz ausgestrichen. Der restliche PCR-Ansatz bestand aus den folgenden Komponenten:

$1 \mu \mathrm{l}$ Primer fw $(10 \mathrm{pmol} / \mu \mathrm{l})$

$1 \mu \mathrm{l}$ Primer rev (10pmol/ $\mu \mathrm{l})$

$2,5 \mu \mathrm{l}$ dNTP-Mix (2mM)

$5 \mu \mathrm{l}$ xxPuffer farblos

$0,75 \mu \mathrm{l} \mathrm{MgCl} 2$

0,5 $\mu$ l MangoTag-Polymerase

Diese $10,75 \mu \mathrm{l}$ wurden $\mathrm{zu}$ dem angeimpften $\mathrm{H}_{2} \mathrm{O}(14,25 \mu \mathrm{l})$ gegeben und in einem Thermocycler mit folgendem Programm inkubiert: 
$95^{\circ} \mathrm{C} \quad 2 \mathrm{~min}$

$95^{\circ} \mathrm{C} 30 \mathrm{sec}$

$\left.60^{\circ} \mathrm{C} 30 \mathrm{sec}\right\} 21 \mathrm{x}$

$72^{\circ} \mathrm{C} \quad 30 \mathrm{sec}$

$72^{\circ} \mathrm{C} \quad 5 \mathrm{~min}$

$8^{\circ} \mathrm{C} \infty$

\subsubsection{Sequenzanalyse}

Die Sequenzanalyse nach Sanger basiert auf dem Prinzip des Kettenabbruchs (Sanger und Coulson, 1975). Es werden bei einer Sequenz-Reaktion fluoreszenz-markierte Didesoxynukleotide eingefügt, die keine 3'-Hydroxygruppe besitzen. Die Synthese des Stranges bricht an der Stelle ab und in der anschließenden Gelelektrophorese kann über Laserabtastung der jeweilige Fluoreszenzfarbstoff detektiert werden. Der Ansatz für die Sequenz-Reaktion enthielt folgende Komponenten:

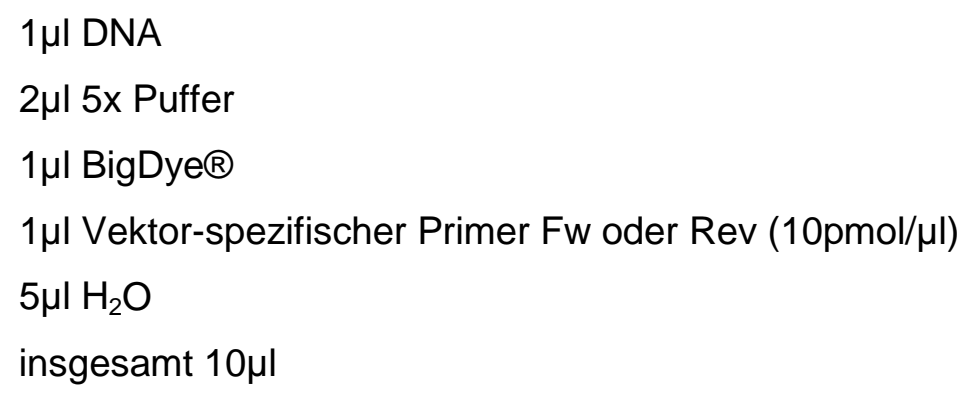

Dieser Ansatz wurde in einem Thermocycler mit folgendem Programm inkubiert:

$95^{\circ} \mathrm{C} 1 \mathrm{~min}$

$95^{\circ} \mathrm{C} \quad 30 \mathrm{sec}$

$\left.60^{\circ} \mathrm{C} 2 \min 30 \mathrm{sec}\right\} 30 \mathrm{x}$

$60^{\circ} \mathrm{C} 5 \mathrm{~min}$

$8^{\circ} \mathrm{C} \infty$

Es wurden $10 \mu \mathrm{l} \quad \mathrm{H}_{2} \mathrm{O}$ zu dem Ansatz hinzugefügt und anschließend erfolgte die gelelektrophoretische Analyse mit der automatischen Sequenzanlage 3500XL der Firma Applied Biosystems (Life Technologies, Darmstadt).

\subsubsection{Reverse Transkription}

Die reverse Transkription (RT)-PCR wurde verwendet um RNA in cDNA zu transkribieren. Die cDNA wurde anschließend für quantitative real time PCR-Analysen verwendet. Das Prinzip der reversen Transkription besteht darin, dass sich die verwendeten oligo(dT)-Primer 
mit den poly(A)-Sequenzen der mRNA paaren. Daraufhin kann die Reverse Transkriptase den Strang verlängern und dadurch die cDNA synthetisieren.

Die Reaktion wurde mit folgendem Ansatz in drei Schritten durchgeführt:

Schritt 1: $\quad 2-5 \mu \mathrm{g}$ RNA

$+0,5 \mu$ l oligo(dT)-Primer $(0,5 \mu \mathrm{g} / \mu \mathrm{l})$

$+0,5 \mu \mathrm{l}$ dNTP $(10 \mathrm{mM})$

ad $6 \mu \mathrm{l} \mathrm{H}_{2} \mathrm{O}$

- $72^{\circ} \mathrm{C} 10 \mathrm{~min}$ Inkubation

Schritt 2: $\quad+2 \mu \mathrm{l} 5 \mathrm{x}$ First Strand buffer

$+1 \mu \mathrm{DTT}(0,1 \mathrm{M})$

- $42^{\circ} \mathrm{C} 2 \mathrm{~min}$ Inkubation

Schritt 3: $\quad+0,25 \mu$ l SuperScript II

$+0,75 \mu \mathrm{l} \mathrm{H}_{2} \mathrm{O}$

- $42^{\circ} \mathrm{C}$ 50min Reverse Transkription

- $70^{\circ} \mathrm{C} 15 \mathrm{~min}$ Hitzeinaktivierung

$-8^{\circ} \mathrm{C} \infty$

Die synthetisierte cDNA wurde anschließend mit $10 \mu \mathrm{l} \mathrm{H}_{2} \mathrm{O}$ verdünnt und mittels StandardPCR mit Primern für sog. housekeeping-Gene überprüft, bevor sie für quantitative real time PCR-Analysen (Kapitel 2.15.6) verwendet wurde.

\subsubsection{Quantitative real time PCR-Analysen}

Die quantitative real time PCR beruht auf dem Prinzip der herkömmlichen PCR, ermöglicht darüber hinaus aber die Quantifizierung des entstandenen Produkts während des Versuchs. Dies ist möglich durch die Messung eines Fluoreszenz-Farbstoffes, welcher an doppelsträngige DNA bindet. In den Untersuchungen dieser Arbeit wurde der PCRMastermix Platinum ${ }^{\circledR}$ SYBR $^{\circledR}$ Green qPCR SuperMix-UDG with Rox (Life Technologies, Darmstadt) verwendet. Der Anstieg der Intensität der Fluoreszenz wird nach jedem Zyklus der PCR mit Hilfe des ABI Prism 7900T Sequence Detection Systems gemessen und daraus eine Kurve erstellt. In der exponentiellen Phase der Reaktion, in der die volle Aktivität der Polymerase vorherrscht und genügend Materialien (Primer, $\mathrm{MgCl}_{2}$ ) vorliegen, wird der sog. threshold-Wert bestimmt und anhand des PCR-Zyklus, in dem dieser erreicht wird, werden die anschließenden Berechnungen zur Quantifizierung vorgenommen (Ct-Wert).

Diese Methode wurde in dieser Arbeit sowohl für Analysen an cDNA verwendet, als auch für Analysen an genomischer DNA nach Chromatinimmunopräzipitation (ChIP). Die cDNA 
wurde hierbei gewöhnlich 1:20 mit $\mathrm{H}_{2} \mathrm{O}$ verdünnt, die genomische DNA lediglich 1:2. Der Versuchsansatz beinhaltete die folgenden Komponenten:

$2,5 \mu \mathrm{I}$ DNA

2,5 $\mu$ l Primer (Fw + Rev 100pmol/ $\mu \mathrm{l})$

$5,0 \mu$ l SYBR ${ }^{\circledR}$ Green

Dieser Ansatz wurde wie folgt inkubiert:

$40 \times\left\{\begin{array}{lll}50^{\circ} \mathrm{C} & 2 \mathrm{~min} & \\ 95^{\circ} \mathrm{C} & 3 \mathrm{~min} & \text { Aktivierung Taq } \\ 94^{\circ} \mathrm{C} & 15 \mathrm{sec} & \text { Denaturierung } \\ 60^{\circ} \mathrm{C} & 30 \mathrm{sec} & \text { Annealing } \\ 72^{\circ} \mathrm{C} & 30 \mathrm{sec} & \text { Elongation } \\ 95^{\circ} \mathrm{C} & 15 \mathrm{sec} & \\ 60^{\circ} \mathrm{C} & 15 \mathrm{sec} & \\ 60^{\circ} \mathrm{C}-95^{\circ} \mathrm{C} & 2{ }^{\circ} \mathrm{C} / \mathrm{min} & \text { Schmelzkurve }\end{array}\right.$

Nach der Messung wurden die Daten mit Hilfe des SDS-Programms (SDS Version 2.1, PE Applied Biosystems) ausgewertet und in Excel (Microsoft) für weitere Berechnungen exportiert.

Für Untersuchungen an cDNA wurde die relative Expression mit der $\Delta \Delta$ Ct-Methode bestimmt. Hierzu wurden folgende Formeln verwendet ${ }^{1}$ :

$$
\begin{aligned}
& \Delta \mathrm{Ct}=\mathrm{Ct}(\mathrm{GOI})-\mathrm{Ct}(\mathrm{HKG}) \\
& \Delta \Delta \mathrm{Ct}=\Delta \mathrm{Ct}(\mathrm{CTR})-\Delta \mathrm{Ct}(\mathrm{SOI}) \\
& \text { relative expression }=2^{\Delta \Delta \mathrm{Ct}}
\end{aligned}
$$

Die mRNA-Expression der housekeeping-Gene TBP (TATA box binding protein) und PBGD (porphobilinogen deaminase) wurden hierbei zur Normalisierung von menschlichen Proben verwendet, bei murinen Proben wurden die housekeeping-Gene Hprt (hypoxanthine-guanine phosphoribosyltransferase) und Tbp (TATA box binding protein) der Maus verwendet.

Für Untersuchungen an durch ChIP gewonnener genomischer DNA wurde die \%Input-Methode verwendet. Hierbei wurde zunächst der Verdünnungsfaktor ermittelt. In den Untersuchungen dieser Arbeit wurde 10\% der Input-Probe verwendet, daher ist der InputFaktor $\log _{2}(10)=3,32$.

\footnotetext{
${ }^{1} \mathrm{GOI}=$ gene of interest; HKG = housekeeping-Gene; CTR = control; SOI = sample of interest
} 
Der Input wurde zunächst mit Hilfe des Verdünnungsfaktors normalisiert:

$\Delta \mathrm{Ct}\left[\right.$ Input norm] $=\mathrm{Ct}$ [Input] $-\left(\log _{2}\right.$ (Verdünnungsfaktor))

Anschließend wurde der Anteil der untersuchten Probe vom Input ausgerechnet:

$\%$ Input $=100 * 2^{(\Delta \mathrm{Ct}[\text { Input norm }]-\mathrm{Ct}[\mathrm{ChIP}])}$

\subsection{Proteinchemische Techniken}

\subsubsection{Isolierung von Gesamtprotein aus Zellkulturen}

Zur Isolierung des Gesamtproteins wurden in einem well einer 6well-Platte bei ca. 90\% Konfluenz ca. 150 $\mu$ l Lysepuffer II hinzugegeben. In einigen Fällen wurde auch Lysepuffer I verwendet. Die Menge an verwendetem Puffer wurde der Konfluenz sowie dem verwendeten Kulturgefäß gemäß angepasst. Nach einer Inkubation von 10min bei RT wurde das Lysat in ein Eppendorf-Gefäß überführt und die unlöslichen Bestandteile durch Zentrifugieren bei $16000 \mathrm{rpm}$ bei $4^{\circ} \mathrm{C}$ für $10 \mathrm{~min}$ pelletiert. Der Überstand wurde in ein neues Eppendorf-Gefäß überführt, die Proteinkonzentration wurde bestimmt (vgl. Kapitel 2.16.2) und das Lysat wurde bei $-20^{\circ} \mathrm{C}$ aufbewahrt .Eine Langzeitlagerung erfolgte bei $-80^{\circ} \mathrm{C}$.

\subsubsection{Konzentrationsbestimmung von Proteinen nach Bradford}

Die Konzentration von Proteinen wurde nach der Methode von Bradford bestimmt (Bradford, 1976). Hierbei wird ein Farbstoff (Coomassie-Brilliant-Blau) verwendet, der in saurer Lösung unspezifisch an kationische und unpolare hydrophobe Seitenketten von Proteinen bindet. Durch diese Bindung wird der Farbstoff in seiner unprotonierten, anionischen Sulfatform stabilisiert, was zu einer Verschiebung des Absorptionsmaximums von 495nm zu 595nm führt.

Bei dieser Methode wird zunächst eine Standardreihe mit einem Proteinstandard gemessen, womit anschließend eine Eichgerade extrapoliert werden kann. Die fünffach konzentrierte Farbstoff-Lösung (Roti ${ }^{\circledR}$-Nanoquant, Carl Roth, Karlsruhe) wurde mit $\mathrm{H}_{2} \mathrm{O}$ auf einfach konzentriert verdünnt. Die Proteine wurden 1:100 verdünnt und jeweils 50 $\mu \mathrm{l}$ in Triplets gemessen. Zu der Proteinlösung wurden 100 $\mu \mathrm{l}$ der Farbstoff-Arbeitslösung gegeben und dies wurde $5 \mathrm{~min}$ bei RT inkubiert. Anschließend wurde die Extinktion mit Hilfe des Plattenlesegerätes SynergyMx (BioTek, Friedrichshall) bestimmt und die Proteinkonzentration mittels des dazugehörigen PC-Programms Gene5 bestimmt. 


\subsubsection{Natriumdodecylsulfat-Polyacrylamidgelelektrophorese}

Die Natriumdodecylsulfat-Polyacrylamidgelelektrophorese (SDS-PAGE) wurde mit Hilfe des NuPAGE $®$-Systems der Firma Life Technologies (Darmstadt) durchgeführt. Durch die aufeinander abgestimmten Komponenten ist ein optimales Ergebnis möglich. Hierfür wurden

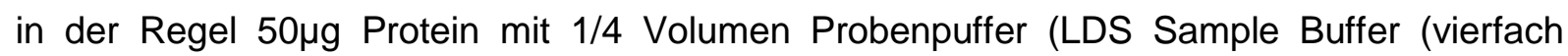
konzentriert), NuPAGE ${ }^{\circ}$, Life Technologies, Darmstadt), der zuvor mit 10\% Dithiothreitol versetzt wurde, gemischt. Die Mischung wurde für $10 \mathrm{~min}$ bei $70^{\circ} \mathrm{C}$ inkubiert und anschließend auf ein NuPAGE $® 4-12 \%$ Bis-Tris Gel geladen. Als Größenstandard wurde ein gefärbter Marker mitgeführt (NuPAGE $®$ See Blue Plus2, Life Technologies, Darmstadt). Die Elektrophorese wurde bei $160 \mathrm{~V}$ und 160mA in MES-Puffer für ca. 1,5h durchgeführt; je nach Molekulargewicht des untersuchten Proteins.

\subsubsection{Transfer von Proteinen auf PVDF-Membranen}

Nach der SDS-PAGE wurden die Proteine durch einen sog. semi-dry Blot auf PVDF-Membranen transferiert. Hierfür wurde die PVDF-Membran auf die geeignete Größe zugeschnitten, in 100\% Methanol für zehn Sekunden aktiviert und anschließend im Transferpuffer Ila für zehn Minuten äquilibriert. Der Aufbau des Blots begann mit drei in Transferpuffer Ila-getränkten Whatman-Filtern auf der Anode, darauf kam die PVDF-Membran gefolgt von dem Polyacrylamidgel mit den zu untersuchenden Proteinen. Als Abschluss wurden erneut drei in Transferpuffer Ila-getränkte Whatman-Filter aufgelegt und der Elektroblotter wurde mit der Kathode geschlossen. Der Transfer wurde bei 25V und 220mA für ca. 1,5h durchgeführt; je nach Größe des untersuchten Proteins.

\subsubsection{Inkubation von membrangebundenen Proteinen mit Antikörpern}

Nach dem Transfer der Proteine auf die PVDF-Membran wurde diese in Blockpuffer I für mindestens 20min inkubiert um unspezifische Bindungen zu blockieren. Anschließend wurde die Membran kurz in TBS-T geschwenkt und mit in TBS-T-verdünntem primären Antikörper über Nacht bei $4^{\circ} \mathrm{C}$ inkubiert. Im Anschluss daran wurde die Membran zweimal 15min in Waschlösung I gewaschen um ungebundene Antikörper zu entfernen. Daraufhin wurde die Membran mit in Blockpuffer I verdünntem sekundären HRP-konjugiertem Antikörper für zwei Stunden bei RT inkubiert. Schließlich wurde die Membran dreimal 15min in Waschlösung I gewaschen und einmal für $5 \mathrm{~min}$ in TBS-T gewaschen um Milchrückstände zu entfernen. Für die Detektion der Signale wurde die ECL Prime Detektionslösung (GE Healthcare, Freiburg) verwendet. Die Signale wurden mit Hilfe eines Detektionsgerätes (FlourChem® Q. Alpha Innotech, Logan, USA) aufgenommen. 


\subsection{Chromatinimmunopräzipitation}

Für die Chromatinimmunopräzipitation-Analysen (ChIP-Analysen) wurde eine spezifische Anzahl von Zellen (in der Regel 20-30Mio.) mit Hilfe des Shearing ChIP Kits der Firma Diagenode (Liège, Belgien) nach Angaben des Herstellers bearbeitet. Zunächst wurden die DNA-gebundenen Proteine durch Behandlung mit Formalin für 10min an die DNA quervernetzt und anschließend wurden die Zellen lysiert und das Chromatin unter Verwendung des Ultraschallgenerators Bioruptor plus UCD-300 (Diagenode, Liège, Belgien) geschert. Dies erfolgte unter Verwendung der Einstellung "high" für 30 Zyklen mit jeweils $30 \mathrm{sec}$ on und $30 \mathrm{sec}$ off. Hierbei wurde das Eis im Wasserbad nach jeweils 10 Zyklen gewechselt, um das Wasser nahe $4^{\circ} \mathrm{C}$ zu halten. Anschließend wurden die Proben bei $14000 \mathrm{rpm}$ und $4^{\circ} \mathrm{C}$ für $5 \mathrm{~min}$ zentrifugiert. Der Überstand enthielt das gescherte Chromatin. Von diesem gescherten Chromatin wurde ein Teil als Input-Probe zurück behalten (1/10 des für die Immunopräzipitation eingesetzten Materials, in dieser Arbeit 0,2Mio Zellen)

Das gescherte Chromatin (einer Menge von 2Mio. Zellen entsprechend) wurde mit Hilfe des OneDay ChIP Kits (Diagenode, Liège, Belgien) nach Angaben des Herstellers zunächst mit einem Antikörper gegen acetyliertes Histon 3 an Lysin 9 (Millipore, Billerica, USA) über Nacht immunselektiert. Nach der Bindung der Antikörper-Chromatin-Komplexe an Protein A-gekoppelte Partikel wurde nach einigen Waschschritten, in denen nicht-gebundene DNA entfernt wurde, die immunselektierte DNA präzipitiert. Schließlich wurde die Quervernetzung der DNA-gebundenen Proteine und der DNA reversiert und die DNA aufgereinigt. Die so erhaltene DNA wurde für quantitative real time Analysen (vgl Kapitel 2.15.6) verwendet. Eine Übersicht der Arbeitsschritte ist in Abb. 2.1 dargestellt. 


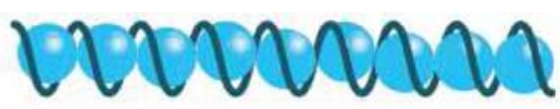

Quervernetzen des Chromatins

Sonifizierung zum Scheren

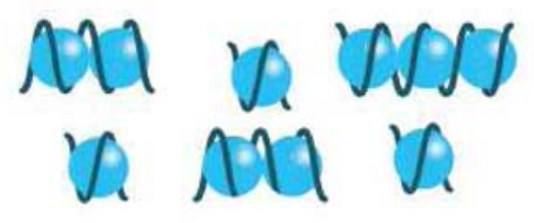

Immunopräzipitation

acH3K9-Antikörper

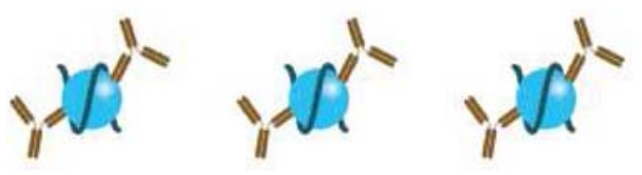

\section{Quervernetzung reversieren}

DNA-Aufreinigung

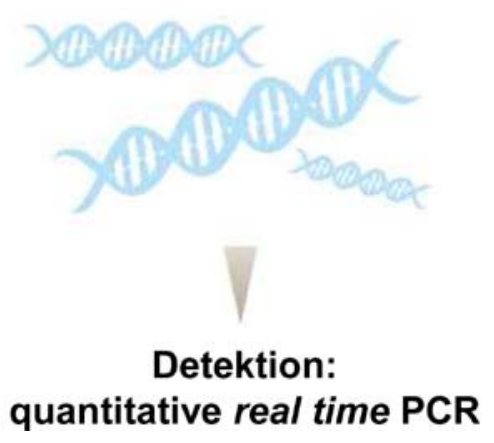

Abbildung 2.1: Übersicht über die Arbeitsschritte bei der Chromatinimmunopräzipitation (ChIP).

Die an die DNA gebundenen Proteine wurden durch Behandlung mit Formalin an die DNA quervernetzt. Nach der Lyse der Zellen wurde das Chromatin durch Sonifizierung geschert. Dieses gescherte Chromatin wurde über Nacht mit einem Antikörper gegen acetyliertes Histon 3 an Lysin 9 (acH3K9) immunselektiert. Anschließend wurden die Chromatin-Antikörper-Komplexe an Protein A-gekoppelte Partikel gebunden und nach mehreren Waschschritten präzipitiert. Nach Reversion der Quervernetzung zwischen DNA-gebundenen Proteinen und DNA wurde die DNA aufgereinigt. Die Detektion der präzipitierten DNA erfolgte mittels quantitativer real time PCR (modifiziert nach Baker, 2010).

\subsection{Zellbiologische Methoden}

\subsubsection{Zellkultur eukaryotischer Zellen}

Die verwendeten Zelllinien wurden in Zellkulturmedium (vgl. Kapitel 2.8.3) bei $37^{\circ} \mathrm{C}$ und $5 \%$ $\mathrm{CO}_{2}$ kultiviert. Je nach Proliferationsrate wurden die Zellen ein- bis zweimal die Woche geteilt. Dies erfolgte durch Inkubation in Trypsin/EDTA (PAN, Aidenbach) bei $37^{\circ} \mathrm{C}$ bis sich 
die Zellen von dem Kulturgefäß lösten. Anschließend wurden die Zellen je nach Proliferationsrate 1:5 bis 1:10 in Kulturmedium verdünnt und wieder in Kultur gebracht.

\subsubsection{Kryokonservierung und Revitalisierung von eukaryotischen Zellen}

Für die Kryokonservierung der Zellen wurden die adhärenten Zellen durch Behandlung mit Trypsin/EDTA wie in Kapitel 2.18.1 beschrieben von dem Kulturgefäß gelöst, die Aktivität des Trypsins wurde durch Zugabe von Kulturmedium gestoppt und die Zellen wurden durch Zentrifugation bei 1000rpm für 5min pelletiert, um das restliche Trypsin zu entfernen. Die Zellpellets wurden in Kulturmedium resuspendiert und die Zellsuspension wurde anschließend mit 10\% DMSO versetzt. Die Zellen wurden zunächst unter Verwendung der Einfrierhilfe Mr. Frosty (Thermo Scientific, Langenselbold) jeweils $1^{\circ} \mathrm{C}$ pro Minute in einem $-80^{\circ} \mathrm{C}$-Gefrierschrank herunter gekühlt. Nach Erreichen einer Temperatur von $-80^{\circ} \mathrm{C}$ wurden die Zellen zur Langzeitlagerung in flüssigen Stickstoff überführt.

Für die Revitalisierung wurden die Zellen bei $37^{\circ} \mathrm{C}$ rasch aufgetaut, mit ca. dreifacher Menge an Medium versetzt und bei 1000rpm für 5 min pelletiert. Die Pellets wurden in Kulturmedium resuspendiert und die Zellen entsprechend Kapitel 2.18.1 kultiviert.

\subsubsection{Test auf Mykoplasmen-Verunreinigungen}

Der Test auf eine Verunreinigung durch Mykoplasmen in den eukaryotischen Zellkulturen wurde routinemäßig ca. einmal im Monat mit Hilfe des MycoAlert ${ }^{\circledR}$ Mycoplasma Detektions Kits (Lonza, Köln) nach Angaben des Herstellers, jedoch lediglich mit der Hälfte des Ansatzes, durchgeführt. Dieser Test basiert auf der Aktivitätsmessung der Mykoplasmen-Enzyme durch ATP-Bestimmung vor und nach Zugabe des spezifischen Substrates.

\subsubsection{Transfektion eukaryotischer Zellen}

In dieser Arbeit wurde die Transfektion der pimären PCa-Zellen 2E sowie der murinen Fibroblasten NIH/3T3 mit Hilfe des TurboFect ${ }^{\mathrm{TM}}$ siRNA-Transfektionsreagenz nach den Angaben des Herstellers durchgeführt. Es handelt sich hierbei um ein kationisches Polymer, das kompakte, stabile und positiv geladene Komplexe mit siRNA bildet und diese ins Zytoplasma der Zelle bringt. Durch die Transfektion mit siRNA kann post-transkriptional die Expression eines Zielgens vermindert werden.

In dieser Arbeit wurden drei verschiedene siRNAs gegen Cyclin D2 (MSS236126, MSS236127, MSS236128, Stealth RNAi ${ }^{\mathrm{TM}}$ siRNA, Life Technologies, Darmstadt) verwendet sowie eine siRNA gegen das Luciferase-Gen (Eurogentec, Köln) als Kontrolle. Die Konzentration im Transfektionsmedium betrug 50nM. Nach 24h konnte eine effektive 
Inhibierung der Expression detektiert werden und die Zellen wurden auf ihre Proliferation hin untersucht (bei der Untersuchung der primären PCa-Zellen 2E nach VPA-Behandlung).

\subsection{Funktionelle Analysen eukaryotischer Zellen}

\subsubsection{Migrationsassay}

Für den in vitro-Zellmigrationsassay wurden die Zellen für $48 \mathrm{~h}$ mit $5 \mathrm{mM}$ bzw. 10mM VPA vorinkubiert. Anschließend wurden 70000 Zellen in die sog. Inserts des Assays (Millicell 8.0 $\mu \mathrm{m}$ hanging PET inserts, Millipore, Billerica, USA) überführt und unter weiterer VPA-Gabe für 24h inkubiert. Schließlich wurden die Zellen, die durch die Membran der Inserts migriert sind, unter Verwendung des Diff-Quick Färbesets (Dade Behring $\mathrm{GmbH}$, Marburg) angefärbt und auf Objektträgern in Öl fixiert. Es wurden jeweils fünf Felder bei 40 - bis 100 -facher Vergrößerung unter Verwendung eines Mikroskops ausgezählt.

\subsubsection{Invasionsassay}

Für die Bestimmung der in vitro-Zellinvasion wurden BioCoat ${ }^{\mathrm{TM}}$ Matrigel $^{\mathrm{TM}}$ Invasion Chambers (BD Bioscience, San Jose, USA) verwendet. Die Membranen der Inserts des Assays sind mit Matrigel ${ }^{\mathrm{TM}}$ beschichtet. Dieses stellt die Basalmembran in vitro dar. Lediglich invasive Zellen können diese Schicht passieren und so auf die Unterseite des Inserts gelangen.

Die primären PCa-Zellen 2E wurden für 24h mit VPA vorinkubiert und es wurden anschließend 70000 Zellen in Medium mit 10\% FKS und der entsprechenden Konzentration von VPA in das Insert überführt. Die Zellkulturplatte enthielt Medium mit 20\% FKS und der jeweiligen VPA-Konzentration, um einen Konzentrationsgradienten zu schaffen entlang dessen die Zellen migrieren und schließlich invadieren können. Die Zellen wurden für 48h im Assay belassen und die Färbung der Zellen sowie die Analyse der invasiven Zellen erfolgte entsprechend Kapitel 2.19.1.

\subsubsection{Proliferationsassay}

Im Rahmen dieser Arbeit wurden die primären PCa-Zellen 2E sowie die PCa-Zellen LNCaP nach Behandlung mit den beiden Gesamtextrakten aus Belamcanda chinensis auf ihre Proliferation hin untersucht. Zudem wurden fast alle im Kapitel 2.9.2 genannten Zelllinien nach VPA-Behandlung sowie 2E-Zellen und NIH/3T3-Zellen nach Herunterregulierung der Cyclin D2-Expression mittels siRNA auf ihre Proliferation hin untersucht. Dieser Assay beruht auf dem Prinzip, dass von lebenden Zellen schwach gefärbte Tetrazoliumsalze (MTS) in intensiv gefärbte Formazanderivate umgewandelt werden. Diese Reaktion erfordert aktive 
Mitochondrien, die nur in lebenden Zellen vorhanden sind. Durch Messung der Intensität der Färbung können Rückschlüsse auf die Zellproliferation gezogen werden. Für diesen Assay wurden 3000 Zellen pro well in einer flachbodigen 96well Platte ausplattiert. Nach Adhärenz der Zellen (ca. 2h) wurde das entsprechende Medium mit dem Gesamtextrakt aus Belamcanda chinensis bzw. VPA zugegeben. Die weiteren Arbeitsschritte erfolgten nach Angaben des Herstellers. Es wurde der CellTiter $96 \AA$ AQueous Non-Radioactive Cell Proliferation Assay (MTS) (Promega, Mannheim) verwendet.

\subsubsection{Koloniebildungsassay}

Für den Koloniebildungsassay wurden die primären PCa-Zellen $2 \mathrm{E}$ in sehr niedriger Zelldichte (800 Zellen pro well einer 6well Platte) ausplattiert und für $24 \mathrm{~h}$ in normalem Kulturmedium inkubiert. Anschließend wurde das Kulturmedium auf VPA-enthaltendes Kulturmedium gewechselt. Dieses Medium wurde routinemäßig zweimal die Woche gewechselt. Nach deutlicher Koloniebildung (nach ca. 14 Tagen) wurden die Zellen für 20min in Ethanol fixiert und mit Hämalaun/Eosin angefärbt. Die Zellkolonien wurden mit Hilfe eines Lichttisches ausgezählt.

\subsection{Immunfärbungen}

\subsubsection{Immunfluoreszenz-Färbung eukaryotischer Zellen}

Für die Immunfluoreszenz-Färbungen wurden die Zellen zunächst auf 4-Kammer-Slides in mittlerer Zelldichte (ca. 25000 Zellen pro Kammer) ausgesät und für $24 \mathrm{~h}$ in normalem Kulturmedium inkubiert. Anschließend wurde das Kulturmedium zu VPA- bzw. Gesamtextrakt-enthaltendem Medium gewechselt und die Zellen für weitere $24 \mathrm{~h}$ inkubiert. Fixiert wurden die Zellen mit 3,7\% Formaldehyd in PBS für 20min. Nach kurzem Waschen mit PBS wurden die Zellmembranen durch eine 10-minütige Behandlung mit 0,1\% Triton-X-100 in PBS permeabilisiert. Nachdem die Zellen erneut mit PBS gewaschen wurden, wurden die unspezifischen Bindungsstellen durch Inkubation mit Blockpuffer II blockiert. Anschließend wurden die Zellen mit dem primären Antikörper verdünnt in Blockpuffer II über Nacht bei $4^{\circ} \mathrm{C}$ inkubiert. Nach dieser Inkubation wurden die Zellen zweimal 10min in PBS gewaschen und anschließend der sekundäre Cy3-gekoppelte Antikörper in Blockpuffer II zusammen mit FITC-konjugiertem Phalloidin auf die Zellen gegeben. Nach einer Inkubation von $2 \mathrm{~h}$ wurden die Zellen erneut zweimal für 10min in PBS gewaschen, gefolgt von einem 10-minütigen Waschschritt in $\mathrm{H}_{2} \mathrm{O}$. Schließlich wurden die Präparate mit Vectashield/DAPI eingedeckt und mit dem konfokalen Laserscanning Mikroskop FluoView1000 (Olympus, Hamburg) fotografiert. 


\subsubsection{Immunhistochemische Färbung von Patientengewebe}

Es wurden in Zusammenarbeit mit Dr. F. Bremmer aus der Abteilung Pathologie der Universitätsmedizin Göttingen sechs tumorfreie Prostatagewebe, 15 Gewebeproben von PCa sowie eine Lymphknotenmetastase von insgesamt 21 Männern untersucht. Diese Untersuchungen an Patientenmaterial wurden von der Ethikkommission der Universitätsmedizin Göttingen genehmigt.

Die immunhistochemischen Färbungen wurden an $3 \mu \mathrm{m}$ bis $5 \mu \mathrm{m}$ dicken Gewebeschnitten aus Formalin-fixierten und in Paraffin eingebetteten Präparaten durchgeführt. Nach der Deparaffinisierung sowie Rehydrierung wurden die Präparate in Zitratpuffer $(\mathrm{pH} 6)$ inkubiert. Anschließend erfolgte die Inkubation mit den primären Antikörpern für $30 \mathrm{~min}$ bei RT (Cyclin D1 1:100 verdünnt, NeoMarkers, Westinghouse, USA; und Cyclin D2 1:200 verdünnt, Santa Cruz, Heidelberg). Daraufhin wurden die Präparate mit dem sekundären biotinylierten Antikörper (REAL biotinylated secondary antibodies, Dako, Hamburg) inkubiert und anschließend wurde Streptavidin-alkalische Phosphatase hinzugegeben. Als Chromogen wurde Fast Red (Dako, Hamburg) verwendet. Die Präparate wurden nach Gegenfärbung mit Meyer's Hämatoxilin mit Hilfe eines Lichtmikroskops fotografiert.

\subsection{Microarray-Analyse}

Für die genomweite Transkriptionsanalyse der mit Tectorigenin der Firma Shenzhen (Shenzhen Sungening Bio-Tech Co., Ltd, Guangdong, China) behandelten humanen PCaZellen LNCaP wurde eine Microarray-Analyse durchgeführt. Es wurde der GeneChip ${ }^{\circledR}$ Human Gene 1.0 ST Array der Firma Affymetrix (Santa Clara, USA) sowie der dazugehörige GeneChip ${ }^{\circledR}$ Whole Transcript (WT) Sense Target Labeling Assay verwendet. Die Analysen wurden in Zusammenarbeit mit dem Transkriptomanalyselabor der Georg-August-Universität Göttingen durchgeführt.

\subsubsection{Behandlung und Ernte der Zellen}

Die humanen PCa-Zellen wurden für 24h mit Tectorigenin der Firma Shenzhen (Shenzhen Sungening Bio-Tech Co., Ltd, Guangdong, China) behandelt, anschließend durch Behandlung mit Trypsin/EDTA von dem Kulturgefäß gelöst und die Reaktion wurde durch Zugabe von Kulturmedium gestoppt. Die Zellen wurden durch Zentrifugation bei 1000rpm für 5 min pelletiert und nach einmaligem Waschen mit DPBS erneut zentrifugiert. Die Zell-Pellets wurden bis zur weiteren Untersuchung bei $-80^{\circ} \mathrm{C}$ eingefroren. Es wurden jeweils drei unabhängige Behandlungen durchgeführt. Als Kontrolle dienten mit DMSO behandelte Zellen. 


\subsubsection{Isolierung der RNA}

Die Isolierung der RNA erfolgte nach Angaben des Herstellers. Vor Arbeitsbeginn wurden alle Arbeitsutensilien sowie der Arbeitsplatz mit RNaseZAP ${ }^{\circledR}$ (Sigma-Aldrich, Deisenhofen) behandelt, um eine Kontamination mit RNasen zu verhindern. Für die Isolierung der RNA wurde TRIzol ${ }^{\circledR}$ (Life Technologies, Darmstadt) verwendet. Es handelt sich hierbei um eine gebrauchsfertige Lösung für die Isolation von RNA aus Geweben und Zellen, die aus einer einphasigen Lösung aus Phenol und Guanidin-Isothiocyanat besteht.

Anschließend an die Isolation der RNA wurde die Quantität mit Hilfe des Eukaryote Total RNA Nano Assays im Bioanalyser 2100 (Agilent, Waldbronn) und die Quantität mit Hilfe eines Photometers (Nanodrop, Thermo Scientific, Wilmington, USA) bestimmt. Die isolierte RNA wurde bei $-80^{\circ} \mathrm{C}$ gelagert.

\subsubsection{Labeling und Hybridisierung der Proben, Auswertung der Daten}

Die Arbeitsschritte wurden nach Angaben des Herstellers durchgeführt. Ein Überblick über die Arbeitsschritte gibt Abbildung 2.2. Aus der isolierten RNA wurde zunächst die Erststrang-cDNA und nachfolgend die Zweitstrang-cDNA synthetisiert. Daraus wurde die cRNA synthetisiert, aus der eine weitere Erststrang-cDNA synthetisiert wurde, in die Biotinmarkierte Basen eingefügt wurden. Diese cDNA wurde nach der Hydrolyse der cRNA aufgereinigt und fragmentiert. Anschließend erfolgte die Hybridisierung mit den Microarrays. Nach einem Waschschritt wurden die Microarrays mit R-Phycoerythrin-markiertem Streptavidin gefärbt. Zur Amplifikation des Signals wurde diese Lösung nach Zugabe eines biotinylierten anti-Streptavidin-Antikörpers erneut zugegeben. Schließlich wurden die Microarrays gescannt (GeneChip ${ }^{\circledR}$ Scanner 3000, Affimetrix, Santa Clara, USA) und die Daten statistisch ausgewertet. Es wurden ein ANOVA-Modeling, nicht-lineare Regressionsnormalisierung und die Bestandteile des betreffenden t-Tests durchgeführt. Außerdem wurden p-Wert-Abgleichungen durchgeführt und die false discovery rate (FDR) sowie die family-wise error rate (FWER) bestimmt. 


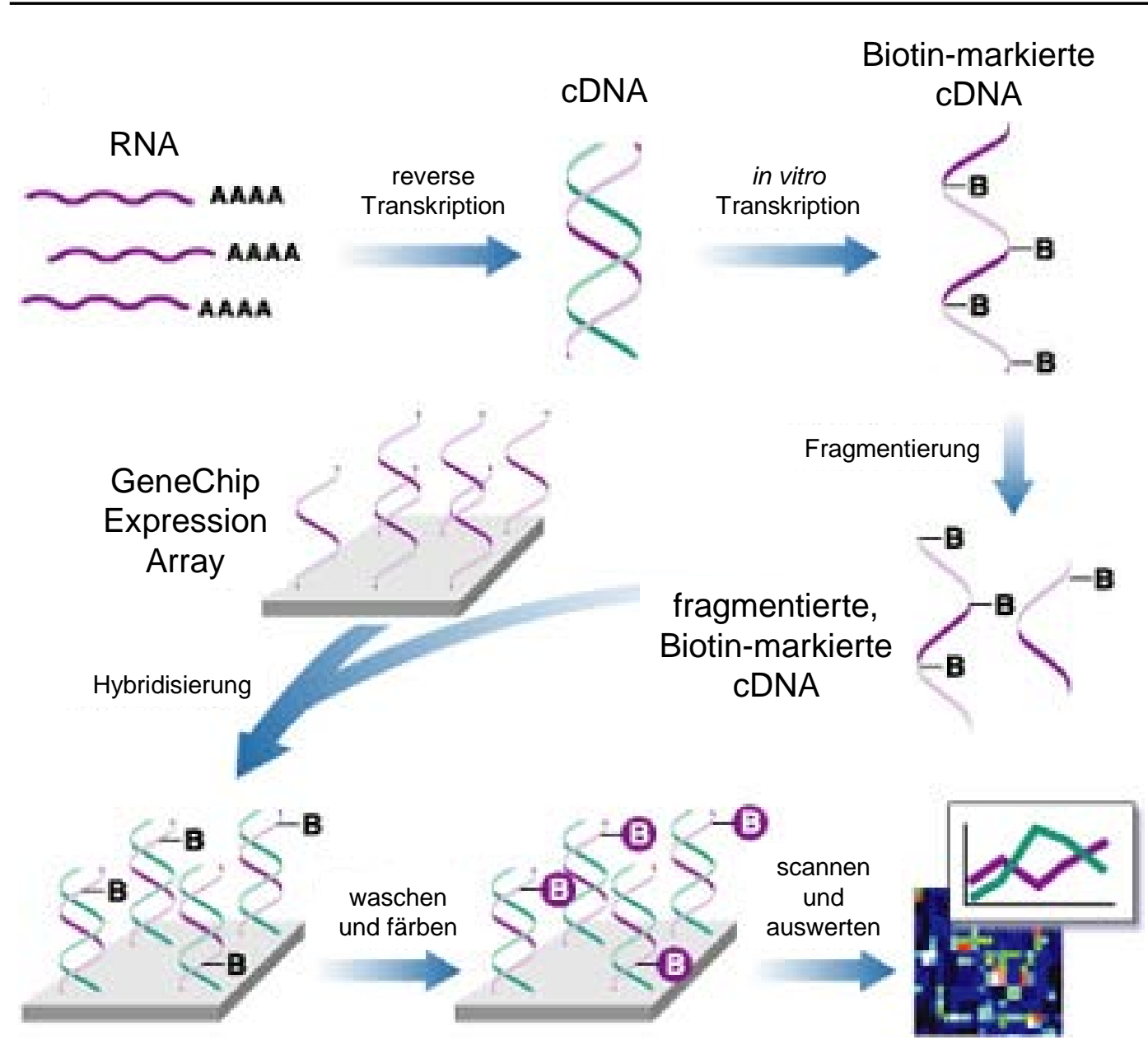

Abbildung 2.2: Schematischer Überblick über die Durchführung der Microarray-Analyse.

Die RNA wurde durch reverse Transkription in cDNA umgeschrieben. Nach einer cRNA-Synthese (hier nicht abgebildet) wurde die cDNA unter der Verwendung Biotin-markierter Basen (CTP und UTP) durch in vitro-Transkription synthetisiert. Diese CDNA wurde fragmentiert. Die fragmentierte, Biotin-markierte cDNA wurde mit dem GeneChip $®$ Expression Array hybridisiert. Anschließend wurde der hybridisierte Array gewaschen und mit R-Phycoerythrin-markiertem Streptavidin gefärbt (modifiziert nach Witt, 2009).

\subsection{In vivo-Untersuchungen}

Die in vivo-Untersuchungen wurden durch das Niedersächsische Landesamt für Verbraucherschutz und Lebensmittelsicherheit genehmigt.

\subsubsection{Subkutane Injektion von Zellen in Nacktmäuse}

Es wurden die humanen PCa-Zellen LNCaP für die Injektionen in die Flanken von Nacktmäusen verwendet. Hierfür wurden die Zellen in der Wachstumsphase von dem Kulturgefäß durch Behandlung mit Trypsin/EDTA gelöst. Die Reaktion wurde durch Zugabe von Kulturmedium abgestoppt und die Zellen wurden durch Zentrifugation bei 1000rpm für 5 min pelletiert. Die Zell-Pellets wurden zweimal mit DPBS gewaschen und die gewaschenen Zell-Pellets wurden anschließend in DPBS resuspendiert und gezählt. Das Matrigel ${ }^{\mathrm{TM}}$ wurde 
auf Eis aufgetaut und 1:1 mit RPMI mit 20\% FKS gemischt und auf Eis aufbewahrt. Die Zellen wurden erneut pelletiert und die Zell-Pellets in einer geeigneten Menge an RPMI mit 20\% FKS resuspendiert. Anschließend wurden die Zellen 1:1 mit dem verdünnten Matrigel ${ }^{\mathrm{TM}}$ vermischt, so dass das Endverhältnis von Zellen zu Matrigel 4:1 betrug. Pro Maus wurden hiervon 1 Mio Zellen in $150 \mu$ Volumen in jede Flanke injiziert.

\subsubsection{Fütterung mit Tectorigenin-haltigem Futter}

Die Untersuchungen in TRAMP-Mäusen wurden in Zusammenarbeit mit den Abteilungen Pathologie und Urologie der Universitätsmedizin Göttingen durchgeführt. Die Behandlung der TRAMP-Mäuse erfolgte mit Tectorigenin-haltigem Futter $(500 \mathrm{mg} / \mathrm{kg}$ in sojafreiem Futter, ssniff Spezialdiäten $\mathrm{GmbH}$, Soest, Tectorigenin der Firma Girindus, Bergisch Gladbach) bzw. sojafreiem Futter (ssniff Spezialdiäten $\mathrm{GmbH}$, Soest) als Kontrolle ab einem Alter von sechs Wochen. Im Alter von 30 Wochen wurden die Mäuse abgetötet und die Prostatae sowie das Metastasengewebe wurden histopathologisch ausgewertet.

Für die LNCaP-Xenograft-Versuche wurde die Fütterung der Tiere mit Tectorigenin-haltigem Futter ab der Injektion der LNCaP-Zellen (vgl. Kapitel 2.22.1) durchgeführt. Es wurde das Tectorigenin der Firma Shenzhen (Shenzhen Sungening Bio-Tech Co., Ltd, Guangdong, China) verwendet, welches in einer Konzentration von $500 \mathrm{mg} / \mathrm{kg}$ sojafreiem Futter (ssniff Spezialdiäten $\mathrm{GmbH}$, Soest) beigemischt wurde. Als Kontrolle dienten mit sojafreiem Futter (ssniff Spezialdiäten $\mathrm{GmbH}$, Soest) gefütterte Tiere. Die Abbruchkriterien für diesen Versuch waren eine Behandlungsdauer von zwölf Monaten sowie eine Tumorgröße von $1,5 \mathrm{~cm}^{3}$. Nach Erreichen des Abbruchkriteriums für eine Maus wurde die gesamte Gruppe abgetötet. Es wurden zwei Versuchsgruppen untersucht. In der ersten Gruppe wurden die Mäuse für 146 Tage, in der zweiten Gruppe für 91 Tage behandelt. Nach diesen Behandlungsdauern erreichte jeweils eine Maus der jeweiligen Gruppe das Abbruchkriterium der Tumorgröße. In der ersten Gruppe wurden vier kontrollbehandelte und fünf Tectorigenin-behandelte Mäuse untersucht, wobei eine Tectorigenin-behandelte Maus frühzeitig verstarb. In der zweiten Versuchsgruppe wurden sechs Kontroll-Mäuse, von denen zwei frühzeitig verstarben, und vier Tectorigenin-behandelte Mäuse untersucht.

\subsubsection{Fütterung von TRAMP-Mäusen mit Valproinsäure über das Trinkwasser}

Alle untersuchten Mäuse wurden mit einer Endkonzentration von 0,4\% w/v VPA über das Trinkwasser behandelt. Hierbei wurde jeweils in der ersten Versuchswoche VPA eingeschlichen, da 0,4\% w/v VPA nicht sofort von den Mäusen toleriert wird. Das Einschleichen erfolgte von einer Konzentration von 0,1\% w/v VPA an in 0,1\%-Schritten jeden zweiten Tag der Behandlung bis zur Endkonzentration von 0,4\% w/v VPA am 7. Tag der Behandlung. Zu dem Trinkwasser wurden haushaltsübliche Süßstofftabletten der Marke 
"Das gesunde PLUS" (dm-drogerie markt GmbH + Co. KG, Karlsruhe) hinzugefügt (1 Tablette pro 100ml Trinkwasser). Die Inhaltsstoffe dieser Süßstofftabletten sind: Süßstoff Natriumclyclamat, Säureregulator Natriumhydrogencarbonat, Säuerungsmittel Natriumcitrate, Süßstoff Saccharin-Natrium, Lactose. Als Kontrolle dienten Mäuse, die Trinkwasser erhielten, dem lediglich der genannte Süßstoff zugefügt wurde.

Der Versuch wurde in drei Gruppen eingeteilt, wobei jede Gruppe 15 VPA-behandelte und 15 Kontroll-behandelte Mäuse beinhaltete. Eine Übersicht über den Versuchsablauf ist in Abb. 2.3 dargestellt.

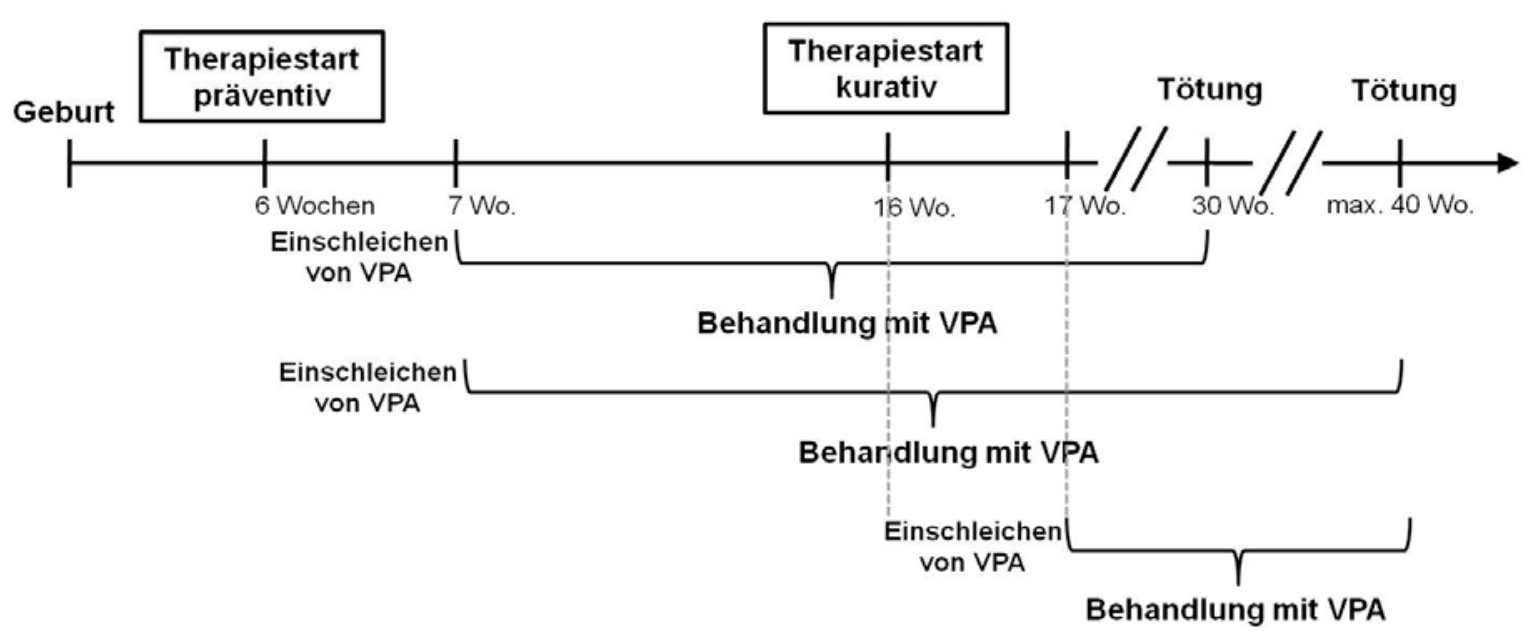

Abbildung 2.3: Darstellung des Versuchsablaufs der VPA-Behandlung im TRAMP-Maus-Modell.

Die erste Gruppe wurde ab einem Alter von sechs Wochen präventiv behandelt, das Versuchsende war auf ein Alter von 30 Wochen terminiert. Die zweite Versuchsgruppe wurde auch präventiv ab einem Alter von sechs Wochen behandelt, es handelte sich hierbei allerdings um eine Überlebensstudie, die maximal bis zu einem Alter von 40 Wochen durchgeführt wurde. Die dritte Gruppe erhielt kurativ VPA ab einem Alter von 16 Wochen und es handelte sich, wie in der ersten Gruppe, um eine bis maximal zu einem Alter von 40 Wochen durchgeführte Studie. Diese Zeitpunkte wurden gewählt, da im TRAMP-MausModell bei Mäusen im Alter von sechs Wochen noch keine maligne Veränderung der Prostata detektiert werden sollte. Im Alter von 16 Wochen sollte die Karzinomentwicklung jedoch bereits begonnen haben. Im Alter von 40 Wochen sollten alle Mäuse ein PCa entwickelt haben, während im Alter von 30 Wochen die Tumorprogression noch fortschreitet und damit zu diesem Zeitpunkt die Analyse der Tumorprogression möglich ist (MentorMarcel et al., 2001).

Abbruchkriterien bei allen Gruppen waren die folgenden: Gewichtsverlust von mehr als 20\% über 48 Stunden, Verhaltensauffälligkeiten (Apathie, auffallende Aggressivität beim Palpieren, motorische Auffälligkeiten wie Lähmungen, anormale Körperhaltung) sowie ein deutlich palpierbarer Tumor, der zu den oben genannten Verhaltensauffälligkeiten führte. 


\subsection{Statistik}

Für die Untersuchungen zur statistischen Signifikanz der Versuchsergebnisse wurde der ungepaarte t-Test verwendet. Die Ergebnisse wurden wie folgt dargestellt:

* $0.01<p \leq 0.05$ entspricht "knapp signifikant"

** $0.001 \leq p<0.01$ entspricht "signifikant"

*** $p \leq 0.001$ entspricht "hoch signifikant"

Die weiteren statistischen Auswertungen wurden in Zusammenarbeit mit der Arbeitsgruppe Statistische Bioinformatik der Abteilung Medizinische Statistik der Universitätsmedizin Göttingen durchgeführt. 


\section{Ergebnisse}

\subsection{Das Zellmodell TRAMP 2E}

In dieser Arbeit wurde vorwiegend mit den primären Prostatakarzinomzellen 2E gearbeitet. Diese Zellen wurden aus einem Prostatakarzinom der TRAMP-Maus 2E im Rahmen der Dissertation von Frau Dr. Sandra von Hardenberg (Hardenberg, 2010) isoliert. Die Isolierung der Zellen wurde bereits im Rahmen der dieser Dissertation vorangegangenen Diplomarbeit beschrieben (Witt, 2009). Die isolierten Tumorzellen wurden regelmäßig hinsichtlich der Expression des SV40 large T Antigens untersucht (Abb. 3.1; Witt et al., 2013). Die verwendeten primären PCa-Zellen in den Versuchen dieser Arbeit waren stets überwiegend (nahe 100\%) positiv für die Expression des SV40 large T Antigens. Es konnte in vorherigen Studien gezeigt werden, dass die primären PCa-Zellen 2E invasiv wachsen und den Igf1r (insulin-like growth factor $\underline{1}$ receptor), den $\operatorname{Ar}$ (Androgenrezeptor) sowie beide Östrogenrezeptoren (Esr1 und Esr2) exprimieren (Witt, 2009).
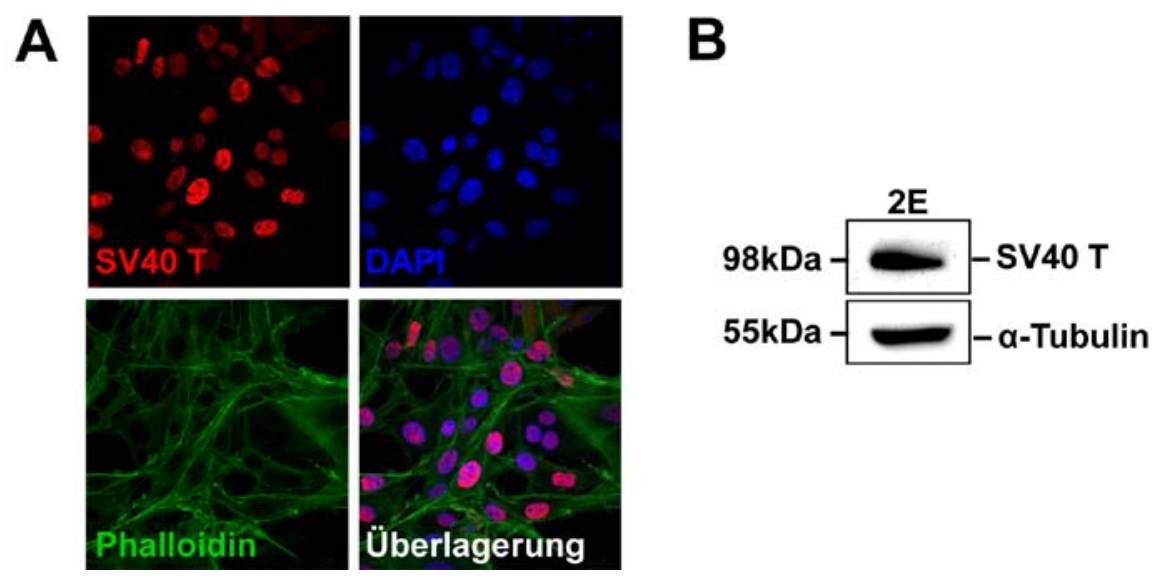

Abbildung 3.1: Nachweis des epithelialen Ursprungs der primären, murinen Prostatakarzinomzellen 2E.

Die Zellen wurden aus dem Prostata-Tumor der TRAMP-Maus 2E, wie bereits in Witt (2009) beschrieben, generiert. Die Expression des SV40 large T Antigens wurde regelmäßig kontrolliert. (A) Die Zellen wurden fixiert und mittels Immunfluoreszenz mit einem Antikörper gegen das SV40 large T Antigen gefärbt. Die Zellkerne wurden durch DAPI-Färbung sichtbar gemacht, das Zytoskelett durch FITC-gekoppeltes Phalloidin. Die hier abgebildeten Zellen stellen beispielhaft die Anzahl der SV40 large T Antigen-positiven Zellen dar. Nahezu 100\% der Zellen waren positiv. Die Bilder wurden mit einer 600-fachen Vergrößerung an einem Laser-Scanning-Mikroskop aufgenommen. (B) Western Blot-Analyse der SV40 large T-Expression in 2E Zellen. Das Gesamtprotein der PCa-Zellen 2E wurde isoliert und es konnte eine starke Proteinexpression des SV40 large T Antigens detektiert werden (modifiziert nach Witt et al., 2013). 


\subsection{Das Phytoöstrogen Tectorigenin}

\subsubsection{Untersuchungen zum Tectorigenin enthaltenden Gesamtextrakt aus Belamcanda chinensis}

Es wurden bereits Analysen zur Wirkung von Tectorigenin auf PCa-Zellen in Witt (2009) vorgenommen. Aufgrund von Differenzen zwischen den beobachteten Effekten von Tectorigenin der Firma Bionorica auf die humanen PCa-Zellen LNCaP und Tectorigenin der Firma Girindus auf die murinen PCa-Zellen 2E sollte zunächst untersucht werden, ob der Gesamtextrakt aus Belamcanda chinensis die gleichen Effekte auf die murinen PCa-Zellen 2E hat wie auf die humanen PCa-Zellen LNCaP, die bereits in der Literatur beschrieben wurden (Thelen et al., 2005; Thelen et al., 2007). Diese Effekte beinhalten vor allem die Inhibition der Proliferation und die Herunterregulierung der Expression des AR, des AR-Zielgens PSA (prostate specific antigen) sowie des IGF-IR in den humanen PCa-Zellen LNCaP nach Behandlung mit dem Gesamtextrakt aus Belamcanda chinensis. Es wurden in dieser Arbeit zwei verschiedene Gesamtextrakte verwendet. Zum einen der Gesamtextrakt R und der Gesamtextrakt O der Firma Orgentis.

\subsubsection{Analysen zur Proliferation nach Behandlung von Prostatakarzinomzellen mit Gesamtextrakten aus Belamcanda chinensis}

Sowohl die murinen, primären PCa-Zellen 2E als auch die etablierten humanen PCa-Zellen LNCaP wurden mittels eines MTT-Assays auf Veränderung der Proliferation nach Behandlung mit den Gesamtextrakten untersucht. Die primären PCa-Zellen 2E konnten dabei mit einer deutlich höheren Konzentration des Gesamtextraktes behandelt werden (bis zu $800 \mu \mathrm{g} / \mathrm{ml}$ ) als die humanen LNCaP ( $\max .100 \mu \mathrm{g} / \mathrm{ml}$ ), da höhere Konzentrationen in den LNCaP-Zellen toxisch waren. Die Zellen wurden jeweils mit den beiden Gesamtextrakten (R und O) behandelt und nach 24, 48, 72 und 144 Stunden wurde die Zellproliferation bestimmt. Sowohl die Behandlung der PCa-Zellen mit dem Gesamtextrakt R (Abb. 3.2, in gelb dargestellt) als auch dem Gesamtextrakt $\mathrm{O}$ (Abb. 3.2, in grün dargestellt) führten zu einer Inhibition der Proliferation beider untersuchter Zelllinien, wobei letztere einen deutlich stärkeren Effekt bewirkte. 


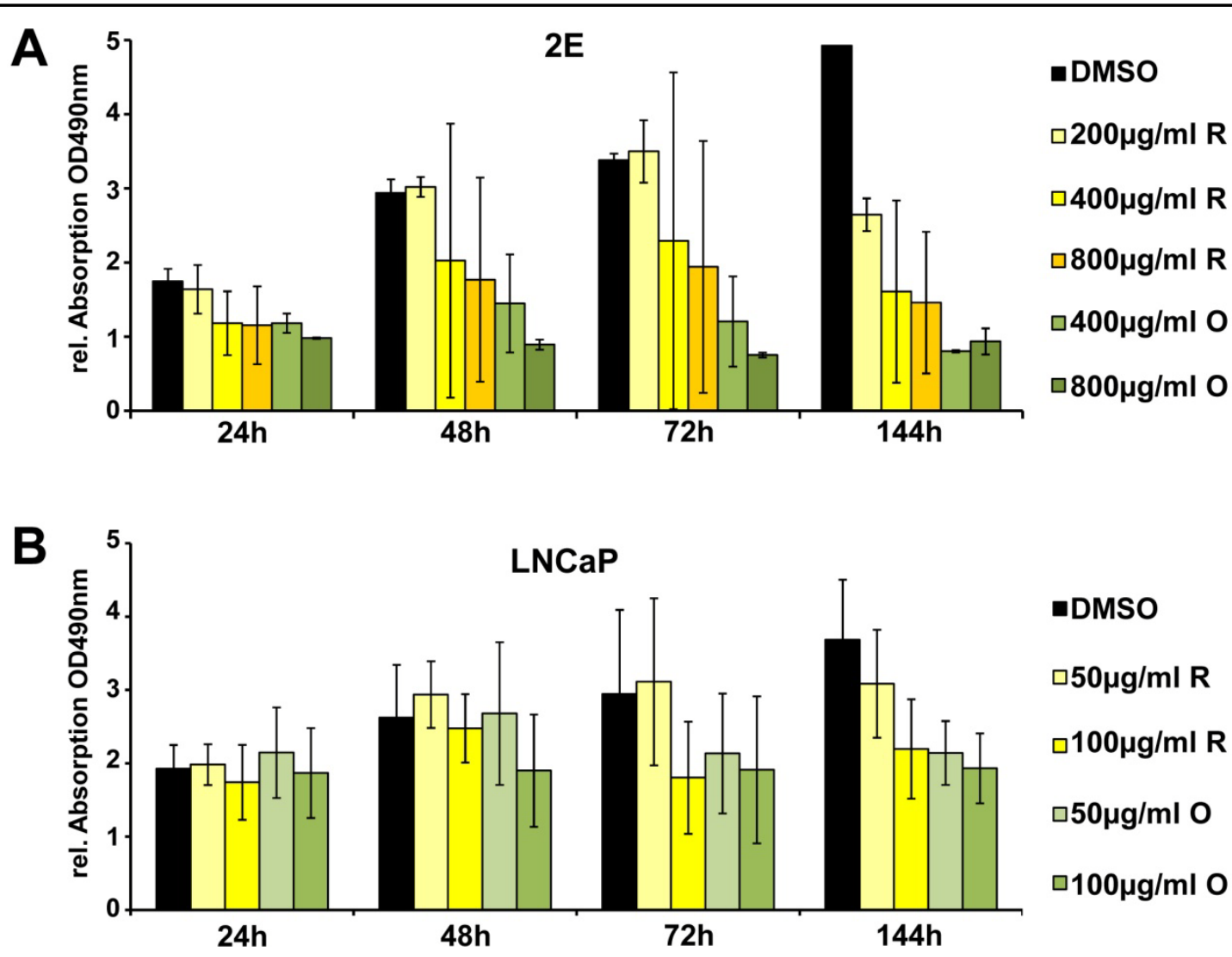

Abbildung 3.2: Proliferation von PCa-Zellen nach Behandlung mit zwei verschiedenen Gesamtextrakten aus Belamcanda chinensis.

Die primären PCa-Zellen 2E als auch die humanen PCa-Zellen LNCaP wurden jeweils mit zwei Gesamtextrakten ( $R$ in gelb, $O$ in grün) aus Belamcanda chinensis behandelt. Nach 24, 48, 72 und 144 Stunden wurde ein MTT-Assay durchgeführt. Sowohl in den primären PCa-Zellen 2E (A) als auch in den humanen PCa-Zellen LNCaP (B) wurde die Zellproliferation durch beide Gesamtextrakte gehemmt, wobei bei höheren Konzentrationen Zytotoxizität zu beobachten war. Insgesamt war die Inhibition der Proliferation bei beiden Zelllinien durch den Gesamtextrakt O stärker ausgeprägt als durch den Gesamtextrakt R.

\subsubsection{Expressionsanalysen nach Behandlung mit Gesamtextrakten aus Belamcanda chinensis in Prostatakarzinomzellen}

Zur Analyse der Veränderung der Expression von bestimmten Zielgenen wurden die primären PCa-Zellen 2E als auch die humanen PCa-Zellen LNCaP mit den zwei verschiedenen Gesamtextrakten ( $R$ und $O$ ) für 24, 72 und 144 Stunden behandelt. Anschließend wurde sowohl die Gesamt-RNA als auch das Gesamtprotein isoliert.

Bei den primären PCa-Zellen 2E konnte nach der Behandlung mit beiden Gesamtextrakten

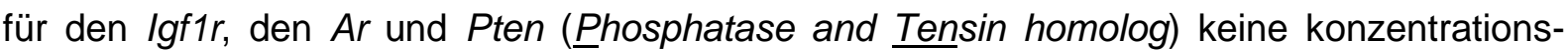
oder zeitabhängige Veränderung der Expression auf RNA-Ebene gezeigt werden (Abb. 3.3A). Lediglich die höchste eingesetzte Konzentration beider Gesamtextrakte führte zu einer leicht verminderten Expression der Igf1r- und Ar-mRNA. Auf Proteinebene konnte nach 72 Stunden eine verringerte Expression des Igf1r und des Ar nach Behandlung der primären PCa-Zellen 2E mit den beiden Gesamtextrakten detektiert werden (Abb. 3.3B). 


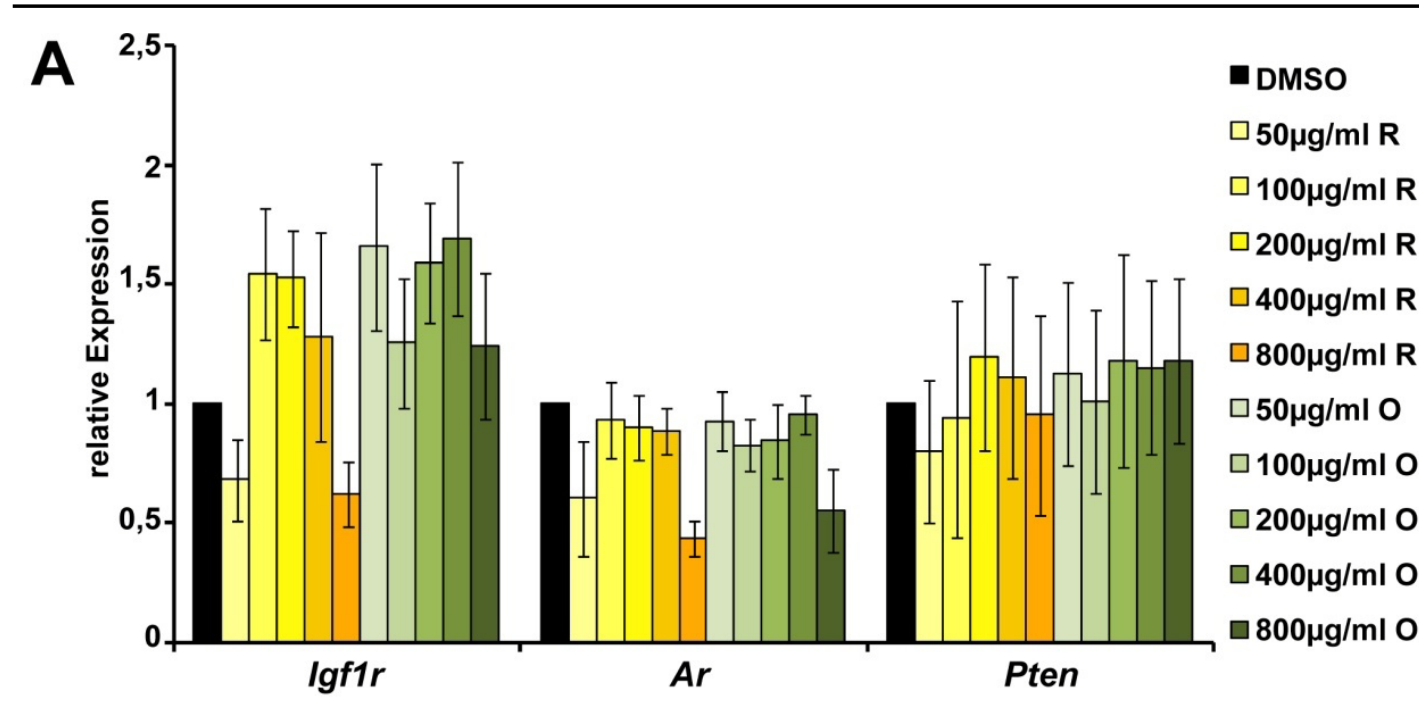

B

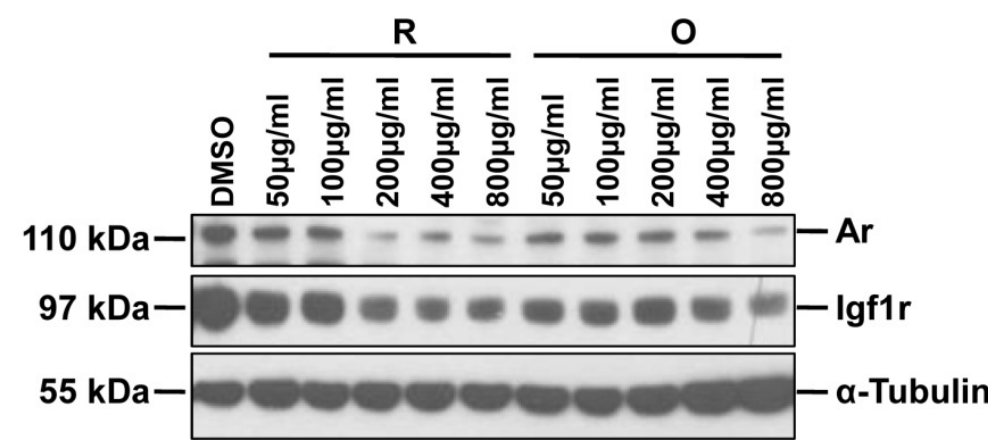

Abbildung 3.3: Expressionsanalysen in den primären PCa-Zellen 2E nach der Behandlung mit zwei verschiedenen Gesamtextrakten aus Belamcanda chinensis.

Die primären PCa-Zellen 2E wurden mit verschiedenen Konzentrationen von zwei verschiedenen Gesamtextrakten (R und $O$ ) für 72 Stunden behandelt und anschließend wurde die Gesamt-RNA (A) und das Gesamtprotein (B) isoliert. (A) Die qRT-PCR-Analyse zeigte, dass sich die Expression des Igf1r, des Ar und von Pten kaum änderte, lediglich die höchste eingesetzte Konzentration bewirkte eine Reduktion der Expression des Igf1r und des Ar. (B) Auf Proteinebene hingegen war nach 72 Stunden Behandlung sowohl eine Reduktion der Expression des Ar als auch des Igf1r zu detektieren.

Bei den humanen PCa-Zellen LNCaP führte die Behandlung mit dem Gesamtextrakt $\mathrm{R}$ zu einer leichten Abnahme der AR-mRNA-Expression im Vergleich zur Kontrolle. Die Behandlung mit dem Gesamtextrakt $O$ hingegen führte zu einer deutlichen Inhibition der Expression des AR. Für die beiden AR-Zielgene PDEF und PSA konnte eine deutliche Abnahme der Expression detektiert werden, die im Fall von PSA stark konzentrationsabhängig war (Abb. 3.4A). Für den IGF-IR konnte sowohl auf RNA(Abb. 3.4A) als auch auf Proteinebene (Abb. 3.4C) eine deutliche Reduktion der Expression durch die Behandlung mit beiden Gesamtextrakten verzeichnet werden. Auf Proteinebene wurde hierbei eine Konzentrationsabhängigkeit detektiert. Das IGFBP-3 zeigte nach der Behandlung mit dem Gesamtextrakt $\mathrm{R}$ eine deutliche Steigerung der Expression, dies wurde nach der Behandlung mit dem Gesamtextrakt O nur mäßig detektiert (Abb. 3.4B). 

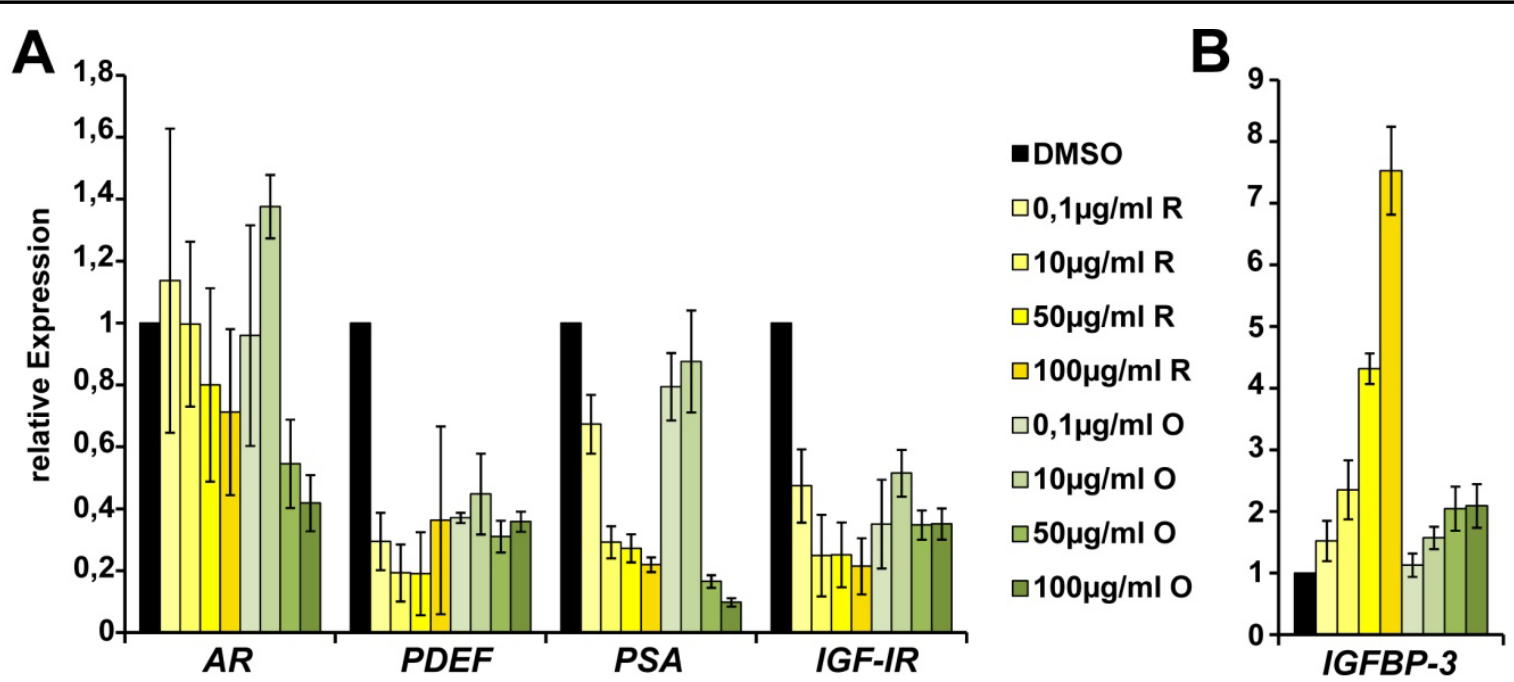

C

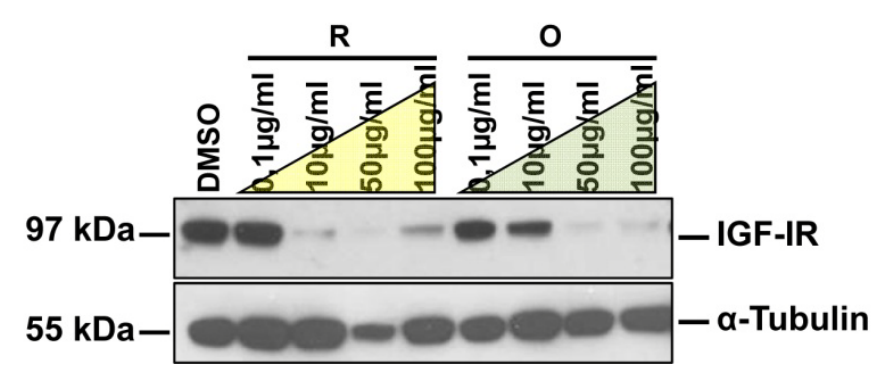

Abbildung 3.4: Expressionsanalysen an LNCaP-Zellen nach Behandlung mit zwei Gesamtextrakten aus Belamcanda chinensis.

Die humanen PCa-Zellen LNCaP wurden mit steigenden Konzentrationen der beiden Gesamtextrakte aus Belamcanda chinensis ( $\mathrm{R}$ und $\mathrm{O}$ ) behandelt. Es wurde nach 72 Stunden Behandlung die Gesamt-RNA (A und B) und das Gesamtprotein (C) isoliert. (A) Die qRT-PCR-Analyse zeigte, dass nach der Behandlung der humanen PCa-Zellen LNCaP mit beiden Extrakten die Expression des $A R$ vermindert war und die Expression der beiden AR-Zielgene PDEF und PSA noch stärker reduziert war. (A und C) Sowohl auf RNA- als auch auf Proteinebene war eine Reduktion der Expression des IGF-IR nach Behandlung mit beiden Extrakten zu detektieren. (B) Die Expression des IGFBP-3 wurde durch den Gesamtextrakt O nur mäßig und durch den Gesamtextrakt R deutlich verstärkt.

\subsubsection{Analysen mittels Immunfluoreszenz zur Veränderung der Expression und Lokalisation von Zielproteinen und der Zellmorphologie nach Behandlung von Prostatakarzinomzellen mit einem Gesamtextrakt aus Belamcanda chinensis}

Zur Untersuchung der Expression und Lokalisation von Zielproteinen wurden die primären PCa-Zellen 2E mit dem Gesamtextrakt R aus Belamcanda chinensis für 24 Stunden behandelt. Als Kontrolle diente das Lösungsmittel DMSO. Die Zellen wurden fixiert und anschließend mittels Immunfluoreszenz auf die Expression und Lokalisation des Ar und der beiden Östrogenrezeptorea und $\beta$ (E sr1 und Esr2) hin untersucht. Die Belichtungseinstellungen am Mikroskop während der Aufnahmen wurden nicht verändert, so dass eine schwächere Färbung auch als diese erkennbar war. Die Östrogenrezeptoren wurden untersucht, da bereits in der Literatur ein Effekt auf die Expression nach Behandlung 
von LNCaP-Zellen mit dem Gesamtextrakt aus Belamcanda chinensis sowie Tectorigenin beschrieben wurde (Thelen et al., 2007; Stettner et al., 2007).

Untersucht wurde zunächst die Expression des Ar. Dieser war in den kontrollbehandelten Zellen deutlich im Kern angefärbt. Nach der Behandlung der primären PCa-Zellen 2E mit dem Gesamtextrakt R konnte kein eindeutiges Ergebnis gezeigt werden: zum einen konnte eine stärkere Expression des Ar mit einhergehender stärkerer Färbung des Zytoplasmas der Zelle detektiert werden, zum anderen konnten auch Zellen detektiert werden, die sich nicht von den kontrollbehandelten Zellen unterschieden (Abb. 3.5).

DMSO
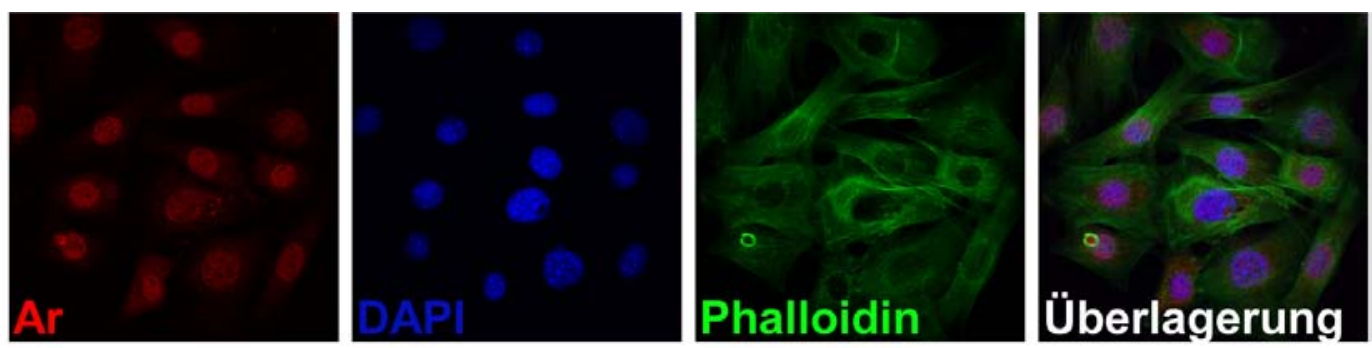

\section{Extrakt R $400 \mu \mathrm{g} / \mathrm{ml}$ \\ 24h}
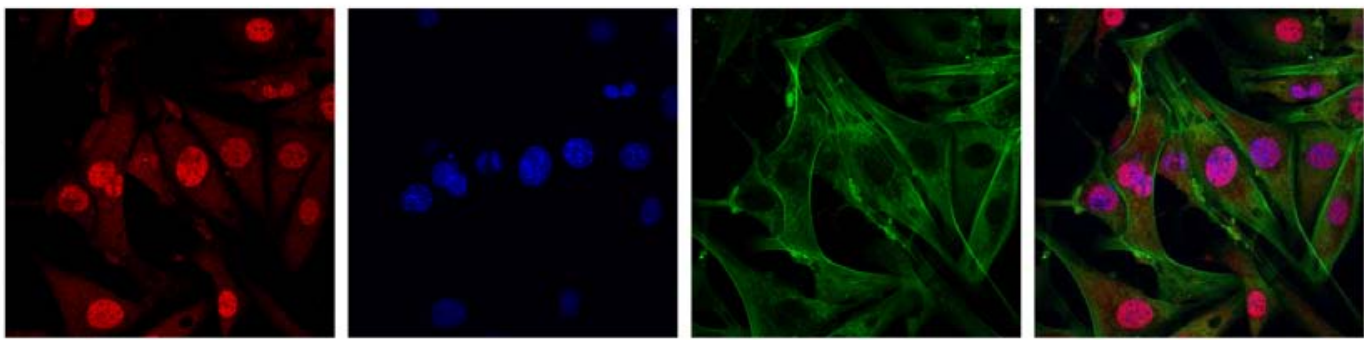

\section{Extrakt R $400 \mu \mathrm{g} / \mathrm{ml}$ $24 \mathrm{~h}$}
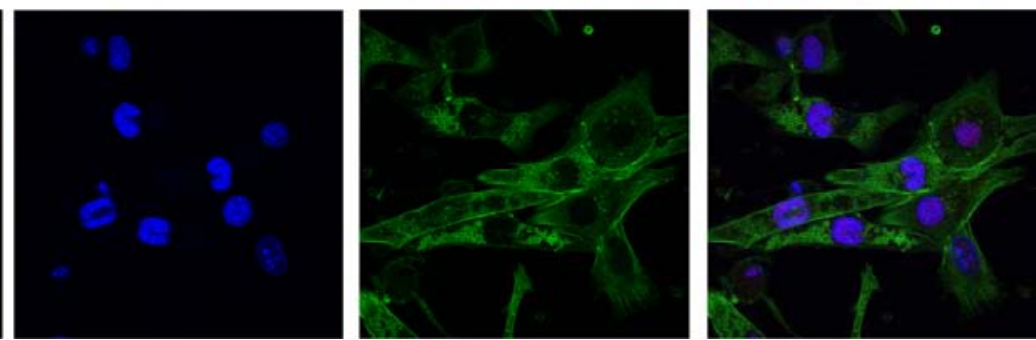

Abbildung 3.5: Immunfluoreszenz-Färbung des Androgenrezeptors (Ar) nach Behandlung der primären PCa-Zellen 2E mit dem Gesamtextrakt R aus Belamcanda chinensis.

Die primären PCa-Zellen 2E wurden für 24 Stunden mit $400 \mu \mathrm{g} / \mathrm{ml}$ des Gesamtextrakts R aus Belamcanda chinensis behandelt. Anschließend wurden die Zellen fixiert und mit einem Antikörper gegen den AR angefärbt. Das Zytoskelett wurde durch FITC-gekoppeltes Phalloidin sichtbar gemacht, der Zellkern durch eine Färbung mit DAPI. In den mit DMSO kontrollbehandelten Zellen wurde der Ar mäßig und im Kern exprimiert detektiert. Nach der Behandlung mit dem Gesamtextrakt R konnte einerseits eine verstärkte Expression detektiert werden (mittlere Reihe), die allerdings auch verstärkt im Zytoplasma lokalisiert war. Andererseits konnten auch Zellen beobachtet werden, die sich nicht von den kontrollbehandelten unterschieden (untere Reihe).

Des Weiteren wurde die Expression des Esr1 überprüft. In den mit DMSO kontrollbehandelten PCa-Zellen 2E konnte eine starke Expression mit überwiegender Lokalisation im Kern detektiert werden (Abb. 3.6). Diese Expression war nach der Behandlung mit dem Gesamtextrakt R deutlich reduziert. Die Färbung des Zytoplasmas im 
Vergleich zu den kontrollbehandelten Zellen änderte sich nicht, lediglich die Kernfärbung nahm ab.

DMSO
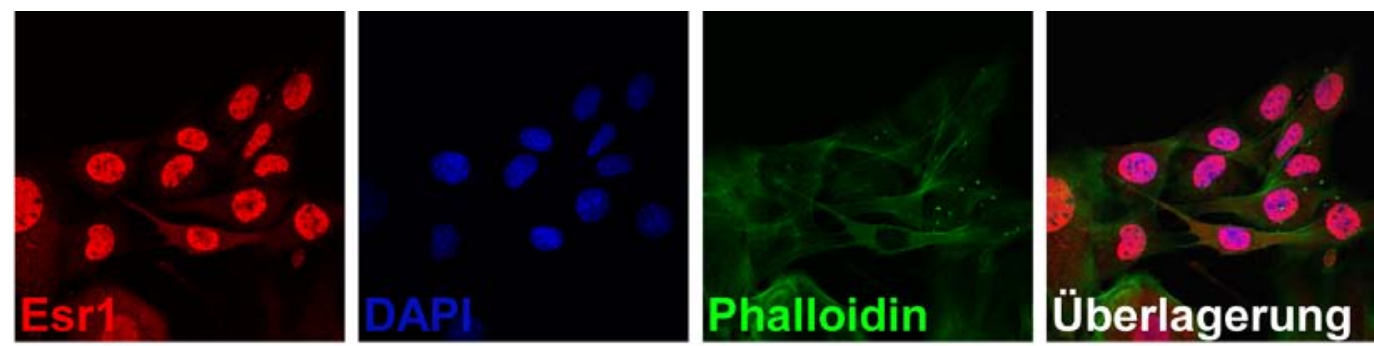

Extrakt R $400 \mu \mathrm{g} / \mathrm{ml}$ $24 \mathrm{~h}$
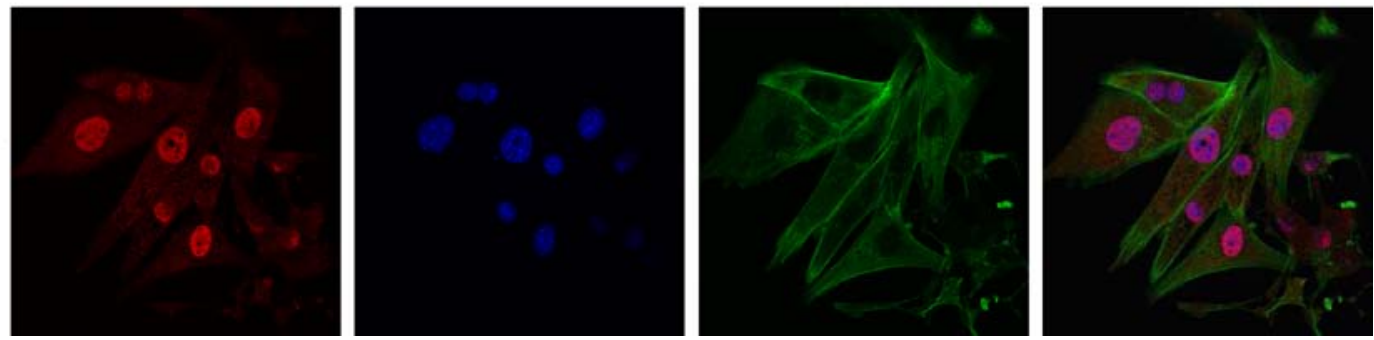

Abbildung 3.6: Immunfluoreszenz-Färbung des Östrogenrezeptors

(Esr1) nach Behandlung der primären PCa-Zellen 2E mit dem Gesamtextrakt R aus Belamcanda chinensis.

Die primären PCa-Zellen 2E wurden für 24 Stunden mit $400 \mu \mathrm{g} / \mathrm{ml}$ des Gesamtextrakts R aus Belamcanda chinensis behandelt. Anschließend wurden die Zellen fixiert und mit einem Antikörper gegen den Esr1 angefärbt. Das Zytoskelett wurde durch FITC-gekoppeltes Phalloidin sichtbar gemacht, der Zellkern durch eine Färbung mit DAPI. Die Expression des Esr1 war in den kontrollbehandelten Zellen (DMSO) deutlich im Kern lokalisiert. Im Gegensatz zu der starken Expression in den kontrollbehandelten Zellen war in den mit dem Gesamtextrakt behandelten Zellen nur eine schwache Expression des Esr1 zu detektieren.

Neben dem Esr1 wurde auch der Esr2 untersucht (Abb. 3.7). In den mit DMSO kontrollbehandelten primären PCa-Zellen 2E konnte keine Expression des Esr2 beobachtet werden. Im Gegensatz dazu exprimierten die mit dem Gesamtextrakt behandelten primären PCa-Zellen 2E den Esr2 stark, sowohl im Zytoplasma als auch im Kern. Weiterhin konnte gezeigt werden, dass der Esr2 im Zytoplasma punktuell um den Zellkern herum lokalisiert war und sich nicht über das gesamte Zytoplasma verteilte. 
DMSO
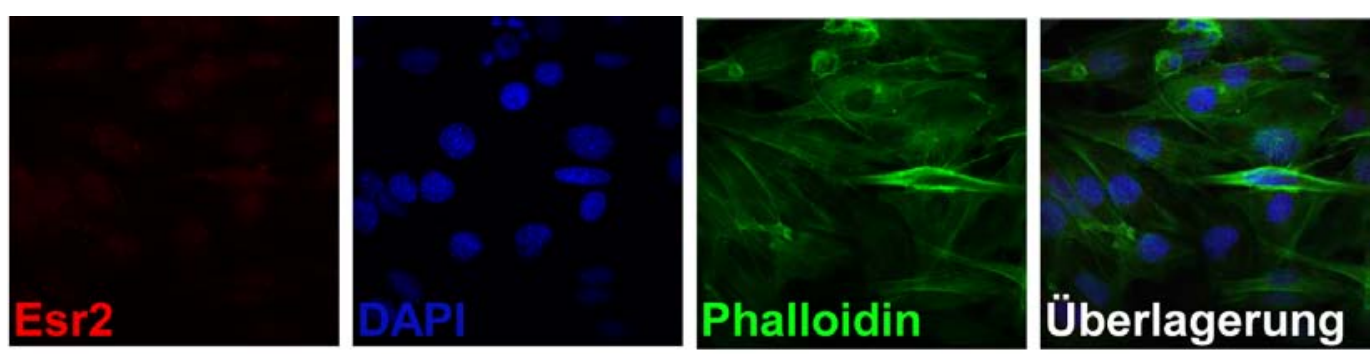

\section{Extrakt R $400 \mu \mathrm{g} / \mathrm{ml}$} 24h
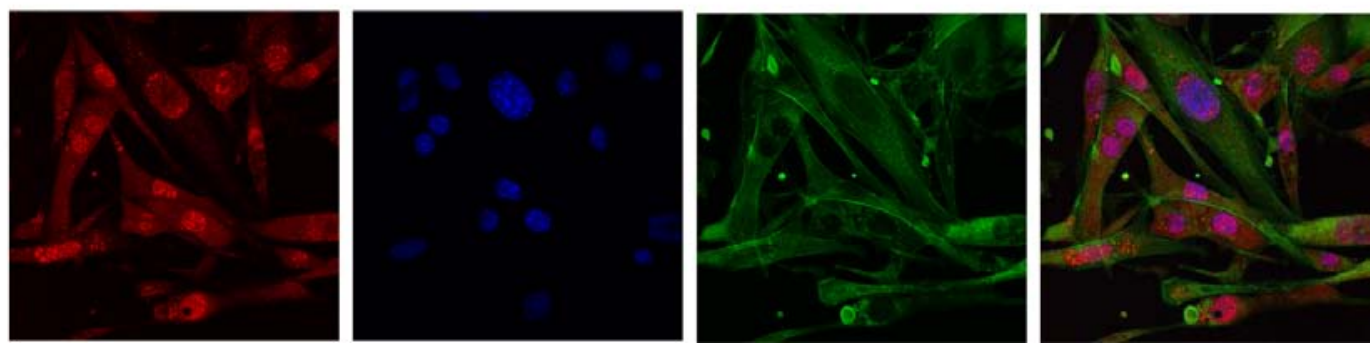

Abbildung 3.7: Immunfluoreszenz-Färbung des Östrogenrezeptorß

(Esr2) nach Behandlung der primären PCa-Zellen 2E mit dem Gesamtextrakt R aus Belamcanda chinensis.

Die primären PCa-Zellen 2E wurden für 24 Stunden mit $400 \mu \mathrm{g} / \mathrm{ml}$ des Gesamtextrakts R aus Belamcanda chinensis behandelt. Anschließend wurden die Zellen fixiert und mit einem Antikörper gegen den Esr2 angefärbt. Das Zytoskelett wurde durch FITC-gekoppeltes Phalloidin sichtbar gemacht, der Zellkern durch eine Färbung mit DAPI. Die mit DMSO kontrollbehandelten primären PCa-Zellen 2E zeigten keine Expression des Esr2 (obere Reihe), die Behandlung mit dem Gesamtextrakt hingegen führte zu einer starken Expression des Esr2 sowohl im Kern als auch im Zytoplasma. Die Expression im Zytoplasma war punktuell und nahe dem Kern lokalisiert (untere Reihe).

Zur Kontrolle der beobachteten Re-Expression des Esr2 wurden anschließend die humanen Mammakarzinomzellen MCF7 untersucht (Abb. 3.8). Auch hier konnte in den kontrollbehandelten Zellen keine Expression des ESR2 nachgewiesen werden. Nach der Behandlung mit dem Gesamtextrakt war eine konzentrationsabhängige Re-Expression des ESR2 zu erkennen. Die Expression war sowohl im Zytoplasma als auch im Kern zu detektieren. 


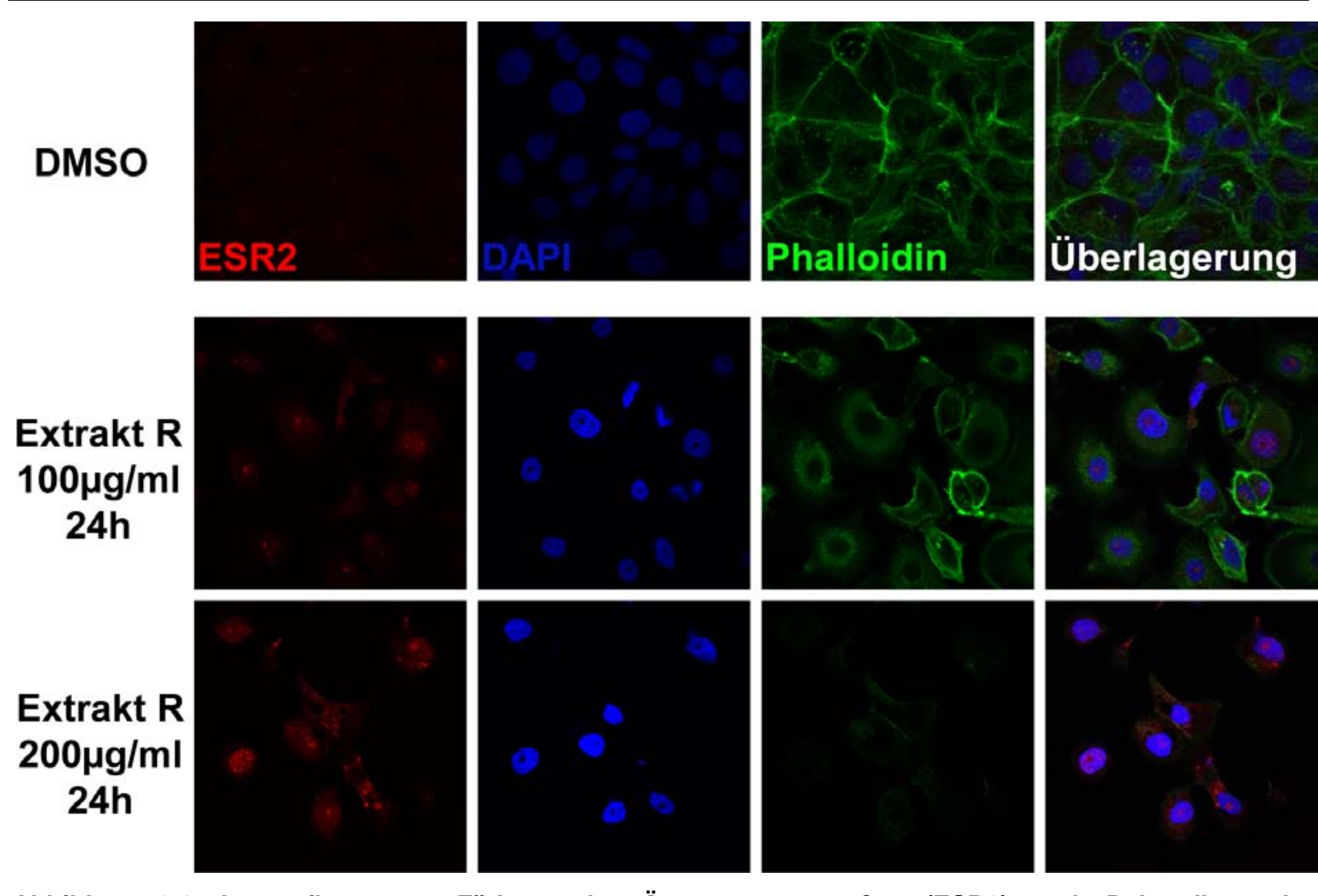

Abbildung 3.8: Immunfluoreszenz-Färbung des Östrogenrezeptorß (ESR2) nach Behandlung der humanen Mammakarzinomzellen MCF7 mit dem Gesamtextrakt R aus Belamcanda chinensis.

Die humanen Mammakarzinomzellen MCF7 wurden für 24 Stunden mit 100 $\mu \mathrm{g} / \mathrm{ml}$ bzw. 200 $\mu \mathrm{g} / \mathrm{ml}$ des Gesamtextrakts R aus Belamcanda chinensis behandelt. Anschließend wurden die Zellen fixiert und mit einem Antikörper gegen den ESR2 angefärbt. Das Zytoskelett wurde durch FITC-gekoppeltes Phalloidin sichtbar gemacht, der Zellkern durch eine Färbung mit DAPI. Die mit DMSO kontrollbehandelten humanen Mammakarzinomzellen MCF7 zeigten keine Expression des ESR2 (obere Reihe). Bei steigender Konzentration der Behandlung mit dem Gesamtextrakt konnte gezeigt werden, dass die Expression des ESR2 sowohl im Kern als auch im Zytoplasma zunahm (mittlere und untere Reihe).

Während der Immunfluoreszenz-Analysen wurde bemerkt, dass in den primären PCa-Zellen 2E und auch in den MCF7-Zellen, die mit dem Gesamtextrakt behandelt wurden, sich durch Phalloidin-Färbung detektierbare Vesikel bildeten. In den kontrollbehandelten Zellen konnten diese Vesikel nicht nachgewiesen werden. Die Vesikel befanden sich im gesamten Zytoplasma, sowohl in Kernnähe als auch an Zell-Zell-Kontakten (Abb. 3.9). 

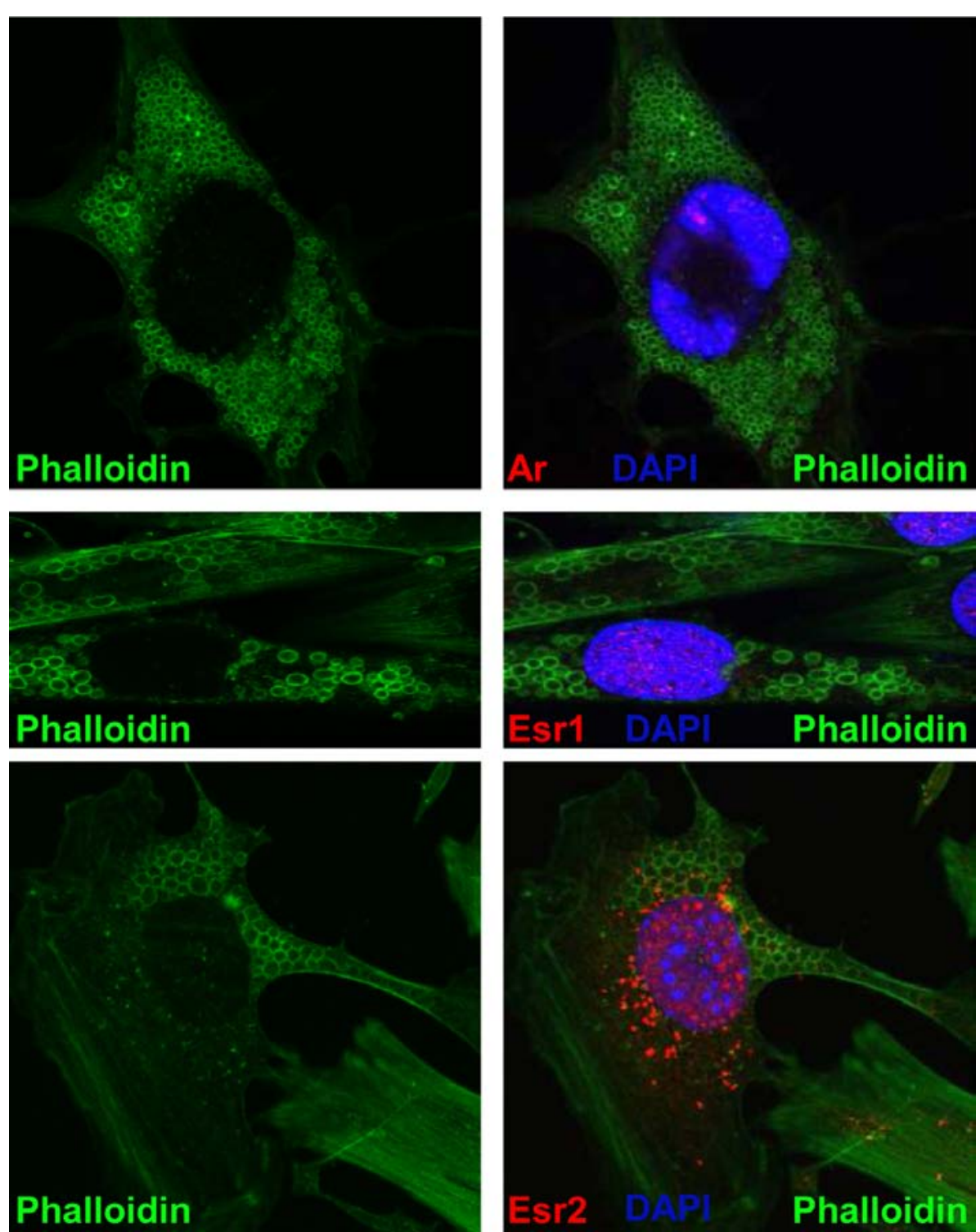

Abbildung 3.9: Immunfluoreszenz-Färbung nach Behandlung der primären PCa-Zellen 2E mit dem Gesamtextrakt R für 24 Stunden.

Die primären PCa-Zellen 2E wurden mit $400 \mu \mathrm{g} / \mathrm{ml}$ Gesamtextrakt R für 24 Stunden behandelt. Anschließend wurden sie fixiert und mit den angegebenen Antikörpern angefärbt. FITC-gekoppeltes Phalloidin färbte das Zytoskelett und DAPI den Zellkern. Es wurde bei allen Zellen nach der Behandlung mit dem Gesamtextrakt R eine starke Vesikelbildung detektiert.

\subsubsection{Expressionsanalysen nach Behandlung von Prostatakarzinomzellen mit Tectorigenin verschiedener Bezugsquellen}

Wie bereits in Kapitel 3.2.1 beschrieben, gab es in vorangegangenen Studien (Witt, 2009)

Differenzen zwischen der Wirkung des Tectorigenins der Firma Girindus und Bionorica. Es wurden daher weitere Herstellerfirmen untersucht. Zum einen wurde das Tectorigenin der Firma PhytoLab, welches die Firma als Referenzsubstanz vertreibt, untersucht. Zum anderen wurde aus dem in Kapitel 3.2.1 beschriebenen Gesamtextrakt $O$ (für Orgentis) das Tectorigenin isoliert und hinsichtlich seiner Wirksamkeit in PCa-Zellen untersucht. 
Die primären PCa-Zellen 2E wurden für 24 und 72 Stunden mit beiden Substanzen (PhytoLab und Orgentis) behandelt und das Gesamtprotein wurde isoliert. Die Western Blot-Analyse zeigte, dass sowohl das Tectorigenin der Firma PhytoLab als auch das aus dem Gesamtextrakt $O$ isolierte Tectorigenin der Firma Orgentis keine Änderung der Expression des Igf1r in den primären PCa-Zellen 2E bewirkte (Abb. 3.10). Lediglich nach 72 Stunden Behandlung mit dem Tectorigenin der Firma Orgentis konnte eine leichte Verringerung der Expression des Igf1r detektiert werden, die höchste eingesetzte Konzentration war allerdings zytotoxisch (Abb. 3.10B). Die Expression des Esr2 blieb nach der Behandlung der primären PCa-Zellen 2E mit dem Tectorigenin der Firma PhytoLab unverändert (Abb. 3.10A), jedoch nach der Behandlung mit dem Tectorigenin der Firma Orgentis konnte eine konzentrationsabhängige leichte Steigerung der Esr2-Expression gezeigt werden (Abb. 3.10B).
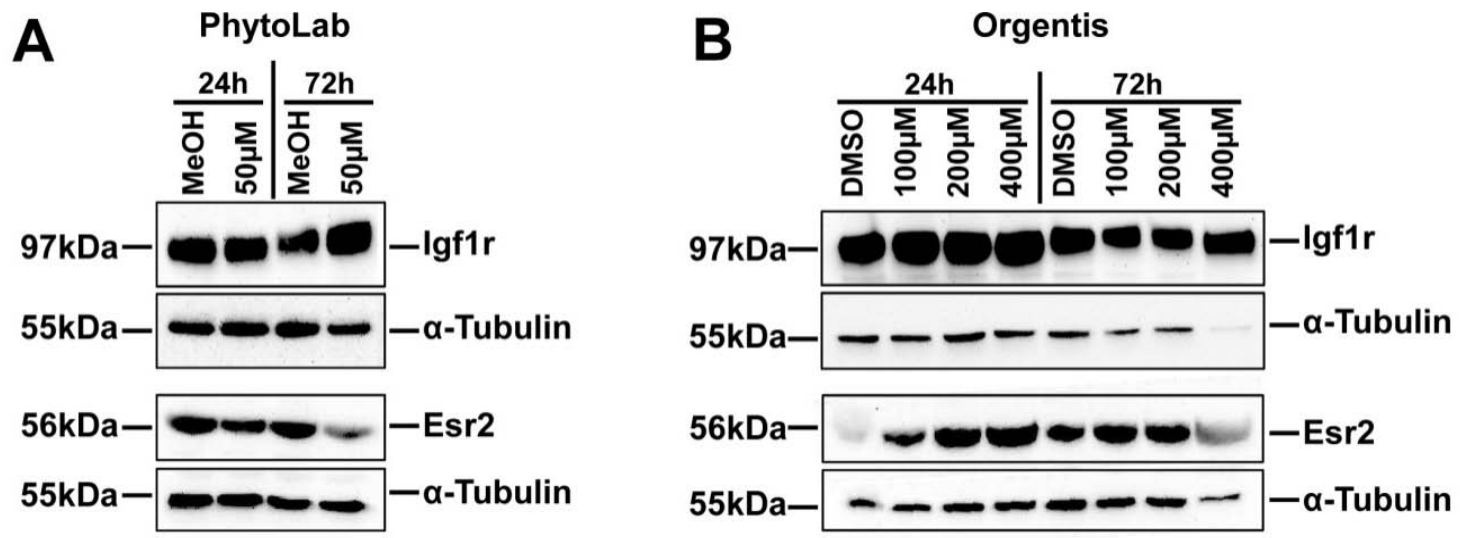

Abbildung 3.10: Expressionsanalysen nach der Behandlung der primären PCa-Zellen 2E mit Tectorigenin zwei verschiedener Hersteller.

(A) Die primären PCa-Zellen 2E wurden mit Tectorigenin der Firma PhytoLab in der Konzentration 50 $\mu \mathrm{M}$ behandelt. Methanol diente als Lösungsmittelkontrolle. Nach 24 und 72 Stunden Behandlung der Zellen wurde das Gesamtprotein isoliert. In den Western Blot-Analysen konnte gezeigt werden, dass sich weder die Expression des Igf1r noch die Expression des Esr2 nach der Behandlung änderte.

(B) Die primären PCa-Zellen 2E wurden mit verschiedenen Konzentrationen des aus dem Gesamtextrakt $\mathrm{O}$ gewonnenen Tectorigenin der Firma Orgentis für 24 und 72 Stunden behandelt und anschließend das Gesamtprotein isoliert. Die Western Blot-Analyse zeigte, dass die höchste verwendete Konzentration von Tectorigenin nach 72 Stunden Behandlung zytotoxisch wirkte. Des Weiteren konnte eine Abnahme der Expression des Igf1r detektiert werden, die Expression des Esr2 lag nach 72 Stunden Behandlung der Zellen leicht erhöht vor.

Für weitere Analysen wurden die bereits in der Literatur beschriebenen LNCaP-Zellen verwendet. Es wurde hier das Tectorigenin von drei verschiedenen Herstellern verglichen: das Tectorigenin der Firma Biopurify, das bereits in Witt (2009) verwendete Tectorigenin der Firma Girindus und das Tectorigenin der Firma Shenzhen, das direkt aus China, dem Ursprungsland von Belamcanda chinensis, bezogen wurde. 
Die humanen PCa-Zellen LNCaP wurden mit jeweils 50 $\mu \mathrm{M}$ des jeweiligen Tectorigenins für 24 und 72 Stunden behandelt. Anschließend wurde sowohl die Gesamt-RNA als auch das Gesamtprotein isoliert. Es konnte für alle untersuchten Proben eine mRNA-Abnahme des IGF-IR sowie des PSA detektiert werden. Die Expression des $A R$ blieb unverändert, die Expression des IGF-BP3 stieg nach 72 Stunden Behandlung an (Abb. 3.11A). Die Western Blot-Analyse zeigte, dass die Expression des IGF-IR nach der Behandlung mit dem Tectorigenin der Firma Shenzhen am stärksten vermindert war (Abb. 3.11B).

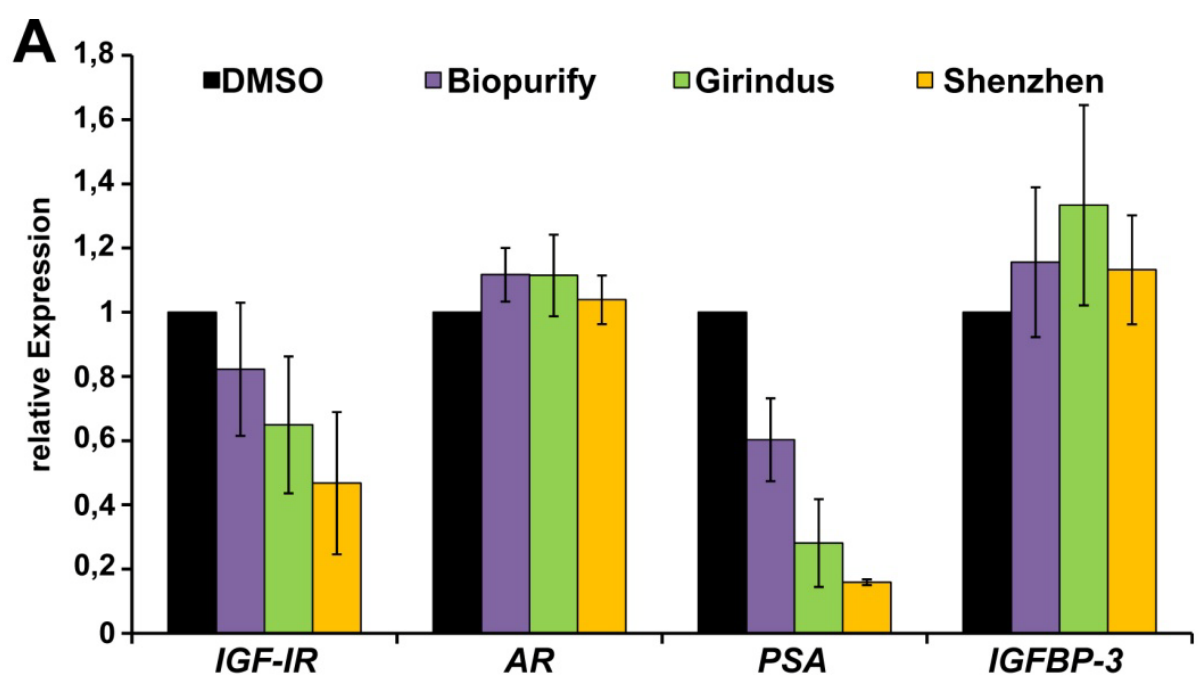

B

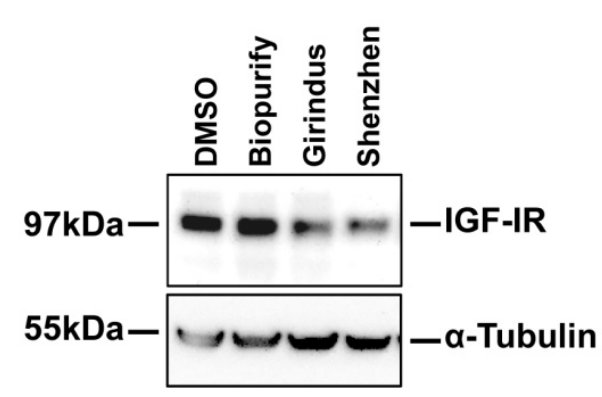

Abbildung 3.11: Expressionsanalysen nach der Behandlung von humanen PCa-Zellen mit Tectorigenin verschiedener Hersteller.

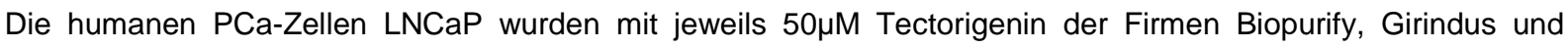
Shenzhen für 24 Stunden behandelt. Anschließend wurde die Gesamt-RNA (A) und das Gesamtprotein (B) isoliert. Sowohl die qRT-PCR-Analyse als auch die Western Blot-Analyse zeigten, dass nach der Behandlung mit allen verwendeten Tectorigenin-Proben die Expression des IGF-IR abnahm. Auch die mRNA-Expression von $P S A$ war vermindert. Die Expression des AR und des IGFBP-3 blieb unverändert.

\subsubsection{Microarray-Analyse nach der Behandlung von Prostatakarzinomzellen mit dem Tectorigenin der Firma Shenzhen}

Das Tectorigenin der Firma Shenzhen zeigte in den vorhergehenden Expressionsanalysen zufriedenstellende Ergebnisse. Daher wurde es für weitere Analysen verwendet. Es wurde ein Microarray an drei biologischen Replikaten der Behandlung von humanen PCa-Zellen LNCaP für 24 Stunden mit Tectorigenin der Firma Shenzhen durchgeführt. Die heatmap 
zeigte eine klare Abgrenzung der Kontrollgruppe von der mit Tectorigenin behandelten Gruppe (Abb. 3.12). Es sind die Top 50 Kandidatengene aufgeführt. Unter ihnen befinden sich unter anderem der IGF-IR und PSA (KLK3), die nach Tectorigenin-Behandlung der PCa-Zellen LNCaP vermindert exprimiert werden im Vergleich zu kontrollbehandelten LNCaP-Zellen.

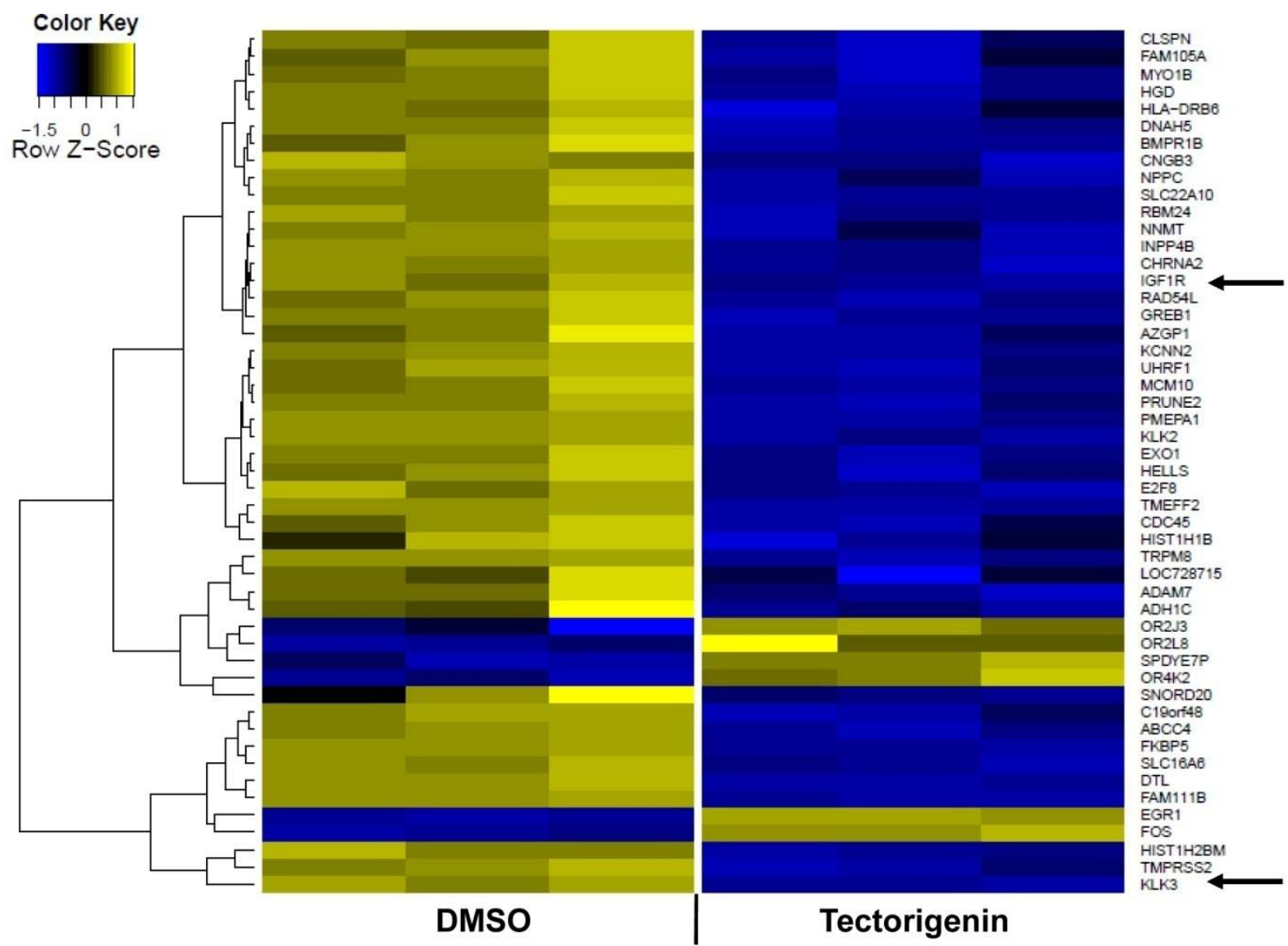

Abbildung 3.12: Heatmap der im Microarray identifizierten Top 50 differentiell exprimierten Gene.

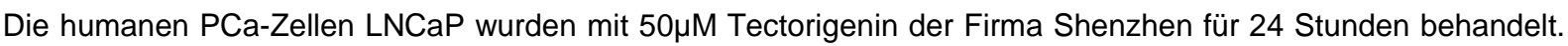
Die Behandlung der Zellen mit dem Lösungsmittel DMSO diente als Kontrolle. Die anschließende Microarray-Analyse zeigte einige differentiell exprimierte Gene nach der Tectorigenin-Behandlung im Vergleich zur Kontrollbehandlung. Mit dem Pfeil markiert sind der IGF-IR und PSA (KLK3), die in den mit Tectorigenin behandelten Proben vermindert exprimiert detektiert wurden im Vergleich zu den mit DMSO kontrollbehandelten Proben.

\subsubsection{Tectorigenin-Behandlung in vivo}

In Zusammenarbeit mit der Urologie und der Pathologie der Universitätsmedizin Göttingen wurden in vivo-Versuche an TRAMP-Mäusen durchgeführt. Diese Versuche wurden vor der Untersuchung verschiedener Aufreinigungen von Tectorigenin unterschiedlicher Hersteller durchgeführt. Daher wurde hier das Tectorigenin der Firma Girindus verwendet. Die Analysen wurden an TRAMP-Mäusen durchgeführt, da dieses Modell eine geeignete Grundlage für die Untersuchung der Tumorinitiation und -progression sowie der 
Metastasierung darstellte. Die TRAMP-Mäuse wurden ab einem Alter von sechs Wochen bis zu einem Alter von 30 Wochen mit Tectorigenin-haltigen Futterpellets gefüttert. Als Kontrolle diente eine Gruppe mit sojafreiem Futter. Die Ergebnisse der histopathologischen Studien der Prostatae sowie der Metastasen in anderen Organen (z.B. Lymphknoten, Lunge und Leber) sind in Abb. 3.13 dargestellt.

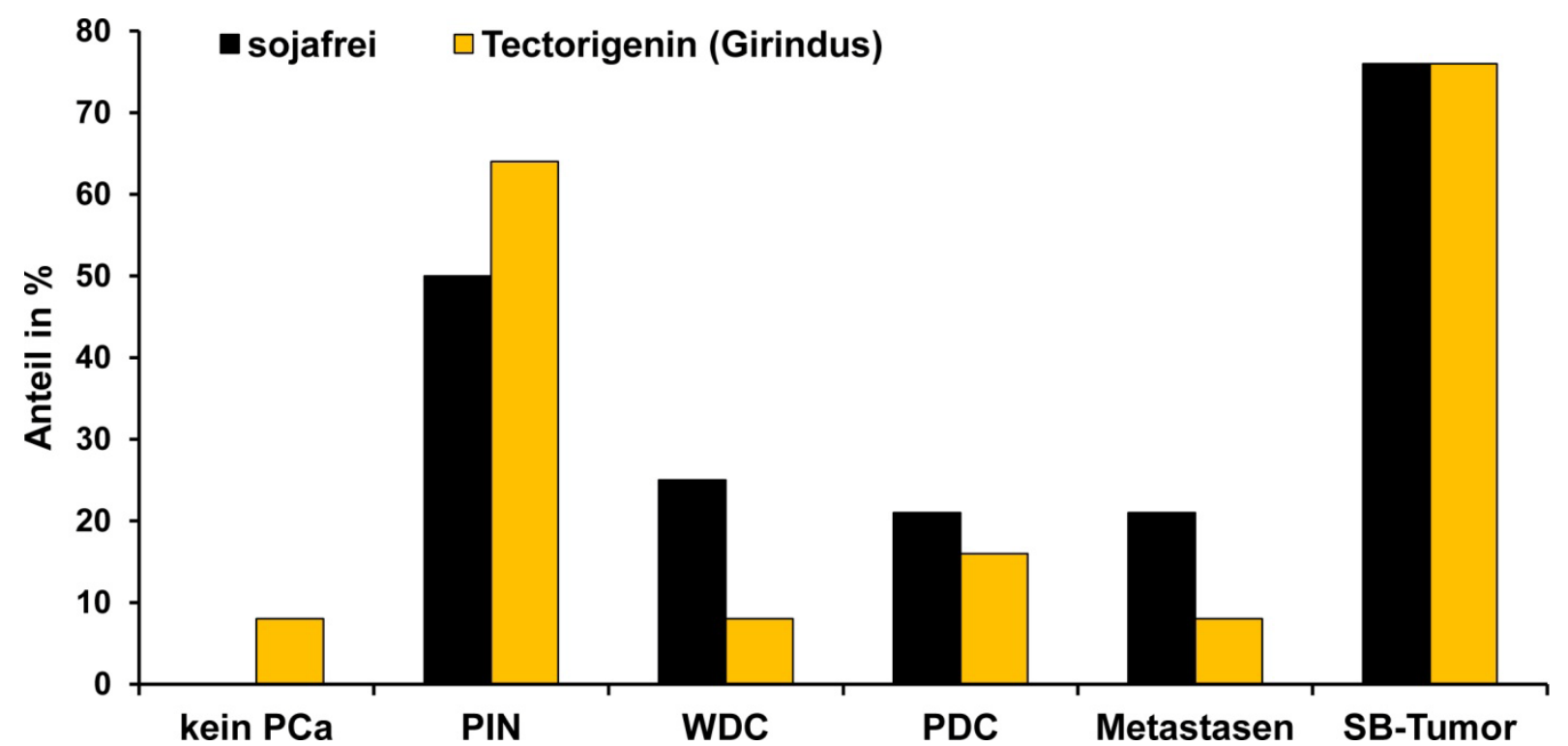

Abbildung 3.13: Auswertung zur histopathologischen Analyse der mit Tectorigenin-haltigem (TG-haltigem) Futter behandelten TRAMP-Mäuse.

Der Anteil an TG-gefütterten Mäusen ohne PCa war höher. Allerdings entwickelten mehr TG-gefütterte Mäuse eine PIN (prostatische intraepitheliale Neoplasie). Weniger TG-behandelte Mäuse entwickelten ein WDC (well differentiated carcinoma), der Anteil an TG-behandelten Mäusen mit PDC (poorly differentiated carcinoma) lag hingegen nur leicht unter den mit sojafreiem Futter gefütterten Kontrollmäusen. Der Anteil von Mäusen mit einem Samenblasentumor (SB-Tumor) war in beiden untersuchten Gruppen gleich hoch. Es wurden 24 TG-behandelte Mäuse und 23 Kontrollmäuse untersucht.

In diesen Studien konnten Hinweise auf die Wirksamkeit von Tectorigenin gezeigt werden. Diese waren ein selteneres Auftreten eines PCa in den TG-behandelten Mäusen sowie ein geringerer Anteil an Mäusen mit einem WDC (well differentiated carcinoma), PDC (poorly differentiated carcinoma) und eine geringere Metastasenbildung im Vergleich zu kontrollbehandelten Mäusen. Der Anteil von Mäusen mit einer PIN (prostatische intraepitheliale Neoplasie) hingegen lag bei den Tectorigenin-behandelten Mäusen leicht höher als bei den kontrollbehandelten Mäusen. Einen Samenblasentumor entwickelten Tiere aus beiden Gruppen zum gleichen Anteil. Abb. 3.14 zeigt exemplarisch einige histochemische Analysen der mit Tectorigenin- und kontrollbehandelten TRAMP-Mäuse. 

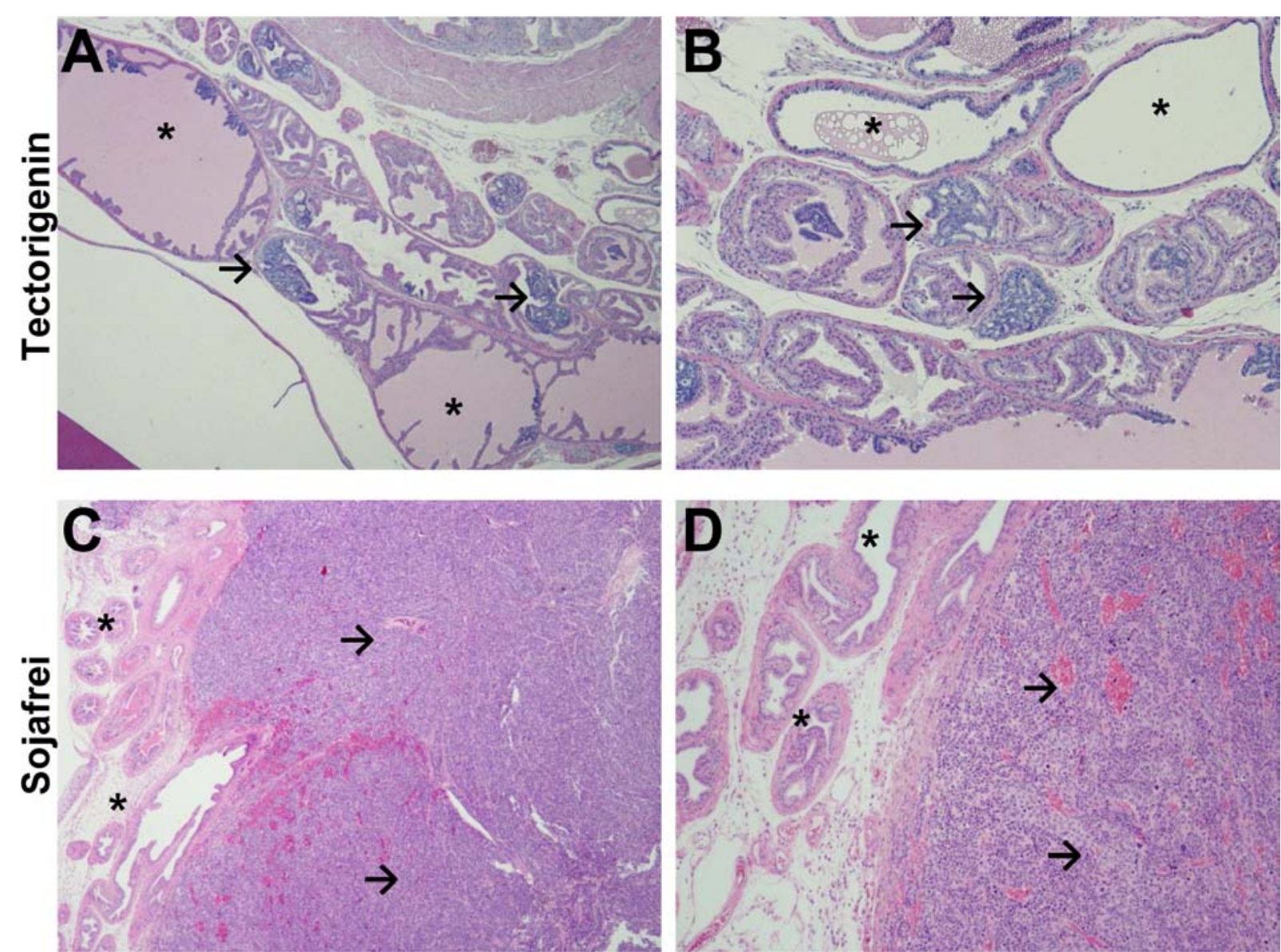

Abbildung 3.14: Histochemische Analysen von mit Tectorigenin-behandelten und kontrollbehandelten TRAMP-Prostatae.

Es wurden Hämatoxilin-Eosin-Färbungen von Prostatagewebeschnitten von TRAMP-Mäusen angefertigt, die entweder mit Tectorigenin-haltigem Futter (A, B) oder sojafreiem Futter als Kontrolle (C, D) behandelt wurden. Die mit Tectorigenin gefütterte TRAMP-Maus zeigte noch eine normale Struktur der Prostata $\left(^{*}\right)$ mit einem multifokalen Übergang in eine sehr frühe Vorstufe des Prostatakarzinoms, eine sog. prostatische intraepitheliale Neoplasie (PIN) $(\rightarrow)(A, x 40 ;$ B, x100). Die Soja-frei-gefütterte TRAMP-Maus (Kontrolle) zeigte hingegen neben der normalen Prostata $\left(^{\star}\right)$ bereits einen Übergang in ein geringdifferenziertes, d.h. weit fortgeschrittenes Prostatakarzinom $(\rightarrow)(C, x 40 ; D, x 100)$.

$\mathrm{Da}$ in diesen Studien keine Wirksamkeit von Tectorigenin auf die Tumorinitiation gezeigt werden konnte, wurde für weitere Versuche das bereits in der Literatur für Untersuchungen zur Wirksamkeit des Gesamtextraktes aus Belamcanda chinensis verwendete LNCaP-Xenograft-Modell verwendet (Thelen et al., 2005; Thelen et al., 2006). Für diese in vivo-Versuche wurde das im Rahmen der vorliegenden Arbeit getestete Tectorigenin der Firma Shenzhen unter sojafreies Futter gemischt. Als Kontrollfutter diente sojafreies Futter. Die etablierte humane PCa-Zelllinie LNCaP wurde beidseitig in die Flanken von Nacktmäusen injiziert. Die Behandlung wurde ab der Injektion begonnen. Die Gruppen wurden zufällig unterteilt in sojafreie Nahrung und Tectorigenin-haltige Nahrung.

Die Anwachsrate in beiden Gruppen war vergleichbar. In der sojafreien Gruppe lag sie bei sieben von 18 (38\%) möglichen Tumoren und in der Tectorigenin-Gruppe bei sechs von 16 
(37,5\%). Die Behandlung wurde nach Erreichen des Abbruchkriteriums der Tumorgröße von $1,5 \mathrm{~cm}^{3}$ (vgl. Kapitel 2.21.2) für ein Tier für beide Gruppen beendet.

$\mathrm{Zu}$ diesem Zeitpunkt war das mittlere Tumorgewicht in den Tectorigenin-behandelten Mäusen deutlich kleiner $(0,09 \mathrm{~g})$ im Vergleich zu den kontrollbehandelten Mäusen $(0,75 \mathrm{~g})$ und auch das mittlere Tumorvolumen war bei der Tectorigenin-behandelten Gruppe eindeutig geringer $\left(85 \mathrm{~mm}^{3}\right)$ im Vergleich zu den kontrollbehandelten Mäusen $\left(414 \mathrm{~mm}^{3}\right)$ (Abb. 3.15).
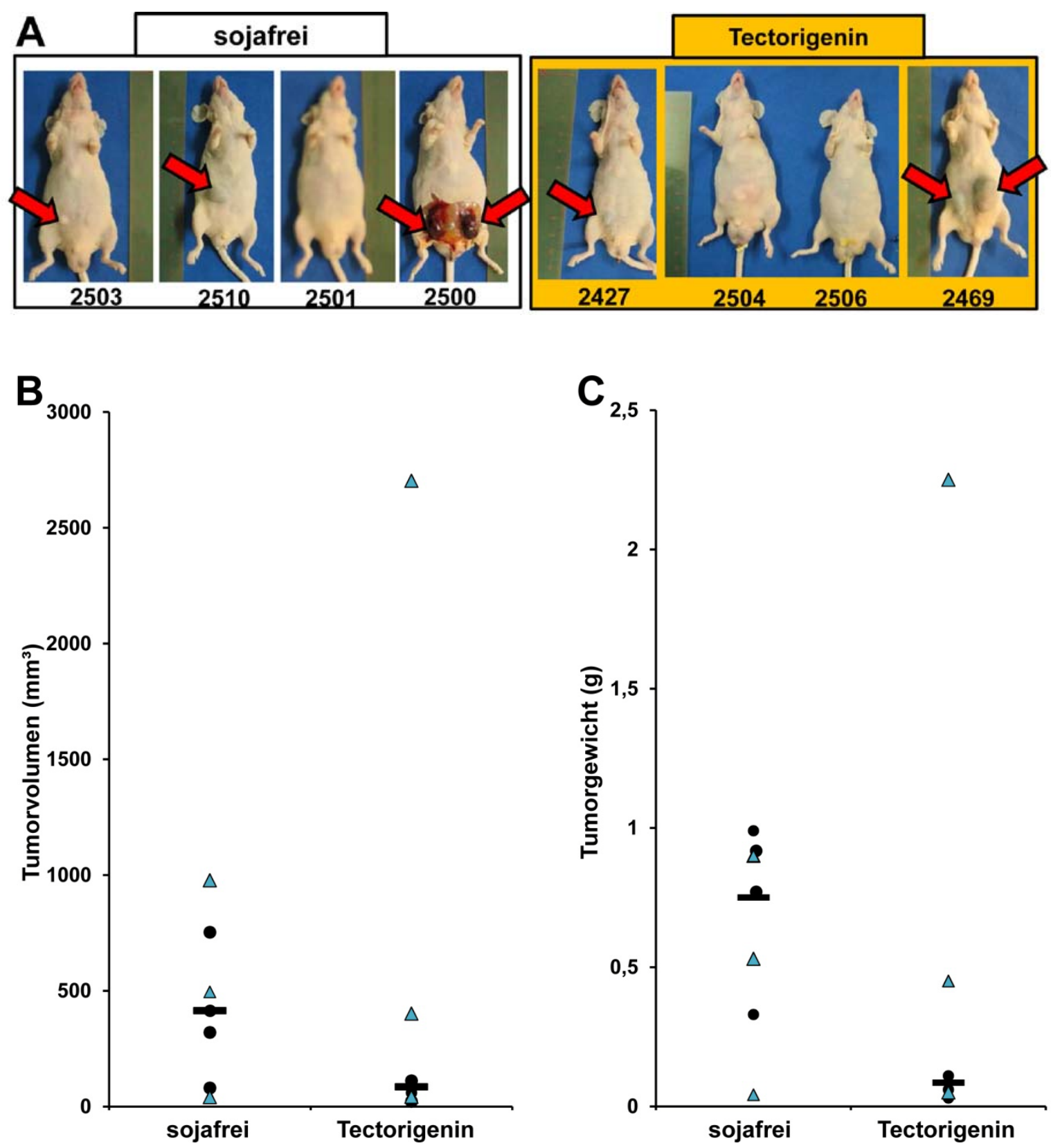

Abbildung 3.15: Analyse des Tumorgewichts und der Tumorgröße von subkutanen Prostatatumoren aus LNCaP-Zellen im Nacktmaus-Modell mit anschließender Tectorigenin-Behandlung.

Die humanen PCa-Zellen LNCaP wurden beidseitig in die Flanken von Nacktmäusen gespritzt. Es wurden zwei Versuchsgruppen untersucht (dargestellt mit • für Gruppe 1 und $\Delta$ für Gruppe 2). Die Tiere wurden jeweils zufällig in die Kontrollgruppe mit sojafreiem Futter oder die Versuchsgruppe mit Tectorigenin-haltigem Futter eingeteilt. 
Nach Erreichen des Abbruchkriteriums für eine Maus wurden beide Gruppen beendet und die Tumore präpariert. (A) In Orange hinterlegt sind einige repräsentative Beispiele für Tectorigenin-behandelte Mäuse (hierbei auch die Maus Nummer 2469, die das Abbruchkriterium der Tumorgröße in Gruppe 2 erreichte). In weiß hinterlegt sind einige repräsentative Beispiele für kontrollbehandelte Mäuse, die sojafreies Futter erhielten. (B) Die Auswertung des mittleren Tumorgewichts zeigte ein deutlich geringeres Gewicht für die Tectorigenin-behandelte Gruppe, auch wenn die Varianz aufgrund von der oben genannten Maus Nummer 2469 sehr hoch war. (C) Das mittlere Tumorvolumen war in der Tectorigenin-behandelten Gruppe eindeutig geringer als in der kontrollbehandelten Gruppe, auch wenn die Varianz wie bei (B) beschrieben hoch war.

In den Abbildungen $B$ und $C$ ist jeweils der Median beider Versuchsgruppen zusammengefasst dargestellt.

\subsection{Der Histondeacetylase-Inhibitor Valproinsäure}

\subsubsection{Funktionelle Effekte der Valproinsäure-Behandlung in Prostatakarzinomzellen}

\subsubsection{Analyse der Histonacetylierung nach Behandlung von Prostatakarzinomzellen mit Valproinsäure}

Um zu prüfen, ob die von VPA ausgeübte Histondeacetylase-Aktivität in unseren Modellsystemen funktionell ist, wurden sowohl die primären murinen PCa-Zellen 2E als auch die etablierten humanen PCa-Zellen PC-3 mit verschiedenen aufsteigenden Konzentrationen von VPA behandelt und das Gesamtprotein isoliert. Mittels Western Blot-Analyse konnte eine konzentrationsabhängige Zunahme der Histonacetylierung für das Histon 3 an Lysin 9 beobachtet werden (Abb. 3.16; Witt et al., 2013).

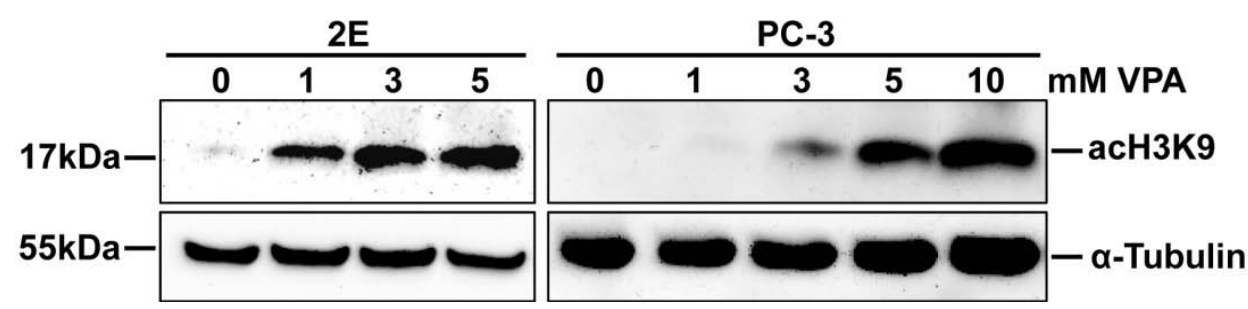

Abbildung 3.16: Analyse der Histonacetylierung nach Behandlung von primären und etablierten PCa-Zellen mit VPA.

Sowohl die primären als auch die etablierten PCa-Zellen 2E und PC-3 wurden für 24 Stunden mit VPA in den angegebenen Konzentrationen behandelt. Das Gesamtprotein wurde isoliert und mittels Western Blot-Analyse mit einem Antikörper gegen acetyliertes Histon 3 an Lysin 9 untersucht. Die Behandlung mit dem HistondeacetylaseInhibitor VPA führte konzentrationsabhängig zu einer verstärkten Acetylierung von Histon 3 an Lysin 9 (modifiziert nach Witt et al., 2013).

\subsubsection{Untersuchungen zur Proliferation nach Behandlung von Prostatakarzinomzellen mit Valproinsäure}

Die primären Prostatakarzinomzellen 2E wurden mit aufsteigenden Konzentrationen von VPA (1mM bis 10mM) behandelt. Die Proliferation wurde mittels eines MTT-Assays nach 72 
bzw. 144 Stunden VPA-Behandlung bestimmt. Bereits nach 72 Stunden Behandlung mit VPA konnte eine deutliche Reduktion der Zellproliferation beobachtet werden (Abb. 3.17). Für die höchste Konzentration von VPA lag diese bei 51\%. Nach der Behandlung mit VPA für 144 Stunden war eine deutliche konzentrationsabhängige Inhibierung der Proliferation der PCa-Zellen 2E zu detektieren (Abb. 3.17; Witt et al., 2013). Diese lag zwischen 33\% Inhibition für die geringste eingesetzte Konzentration von VPA (1mM) bis zu 72\% Inhibition bei Behandlung der Zellen mit 10mM VPA.

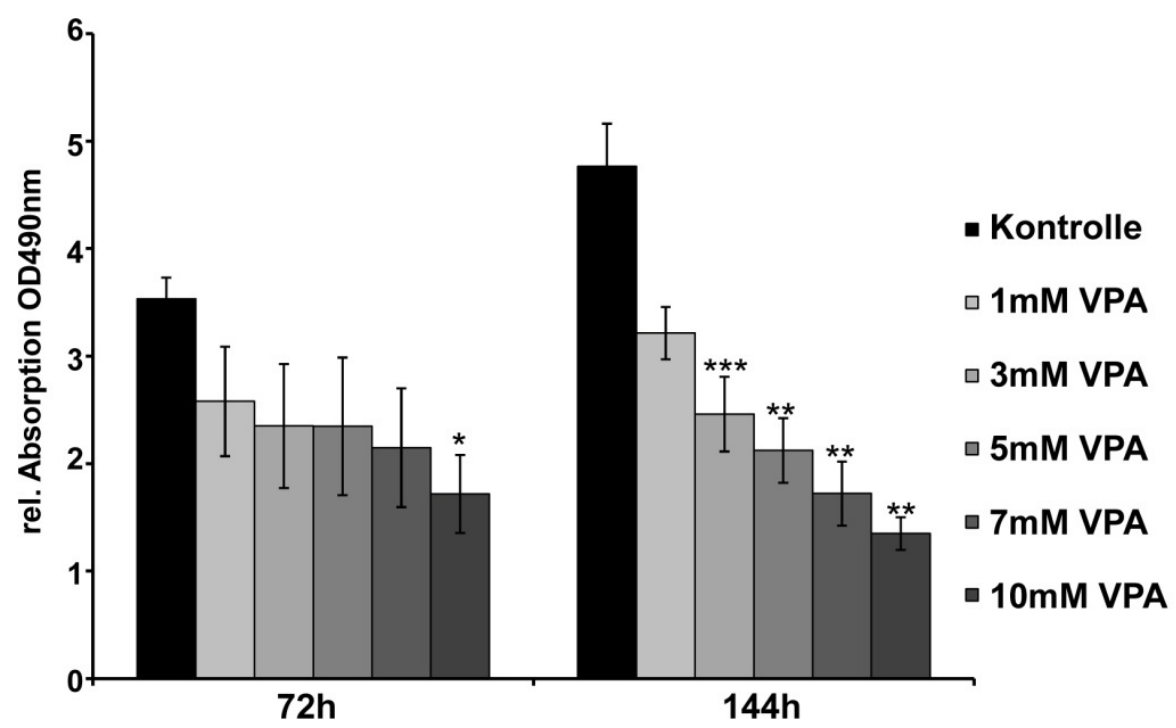

Abbildung 3.17: Analyse der Proliferation der primären PCa-Zellen 2E nach Behandlung mit VPA.

Die PCa-Zellen 2E wurden mit aufsteigenden Konzentrationen von VPA behandelt und die Proliferation wurde nach 72 bzw. 144 Stunden mittels eines MTT-Assays gemessen. Bereits nach 72 Stunden VPA-Behandlung konnte eine deutliche Reduktion der Zellproliferation detektiert werden. Diese war nach 144 Stunden Behandlung der PCa-Zellen 2E mit VPA konzentrationsabhängig von 33\% für 1mM VPA bis 72\% Inhibition der Proliferation für 10mM VPA zu beobachten (modifiziert nach Witt et al., 2013). ${ }^{*} 0.01<p \leq 0.05,{ }^{* *} 0.001 \leq p<0.01,{ }^{* * *} p \leq 0.001$

Als zweite Methode zur Analyse der Zellproliferation wurde ein Koloniebildungsassay durchgeführt. Hierbei wurden die primären Prostatakarzinomzellen $2 \mathrm{E}$ in sehr geringer Dichte ausgesät und nach 24 Stunden wurde das Medium durch Medium mit VPA ausgetauscht. Dieses Medium wurde regelmäßig erneuert bis deutliche Zellkolonien sichtbar waren (nach ca. 14 Tagen). Die Zellkolonien wurden mittels Hämalaun/Eosin angefärbt und ausgezählt. Die Anzahl der Kolonien in den mit VPA behandelten Zellen war bereits bei der Behandlung der Zellen mit 1mM VPA 48\% geringer als in den kontrollbehandelten Zellen (Abb. 3.18; Witt et al., 2013). Bei einer Behandlung der Zellen mit 5mM VPA waren nur noch $5 \%$ der Kolonien im Vergleich zu den kontrollbehandelten Zellen sichtbar. Bei den Zellen, die mit der höchsten VPA-Konzentration behandelt wurden $(10 \mathrm{mM})$, konnte keine Kolonie detektiert werden. 


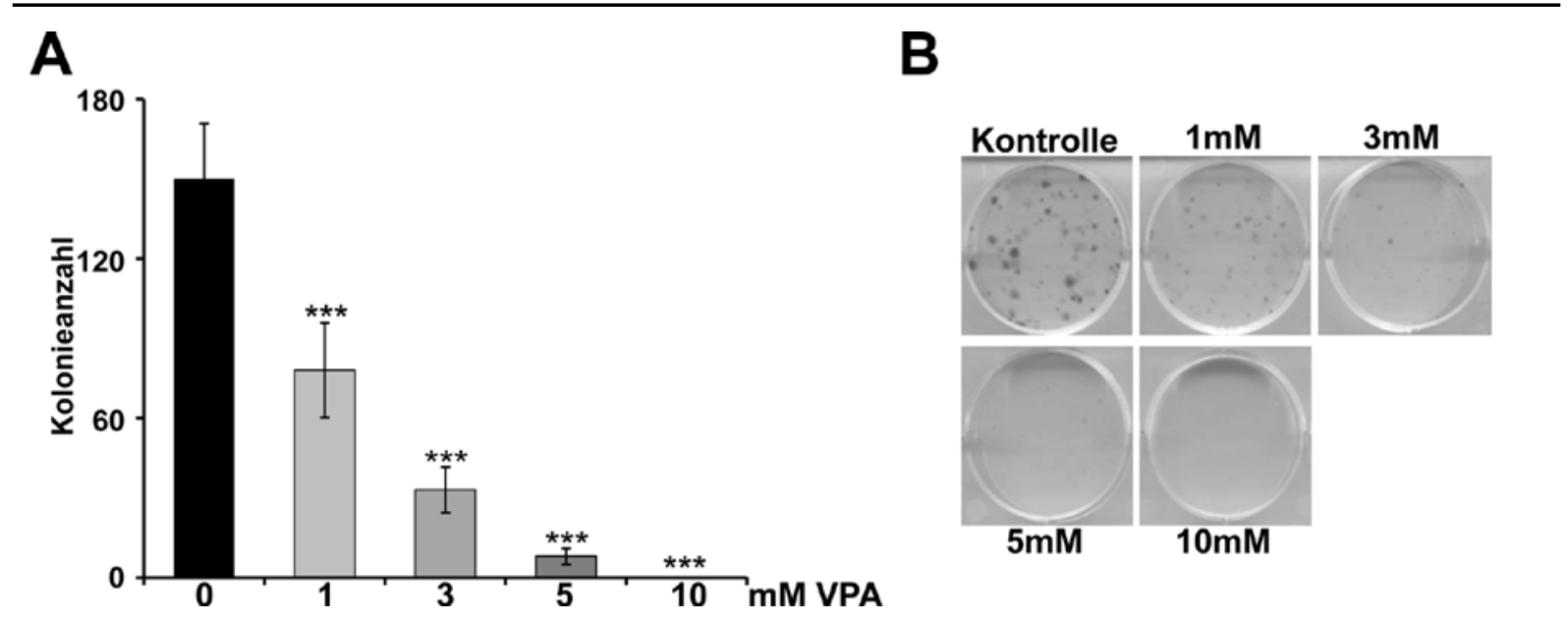

Abbildung 3.18: Koloniebildungsassay nach Behandlung der primären PCa-Zellen 2E mit VPA.

Die PCa-Zellen 2E wurden in sehr geringer Dichte ausgesät. Anschließend wurden sie mit aufsteigenden Konzentrationen von VPA behandelt bis eine deutliche Koloniebildung sichtbar war. Die Kolonien wurden mit Hilfe von Hämalaun/Eosin-Färbung gefärbt und ausgezählt. (A) Bereits die Behandlung mit 1mM VPA verringerte die Anzahl der Kolonien um 48\% im Vergleich zu den kontrollbehandelten Zellen. Für die beiden höchsten verwendeten Konzentrationen von VPA konnten lediglich 5\% (5mM VPA) bzw. keine Kolonie (10mM VPA) im Vergleich zu den kontrollbehandelten Zellen ausgezählt werden. (B) Repräsentative Beispiele der Koloniebildungsassays (modifiziert nach Witt et al., 2013). ${ }^{\star \star \star} p \leq 0.001$

Auch die etablierte humane Prostatakarzinom-Zelllinie PC-3 wurde mit VPA behandelt und die Proliferation der Zellen mittels eines MTT-Assays bestimmt. Hierbei wurden die Zeitpunkte 24, 48, 72 und 144 Stunden für die VPA-Behandlung ausgewählt. Es konnte eine deutliche Inhibierung der Proliferation der humanen PCa-Zellen PC-3 nach der Behandlung mit VPA beobachtet werden, die sowohl konzentrations- als auch zeitabhängig war (Abb. 3.19; Witt et al., 2013). 


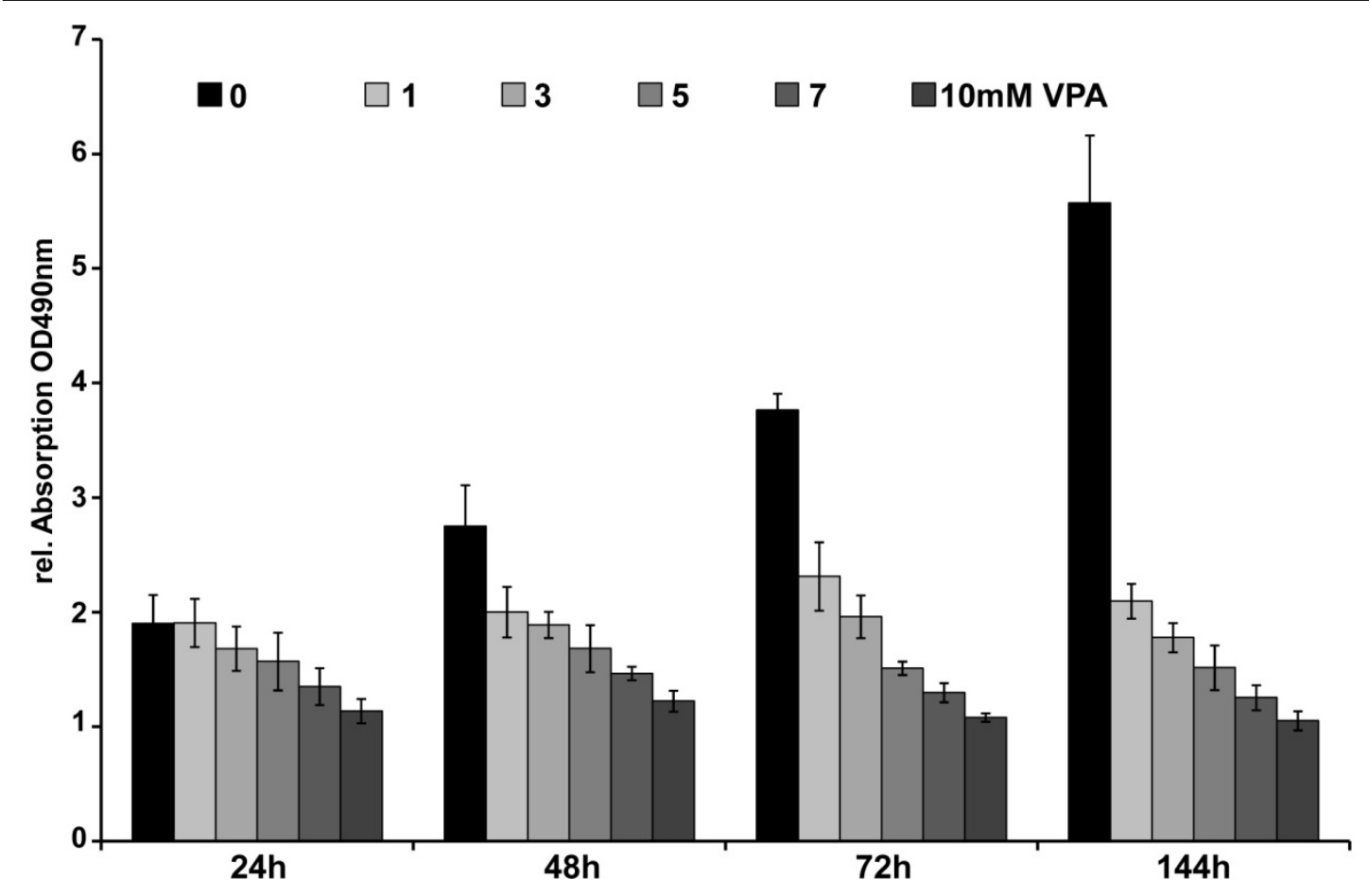

Abbildung 3.19: Analyse der Proliferation der humanen PCa-Zellen PC-3 nach Behandlung mit VPA.

Die PCa-Zellen PC-3 wurden mit aufsteigenden Konzentrationen von VPA behandelt. Nach 24, 48, 72 und 144 Stunden wurde jeweils ein MTT-basierter Proliferationsassay durchgeführt. Die Inhibition der Proliferation nach VPA-Behandlung wurde bereits nach 24 Stunden detektiert. Diese Inhibition verstärkte sich mit der Zeit konzentrationsabhängig (modifiziert nach Witt et al., 2013).

\subsubsection{Analysen zur Migrations- und Invasionsfähigkeit von primären Prostatakarzinomzellen nach Valproinsäure-Behandlung}

Die primären PCa-Zellen 2E wurden mit zwei verschiedenen Konzentrationen von VPA für 48 Stunden behandelt $(5 \mathrm{mM}$ und $10 \mathrm{mM})$. Die Migrationsfähigkeit der Zellen wurde mittels eines Transwell-Migrationsassays untersucht. Die Migrationsfähigkeit der PCa-Zellen 2E nahm konzentrationsabhängig ab und war bei einer Behandlung mit 10mM VPA um ca. 50\% reduziert im Vergleich zu kontrollbehandelten Zellen (Abb. 3.20; Witt et al., 2013). 


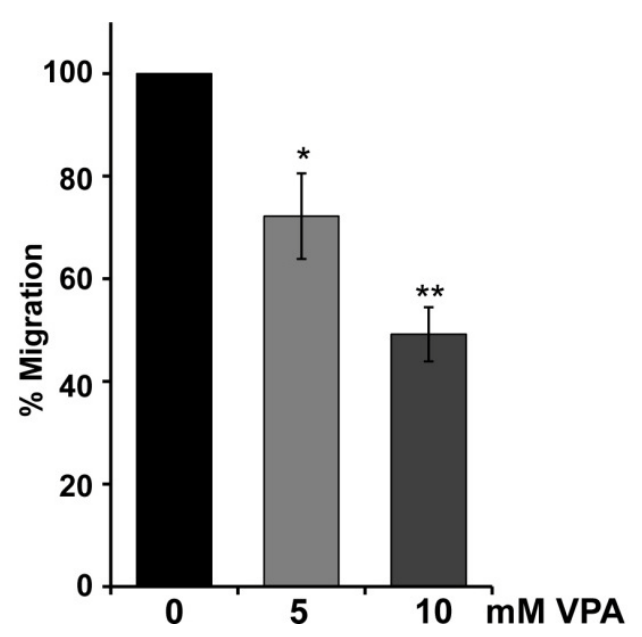

Abbildung 3.20: Analyse der Migrationsfähigkeit der primären PCa-Zellen 2E nach VPA-Behandlung.

Die primären PCa-Zellen 2E wurden für 48 Stunden mit VPA in zwei unterschiedlichen Konzentrationen behandelt $(5 \mathrm{mM}$ und $10 \mathrm{mM})$. Anschließend wurden die Zellen auf einen Transwell-Migrationsassay transferiert und darin 24 Stunden inkubiert. Nach der Inkubation wurden die Zellen fixiert und mittels Hämalaun/Eosin angefärbt und unter dem Mikroskop ausgezählt. Bereits eine Behandlung mit 5mM VPA rief eine signifikante Inhibition der Migration hervor. Die Behandlung mit 10mM VPA führte zu einer etwa 50\%igen Inhibierung der Migrationsfähigkeit der primären PCa-Zellen 2E (modifiziert nach Witt et al., 2013). * $0.01<p \leq 0.05,{ }^{* *} 0.001 \leq p$ $<0.01$

Die Invasionsfähigkeit der PCa-Zellen 2E wurde mit Hilfe eines Boyden-Kammer-Matrige| $®$-Invasionsassays bestimmt. Bereits eine Behandlung mit $5 \mathrm{mM}$ VPA reduzierte die Invasionsfähigkeit der Zellen um etwa die Hälfte. Eine Steigerung der VPA-Konzentration auf 10mM VPA für die Behandlung hatte allerdings keinen additiven Effekt, auch hierbei wurde die Invasionsfähigkeit um etwa die Hälfte gemindert (Abb. 3.21; Witt et al., 2013).

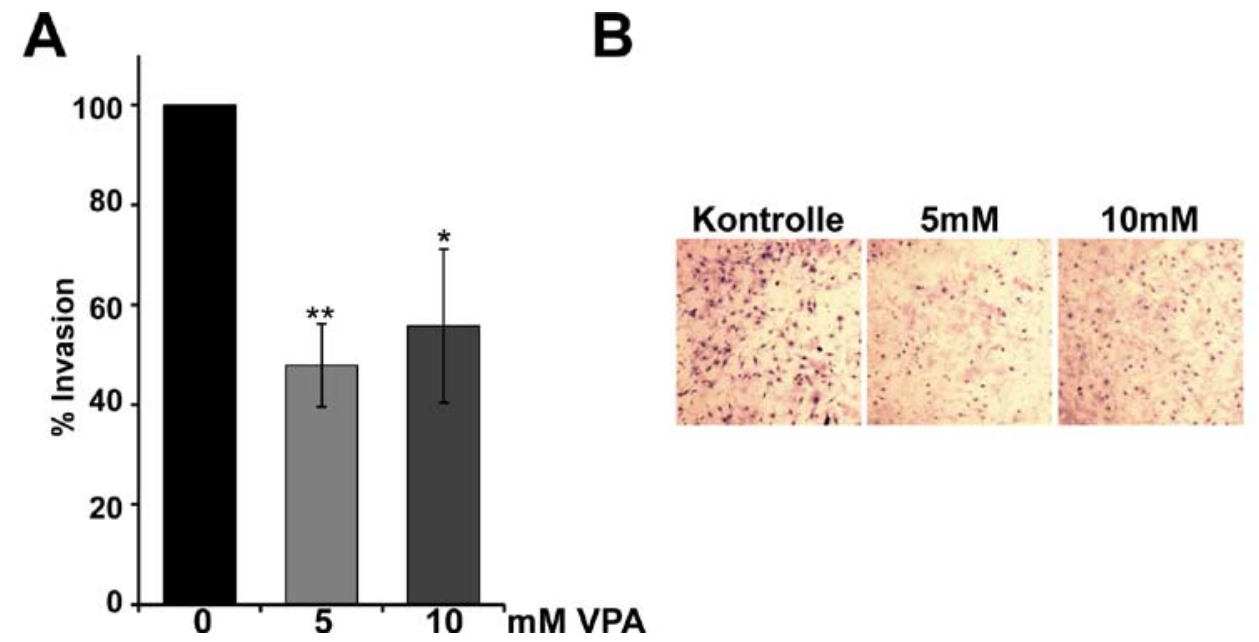

Abbildung 3.21: Analyse der Invasionsfähigkeit der primären PCa-Zellen 2E nach VPA-Behandlung.

Die primären PCa-Zellen 2E wurden für 24 Stunden mit VPA vorinkubiert und anschließend in Medium mit $10 \%$ FKS in ein sog. Insert des Invasionsassays überführt. Die Zellen wurden für 48 Stunden in dem Assay belassen, schließlich fixiert, mittels Hämalaun/Eosin-Färbung angefärbt und unter dem Mikroskop ausgezählt. (A) Bereits die Behandlung der Zellen mit der geringeren VPA-Konzentration (5mM) verursachte eine Reduktion der Invasionsfähigkeit der PCa-Zellen 2E um etwa die Hälfte. Die verwendete höhere Konzentration von VPA (10mM) 
zeigte keine additiven Effekte. Die Inhibition der Invasion lag hier ebenfalls bei etwa 55\%. (B) Repräsentatives Beispiel der angefärbten PCa-Zellen 2E auf der Unterseite der Membranen nach der Invasion (modifiziert nach Witt et al., 2013). * $0.01<p \leq 0.05,{ }^{* *} 0.001 \leq p<0.01$

\subsubsection{Expressionsanalysen nach Valproinsäure-Behandlung von primären Prostatakarzinomzellen}

Es wurden einige Kandidatengene zur Untersuchung ihrer Expression nach Behandlung der primären PCa-Zellen 2E mit VPA aufgrund bekannter Regulationen aus der Literatur ausgewählt.

\subsubsection{Analyse der Expression des Androgenrezeptors nach Valproinsäure- Behandlung von Prostatakarzinomzellen}

VPA vermindert in Hefezellen die Aktivität des AR (Death et al., 2005). Zudem ist bekannt, dass die Effekte wie Inhibition der Proliferation von PCa-Zellen durch eine VPA-Behandlung androgenabhängig sind (lacopino et al., 2008). Daher wurde zunächst die Expression des $\mathrm{Ar}$ nach VPA-Behandlung der primären PCa-Zellen 2E untersucht.

Die Expression des $A r$ wurde nach 24 bzw. 72 Stunden VPA-Behandlung der primären PCa-Zellen 2E mit verschiedenen Konzentrationen von VPA bestimmt. Hierfür wurde die Gesamt-RNA isoliert. Die qRT-PCR-Analysen zeigten eine Reduktion der Ar-Expression sowohl nach 24 als auch nach 72 Stunden VPA-Behandlung (Abb. 3.22A). Zusätzlich wurde die Expression des Ar nach der Behandlung der primären PCa-Zellen 2E mit VPA mittels Immunfluoreszenz bestimmt. Hierfür wurden die primären PCa-Zellen 2E mit 5mM VPA behandelt, anschließend fixiert und mit einem spezifischen Antikörper gegen den $\mathrm{Ar}$ angefärbt. Die mikroskopischen Aufnahmen wurden mit festgesetzten Belichtungseinstellungen für alle Behandlungen durchgeführt (Kontrollzellen und VPAbehandelte Zellen). Nach der VPA-Behandlung der primären PCa-Zellen 2E konnte ebenfalls auf Proteinebene eine Reduktion der Expression des Ar beobachtet werden (Abb. 3.22B). 


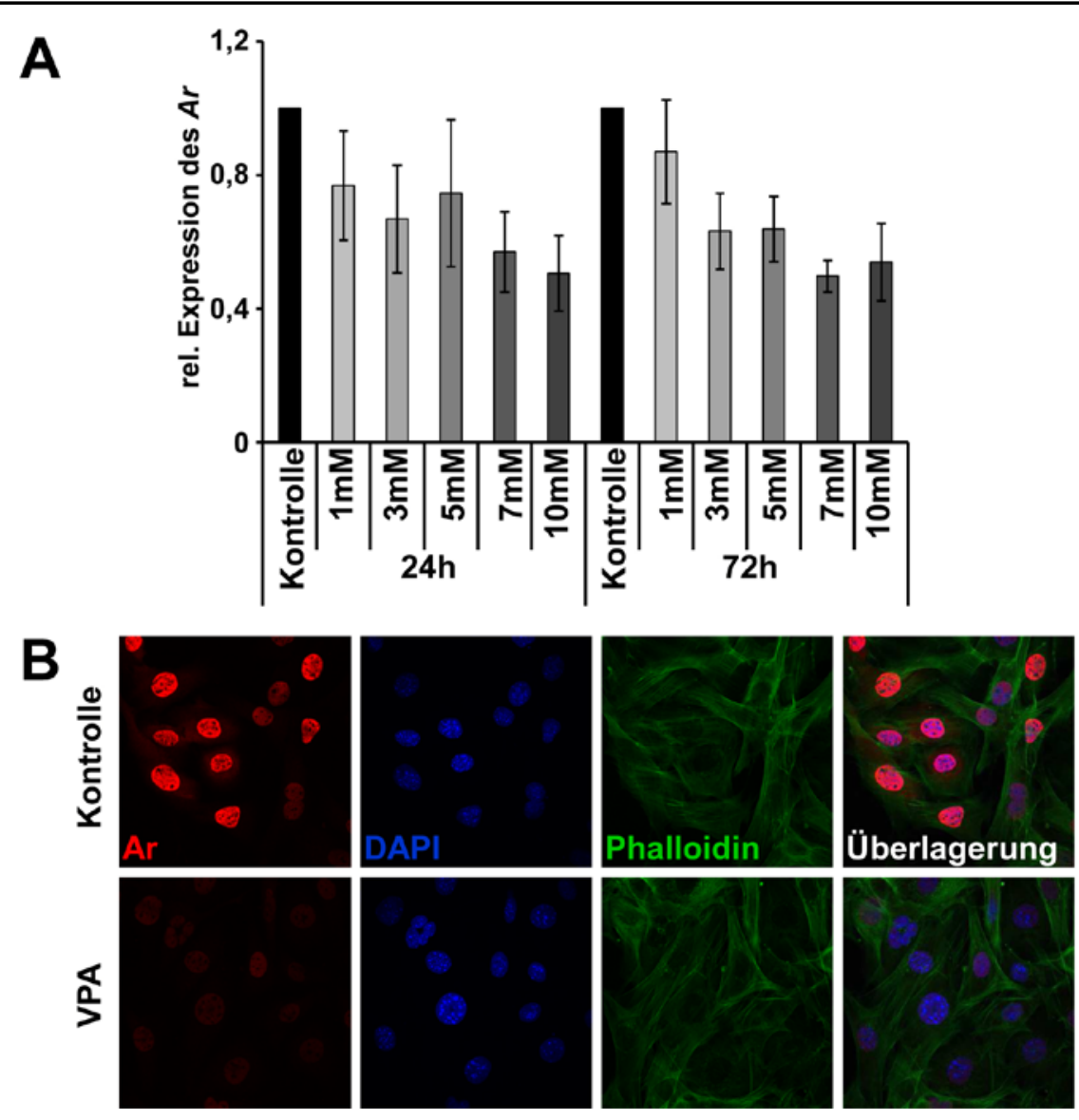

Abbildung 3.22: Analyse der Expression des Androgenrezeptors (Ar) nach Behandlung von primären PCa-Zellen mit VPA

(A) Die primären PCa-Zellen 2E wurden jeweils für 24 bzw. 72 Stunden mit unterschiedlichen VPA-Konzentrationen behandelt und anschließend die Gesamt-RNA isoliert. Die qRT-PCR-Analyse zeigte, dass die Expression des Ar nach der Behandlung der primären PCa-Zellen 2E mit VPA im Vergleich zu kontrollbehandelten Zellen konzentrationsabhängig verringert war.

(B) Die primären PCa-Zellen 2E wurden mit 5mM VPA behandelt, fixiert und mit einem spezifischen Antikörper gegen den Ar angefärbt. Die Zellkerne wurden mit DAPI und das Zytoskelett der Zellen mit FITC-gekoppeltem Phalloidin angefärbt. Nach der VPA-Behandlung der PCa-Zellen 2E konnte eine deutliche Abschwächung der Ar-Expression im Vergleich zu kontrollbehandelten Zellen gezeigt werden. Alle Aufnahmen wurden mit einer 600-fachen Vergrößerung an einem Laser-Scanning-Mikroskop erstellt.

\subsubsection{Expressionsanalysen $\mathrm{zu}$ Apoptose-assoziierten Proteinen nach Valproinsäure-Behandlung von Prostatakarzinomzellen}

VPA induziert in den humanen PCa-Zellen VCaP Apoptose (Fortson et al., 2011). Es konnte eine erhöhte Aktivierung der Caspasen 3 und 7 gezeigt werden (Fortson et al., 2011). Weitere Zielgene der Apoptose nach der VPA-Behandlung von PCa-Zellen sind weitestgehend unerforscht. Daher wurden hier die Expression der proapoptotischen Proteine Bim, Bok und Bax und des antiapoptotischen Proteins Bcl-2 sowie die Aktivierung von Caspase 3 (als Repräsentant für sowohl intrinsische als auch extrinsische Apoptose) untersucht. 
Zur Untersuchung von Apoptose-Signalwegen wurden die primären PCa-Zellen 2E mit verschiedenen Konzentrationen von VPA behandelt und anschließend das Gesamtprotein aus den adhärenten Zellen sowie den Zellen aus dem Überstand gemeinsam isoliert. Es konnte festgestellt werden, dass das proapoptotische Protein Bim nach der VPA-Behandlung von PCa-Zellen 2E verstärkt exprimiert wurde (Abb. 3.23A). Die Expression der proapoptotischen Proteine Bok und Bax blieb während der VPA-Behandlung der primären PCa-Zellen 2E unverändert (Abb. 3.23A und B). Auch die Expression des antiapoptotischen Proteins Bcl-2 war während der VPA-Behandlung nach 24 Stunden zunächst etwas vermindert, nach 72 Stunden Behandlung konnte allerdings kein Unterschied zu den kontrollbehandelten Zellen mehr detektiert werden (Abb. 3.23B). Untersuchungen zur Aktivierung der Caspase 3 zeigten keine Aktivierung nach VPA-Behandlung der primären PCa-Zellen 2E (Abb. 3.23A). 
$-68-$
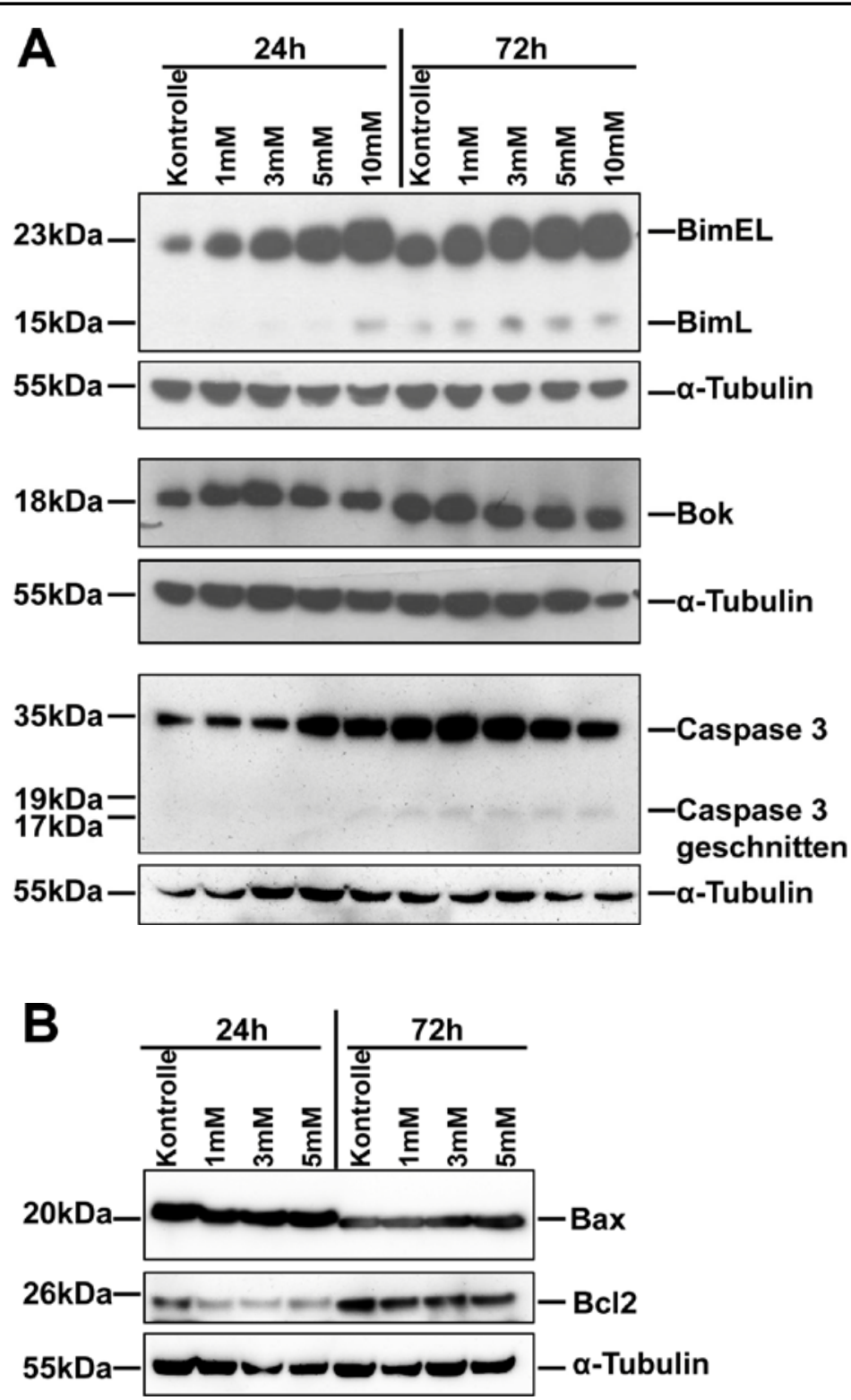

Abbildung 3.23: Expressionsanalyse von Apoptose-assoziierten Proteinen nach der Behandlung von PCa-Zellen mit VPA.

Die primären PCa-Zellen 2E wurden mit verschiedenen Konzentrationen von VPA für 24 bzw. 72 Stunden behandelt. Anschließend wurde das Gesamtprotein der adhärenten Zellen sowie der Zellen aus dem Überstand isoliert. (A) Die Western Blot-Analysen zeigten, dass die Expression der beiden Isoformen des proapoptotischen Proteins Bim nach der Behandlung der PCa-Zellen 2E mit VPA anstieg (EL: extra large; L: large). Dieser Effekt wurde sowohl nach 24 als auch nach 72 Stunden VPA-Behandlung beobachtet. (A und B) Die Expression der beiden proapoptotischen Proteine Bok und Bax sowie des antiapoptotischen Proteins Bcl-2 war nach 72 Stunden Behandlung der PCa-Zellen 2E mit VPA nicht verändert. Lediglich für die Expression von Bcl-2 wurde eine leichte Abnahme nach 24 Stunden detektiert. Die Expression von Bok und Bax war nach 24 Stunden im Vergleich zu kontrollbehandelten Zellen unverändert. (A) Untersuchungen zur Spaltung von Caspase 3 zeigten, dass die VPABehandlung der primären PCa-Zellen 2E keine Änderung der Spaltung von Caspase 3 im Vergleich zu kontrollbehandelten Zellen hervorrief. 


\subsubsection{Expressionsanalysen zu Zellzyklus-assoziierten Proteinen nach Valproinsäure-Behandlung von Prostatakarzinomzellen}

Die VPA-Behandlung von PCa-Zellen führt zu einer Steigerung an Zellen, die sich in der G0/G1-Phase befinden, wobei sich sowohl weniger Zellen in der G2/M- als auch in der SPhase befinden (Wedel et al., 2011d; Shabbeer et al., 2007). Hierbei wurde vor allem eine verstärkte Expression von p21 nachgewiesen (Wedel et al., 2011b; Shabbeer et al., 2007). Für die VPA-Behandlung der primären PCa-Zellen 2E wurden daher verstärkt Kandidatengene des Zellzyklus untersucht, die an einer Progression von der G1- zur SPhase beteiligt sind.

Die primären PCa-Zellen 2E wurden für 24 bzw. 72 Stunden mit VPA in verschiedenen Konzentrationen behandelt, anschließend wurde sowohl die Gesamt-RNA als auch das Gesamtprotein isoliert. Die mRNA-Expression des Cyclin D/Cdk4/6-regulierenden Faktors

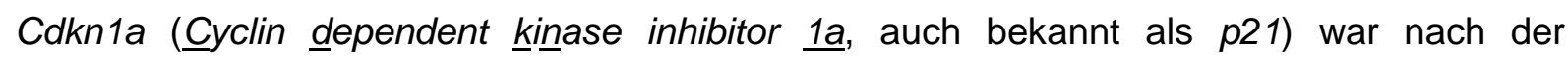
VPA-Behandlung leicht erhöht. Pak3 (ㅁ21 protein (Cdc42/Rac)-activated kinase $\underline{3}$ ) als durch p21-aktivierte Kinase zeigte sowohl nach 24 als auch nach 72 Stunden VPA-Behandlung eine leichte Erhöhung (zweifach) der mRNA-Expression (Abb. 3.24A). Die Expression von Cdk4 (Cyclin dependent kinase 4) war nach der Behandlung mit VPA vermindert, wohingegen die Expression von Cdk6 (Cyclin dependent kinase 6) kaum verändert vorlag. Lediglich nach 72 Stunden Behandlung konnte eine leichte Erhöhung der Expression detektiert werden (Abb. 3.24B).

Die Western Blot-Analyse von p15 und p27 zeigte kaum eine Veränderung der Expression. Die Expression von pRb hingegen war nach 24 Stunden Behandlung der primären PCa-Zellen 2E mit VPA erhöht. Nach 72 Stunden Behandlung konnte dieser Effekt noch moderat detektiert werden (Abb. 3.24C). 


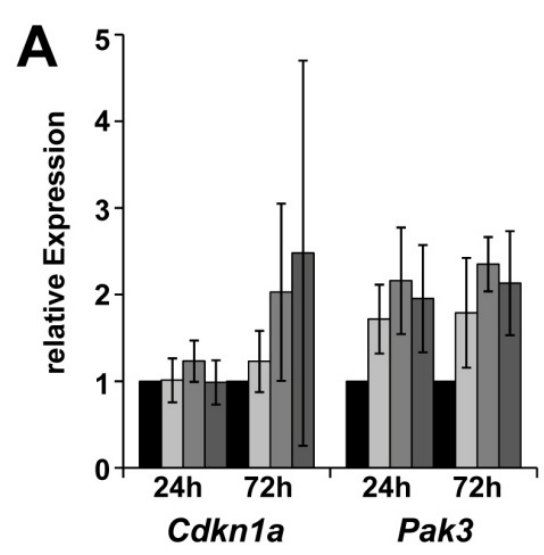

C
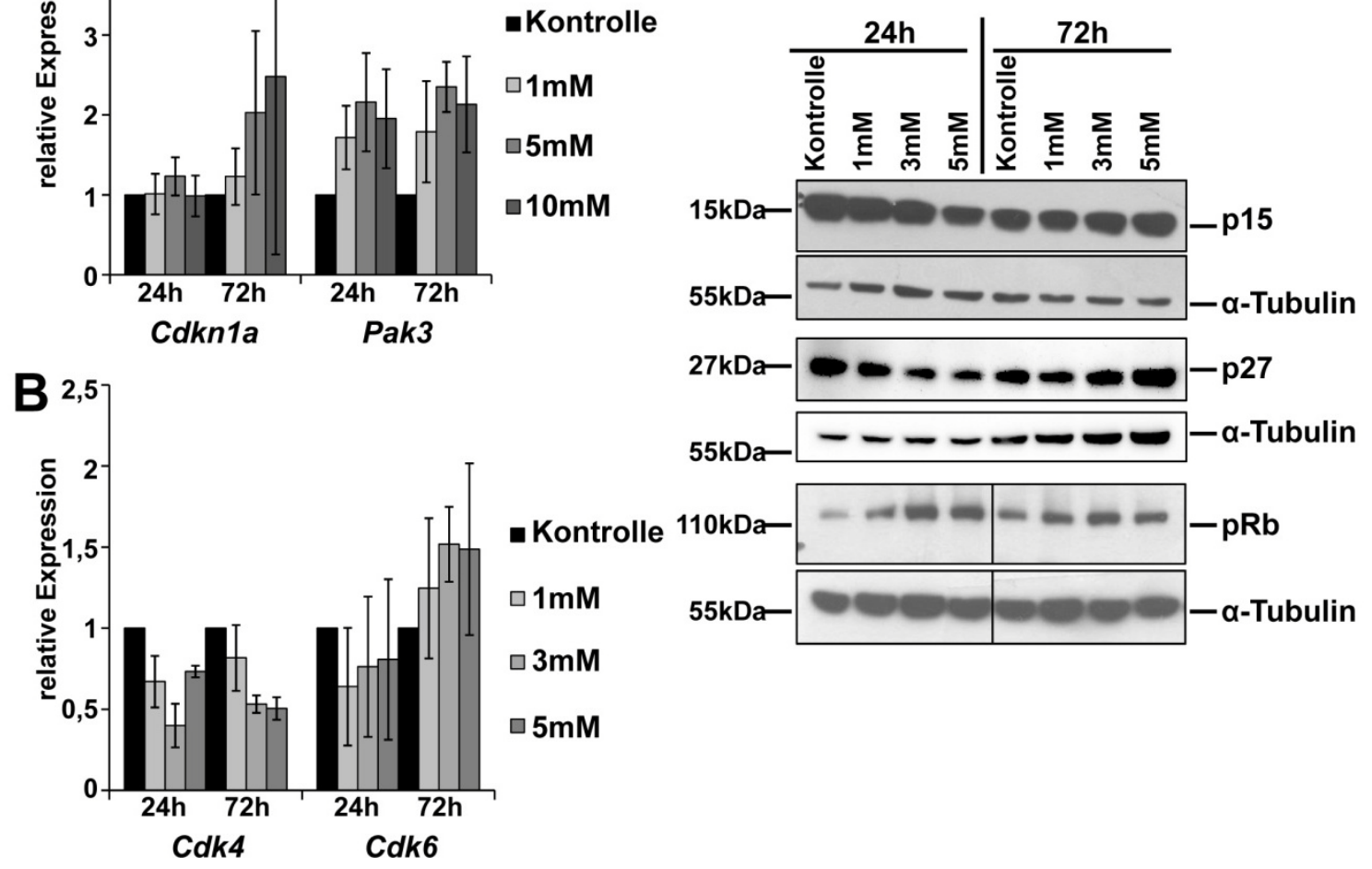

Abbildung 3.24: Expressionsanalysen von Zellzyklus-assoziierten Proteinen nach VPA-Behandlung von PCa-Zellen.

Die primären PCa-Zellen 2E wurden mit VPA in verschiedenen Konzentrationen für 24 und 72 Stunden behandelt. Die Gesamt-RNA als auch das Gesamtprotein wurden isoliert. (A) Die qRT-PCR-Analyse für Cdkn1a zeigte nach 72 Stunden Behandlung mit VPA eine leichte Erhöhung (zweifach) der Expression. Auch die Expression von Pak3 war nach 24 und 72 Stunden VPA-Behandlung leicht erhöht. (B) Die Expression von Cdk4 war sowohl nach 24 als auch nach 72 Stunden VPA-Behandlung in den primären PCa-Zellen vermindert. Die Expression von Cdk6 hingegen lag nach 72 Stunden VPA-Behandlung leicht erhöht vor. (C) Mittels Western Blot-Analyse konnte keine signifikante Änderung der Expression von p15 und p27 detektiert werden. Lediglich für pRb konnte nach 24 Stunden eine verstärkte Expression gezeigt werden, die nach 72 Stunden VPA-Behandlung noch moderat detektiert werden konnte.

\subsubsection{Expressionsanalysen zu Angiogenese-assoziierten Faktoren nach Valproinsäure-Behandlung von Prostatakarzinomzellen}

Aus der Literatur ist bekannt, dass eine VPA-Behandlung die Angiogenese von PCaTumoren in vivo im Xenograft-Modell hemmt (Shabbeer et al., 2007; Gao et al., 2007). Es konnte bereits gezeigt werden, dass eine VPA-Behandlung zur Verminderung der Expression des VEGF (vascular endothelial growth factor) führt (Gao et al., 2007). Da die molekularen Mechanismen der Angiogenese-Hemmung von PCa-Zellen nach VPA-Behandlung weitestgehend unbekannt sind, wurde hier zunächst geprüft, ob auch in den murinen PCa-Zellen 2E eine Verminderung der Expression des Vegfa sowie von Hif1a (hypoxia inducible factor $\underline{1}$, $\underline{\alpha}-$ Untereinheit), einem weiteren wichtigen Regulator der Angiogenese, vorliegt. 
Die primären PCa-Zellen 2E wurden mit verschiedenen Konzentrationen von VPA für 24 und 72 Stunden behandelt. Anschließend wurde die Gesamt-RNA isoliert. Die qRT-PCR-Analyse zeigte eine Verringerung der Expression des Vegfa nach 24 Stunden VPA-Behandlung. Nach 72 Stunden konnte diese für die hohen verwendeten Konzentrationen von VPA auch detektiert werden. Die Expression von Hif1a hingegen lag sowohl nach 24 als auch nach 72 Stunden VPA-Behandlung der primären PCa-Zellen 2E leicht erhöht vor (Abb. 3.25).

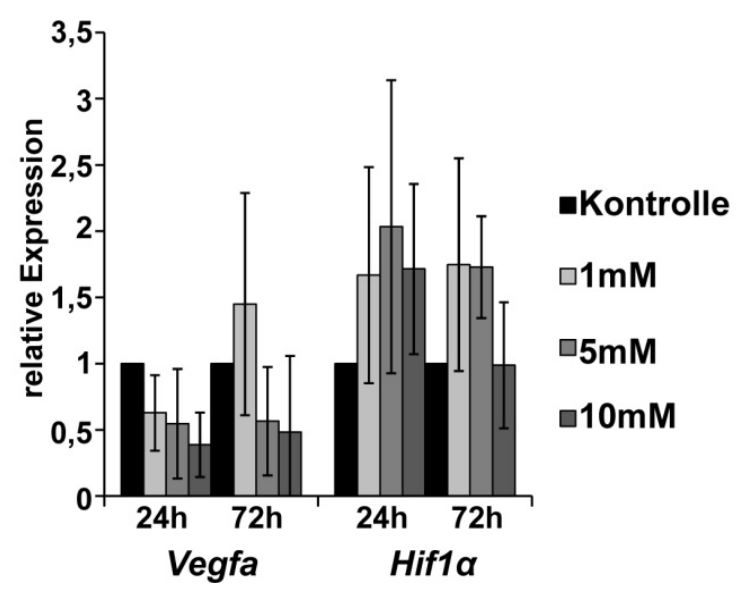

Abbildung 3.25: Expressionsanalyse zu Angiogenese-assoziierten Faktoren nach VPA-Behandlung von PCa-Zellen.

Die primären PCa-Zellen 2E wurden mit verschiedenen Konzentrationen von VPA für 24 und 72 Stunden behandelt. Die Gesamt-RNA wurde isoliert. Die qRT-PCR-Analyse zeigte eine verminderte Expression für Vegfa sowie eine leicht erhöhte Expression von Hif1a.

\subsubsection{Expressionsanalysen zu regulatorischen Faktoren nach Valproinsäure-} Behandlung von Prostatakarzinomzellen

Die regulatorischen Faktoren Foxo1 ( $\underline{f o r k h e a d ~ b o x ~} \underline{01}$ ) und Gsk3 $\beta$ (glycogen synthase kinase $\underline{3} \underline{\beta}$ ) wurden aufgrund ihres übergreifenden Einflusses auf den Zellzyklus, die Apoptose und die Angiogenese ausgewählt. Die primären PCa-Zellen 2E wurden mit verschiedenen VPA-Konzentrationen behandelt und anschließend die Gesamt-RNA isoliert. Die qRT-PCR-Analyse zeigte eine verstärkte, konzentrationsabhängige Expression von Foxo1 sowie eine leicht erhöhte Expression von Gsk3ß (Abb. 3.26). 


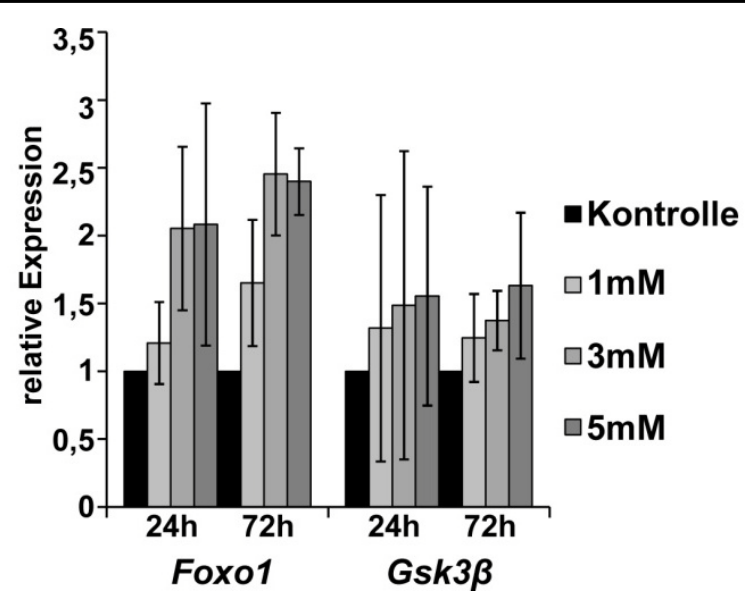

Abbildung 3.26: Expressionsanalyse von regulatorischen Faktoren nach der VPA-Behandlung von PCa-Zellen.

Die primären PCa-Zellen 2E wurden mit verschiedenen Konzentrationen von VPA für 24 bzw. 72 Stunden behandelt. Die Gesamt-RNA wurde isoliert und die anschließende qRT-PCR-Analyse zeigte einen konzentrationsabhängigen Anstieg der Foxo1-Expression sowie einen moderaten Anstieg der Gsk3 $\beta$-Expression.

\subsubsection{Analyse differentiell exprimierter Gene nach Behandlung primärer Prostatakarzinomzellen mit Valproinsäure}

In einer cDNA-Microarray-Analyse, die in der dieser Arbeit vorangegangenen Diplomarbeit (Witt, 2009) durchgeführt wurde, konnten zahlreiche Kandidatengene identifiziert werden, die nach 24 Stunden VPA-Behandlung der primären PCa-Zellen 2E mit 1mM VPA differentiell exprimiert vorlagen (Abb. 3.27A; Witt et al., 2013). Es wurden im Rahmen dieser Arbeit acht Kandidatengene aufgrund ihrer Expression in der Prostata und ihrem bereits beschriebenen Zusammenhang mit Tumoren für weiterführende Studien ausgewählt.

Die ausgewählten vermindert exprimierten Kandidaten nach der VPA-Behandlung der primären PCa-Zellen 2E waren die folgenden Gene: chemokine ( $C-X-C$ motif) ligand 15 (CxCl15), welcher für ein Cytokin der CXC Chemokin-Familie kodiert, RCC1 and BTB domain-containing protein 2 (Rcbtb2) kodiert für ein Mitglied der RCC1-verwandte GEF Familie, beide Transkriptvarianten von Ceruloplasmin (Cp), welches das HauptKupfertransportprotein des Blutes ist und der leukemia inhibitory factor (Lif), welcher für ein Interleukin der Klasse 6 kodiert. Verstärkt exprimiert waren die folgenden drei Kandidatengene: ubiquitin carboxy-terminal hydrolase L1 (Uchl1), welches für ein deubiquitinierendes Enzym kodiert, tyrosine-protein phosphatase-like $N$ (Ptprn), welches für ein Mitglied der Protein Tyrosin Phosphatase Familie kodiert und zuletzt Cyclin D2 (Ccnd2), welches für ein Mitglied der stark konservierten Cyclin D Protein Familie kodiert.

Die primären PCa-Zellen 2E wurden mit verschiedenen Konzentrationen von VPA für 24 bzw. 72 Stunden behandelt und anschließend die Gesamt-RNA isoliert. In einer qRT-PCR-Analyse konnte die in der Microarray-Analyse detektierte differentielle Expression für alle ausgewählten Kandidatengene bestätigt werden. Zudem konnte eine zeit- und 
konzentrationsabhängige Änderung der Expression für alle Kandidatengene festgestellt werden (Abb. 3.27B und C; Witt et al., 2013).
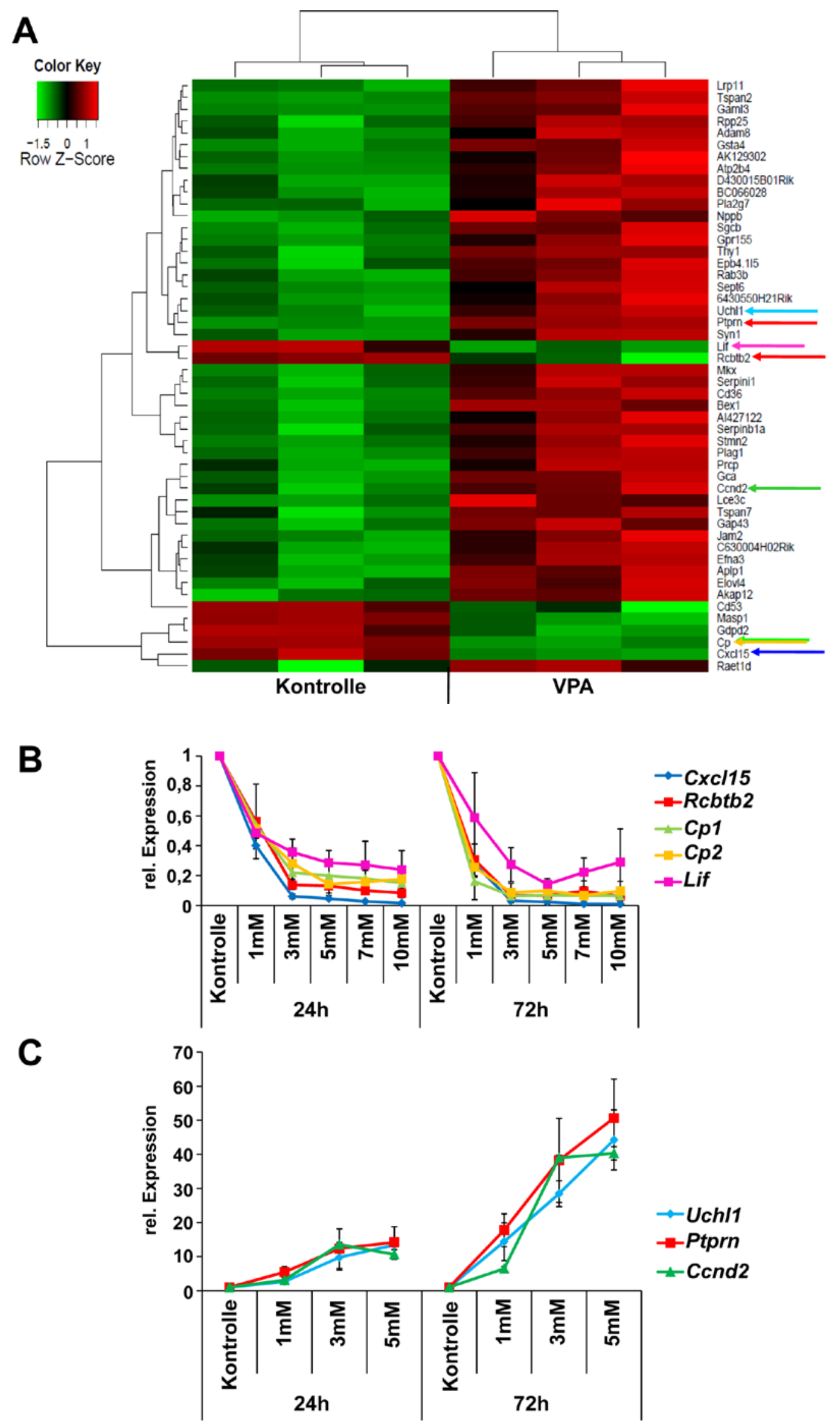
Abbildung 3.27: Untersuchungen differentiell exprimierter Gene nach Behandlung primärer PCa-Zellen mit VPA.

(A) Heatmap der bereits in Witt (2009) beschriebenen Microarray-Analyse mit zusätzlichen Clustering-Informationen. Farblich markiert sind die für weiterführende Analysen ausgewählten Kandidatengene. Die primären PCa-Zellen wurden für die Microarray-Analyse für 24 Stunden mit 1mM VPA behandelt. (B und C) Die primären PCa-Zellen 2E wurden für 24 bzw. 72 Stunden mit den angegebenen Konzentrationen von VPA behandelt. Die Gesamt-RNA wurde isoliert. Mittels qRT-PCR konnten die im Microarray detektierten differentiellen Expressionen für alle ausgewählten Kandidatengene bestätigt werden. Zusätzlich konnte eine zeitund konzentrationsabhängige Regulation der Gene nach VPA-Behandlung der PCa-Zellen 2E beobachtet werden (modifiziert nach Witt et al., 2013).

\subsubsection{Studien zur Acetylierung des Promotorbereichs der differentiell exprimierten Gene nach Valproinsäure-Behandlung der Prostatakarzinomzellen 2E}

Um zu zeigen, ob die differentielle Expression der Kandidatengene aufgrund von veränderter Acetylierung im Promotorbereich hervorgerufen wird, wurden zunächst die primären PCa-Zellen 2E mit VPA behandelt und die genomische DNA isoliert. Anschließend wurde eine Chromatin-Immunopräzipitation (ChIP) mit einem Antikörper gegen acetyliertes Histon 3 an Lysin 9 durchgeführt. Die vier untersuchten Gene (Cp, Cxcl15, Lif und Rcbtb), die nach der VPA-Behandlung der PCa-Zellen 2E vermindert exprimiert wurden, zeigten weder nach 24 noch nach 72 Stunden VPA-Behandlung eine signifikant veränderte Acetylierung des Promotorbereichs. Dagegen zeigten die Kandidatengene (Ptprn und Uchl1), die nach einer VPA-Behandlung verstärkt exprimiert wurden, eine erhöhte, zeitabhängige Acetylierung des Promotorbereichs (Abb. 3.28; Witt et al., 2013).

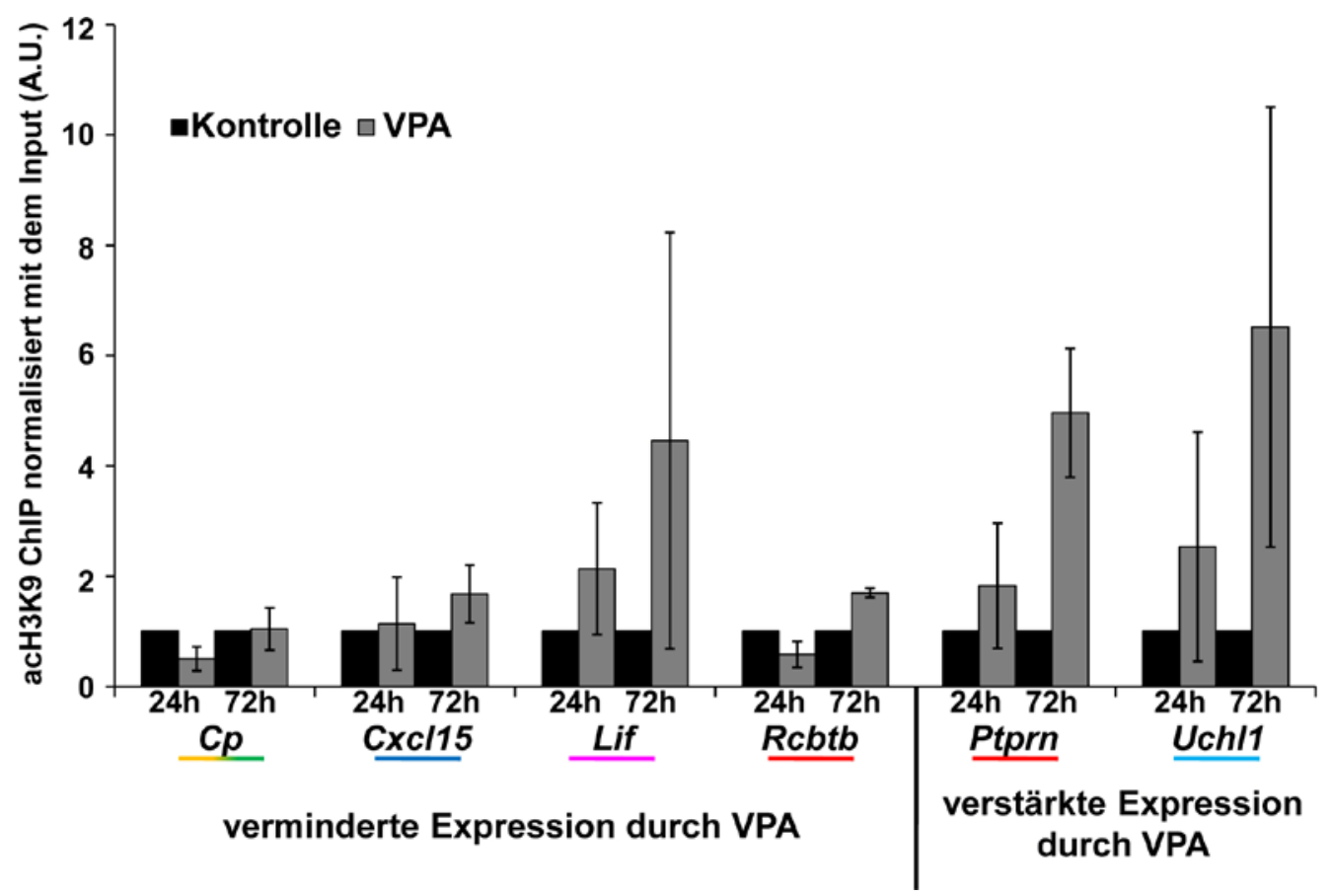

Abbildung 3.28: Untersuchungen zur Acetylierung des Promotorbereichs differentiell exprimierter Gene nach VPA-Behandlung der PCa-Zellen 2E. 
Die primären PCa-Zellen 2E wurden mit 5mM VPA für 24 bzw. 72 Stunden behandelt. Anschließend wurde die genomische DNA isoliert und eine Chromatin-Immunopräzipitation (ChIP) mit einem Antikörper gegen acetyliertes Histon 3 an Lysin 9 (acH3K9) durchgeführt und die Promotorbereiche mittels qRT-PCR untersucht. Es konnte gezeigt werden, dass für alle Kandidatengene ( $C p, C x c / 15$, Lif und Rcbtb), die nach VPA-Behandlung vermindert exprimiert werden, die Acetylierung des Promotorbereichs nicht signifikant verändert ist. Hingegen ist die Acetylierung der nach VPA-Behandlung verstärkt exprimierten Gene (Ptprn und Uchl1) im Promotorbereich erhöht. Die farbliche Zuordnung ist entsprechend Abbildung 3.27 (modifiziert nach Witt et al., 2013).

Die Analyse der Acetylierung des Promotorbereichs von Ccnd2 wurde entsprechend der oben beschriebenen ChIP-Analyse durchgeführt. Es wurde hierbei allerdings die Acetylierung an drei unabhängigen Abschnitten im Promotorbereich des Ccnd2-Gens untersucht. Es konnte hierbei gezeigt werden, dass der Promotorbereich des Ccnd2-Gens in den primären PCa-Zellen 2E nach der Behandlung mit 5mM VPA in allen untersuchten Abschnitten verstärkt acetyliert ist (Abb. 3.29; Witt et al., 2013).
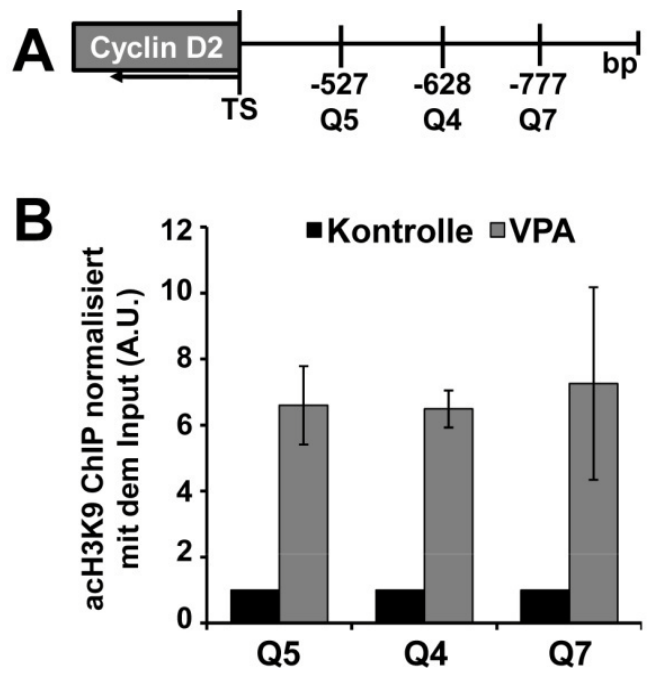

Abbildung 3.29: Untersuchungen zur Acetylierung des Promotorbereichs des Ccnd2-Gens nach VPA-Behandlung der PCa-Zellen 2E.

Die primären PCa-Zellen 2E wurden mit VPA behandelt und die genomische DNA wurde extrahiert. Anschließend wurde eine ChIP durchgeführt und die präzipitierte DNA mittels qRT-PCR mit Primern, die in der Promotorregion des Ccnd2-Gens liegen, analysiert. (A) Schematische Darstellung der Lokalisation der Primer in der Promotorregion von Ccnd2 (TS: Transkriptionsstart, Q4, Q5 und Q7 bezeichnen die verwendeten Primer, Zahlen geben den Abstand in Basenpaaren (bp) vom Transkriptionsstart an). (B) An allen 3 untersuchten Bereichen des Ccnd2-Promotors konnte eine verstärkte Acetylierung der DNA nach der VPA-Behandlung der PCa-Zellen 2E im Vergleich zur DNA kontrollbehandelter Zellen nachgewiesen werden (modifiziert nach Witt et al., 2013). 
3.3.4 Untersuchungen zum Mechanismus der Re-Expression von Cyclin D2 nach Valproinsäure-Behandlung von primären Prostatakarzinomzellen 2E

\subsubsection{Untersuchungen zur spezifischen Re-Expression von Cyclin D2 nach} Valproinsäure-Behandlung der Prostatakarzinomzellen 2E

Die primären PCa-Zellen 2E wurden mit steigenden Konzentrationen von VPA (1mM, 3mM und 5mM) für 24 bzw. 72 Stunden behandelt und anschließend wurde die Gesamt-RNA bzw. das Gesamtprotein isoliert. Sowohl auf RNA- als auch auf Protein-Ebene konnte ein starker Anstieg der Cyclin D2-Expression detektiert werden. Auf RNA-Ebene ist in Abbildung 3.30A ein repräsentatives Beispiel von drei unabhängigen Behandlungen gezeigt (Witt et al., 2013). Ein deutlicher Anstieg der Ccnd2-Expression konnte bereits nach 24 Stunden Behandlung der PCa-Zellen 2E mit VPA nachgewiesen werden. Nach 72 Stunden VPA-Behandlung wurde ein Anstieg der Ccnd2-Expression um das ca. 40-fache im Vergleich zu den kontrollbehandelten Zellen aufgezeigt. Dieser Effekt konnte ebenfalls auf Protein-Ebene verifiziert werden (Abb. 3.30B; Witt et al., 2013). Zudem konnte gezeigt werden, dass die Cyclin D2-Expression in den kontrollbehandelten Zellen kaum nachweisbar vorlag, weshalb im Folgenden von einer Re-Expression und nicht von einer Überexpression von Cyclin D2 gesprochen wird (Abb. 3.30B; Witt et al., 2013).

Cyclin D2 ist ein Familienmitglied der D-Typ Cycline. Zu dieser Familie zählen noch die zwei weiteren Mitglieder Cyclin D1 (Ccnd1) und Cyclin D3 (Ccnd3). Auch die Expression von Ccnd1 und Ccnd3 wurden auf RNA-Ebene mittels qRT-PCR-Analysen bzw. auf Proteinebene mittels Western Blot-Analysen nach der Behandlung der primären PCa-Zellen 2E mit VPA untersucht. Es wurde weder für die Ccnd1-mRNA noch für das Ccnd3-Protein ein vergleichbarer Anstieg nach der VPA-Behandlung der primären PCa-Zellen 2E detektiert wie er für Cyclin D2 nachgewiesen wurde (Abb. 3.30C und D; Witt et al., 2013). 


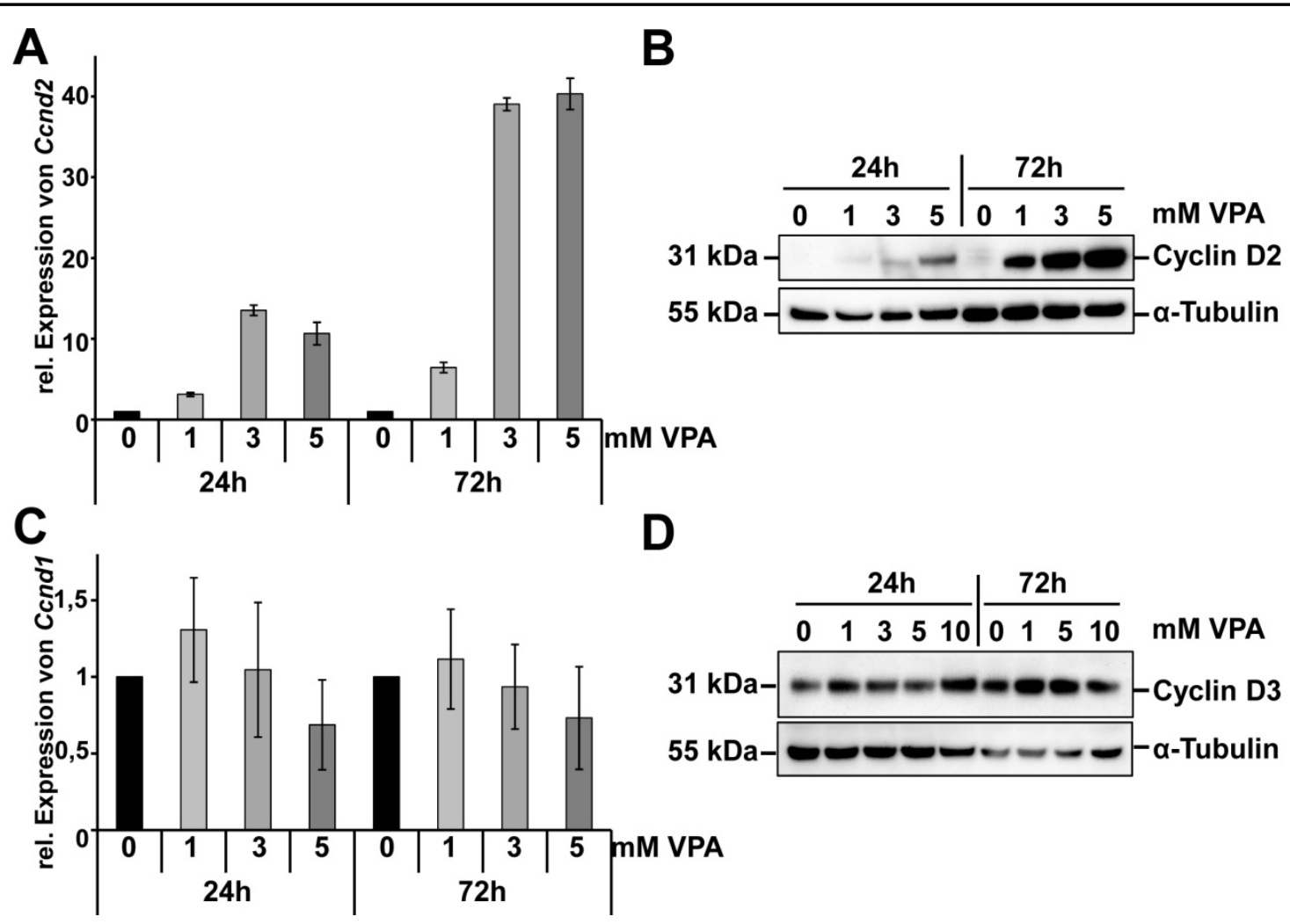

Abbildung 3.30: Analysen zur Expression von Cyclin D1, D2 und D3 nach VPA-Behandlung der primären PCa-Zellen 2E.

Die primären PCa-Zellen 2E wurden für 24 bzw. 72 Stunden mit VPA behandelt. Es wurde sowohl die Gesamt-RNA als auch das Gesamtprotein isoliert. (A) Die qRT-PCR-Analyse zeigte bereits nach 24 Stunden VPA-Behandlung der primären PCa-Zellen 2E eine deutliche Erhöhung der Ccnd2-mRNA-Expression. Dieser Effekt verstärkte sich nach 72 Stunden VPA-Behandlung der PCa-Zellen 2E. (B) Mittels Western Blot-Analyse konnte ebenfalls auf Proteinebene eine zeit- und konzentrationsabhängige verstärkte Expression von Cyclin D2 detektiert werden. (C) Die mRNA-Expression von Ccnd1 lag nach VPA-Behandlung der primären PCa-Zellen 2E nicht signifikant verändert vor. (D) Die Western Blot-Analyse der Expression des Ccnd3-Proteins zeigte nach VPA-Behandlung der PCa-Zellen 2E sowohl nach 24 Stunden als auch nach 72 Stunden keine Änderung (modifiziert nach Witt et al., 2013).

\subsubsection{Untersuchung der Passagen-abhängigen Cyclin D2-Expression in den primären Prostatakarzinomzellen 2E}

Die primären PCa-Zellen 2E wurden in den Analysen im Rahmen dieser Arbeit in niedrigen Passagen (unter Passage 15-20) verwendet. In der Literatur wurde ein Passagen-abhängiger Anstieg der Cyclin D2-Expression in primären Fibroblasten beschrieben (Meyyappan et al., 1998). Es sollte daher hier getestet werden, ob in den primären PCa-Zellen 2E auch ein solcher Effekt zu detektieren ist. Die Untersuchung der Expression von Cyclin D2 in höheren Passagen der primären PCa-Zellen 2E zeigte einen Anstieg mit steigender Passagenanzahl (Abb. 3.31). Es wurden für die höchste untersuchte Passage (Passage 30) drei unabhängige Zellpopulationen untersucht. Die Expression von Ccnd2 variiert in diesen drei Populationen von zehn- bis 20-fach im Vergleich zu Passage 3 , allerdings konnte für alle hohen Passagen der primären PCa-Zellen 2E eine erhöhte 
Cyclin D2-Expression im Vergleich zu niedrigeren Passagen sowohl auf RNA- als auch auf Proteinebene gezeigt werden (Abb. 3.31A und B). Die mRNA-Expression von Ccnd1 wurde dagegen in allen untersuchten Passagen der primären PCa-Zellen 2E vergleichbar stark nachgewiesen (Abb. 3.31A).

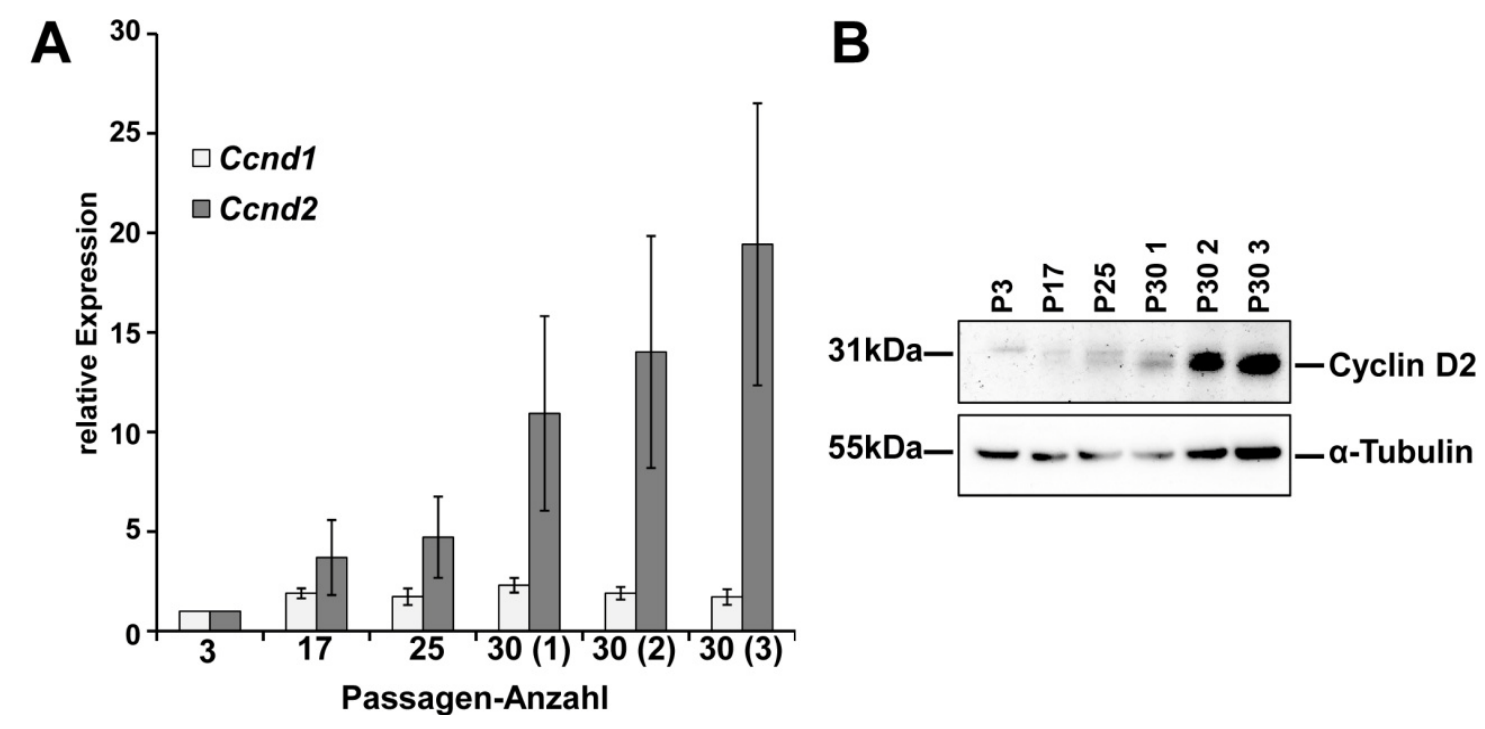

Abbildung 3.31: Untersuchungen zur Expression von Cyclin D2 und Cyclin D1 in den primären PCa-Zellen 2E mit unterschiedlicher Passagenanzahl.

Die primären PCa-Zellen 2E wurden bis zu der angegebenen Passagen-Anzahl kultiviert (3, 17, 25, 30). Für Passage 30 wurden drei unabhängige Zellpopulationen untersucht. Es wurde die Gesamt-RNA und das Gesamtprotein isoliert. (A und B) Sowohl in der anschließenden qRT-PCR-Analyse als auch in der Western Blot-Analyse konnte gezeigt werden, dass die primären PCa-Zellen 2E mit steigender Passage eine erhöhte Expression von Cyclin D2 zeigten, obwohl diese innerhalb einer Passage variabel war. (A) Die mRNA-Expression von Ccnd1 konnte in allen untersuchten Passagen der primären PCa-Zellen 2E vergleichbar stark nachgewiesen werden.

Anschließend wurde untersucht, ob diese endogene Überexpression von Cyclin D2 in den primären PCa-Zellen 2E einen Einfluss auf die Re-Expression von Cyclin D2 nach der VPA-Behandlung ausübt. Dazu wurden die PCa-Zellen $2 \mathrm{E}$ mit verschiedenen Passagenzahlen mit VPA für 24 und 72 Stunden behandelt und die Expression von Cyclin D2 mittels Western Blot analysiert. In allen Passagen wurde Cyclin D2 nach der VPA-Behandlung der primären PCa-Zellen 2E re-exprimiert (Abb. 3.32). Es konnte gezeigt werden, dass Cyclin D2 auch in den hohen Passagen der primären PCa-Zellen 2E schwach exprimiert wird im Vergleich zu dem Expressionslevel, welches nach der VPA-Behandlung der PCa-Zellen 2E erreicht wird. Lediglich die 2E-Zellen der Passage 5 zeigten kaum Re-Expression von Cyclin D2 nach der VPA-Behandlung. 


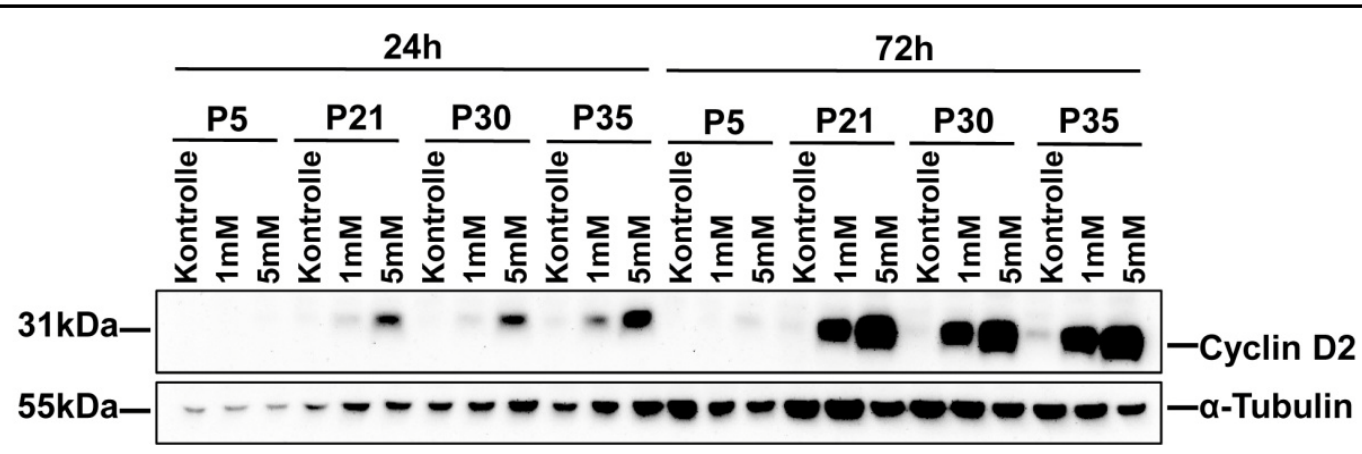

Abbildung 3.32: Untersuchungen zur Cyclin D2-Expression nach VPA-Behandlung der primären PCa-Zellen 2E in verschiedenen Passagen.

Die primären PCa-Zellen 2E wurden in verschiedenen Passagen (P5-P35) mit VPA für 24 bzw. 72 Stunden behandelt und anschließend wurde das Gesamtprotein isoliert. In der Western Blot-Analyse konnte gezeigt werden, dass die Passagenanzahl keinen Einfluss auf die Re-Expression von Cyclin D2 nach VPA-Behandlung hat. Lediglich in den 2E-Zellen der Passage 5 konnte kaum eine Re-Expression von Cyclin D2 nach VPA-Behandlung nachgewiesen werden.

\subsubsection{Analysen zum Einfluss weiterer Histondeacetylase-Inhibitoren auf die Cyclin D2-Expression in primären Prostatakarzinomzellen 2E}

Die primären PCa-Zellen 2E wurden mit jeweils zwei verschiedenen Konzentrationen (Abb. 3.33, C1 und C2) unterschiedlicher Histondeacetylase-Inhibitoren (HDIs; Trichostatin A (TSA): $250 \mathrm{nM}$ und $1 \mu \mathrm{M}$, Suberoylanilide hydroxamic acid (SAHA): $1 \mu \mathrm{M}$ und $5 \mu \mathrm{M}$, Natriumbutyrat ( $\mathrm{NaB}$ ): $1 \mathrm{mM}$ und $5 \mathrm{mM}$ und Apicidin: 1,6 $\mu \mathrm{M}$ und $5 \mu \mathrm{M}$ ) für 24 und 72 Stunden kultiviert. Anschließend wurde die Gesamt-RNA bzw. das Gesamtprotein isoliert und hinsichtlich der Cyclin D2-Expression im Vergleich zu kontrollbehandelten Zellen untersucht. Die HDIs wurden aufgrund ihrer unterschiedlichen Strukturen und ihrer unterschiedlichen Spezifität für die verschiedenen Histondeacetylasen ausgewählt. Die verwendeten Konzentrationen repräsentieren jeweils eine hohe und eine geringe übliche Konzentration für den jeweiligen HDI.

Für alle untersuchten HDIs konnte eine Re-Expression von Cyclin D2 in den primären PCa-Zellen 2E sowohl auf RNA- als auch auf Protein-Ebene gezeigt werden (Abb. 3.33A und B; Witt et al., 2013). Die Expression von Ccnd1 hingegen änderte sich nach der Behandlung der primären PCa-Zellen 2E mit allen vier untersuchten HDIs nur gering (Abb. 3.33C; Witt et al., 2013). 


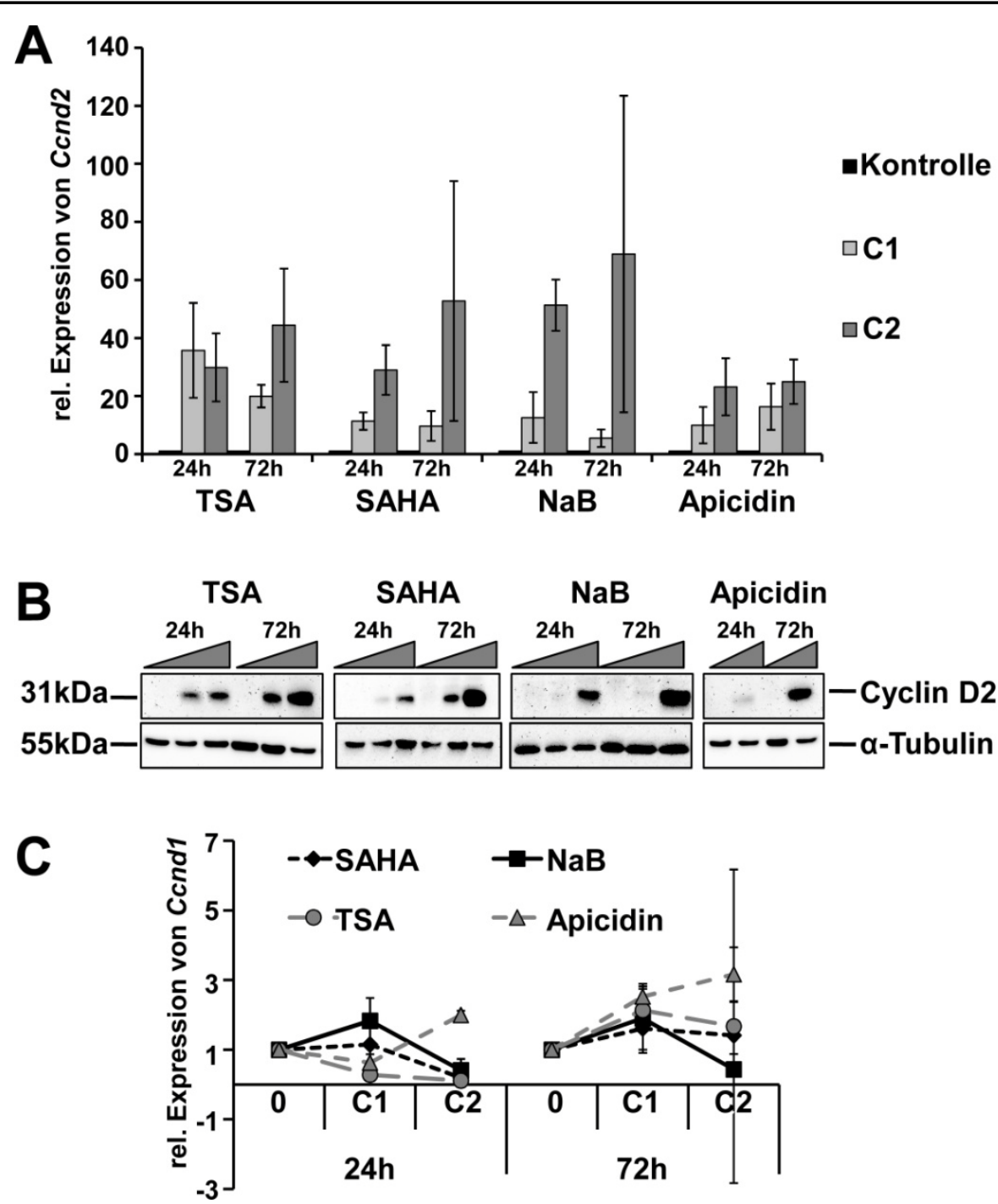

Abbildung 3.33: Analysen zur Cyclin D1- und Cyclin D2-Expression nach Behandlung der primären PCa-Zellen 2E mit vier verschiedenen Histondeacetylase-Inhibitoren.

Die primären PCa-Zellen 2E wurden mit zwei verschiedenen Konzentrationen der HDIs TSA (Trichostatin A), SAHA (Suberoylanilide hydroxamic acid), NaB (Natriumbutyrat) und Apicidin behandelt. Diese Konzentrationen sind als C1 für die geringe und C2 für die hohe Konzentration gekennzeichnet. Die verwendeten Konzentrationen waren die folgenden: TSA $250 \mathrm{nM}$ und $1 \mu \mathrm{M}$, SAHA $1 \mu \mathrm{M}$ und $5 \mu \mathrm{M}$, NaB $1 \mathrm{mM}$ und $5 \mathrm{mM}$ und Apicidin 1,6 $4 \mathrm{M}$ und $5 \mu \mathrm{M}$. Die Gesamt-RNA und das Gesamtprotein wurden isoliert. In den anschließenden qRT-PCR-Analysen (A) sowie den Western Blot-Analysen (B) konnte gezeigt werden, dass sich sowohl auf RNA- als auch auf Protein-Ebene die Expression von Cyclin D2 zeit- und konzentrationsabhängig erhöhte. Im Gegensatz dazu änderte sich die mRNA-Expression von Ccnd1 nach der Behandlung der PCa-Zellen 2E mit allen vier HDIs nicht signifikant (C) (modifiziert nach Witt et al., 2013).

Als Negativkontrolle wurden die primären PCa-Zellen 2E mit dem in vitro nicht aktiven Amid von VPA, Valpromid, behandelt. Valpromid besitzt keine HDI-Aktivität, sondern wird im Körper effektiv zu VPA metabolisiert (Göttlicher et al., 2001; Bialer et al., 1985). In der Zellkultur ist Valpromid daher als HDI inaktiv, da es nicht zu VPA metabolisiert werden kann. Die Untersuchungen hinsichtlich der Cyclin D2- und auch Ccnd1-Expressionsänderung in 
Valpromid-behandelten PCa-Zellen 2E zeigten, dass keine Veränderung der Cyclin D2- und Ccnd1-Expression in PCa-Zellen 2E erfolgte (Abb. 3.34; Witt et al., 2013).
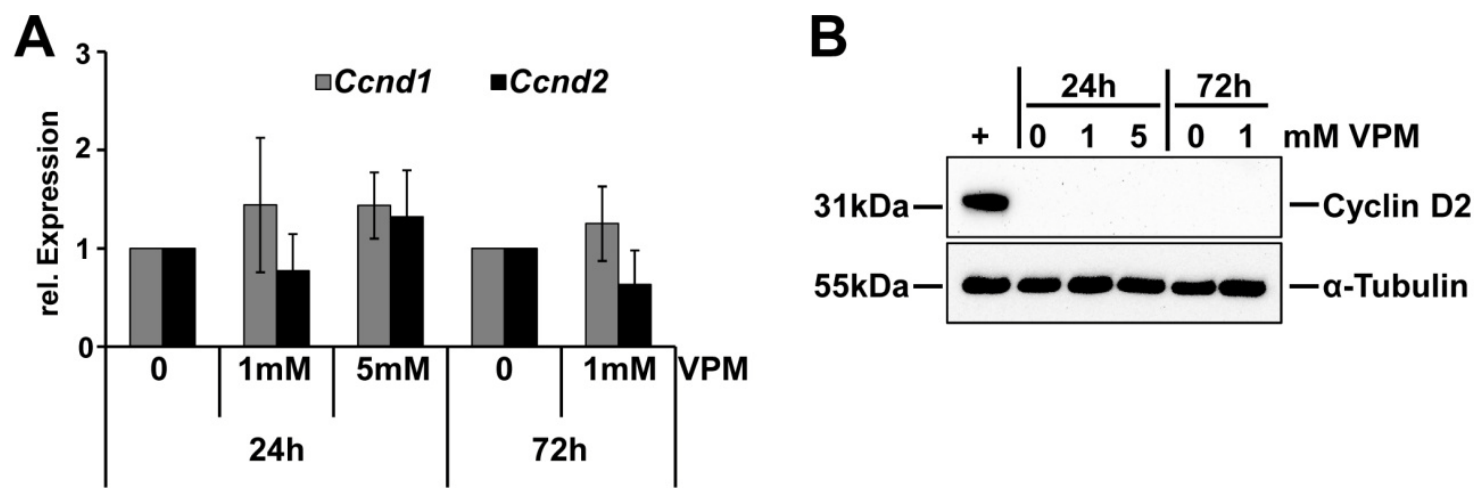

Abbildung 3.34: Untersuchungen zur Cyclin D1- und Cyclin D2-Expression nach der Behandlung der primären PCa-Zellen 2E mit Valpromid.

Die primären PCa-Zellen 2E wurden für 24 bzw. 72 Stunden mit dem in vitro inaktiven Amid von VPA, Valpromid (VPM), in verschieden Konzentrationen behandelt. Die Gesamt-RNA und das Gesamtprotein wurden isoliert. (A) Anschließende qRT-PCR-Analysen zeigten, dass die Valpromid-Behandlung weder die mRNA-Expression von Ccnd1 noch die mRNA-Expression von Cyclin D2 signifikant änderte. (B) In der Western Blot-Analyse wurde gezeigt, dass auch auf Protein-Ebene die Expression von Cyclin D2 unverändert blieb. Die Behandlung der PCa-Zellen 2E mit 5mM Valpromid für 72 Stunden war zytotoxisch. „," stellt die Positivkontrolle dar, d.h. mit 5mM VPA für 72 Stunden behandelte primäre PCa-Zellen 2E (modifiziert nach Witt et al., 2013).

\subsubsection{Untersuchungen zum Einfluss der Methylierung des Ccnd2-Promotors auf die Re-Expression von Cyclin D2 in den primären Prostatakarzinomzellen 2E}

Es sollte geprüft werden, ob der Promotorbereich des Ccnd2-Gens in den primären PCaZellen 2E auch auf DNA-Ebene durch De-Methylierung aktiviert werden kann. Dazu wurden die PCa-Zellen 2E mit dem DNA-Methyltransferase-Inhibitor 5-Aza-2'-deoxycytidine (5aza2) mit der dazugehörigen Lösungsmittelkontrolle Essigsäure $(\mathrm{AcOH})$ behandelt. Als Negativkontrolle diente der Methylgruppendonor S-Adenosylmethionin (SAM). Als Positivkontrolle der Ccnd2-Re-Expression wurden die PCa-Zellen 2E mit VPA behandelt. Dies erfolgte zum einen mit nur einmaligem Mediumwechsel (VPA 1x) und zum anderen mit täglichem Mediumwechsel (VPA tägl.). Diese Vorgehensweise wurde gewählt, da auch eine Kombinationsbehandlung von VPA und SAM durchgeführt wurde, in der das Medium täglich gewechselt wurde. Üblicherweise wurde das Medium bei der VPA-Behandlung der PCa-Zellen während der VPA-Behandlung nicht erneuert. Anschließend an alle Behandlungen der PCa-Zellen 2E wurde sowohl die Gesamt-RNA als auch das Gesamtprotein isoliert.

Sowohl in der qRT-PCR- als auch in der Western Blot-Analyse konnte die Expression von Cyclin D2 nach der Behandlung der PCa-Zellen 2E mit 5aza2 nicht in dem Maße gesteigert werden, wie nach einer VPA-Behandlung der PCa-Zellen 2E (Abb. 3.35A). Durch 5aza2 wurde die mRNA-Expression von Ccnd2 ca. um das fünffache gesteigert, wohingegen die 
Behandlung der PCa-Zellen 2E mit VPA die Ccnd2-Expression ca. 85-130-fach erhöhte. Hierbei konnte gezeigt werden, dass die Re-Expression von Ccnd2 stärker war bei einmaligem Mediumwechsel im Vergleich zu täglichem Mediumwechsel. Mittels qRT-PCR-Analyse konnte zusätzlich gezeigt werden, dass die Expression von Ccnd1 nach allen Behandlungen der PCa-Zellen 2E nicht stark beeinflusst wurde. Die stärkste Überexpression (ca. 15-fach) konnte während der Behandlung mit SAM beobachtet werden. Die Expression von Cyclin D3 nach allen Behandlungen der PCa-Zellen 2E wurde mittels Western Blot-Analyse untersucht. Hierbei konnten kaum Unterschiede in der Cyclin D3-Expression detektiert werden.

Als Positivkontrolle für die 5aza2-Behandlung wurde zusätzlich die Expression von Clusterin untersucht. Aus der Literatur ist bekannt, dass eine 5aza2-Behandlung von den TRAMP-PCa-Zellen TRAMP-C2 die Clusterin-Expression um das fünffache erhöht (Rauhala et al., 2008). In den primären (TRAMP-)PCa-Zellen 2E konnte im hier durchgeführten Experiment nach 5aza2-Behandlung eine ca. 13-fache Steigerung der Clusterin-mRNAExpression gezeigt werden. Zusätzlich wurde auch durch die Behandlung der PCa-Zellen 2E mit VPA die Expression von Clusterin stark erhöht (Abb. 3.35C). 


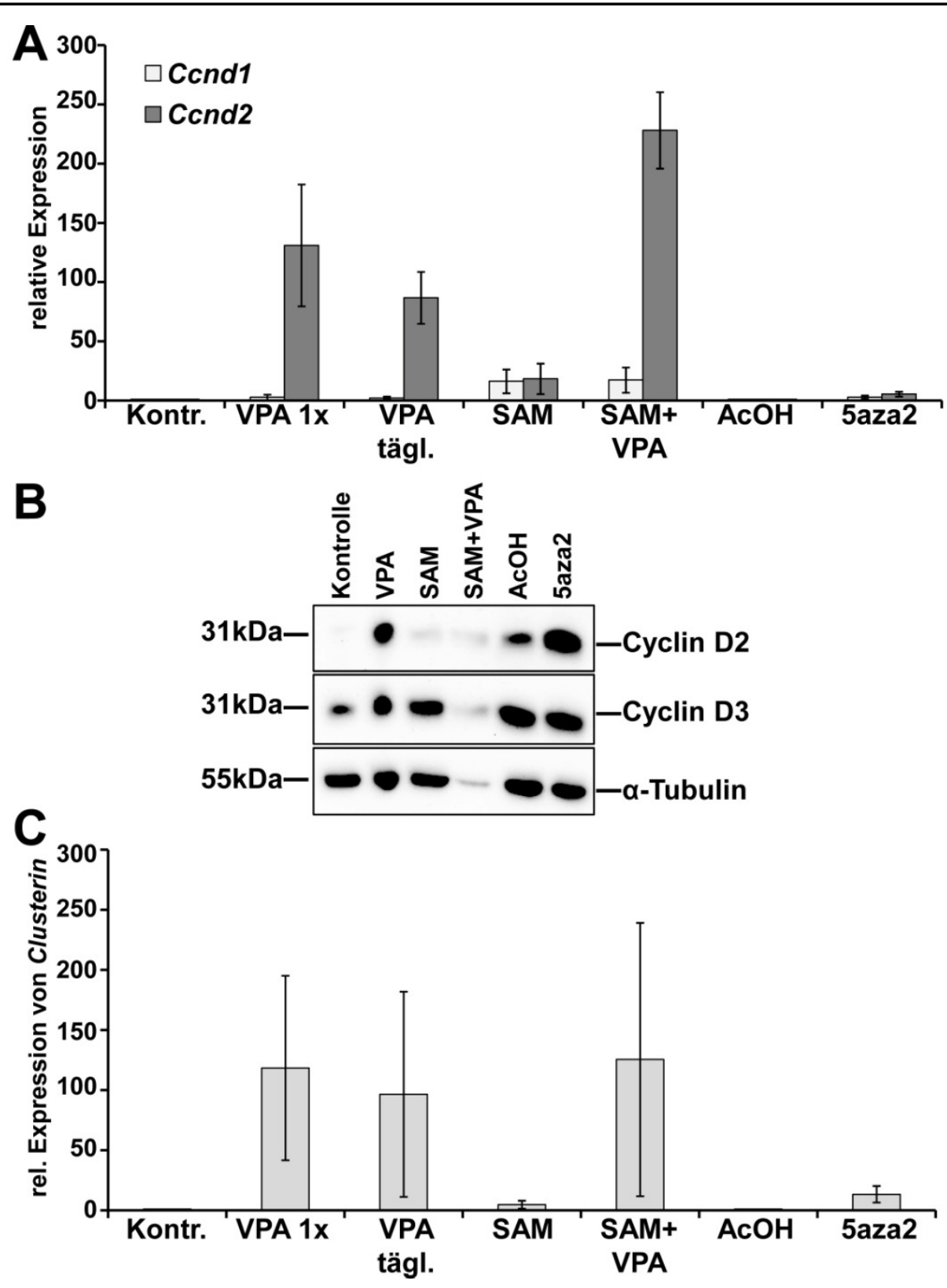

Abbildung 3.35: Analysen der Cyclin D1-, Cyclin D2-, Cyclin D3- und Clusterin-Expression nach Behandlung der PCa-Zellen 2E mit 5aza2, SAM und VPA.

Die primären $\mathrm{PCa}$-Zellen 2E wurden zum einen mit dem DNA-Methyltransferase-Inhibitor 5-Aza-2'-deoxycytidine (5aza2) und der dazugehörigen Lösungsmittelkontrolle Essigsäure (AcOH) für sechs Tage, zum anderen als Negativkontrolle mit dem Methylgruppendonor S-Adenosylmethionin (SAM) für sieben Tage und schließlich mit VPA für 72 Stunden behandelt, wobei in einer Probe das Medium täglich gewechselt wurde (VPA tägl.) und in der anderen das Medium nur einmal zum Anfang der Behandlung erneuert wurde (VPA 1x). Diese unterschiedliche Behandlung wurde vorgenommen als Kontrolle zu der Kombinationsbehandlung aus VPA und SAM, bei der das Medium täglich gewechselt wurde. Die Gesamt-RNA und das Gesamtprotein wurden isoliert. (A) Die qRT-PCR-Analyse zeigte eine starke Ccnd2-Re-Expression nach beiden VPA-Behandlungen sowie der Kombinationsbehandlung aus VPA und SAM. Die Behandlung der Zellen mit 5 aza2 führte zu keiner vergleichbaren Re-Expression der Ccnd2-Expression. Die mRNA-Expression von Ccnd1 wurde lediglich durch die Behandlung der PCa-Zellen 2E mit SAM leicht erhöht, alle anderen Behandlungen bewirkten keine Ccnd1-Expressionsveränderung im Vergleich zu den kontrollbehandelten Zellen. (B) Mittels Western Blot-Analyse konnte die Re-Expression von Cyclin D2 durch VPA bestätigt werden. Die Kombinationsbehandlung war zytotoxisch für die Zellen. Die Behandlung der PCa-Zellen mit 5aza2 führte auf Proteinebene zu einer verstärkten 
Cyclin D2-Expression. Allerdings konnte dies in geringerem Maße auch bereits in der Lösungsmittelkontrolle beobachtet werden. Die Expression von Cyclin D3 wurde durch keine Behandlung der PCa-Zellen 2E verändert. (C) Die qRT-PCR-Analyse zeigte, dass die mRNA-Expression von Clusterin in den PCa-Zellen 2E durch Behandlung mit $5 a z a 2$ induzierbar war. Die Behandlung der PCa-Zellen 2E mit VPA führte zu einem starken Anstieg der Clusterin-Expression.

Um einen Zelllinien-spezifischen Effekt auszuschließen, wurden des Weiteren die etablierten humanen PCa-Zellinien PC-3 und DU145 untersucht. Die Behandlung erfolgte entsprechend der Behandlung der primären PCa-Zellen 2E mit 5aza2, SAM, VPA und der Kombination aus VPA und SAM. Auch hier konnte kein deutlicher Effekt auf die CCND2-Expression nach Behandlung der PCa-Zellen mit 5aza2 detektiert werden. In den humanen PCa-Zellen PC-3 stieg die Expression von CCND2 nach 5aza2-Behandlung um das ca. vierfache. Nach der Behandlung der Zellen mit VPA konnte hier allerdings nur ein Anstieg der Expression von CCND2 um das maximal zehnfache beobachtet werden (Abb. 3.36A). In den humanen PCa-Zellen DU145 hingegen resultierte die Behandlung mit VPA in einem Anstieg der Expression von CCND2 um das maximal 420-fache, nach der Behandlung mit 5aza2 konnte lediglich eine Re-Expression von CCND2 um das 35-fache gezeigt werden (Abb. 3.36B). Die Expression von CCND1 war nach keiner der untersuchten Behandlungen in den PCa-Zellen PC-3 und DU145 im Vergleich zu kontrollbehandelten Zellen verändert (Abb. 3.36A und B). Demnach ist festzuhalten, dass die Histonacetylierung (vgl. Kapitel 3.3.3.2) vermutlich einen höheren Effekt auf die Cyclin D2-Expression ausübt als die Änderung des Methylierungszustandes des Gens, da weder die Behandlung mit 5aza2 die Expression von Cyclin D2 deutlich ansteigen ließ, noch konnte die Re-Expression von Cyclin D2 durch VPA in der Kombinationsbehandlung mit dem Methylgruppendonor SAM inhibiert werden. 


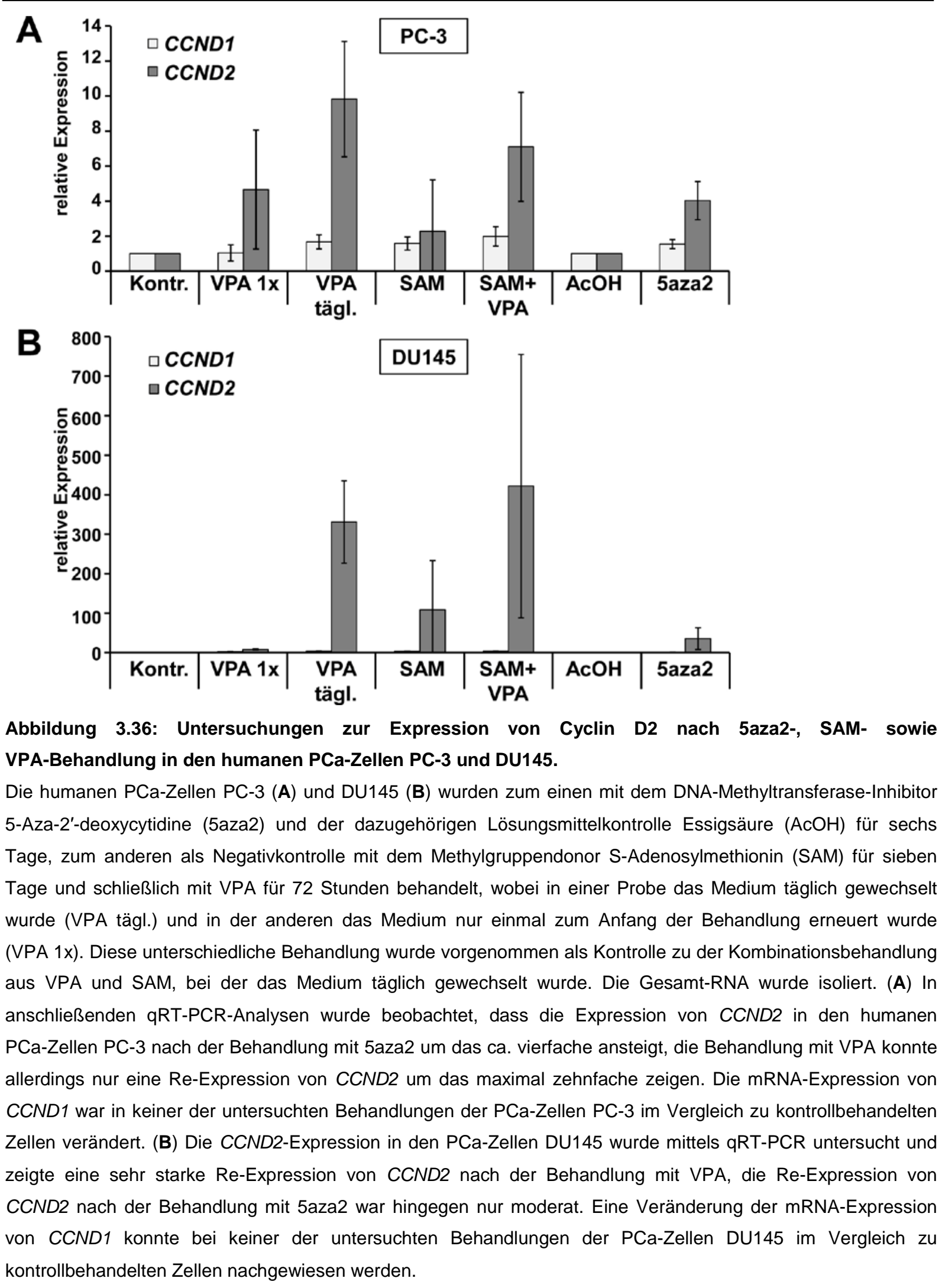


3.3.4.5 Analyse des Methylierungszustandes einer CpG-Insel im Promotorbereich des

Ccnd2-Gens nach Valproinsäure-Behandlung der Prostatakarzinomzellen 2E

Es sollte überprüft werden, ob die VPA-Behandlung der PCa-Zellen 2E auch die Methylierung des Ccnd2-Promotors ändert. Es liegen Studien vor, die eine Änderung der Methylierung von einigen Genen durch eine Behandlung mit VPA beschrieben haben (Milutinovic et al., 2007). Zudem ist bekannt, dass der Promoterbereich des Ccnd2-Gens im PCa methyliert vorliegen soll (Henrique et al., 2006). Es sollte nun durch methylierungsspezifische Sequenzierung die basale Methylierung einer CpG-Insel im Promotor des Ccnd2-Gens sowie die Änderung der Methylierung in diesem Bereich nach Behandlung der primären PCa-Zellen 2E mit VPA analysiert werden.

Hierfür wurden die primären PCa-Zellen 2E für 24 und 72 Stunden mit 5mM VPA behandelt. Anschließend wurde die genomische DNA isoliert und diese wurde mittels Bisulfit-Konversion umgeschrieben. Die Bisulfit-konvertierte DNA wurde nun für eine PCR mit spezifischen Primern, die eine CpG-Insel im Promotorbereich des Ccnd2-Gens flankieren, eingesetzt. Die so erhaltenen PCR-Produkte wurden in das PGEM®-T Easy Vektorsystem ligiert und anschließend mittels PCR amplifiziert. Diese Produkte wurden sequenziert und schließlich auf ihren Methylierungszustand hin untersucht.

Die untersuchten CpGs sind vorwiegend unmethyliert (Abb. 3.37A). In den kontrollbehandelten PCa-Zellen 2E ist der höchste Anteil an Klonen in einem methylierten Zustand 26\% an CpG Nummer 7. Auch bei den für 72 Stunden mit VPA-behandelten PCa-Zellen 2E ist das CpG Nummer 7 am häufigsten methyliert mit bis zu 46\% der Klone (Abb. 3.37B). Insgesamt ändert sich der Methylierungszustand der untersuchten CpG-Insel allerdings nur gering durch die Behandlung der PCa-Zellen 2E mit VPA. 
A

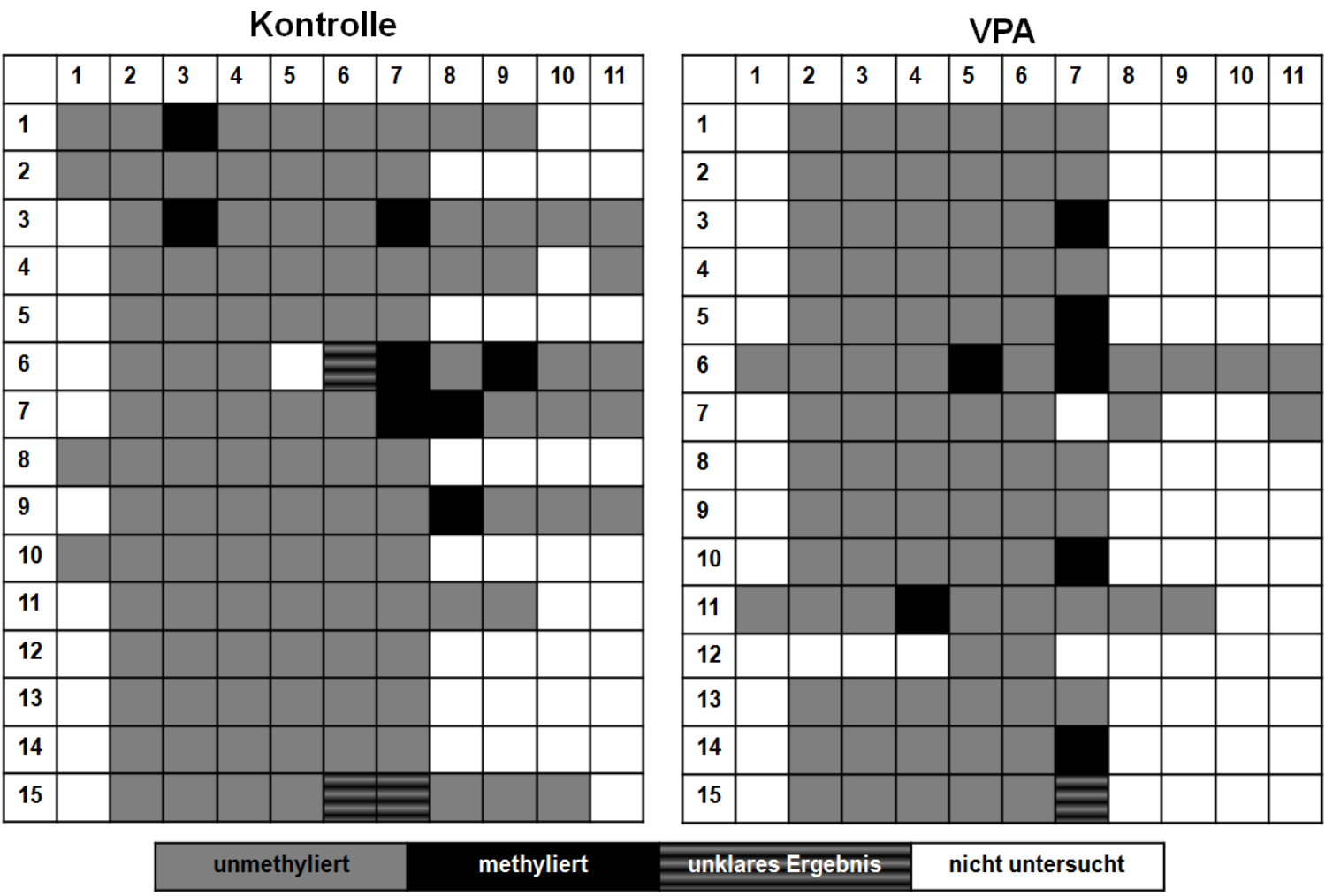

B

\begin{tabular}{|l|c|c|c|c|c|c|c|c|c|c|c|}
\hline & 1 & 2 & 3 & 4 & 5 & 6 & 7 & 8 & 9 & 10 & 11 \\
\hline $\begin{array}{l}\% \text { meth. } \\
\text { Kontrolle }\end{array}$ & 0 & 0 & 13 & 0 & 0 & $0-13$ & $20-26$ & 25 & 12.5 & 0 & 0 \\
\hline $\begin{array}{l}\% \text { meth. } \\
\text { VPA }\end{array}$ & 0 & 0 & 0 & 7.1 & 6.7 & 0 & $38.5-46$ & 0 & 0 & 0 & 0 \\
\hline
\end{tabular}

Abbildung 3.37: Untersuchungen zum Methylierungsstatus einer CpG-Insel im Promotorbereich des Ccnd2-Gens nach Behandlung der PCa-Zellen 2E mit VPA.

Die primären PCa-Zellen 2E wurden mit 5mM VPA für 72 Stunden behandelt und die genomische DNA wurde isoliert. Nach einer Bisulfit-Konversion und anschließender PCR mit Primern, die die CpG-Insel flankieren, wurde das PCR-Produkt in das PGEM®-T Easy Vektorsystem ligiert und anschließend 15 Klone mittels Sequenzierung auf ihren Methylierungszustand hin untersucht. In der untersuchten CpG-Insel befinden sich elf CpGs, die untersucht wurden (obere Reihe der Tabellen). Die erste Spalte in A bezeichnet die untersuchten Klone. (A) Übersicht über den Methylierungszustand jedes CpGs. Die untersuchten CpGs befinden sich sowohl in den Kontrollzellen als auch in den VPA-behandelten PCa-Zellen 2E vorwiegend im unmethylierten Zustand. Am häufigsten liegt das CpG Nummer 7 methyliert vor. (B) Prozentuale Auswertung des Methylierungszustandes der CpGs. Vorwiegend liegt für alle untersuchten CpGs der unmethylierte Zustand vor. Lediglich CpG Nummer 7 ist bereits schon in den kontrollbehandelten Zellen bei ca. einem Viertel der untersuchten Klone methyliert, dies steigt nach der VPA-Behandlung auf bis zu ca. 50\% der untersuchten Klone an. 
3.3.5 Untersuchungen zur Cyclin D2-Expression und Inhibition der Proliferation nach Valproinsäure-Behandlung von verschiedenen Zelllinien

In den vorangegangenen Experimenten wurden bisher ausschließlich PCa-Zellen untersucht. Ziel der folgenden Untersuchungen war es zu prüfen, ob die Basalexpression von Cyclin D2 entscheidend ist für die (Re-)Expression nach der VPA-Behandlung verschiedener Zelltypen und ob hierbei ein Zusammenhang mit der beobachteten Inhibition der Proliferation besteht. Dazu wurden kolorektale Karzinomzellen, Stromazellen der Prostata, verschiedene Fibroblastenzellen und embryonale Nierenzellen nach VPA-Behandlung analysiert.

\subsubsection{Analyse der basalen Cyclin D1- und Cyclin D2-Expression von kolorektalen Karzinomzellen}

Für die weiteren Analysen sollten kolorektale Karzinomzellinien ausgewählt werden, die entweder eine sehr geringe oder eine sehr hohe Basalexpression von Cyclin D2 zeigten. Hierfür wurden die Zellinien HCT 116, SW837, SW480, SW620, DLD-1 und Caco-2 untersucht. Da Cyclin D2 als Schlüsselregulator des Zellzyklus beschrieben ist und als dieser konfluenzabhängig ist, wurden hier unterschiedliche Konfluenzen der Zellkulturen untersucht, zum einen eine niedrige Konfluenz (low) und zum anderen eine sehr hohe Konfluenz (high). Es konnte gezeigt werden, dass HCT 116-, SW837-, DLD-1- und SW620-Zellen eine niedrige Basalexpression von Cyclin D2 aufwiesen, die sich auch bei hoher Konfluenz nicht änderte (Abb. 3.38A). Bei den SW480-Zellen konnte in niedriger Konfluenz eine niedrige Expression von Cyclin D2 detektiert werden, bei hoher Konfluenz stieg diese an. Caco-2Zellen zeigen bei jeder Konfluenz eine starke Basalexpression von Cyclin D2. Zusätzlich wurde die Expression von CCND1 in entsprechender Konfluenzabhängigkeit untersucht (Abb. 3.38B). SW480-Zellen in hoher Konfluenz wurden als Standard gewählt und die Expressionen der anderen Zelllinien darauf bezogen. Es wurde gezeigt, dass alle anderen untersuchten kolorektalen Karzinomzellen eine niedrigere Expression von CCND1 als SW480-Zellen in hoher Konfluenz aufwiesen. Daher wurden für die weiteren Untersuchungen DLD-1- und SW620-Zellen aufgrund der niedrigen Expression von Cyclin D2, Caco-2-Zellen aufgrund der hohen Cyclin D2-Expression und SW480-Zellen aufgrund der Auffälligkeit der Basalexpression von Cyclin D1 und D2 im Vergleich zu den anderen untersuchten Zelllinien ausgewählt. 

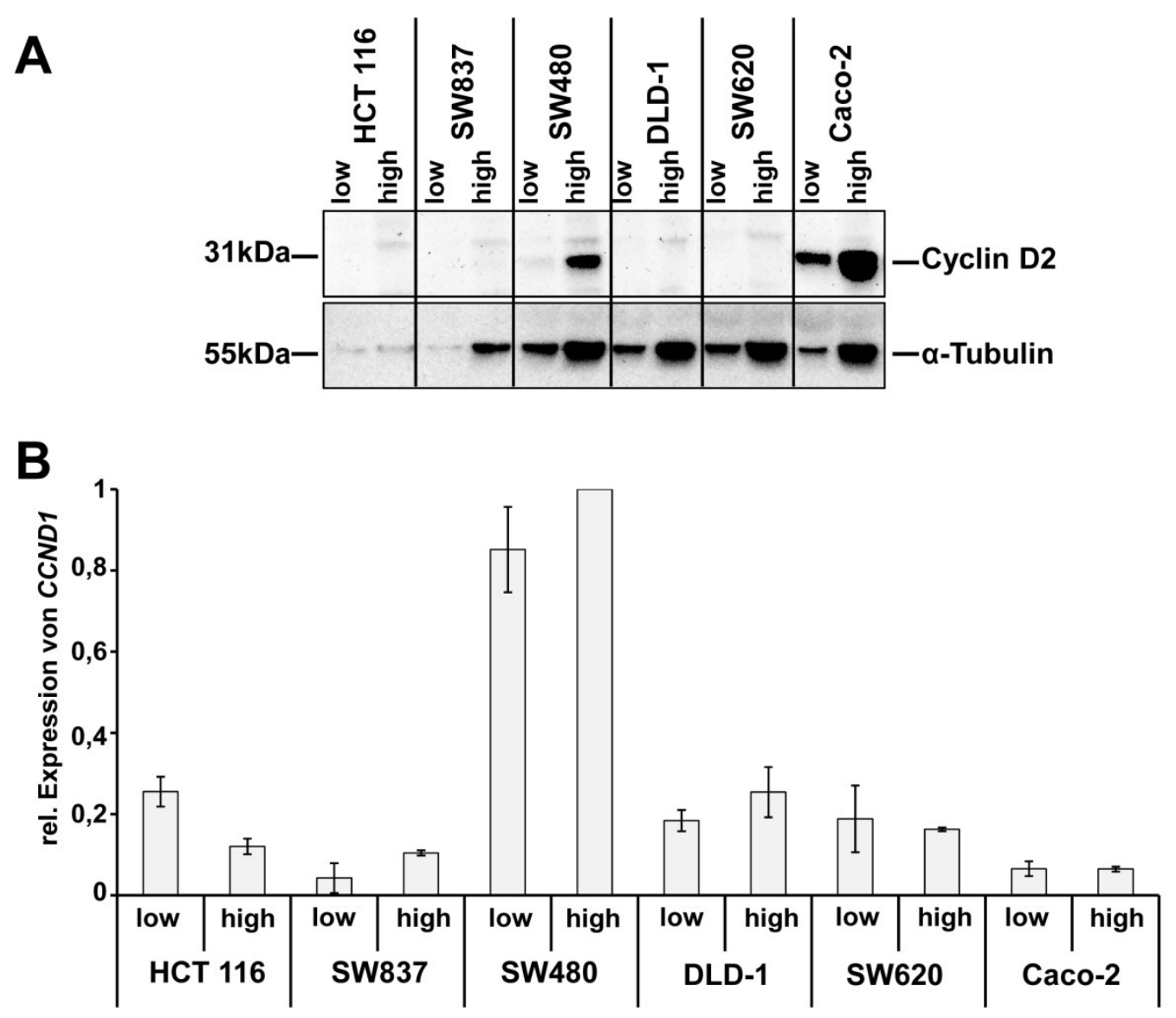

Abbildung 3.38: Untersuchungen zur konfluenzabhängigen Basalexpression von Cyclin D2 und Cyclin D1 in kolorektalen Karzinomzellen.

Die kolorektalen Karzinomzelllinien HCT 116, SW837, SW480, DLD-1, SW620 und Caco-2 wurden in niedriger (low) und sehr hoher (high) Zellanzahl ausgesät. Anschließend wurden sowohl die Gesamt-RNA als auch das Gesamtprotein isoliert. (A) Die anschließende Western Blot-Analyse zeigte, dass HCT 116-, SW837-, DLD-1- und SW620-Zellen unabhängig von der Konfluenz der Kultur eine kaum detektierbare Expression von Cyclin D2 aufwiesen. SW480-Zellen hingegen zeigten einen deutliche Anstieg der Expression bei hoher Konfluenz der Kultur. Caco-2-Zellen zeigten eine starke Cyclin D2-Expression unabhängig von der Konfluenz der Kultur. (B) Bei den qRT-PCR-Analysen zur Expression von CCND1 konnte beobachtet werden, dass SW480-Zellen, welche als Standard (bei hoher Konfluenz) ausgewählt wurden, eine hohe CCND1-Expression im Vergleich zu allen anderen untersuchten kolorektalen Karzinomzelllinien aufwiesen.

\subsubsection{Valproinsäure-Behandlung verschiedener maligner und nicht-maligner Zelllinien}

Zur Untersuchung der Veränderung der Cyclin D2-Expression und der Proliferation nach Behandlung mit VPA wurden verschiedene weitere Zelllinien hinzugezogen. Zum einen wurden die humanen PCa-Zellen PC-3, DU145 und LNCaP sowie die humanen Prostata-Stromazellen PrSC untersucht. Ferner wurde eine Gruppe von unterschiedlichen Fibroblasten analysiert: humane MRC5-Zellen aus der Lunge, murine WT und NxNx-/- aus der Haut (zur Verfügung gestellt von Dr. Frauke Nitzky, Abteilung Humangenetik, Arbeitsgruppe molekulare Entwicklungsgenetik, Universitätsmedizin Göttingen), NIH/3T3 als murine Fibroblasten aus einem Embryo und die murinen Bindegewebsfibroblasten namens 
L-Zellen. Des Weiteren wurden auch die embryonalen Nieren-Zellen HEK293 und, wie im vorherigen Kapitel (3.3.5.1) bereits erwähnt, die humanen kolorektalen Karzinomzelllinien Caco-2, DLD-1, SW620 und SW480 untersucht.

Alle genannten Zellen wurden mit verschiedenen Konzentrationen von VPA für 24 Stunden (hier nicht dargestellt) und 72 Stunden inkubiert. Anschließend wurden Expressionsanalysen an der Gesamt-RNA bzw. dem Gesamtprotein durchgeführt. Zudem wurden die Zellen für 24, 48, 72 und 144 Stunden mit VPA behandelt und anschließend ein MTT-Assay zur Analyse der Proliferation durchgeführt (dargestellt in Abb. 3.39 sind 72 Stunden VPA-Behandlung).

Es konnte gezeigt werden, dass die Expression von Cyclin D1 in allen untersuchten Zelllinien nach VPA-Behandlung kaum verändert vorlag (Abb. 3.39A; Witt et al., 2013). Hingegen wurde in allen untersuchten PCa-Zellen die Expression von Cyclin D2 nach der Behandlung mit VPA konzentrationsabhängig erhöht (Abb. 3.39B und C; Witt et al., 2013), wobei die Basalexpression von Cyclin D2 auf Proteinebene kaum detektiert werden konnte (Abb. 3.39C; Witt et al., 2013). Bei der Untersuchung der Proliferation zeigten alle untersuchten PCa-Zellen eine deutliche Inhibition der Proliferation durch die VPA-Behandlung. Diese Inhibition war bereits für die Behandlung mit der geringen Konzentration von VPA (1mM) sichtbar (Abb. 3.39D; Witt et al., 2013). Die Prostata-Stromazellen PrSC zeigten eine hohe Basalexpression von Cyclin D2. Diese blieb nach der VPA-Behandlung unverändert (Abb. 3.39B und C; Witt et al., 2013). Auch der Einfluss auf die Proliferation der PrSC-Zellen war niedrig, vor allem bei der niedrigen Konzentration von VPA konnte keine Inhibition der Proliferation detektiert werden (Abb. 3.39D; Witt et al., 2013). MRC5-Zellen hingegen zeigten auf RNA-Ebene eine Re-Expression von CCND2 (Abb. 3.39B; Witt et al., 2013). Auf Proteinebene waren sie die einzige Fibroblasten-Zelllinie, die keine Basalexpression von Cyclin D2 aufwies (Abb. 3.39C; Witt et al., 2013). Die auf RNA-Ebene gezeigte ReExpression von CCND2 nach VPA-Behandlung der MRC5-Zellen konnte auf Proteinebene nicht verifiziert werden. Die Proliferation dieser Zellen wurde durch die Behandlung mit VPA mäßig gehemmt, vor allem die niedrige Konzentration von VPA änderte die Proliferationsrate der MRC5-Zellen kaum (Abb. 3.39D; Witt et al., 2013). NIH/3T3-, WT-, NxNx- und HEK293Zellen zeigten eine hohe Basalexpression von Cyclin D2 (Abb. 3.39C; Witt et al., 2013). Diese blieb durch die Behandlung mit VPA unverändert. Auch die Proliferationsrate der Zellen wurde nur mäßig beeinflusst, vor allem die niedrige Konzentration von VPA hatte keinen Einfluss auf die Proliferation der Zellen (Abb. 3.39D; Witt et al., 2013). Im Gegensatz dazu zeigten die L-Zellen eine hohe Basalexpression von Cyclin D2, die allerdings durch eine VPA-Behandlung noch weiter erhöht wurde (Abb. 3.39B und C; Witt et al., 2013). Die LZellen zeigten im Proliferationsassay die stärkste Inhibition der Proliferation unter den Fibroblasten-Zelllinien und ihre Proliferation wurde auch bereits durch die niedrige 
Konzentration von VPA mäßig stark gehemmt (Abb. 3.39D; Witt et al., 2013). Bei den kolorektalen Karzinomzellen wurde die Basalexpression bereits im vorhergehenden Kapitel (3.3.5.1) beschrieben. Lediglich für SW620-Zellen konnte eine Re-Expression von Cyclin D2 detektiert werden (Abb. 3.39B und C; Witt et al., 2013). Die Inhibition der Proliferation war bei allen untersuchten kolorektalen Karzinomzellen nur mäßig, vor allem für die geringe Konzentration von VPA. Lediglich die aufgrund ihres außergewöhnlichen Expressionsprofils ausgewählten SW480-Zellen zeigten eine leichte Inhibition der Proliferation (Abb. 3.39D; Witt et al., 2013). 


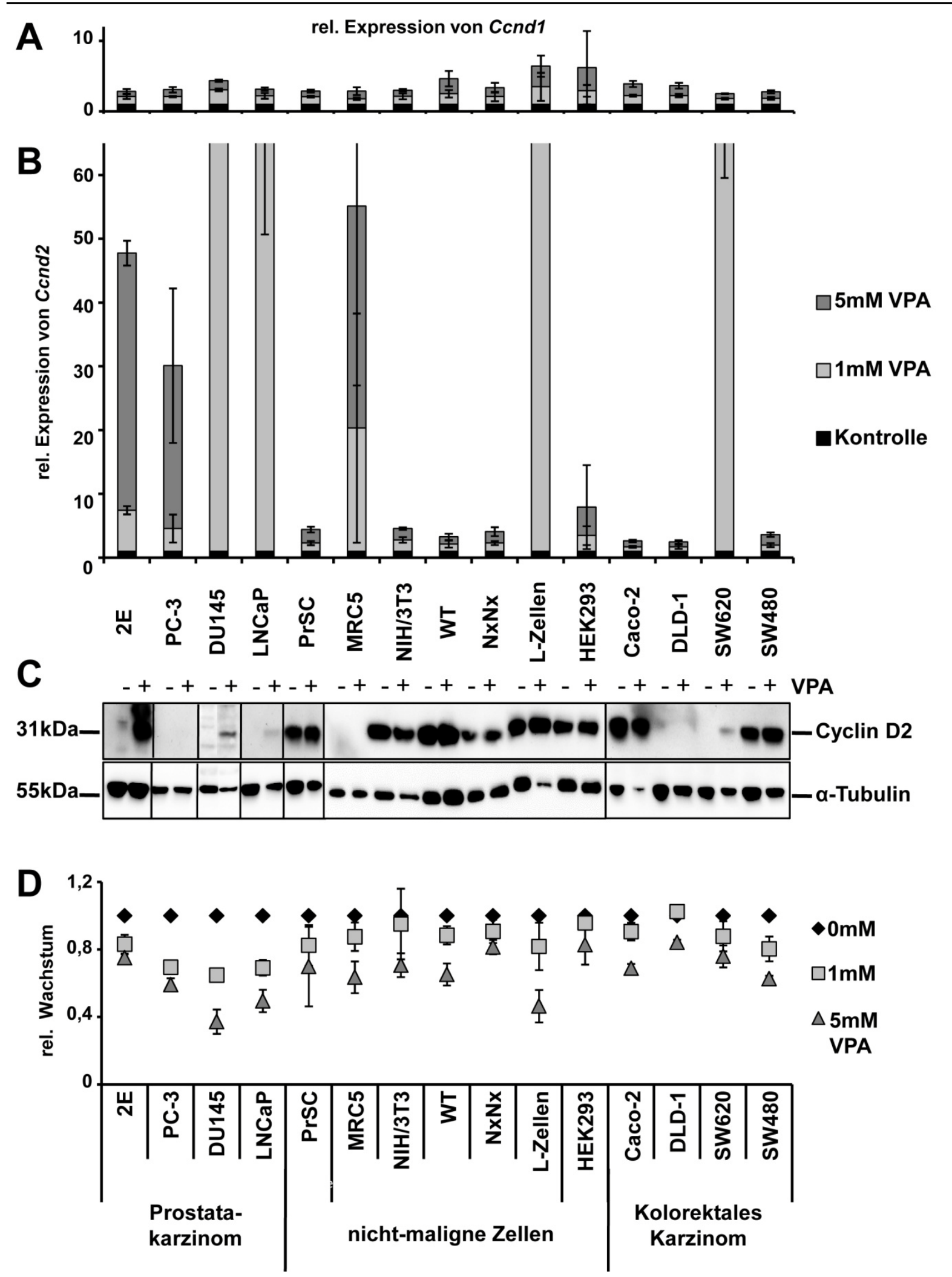

Abbildung 3.39: Analyse zur Expression von Cyclin D1 und Cyclin D2 sowie der Zellproliferation nach Behandlung verschiedener Zelllinien mit VPA.

Es wurden 15 verschiedene Zellinien untersucht. Diese bestanden aus einer Gruppe von verschiedenen PCa-Zellen (2E, PC-3, DU145 und LNCaP), einer Gruppe von nicht-malignen Zellen (Prostatastromazellen PrSC, Fibroblasten-Zellen MRC5, NIH/3T3, WT, NxNx und L-Zellen sowie den embryonale Nierenzellen HEK293) sowie einer Gruppe von kolorektalen Karzinomzellen (Caco-2, DLD-1, SW620 und SW480). Alle Zellen wurden für 72 Stunden mit VPA behandelt und anschließend wurde die Gesamt-RNA und das Gesamtprotein isoliert. 
Zusätzlich wurde nach 72 Stunden VPA-Behandlung der genannten Zelllinien ein MTT-Assay zur Analyse der Proliferationsrate der Zellen durchgeführt. (A) Die mRNA-Expression von Cyclin D1 wurde mittels qRT-PCR-Analyse bestimmt. Es konnte in keiner der untersuchten Zelllinien nach der VPA-Behandlung eine signifikante Veränderung im Vergleich zu kontrollbehandelten Zellen gezeigt werden. (B und C) Analyse der Expression von Cyclin D2 nach VPA-Behandlung in den angegebenen Zelllinien auf RNA-Ebene (B, qRT-PCR) und auf Protein-Ebene (C, Western Blot). Während die PCa-Zellen eine geringe Basalexpression von Cyclin D2 und nach Behandlung mit VPA eine starke Re-Expression aufwiesen, zeigten die Fibroblasten-Zelllinien und die Prostata-Stromazellen eine hohe allgemeine Basalexpression und keine Re-Expression von Cyclin D2 nach VPA. Für die HEK293-Zellen konnte eine starke Basalexpression und keine Re-Expression von Cyclin D2 detektiert werden. Die kolorektalen Karzinomzellen zeigten bis auf SW620-Zellen keine Erhöhung der Cyclin D2 Expression nach VPA-Behandlung. (D) Analyse der Proliferationsrate der angegebenen Zellinien nach Behandlung mit VPA. Die PCa-Zellen zeigten eine starke Inhibition der Proliferation bereits durch die niedrige Konzentration von VPA $(1 \mathrm{mM})$, wohingegen bei den Prostatastromazellen und den Fibroblastenzellen lediglich bei den L-Zellen eine deutliche Inhibition der Proliferation durch die Behandlung mit VPA detektiert wurde. Die kolorektalen Karzinomzellen zeigten eine nur mäßige Inhibition der Proliferation nach der Behandlung mit VPA, die niedrige verwendete Konzentration von VPA (1mM) änderte die Proliferationsrate kaum (modifiziert nach Witt et al., 2013).

\subsubsection{3 siRNA-Studien zur Analyse der Rolle von Cyclin D2 bei der Inhibition der Proliferation}

Um experimentell nachzuweisen, dass die Re-Expression von Cyclin D2 verantwortlich für die beobachtete Inhibition der Proliferation nach VPA-Behandlung ist, wurden zunächst siRNA-Studien in den primären PCa-Zellen 2E durchgeführt. Hierzu wurde die Ccnd2-Expression in den PCa-Zellen 2E mittels siRNA-Transfektion mit drei verschiedenen siRNA-Proben (A, B und C) gegen Ccnd2 herunter reguliert. Die Ccnd2-Expression wurde überprüft und es konnte für alle drei untersuchten siRNA-Proben eine Verringerung der Genexpression von Ccnd2 in den primären PCa-Zellen 2E um ca. $60 \%$ detektiert werden (Abb. 3.40A).

Nach der Transfektion mit Ccnd2-spezifischer siRNA wurden die Zellen mit VPA behandelt und die Proliferation mittels MTT-Assays nach 24, 72 und 144 Stunden gemessen. In Abb. 3.40 sind die Ergebnisse der Proliferation nach 72 Stunden VPA-Behandlung dargestellt. Es wurde erwartet, dass die Herunterregulierung der Ccnd2-Expression bei VPA-Behandlung zu einer Aufhebung der VPA-induzierten Inhibition der Proliferation führt. Allerdings ist zu verzeichnen, dass die Transfektion mit der siRNA A in einer Verminderung der Proliferation resultiert und die siRNAs B und C keinen Effekt auf die Proliferation ausüben.

Daher wurden anschließend Expressionsanalysen mit siRNA-transfizierten und gleichzeitig VPA-behandelten Zellen durchgeführt (Abb. 3.40C). Die qRT-PCR-Analyse zeigte, dass die Behandlung mit den siRNAs nach der Behandlung der Zellen mit VPA keinen Einfluss auf die Expression von Ccnd2 ausübte. Es konnte zwar beobachtet werden, dass die Expression von Ccnd2 nach der VPA-Behandlung in den Ccnd2-siRNA-transfizierten Zellen nicht so 
stark anstieg wie in den kontroll-transfizierten Proben (100-fach vs. 150-fach), allerdings waren auch diese Verringerungen der Expression nicht effektiv genug, um das Proliferationsverhalten zu verändern.
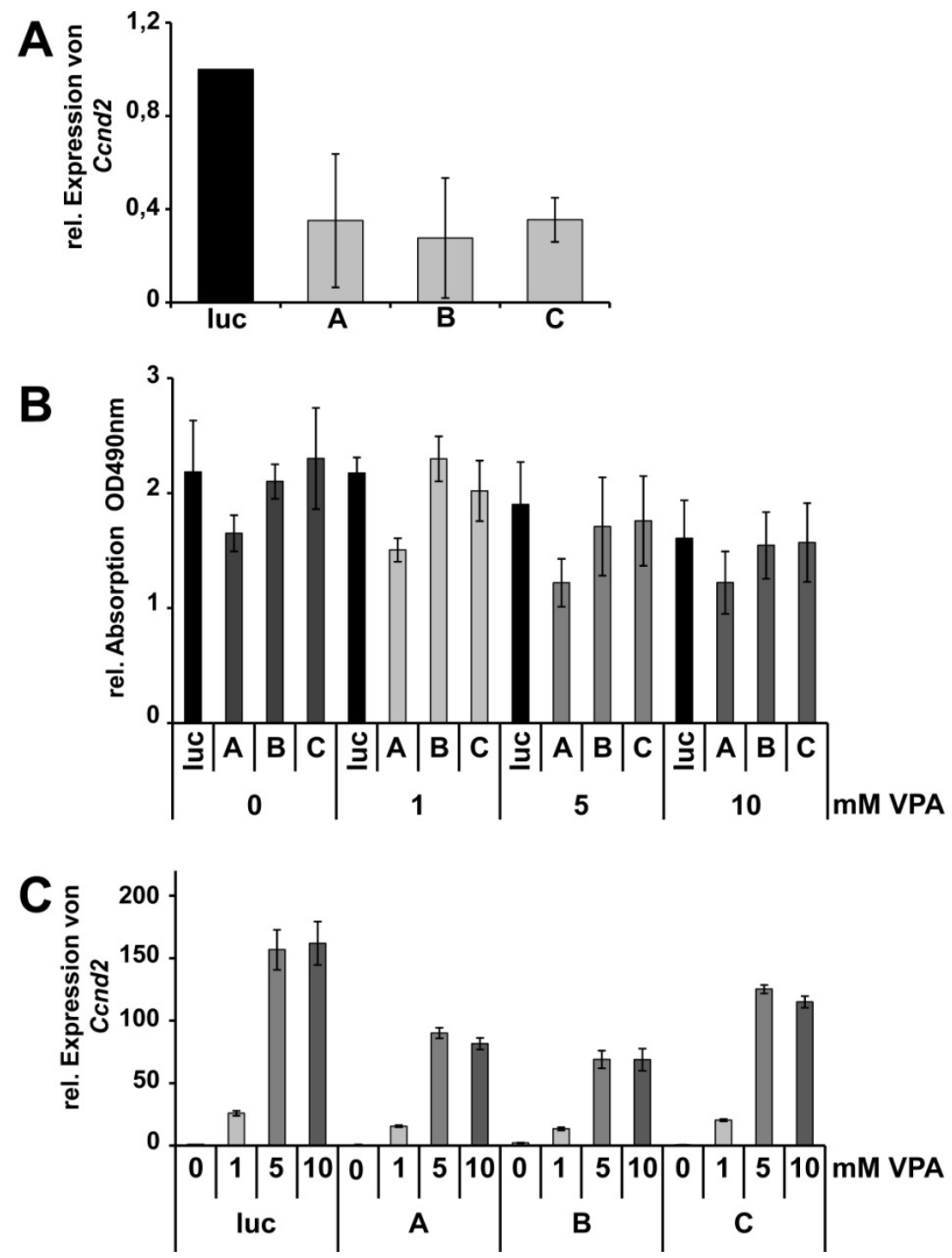

Abbildung 3.40: Analyse der Cyclin D2-Expression und Zellproliferation nach Verminderung der Cyclin D2-Expression mittels siRNA und anschließender Behandlung der PCa-Zellen 2E mit VPA.

Die Genexpression von Ccnd2 wurde in den PCa-Zellen 2E mittels siRNA-Transfektion mit drei verschiedenen siRNA-Proben (A, B und C) verringert. Als Kontrolle dienten PCa-Zellen 2E, die mit siRNA gegen das Luciferase-Gen (luc) transfiziert wurden. (A) Die Effizienz der Ccnd2-Expressionsverringerung wurde nach Isolation der Gesamt-RNA mittels qRT-PCR untersucht. Für alle drei siRNA-Proben konnte eine deutliche Verringerung der Genexpression von Ccnd2 detektiert werden. (B und C) Anschließend wurden die transfizierten Zellen mit verschiedenen Konzentrationen von VPA behandelt. Bei der Analyse der Proliferationsrate (B) der PCa-Zellen 2E konnte beobachtet werden, dass weder die mit der siRNA-Probe B noch die mit der siRNA-Probe $C$ transfizierten Zellen einen Unterschied in der Proliferationsrate zu den mit der Kontroll-siRNA transfizierten Proben zeigten. Die Transfektion mit der siRNA A führte sogar zu einer Verringerung der Zellproliferation. (C) In der anschließenden Analyse der Expression von Ccnd2 mittels qRT-PCR konnte gezeigt werden, dass in allen siRNA-transfizierten Proben die Expression von Ccnd2 nach der Behandlung mit VPA wieder in vergleichbarer Stärke wie in den kontrolltransfizierten Proben induziert wurde. 
Da ein direkter Nachweis des Einflusses der Cyclin D2-Expression auf die Proliferation nach Behandlung mit VPA mit den oben genannten Experimenten nicht möglich war, wurden weitere Studien an murinen NIH/3T3-Zellen durchgeführt. Diese Zellen haben im Gegensatz zu den murinen primären PCa-Zellen $2 \mathrm{E}$ eine hohe Basalexpression von Cyclin D2. Es konnte mit einer der drei verwendeten siRNA-Proben eine effiziente Inhibition der Genexpression hervorgerufen werden (Abb. 3.41A; Witt et al., 2013). In darauffolgenden Proliferationsassays konnte gezeigt werden, dass die mit der siRNA-Probe B transfizierte Probe, in der erfolgreich die Expression von Cyclin D2 vermindert wurde, eine Erhöhung der Proliferationsrate um etwa 20\% zeigte (Abb. 3.41B; Witt et al., 2013). Entgegen der vorherrschenden Meinung aus der Literatur konnte somit gezeigt werden, dass eine Verringerung der Cyclin D2-Expression nicht zu einer Inhibierung, sondern zu einer Erhöhung der Proliferation von Zellen führen kann.

A
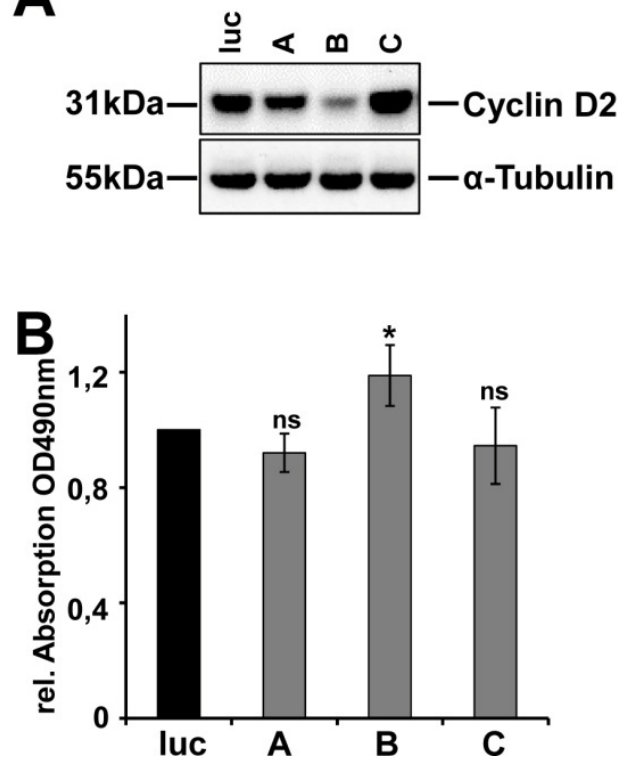

Abbildung 3.41: Analyse der Cyclin D2-Expression und Zellproliferation nach Verminderung der Cyclin D2-Expression mittels siRNA.

Die Cyclin D2-Genexpression wurde in den murinen Fibroblastenzellen NIH/3T3 mittels siRNA-Transfektion mit drei verschiedenen siRNA-Proben (A, B und C) gegen Cyclin D2 herunterreguliert. Anschließend wurde das Gesamtprotein isoliert sowie eine Analyse der Proliferation nach Verminderung der Cyclin D2-Expression durchgeführt. (A) In der Western Blot-Analyse konnte gezeigt werden, dass die siRNA Probe B die Expression von Cyclin D2 effektiv reduzierte. (B) Zudem konnte für diese Probe (siRNA Probe B) eine Erhöhung der Proliferation der transfizierten Zellen um ca. 20\% detektiert werden (modifiziert nach Witt et al., 2013). 
3.3.6 Untersuchung der Cyclin D1- und Cyclin D2-Expression an humanen Prostatakarzinom-Gewebeschnitten

Die Expression von Cyclin D2 bei Patienten mit einem PCa wird als neuer prognostischer Marker gesehen (Phe et al., 2010). Es wurden hierzu an Patientenmaterial bereits die mRNA-Expression sowie der Methylierungszustand des Promotors des Ccnd2-Gens untersucht und ein Verlust der Ccnd2-Expression durch Promotor-Methylierung festgestellt (Padar et al., 2003; Rosenbaum et al., 2005; Henrique et al., 2006; Costa et al., 2007). Zum Zeitpunkt dieser Arbeit ist keine Studie bekannt, die die Expression von Cyclin D2 nicht über RNA- oder DNA-Isolation aus Gewebe, sondern direkt in den Zellen mittels Immunhistochemie untersucht hat. Daher wurden in Zusammenarbeit mit der Pathologie der Universitätsmedizin Göttingen (Dr. med. Felix Bremmer) humane Prostata-Gewebeschnitte auf die Expression von Cyclin D1 und Cyclin D2 hin untersucht. Insgesamt wurden 21 Patienten untersucht, wobei es sich bei dem Material um benachbartes gesundes Prostatagewebe aus einer benignen Prostatahyperplasie (BPH, 6 Präparate), Gewebe aus Prostatakarzinomen (15 Präparate) und eine Lymphknotenmetastase handelte. Cyclin D1 wird in normalem Prostatagewebe schwach exprimiert (Abb. 3.42A; Witt et al., 2013). Im Tumorgewebe und in der Lymphknoten-Metastase war bei der Mehrzahl der Patienten eine deutliche Überexpression von Cyclin D1 zu beobachten (Abb. 3.42A; Witt et al., 2013), was auf die Rolle von Cyclin D1 als Onkogen schließen lässt. Cyclin D2 hingegen wurde im gesunden Prostatagewebe in den proliferierenden Zellen exprimiert (Abb. 3.42B; Witt et al., 2013). Im Tumorgewebe und in der Metastase konnte keine Expression von Cyclin D2 detektiert werden, wobei Zellen im interstitiellen Raum deutlich positiv waren für die Expression von Cyclin D2 und somit als interne Positivkontrolle dienten (Abb. 3.42B; Witt et al., 2013). Dies spricht für die mögliche Funktion von Cyclin D2 als Tumorsuppressor-Gen. 
A

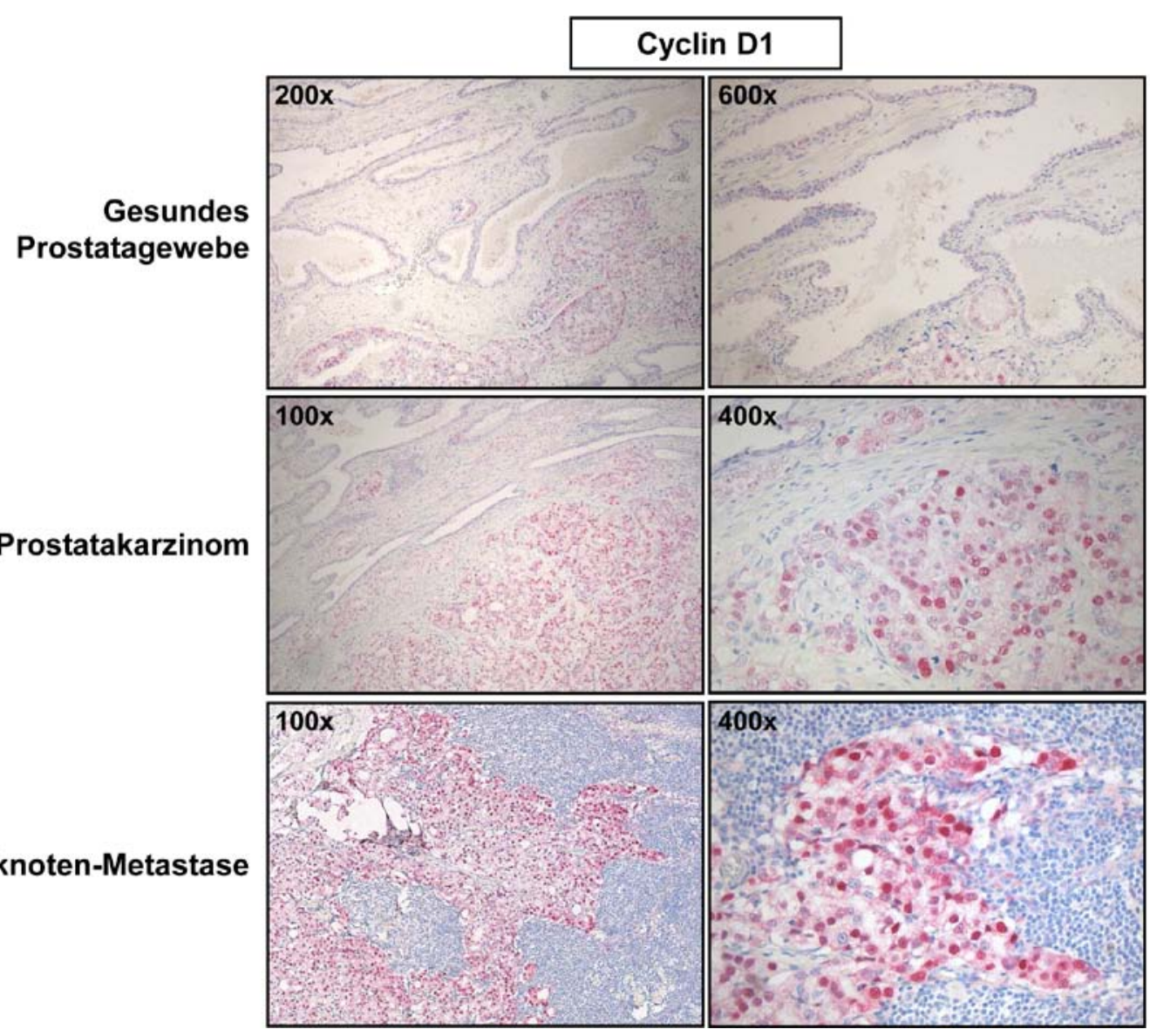

B

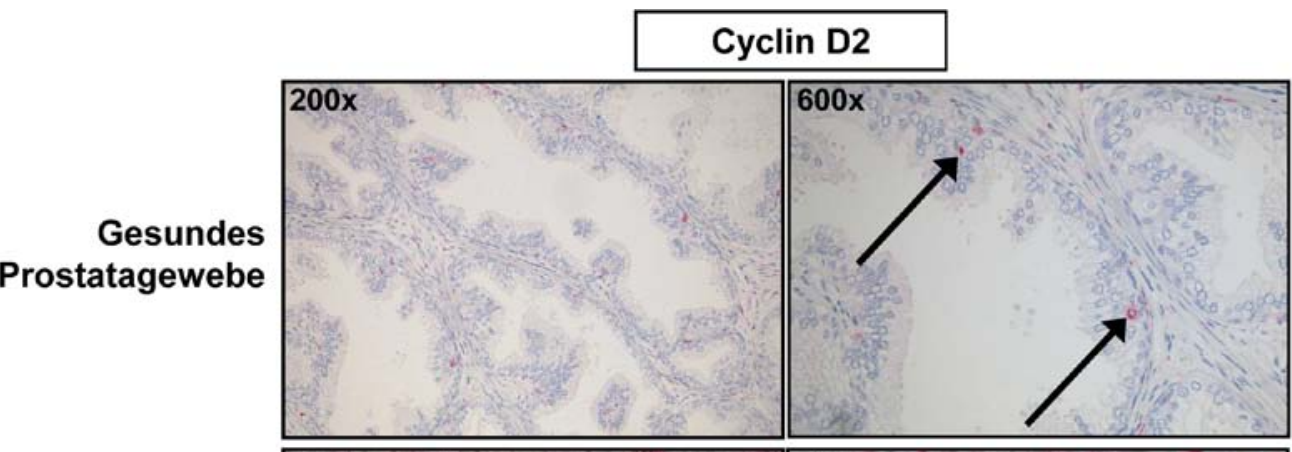

\section{Lymphknoten-Metastase}

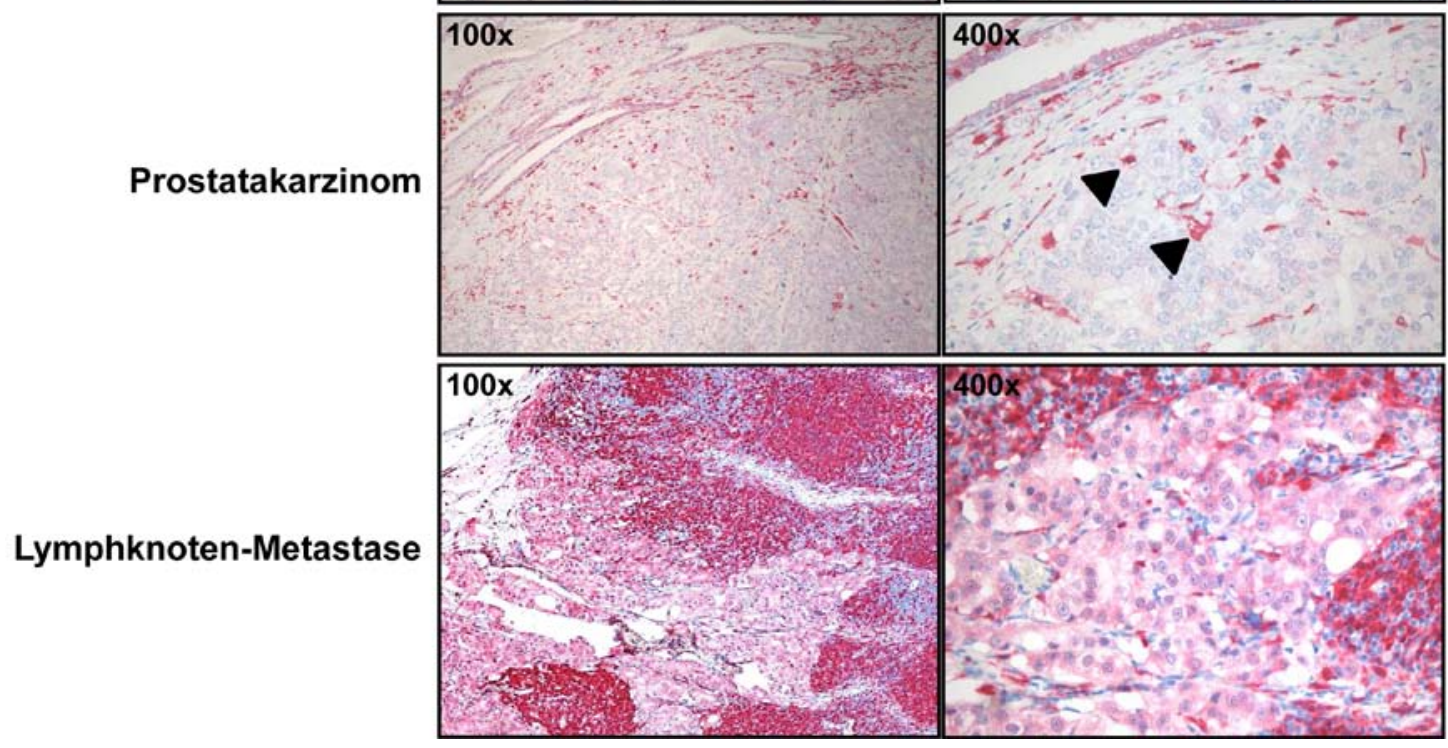

Abbildung 3.42: Analyse der Expression von Cyclin D1 und Cyclin D2 an humanen Gewebeschnitten von gesundem Prostatagewebe, Prostatakarzinomgewebe sowie einer Lymphknotenmetastase. 
Es wurden verschiedene Gewebeschnitte immunhistochemisch auf die Expression von Cyclin D1 und Cyclin D2 hin untersucht. Die Gewebeschnitte stammten aus benachbartem, gesundem Prostatagewebe einer benignen Prostatahyperplasie, Prostatakarzinomgewebe und einer Lymphknotenmetastase. (A) Es wurde gezeigt, dass Cyclin D1 sowohl im gesunden Gewebe der Prostata exprimiert wurde als auch verstärkt in dem Karzinomgewebe sowie der Metastase. (B) Die Expression von Cyclin D2 war im gesunden Prostatagewebe in den proliferierenden Zellen (Pfeile) detektierbar, wohingegen Tumorzellen des Karzinomgewebes und der Metastase keine Expression von Cyclin D2 aufwiesen. Zellen im interstitiellen Raum, z.B. Lymphozyten (Pfeilköpfe), zeigten hingegen eine starke Cyclin D2-Expression und dienten als Positivkontrolle (modifiziert nach Witt et al., 2013).

\subsubsection{Valproinsäure-Behandlung in vivo über das Trinkwasser}

Es wurde in den folgenden in vivo-Versuchen das Trinkwasser von TRAMP-Mäusen mit $0,4 \%$ w/v VPA und zudem mit Süßstoff versetzt. Kontrollbehandelte Mäuse erhielten Trinkwasser mit der gleichen Menge an Süßstoff. Das Trinkwasser wurde zweimal wöchentlich erneuert.

Es wurden drei verschiedene Versuchsgruppen unterteilt. Die erste Gruppe erhielt VPA präventiv ab einem Alter von sechs Wochen und es wurde eine Überlebensstudie im Vergleich zu kontrollbehandelten Mäusen durchgeführt. Die zweite Gruppe erhielt VPA präventiv ab einem Alter von sechs Wochen, allerdings ist der Versuch auf ein Alter von 30 Wochen terminiert um den Tumorprogress im Vergleich zu kontrollbehandelten Mäusen beobachten zu können. Eine dritte Gruppe erhielt VPA als Therapie ab einem Alter von 16 Wochen und es wurde eine Überlebensstudie im Vergleich zu kontrollbehandelten Mäusen durchgeführt. Alle drei Versuchsgruppen konnten im Rahmen dieser Arbeit noch nicht beendet werden. Daher sind die hier präsentierten Daten nur vorläufige Daten, in denen die angegebene Anzahl an Mäusen ausgewertet werden konnte.

Für die präventive Behandlung mit VPA in der Überlebensstudie konnten 10 Kontrolltiere und 13 VPA-behandelte Mäuse untersucht werden (Abb. 3.43). Es konnte ein höheres mittleres Überlebensalter (31 Wochen vs. 37 Wochen; Abb. 3.43A) für die VPA-behandelten Mäuse gezeigt werden. Auch das mittlere Verhältnis des Urogenitaltraktgewichts im Vergleich zum Gesamtgewicht war bei den VPA-behandelten Mäusen deutlich geringer (0,19 vs. 0,12; Abb. 3.43B). Der Anteil von Mäusen mit einem makroskopisch erkennbaren PCa lag nach 40 Wochen bei $60 \%$ für kontrollbehandelte Mäuse und 23\% für VPA-behandelte Mäuse. 

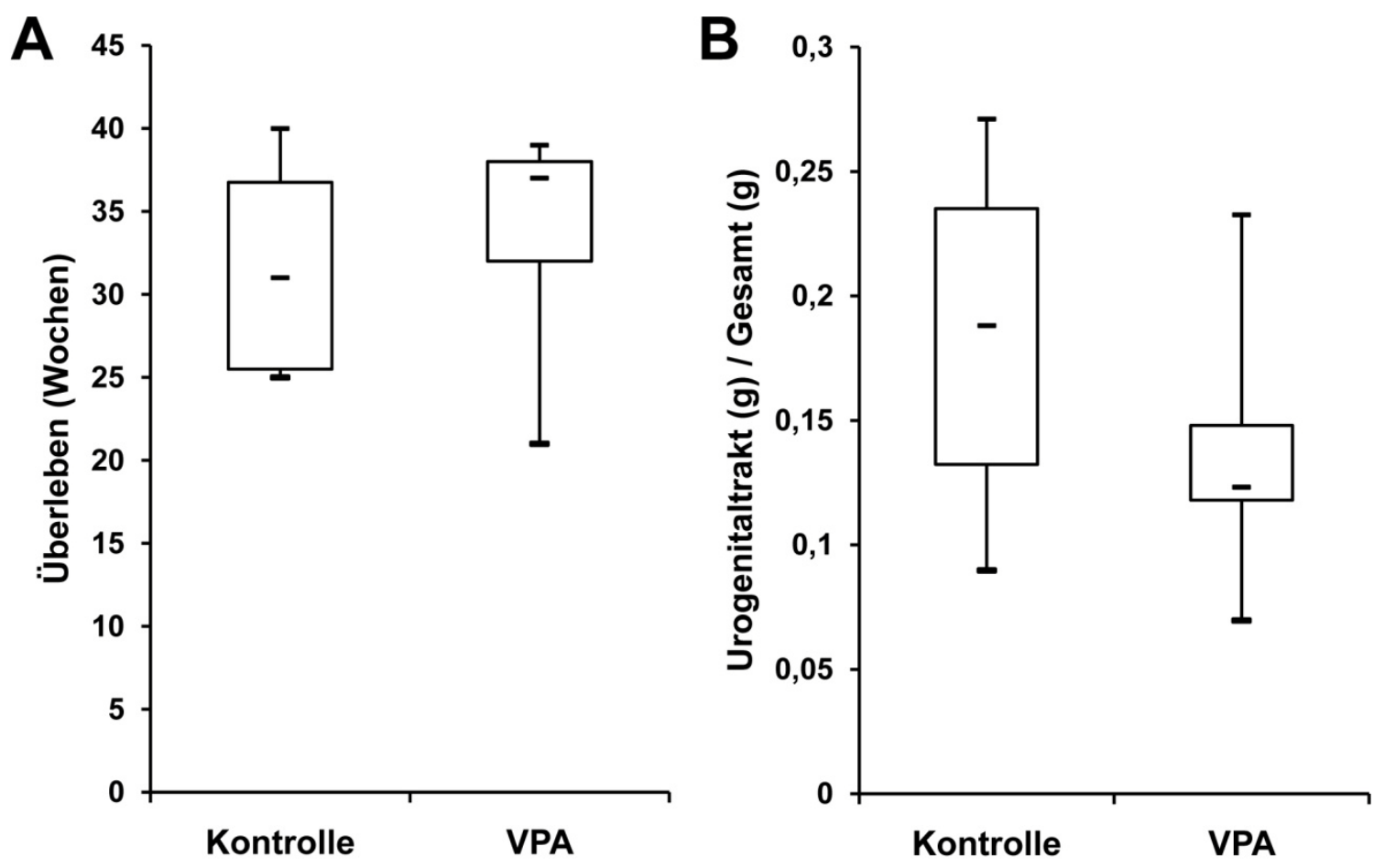
untersuchte Tiere
10
13
Tumoranteil
$6 / 10$ (60\%)
$3 / 13$ (23\%)

\section{Abbildung 3.43: Überlebensstudie nach präventiver Gabe von VPA in TRAMP-Mäusen.}

Untersucht wurden zehn kontrollbehandelte Mäuse und 13 VPA-behandelte Mäuse. VPA wurde mit zugesetztem Süßstoff über das Trinkwasser verabreicht $(0,4 \% \mathrm{w} / \mathrm{v})$. Kontrollbehandelte Mäuse erhielten lediglich Trinkwasser mit zugesetztem Süßstoff. Die Mäuse wurden ab einem Alter von sechs Wochen behandelt und es wurde eine Überlebensstudie durchgeführt. (A) Das mittlere Überleben lag in der kontrollbehandelten Gruppe bei 31 Wochen im Vergleich zu 37 Wochen bei der VPA-behandelten Gruppe. Der prozentuale Anteil von Mäusen mit einem makroskopisch erkennbaren PCa lag nach 40 Wochen Behandlung bei 60\% für die kontrollbehandelten Mäuse, wohingegen lediglich 23\% der VPA-behandelten Mäuse ein PCa entwickelten. (B) Das Verhältnis von Urogenitaltraktgewicht zu Gesamtgewicht lag in den kontrollbehandelten Mäusen bei 0,19 im Vergleich zu 0,12 bei den VPA-behandelten Mäusen.

In dieser Gruppe fehlen lediglich noch zwei Kontrolltiere, die zum Zeitpunkt dieser Arbeit noch unter 30 Wochen alt sind. Es wurde daher mit den bereits vorhandenen Daten eine Verlaufskurve der Tumorprogression erstellt. Es konnte gezeigt werden, dass in der mit VPA-behandelten Gruppe über den gesamten Versuchsverlauf mehr Mäuse eine längere Zeit überlebt haben und dabei auch weniger VPA-behandelte Mäuse ein makroskopisch erkennbares PCa entwickelten (Abb. 3.44). 


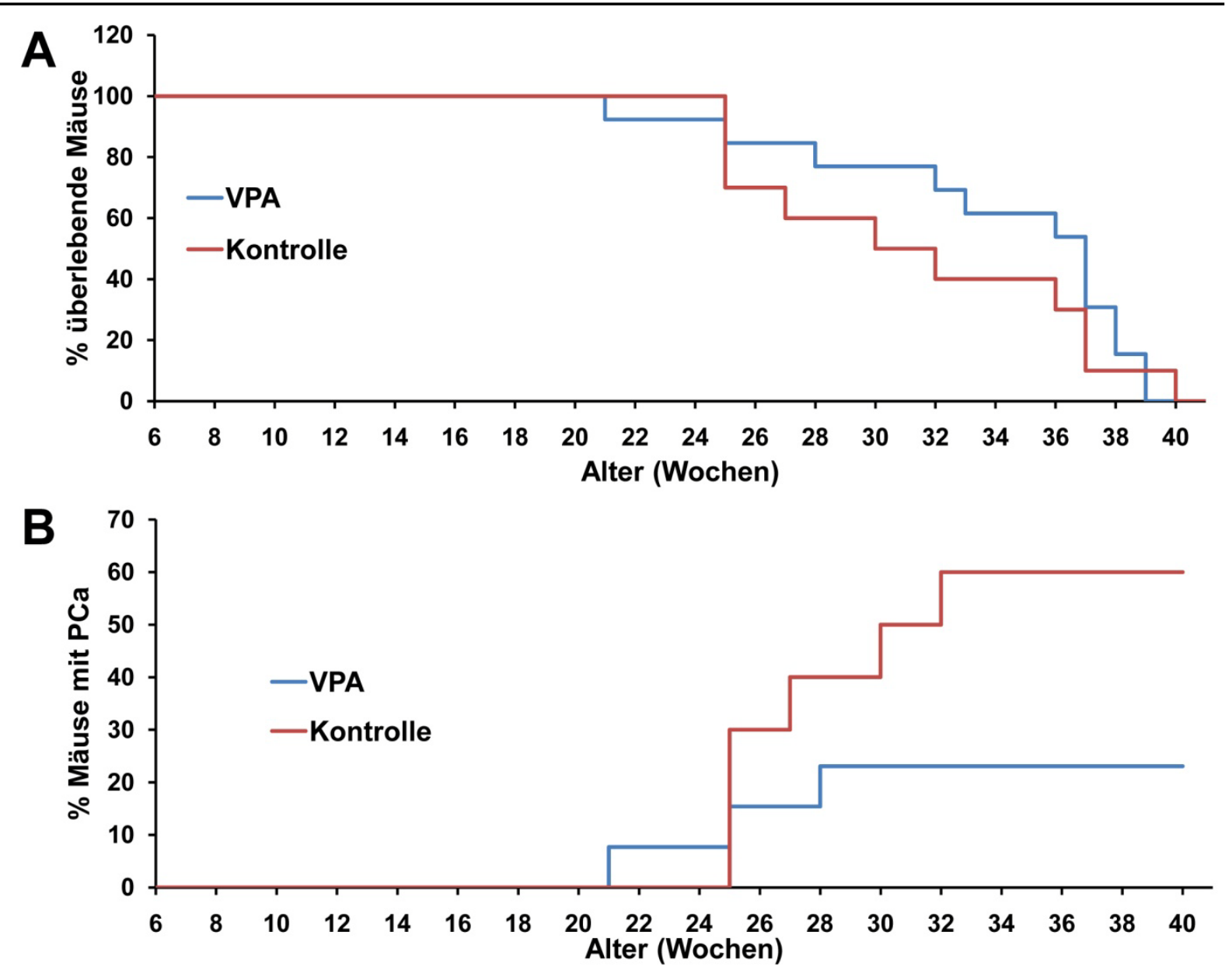

Abbildung 3.44: Überlebensstudie nach präventiver Gabe von VPA in TRAMP-Mäusen.

Untersucht wurden zehn kontrollbehandelte Mäuse und 13 VPA-behandelte Mäuse. VPA wurde mit zugesetztem Süßstoff über das Trinkwasser verabreicht (0,4\% w/v). Kontrollbehandelte Mäuse erhielten lediglich Trinkwasser mit zugesetztem Süßstoff. Die Mäuse wurden ab einem Alter von sechs Wochen behandelt und es handelte sich um eine Überlebensstudie. (A) Das mittlere Überleben war durchschnittlich während des gesamten Untersuchungszeitraums bei den VPA-behandelten Mäusen höher als bei den kontrollbehandelten Mäusen. (B) Der prozentuale Anteil von Mäusen mit einem makroskopisch erkennbaren PCa war durchschnittlich über den gesamten Versuchsverlauf bei den kontrollbehandelten Mäusen deutlich höher als bei den mit VPA-behandelten Mäusen.

Ein bereits beschriebener Effekt bei TRAMP-Mäusen ist die Entwicklung von Samenblasentumoren unabhängig von der Entwicklung eines PCa (Tani et al., 2005; Yeh et al., 2009). Auch in dieser Studie konnte eine erhöhte Anzahl von Mäusen mit einem Samenblasentumor beobachtet werden, allerdings war auch diese Anzahl bei den VPA-behandelten Mäusen durchschnittlich über den gesamten Versuchsverlauf geringer als bei den kontrollbehandelten Mäusen (Abb. 4.45). 


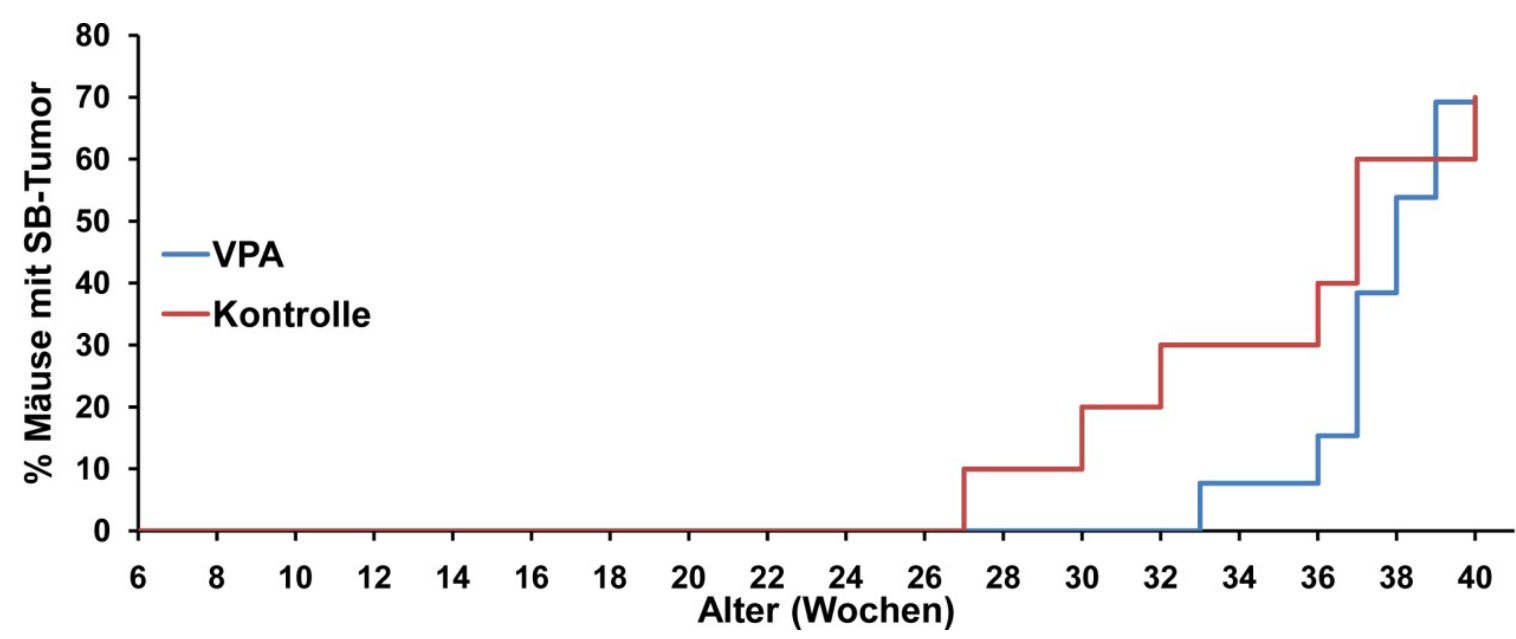

Abbildung 3.45: Überlebensstudie nach präventiver Gabe von VPA in TRAMP-Mäusen.

Untersucht wurden zehn kontrollbehandelte Mäuse und 13 VPA-behandelte Mäuse. VPA wurde mit zugesetztem Süßstoff über das Trinkwasser verabreicht (0,4\% w/v). Kontrollbehandelte Mäuse erhielten lediglich Trinkwasser mit zugesetztem Süßstoff. Die Mäuse wurden ab einem Alter von sechs Wochen behandelt und es wurde eine Überlebensstudie durchgeführt. Der Anteil der Mäuse mit einem makroskopisch erkennbaren Samenblasentumor (SB-Tumor) war bei den kontrollbehandelten Mäusen im Vergleich zu den VPA-behandelten Mäusen über den gesamten Versuchsverlauf erhöht.

In der zweiten Versuchsgruppe wurde den Mäusen wiederum präventiv ab einem Alter von sechs Wochen VPA verabreicht. Zur Analyse der Tumorprogression wurde diese Versuchsgruppe auf ein Alter von 30 Wochen terminiert. Es konnten bis jetzt neun Mäuse in der kontrollbehandelten sowie neun Mäuse in der VPA-behandelten Gruppe untersucht werden. Nicht alle Mäuse haben das Alter von 30 Wochen erreicht (Abb. 4.46B). Das durchschnittliche Verhältnis von Urogenitaltraktgewicht zu Gesamtgewicht war in der kontrollbehandelten Gruppe gleich hoch wie in der VPA-behandelten Gruppe (beide 0,06). Der Anteil der Mäuse mit einem makroskopisch erkennbaren PCa lag in beiden Gruppen bei $11 \%$. 

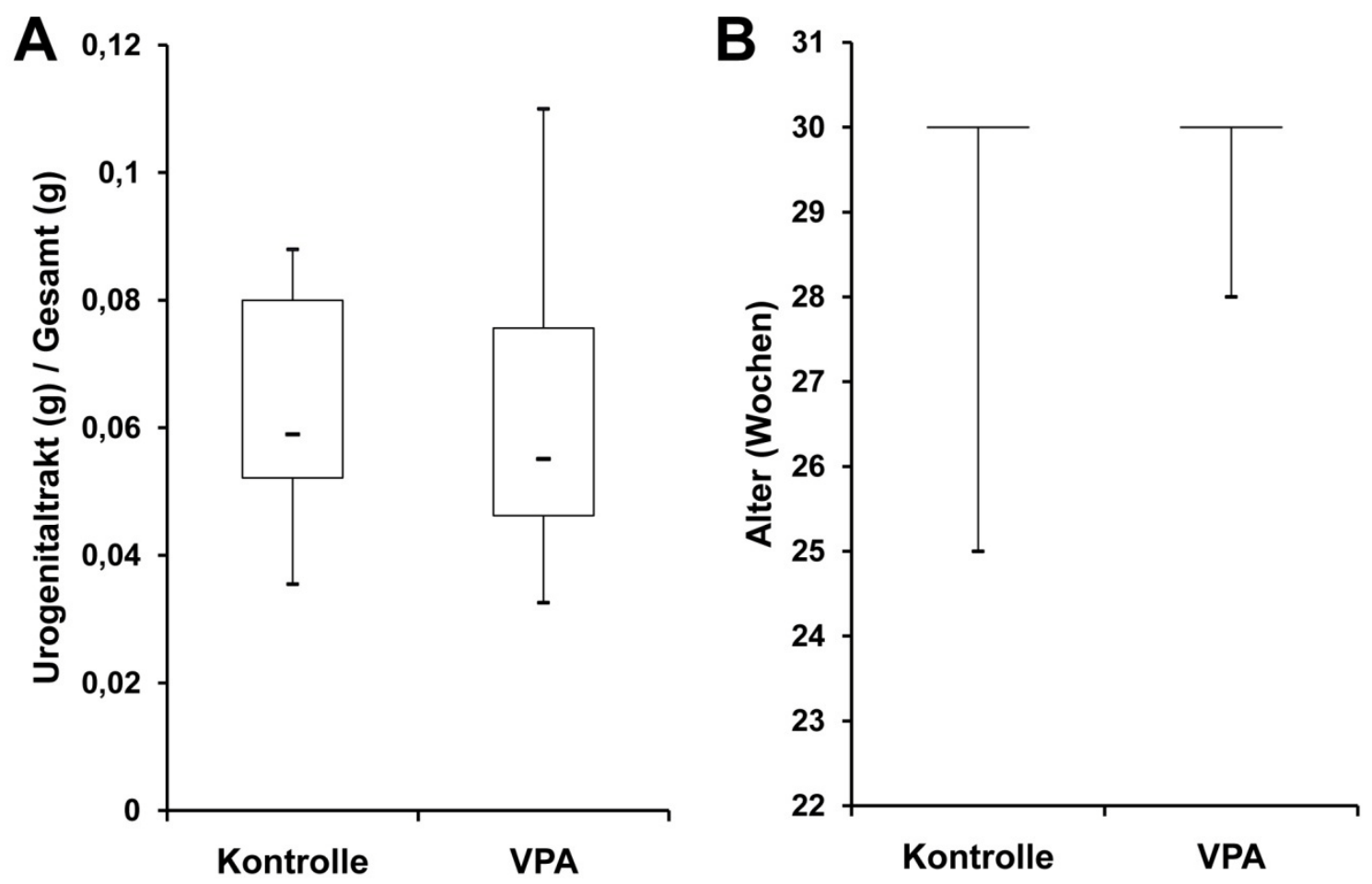

untersuchte Tiere 9

\section{9}

Tumoranteil $\quad 1 / 9(11 \%) \quad 1 / 9(11 \%)$

Abbildung 3.46: Endpunktstudie nach einem Alter von 30 Wochen nach präventiver Gabe von VPA in TRAMP-Mäusen.

Untersucht wurden neun kontrollbehandelte Mäuse und neun VPA-behandelte Mäuse. VPA wurde mit zugesetztem Süßstoff über das Trinkwasser verabreicht $(0,4 \%$ w/v). Kontrollbehandelte Mäuse erhielten lediglich Trinkwasser mit zugesetztem Süßstoff. Die Mäuse wurden ab einem Alter von sechs Wochen behandelt und es wurde eine Endpunktstudie durchgeführt, die nach einem Alter der Mäuse von 30 Wochen terminiert wurde. (A) Das durchschnittliche Verhältnis von Urogenitaltraktgewicht zu Gesamtgewicht war in beiden untersuchten Gruppen vergleichbar hoch (beide 0,06). Der Anteil von Mäusen mit einem makroskopisch erkennbaren PCa lag in beiden Gruppen bei 11\%. (B) Darstellung des Alters der Mäuse bei Versuchsende mittels Boxplot. Nicht alle untersuchten Mäuse haben das Endpunkt-Alter von 30 Wochen erreicht, in der kontrollbehandelten Gruppe war die jüngste untersuchte Maus 25 Wochen alt, in der VPA-behandelten Gruppe 28 Wochen alt.

In der dritten Versuchsgruppe wurden Mäuse therapeutisch ab einem Alter von 16 Wochen mit VPA über das Trinkwasser behandelt. Es konnten bis zu diesem Zeitpunkt lediglich vier Mäuse pro Gruppe analysiert werden (Abb. 3.47). Mit dieser geringen Anzahl von Mäusen konnte bisher in der VPA-behandelten Gruppe ein deutlich höheres Überlebensalter im Vergleich zu den kontrollbehandelten Mäusen gezeigt werden (39 Wochen vs. 28 Wochen). In der kontrollbehandelten Gruppe wiesen 50\% der Mäuse ein makroskopisch erkennbares PCa auf, in der mit VPA-behandelten Gruppe lediglich 25\%. Das mittlere Verhältnis von Urogenitaltraktgewicht zu Gesamtgewicht ist allerdings vergleichbar in beiden Gruppen (0,09 vs 0,1). Aufgrund der geringen Anzahl von untersuchten Tieren wurden noch keine weiteren Analysen zum Tumorverlauf über den Versuchszeitraum durchgeführt. 

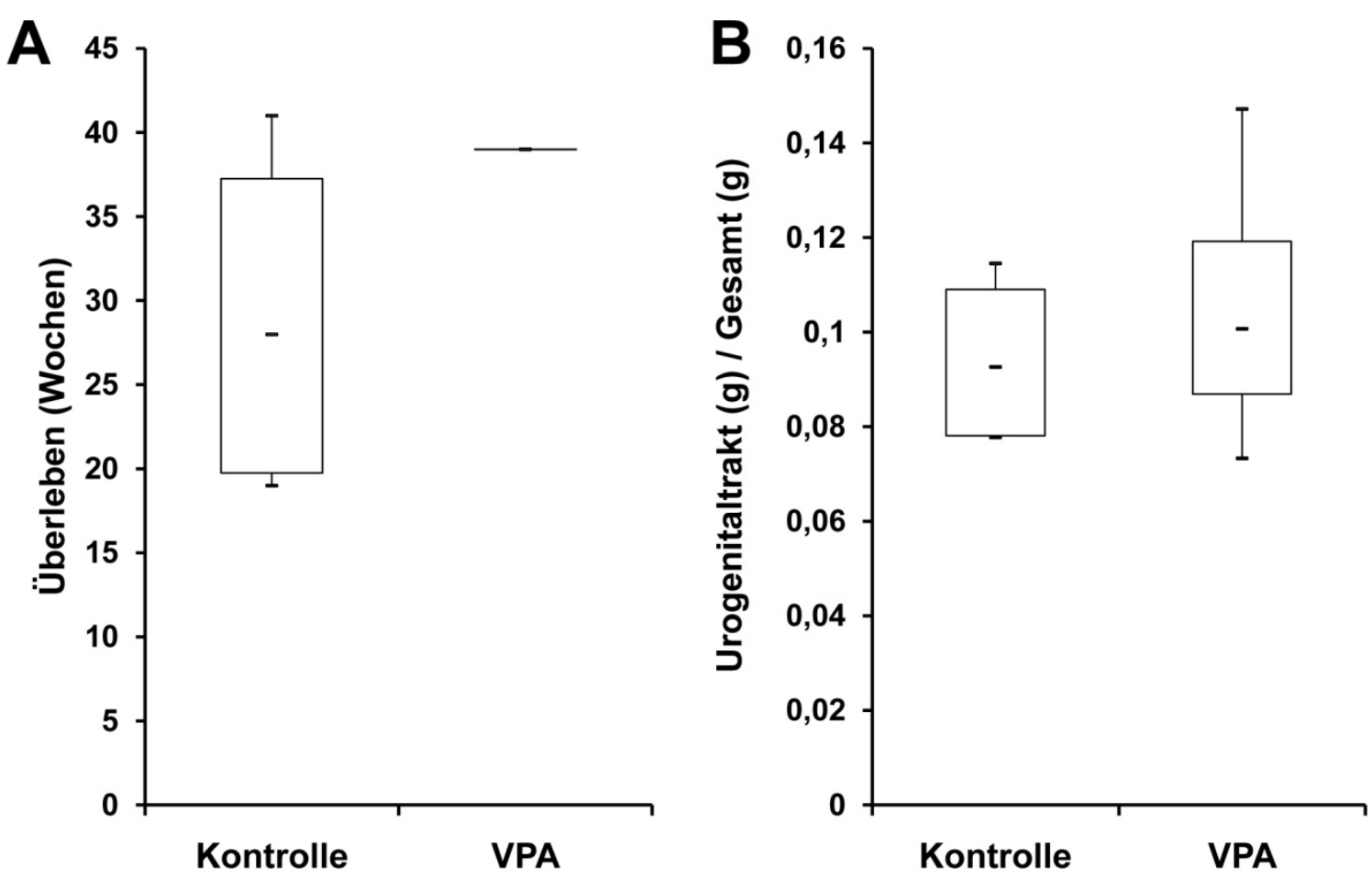

untersuchte Tiere 4 4 Tumoranteil 2/4 (50\%) $\quad 1 / 4(25 \%)$

Abbildung 3.47: Überlebensstudie nach therapeutischer Gabe von VPA in TRAMP-Mäusen.

Untersucht wurden vier kontrollbehandelte Mäuse und vier VPA-behandelte Mäuse. VPA wurde mit zugesetztem Süßstoff über das Trinkwasser verabreicht $(0,4 \%$ w/v). Kontrollbehandelte Mäuse erhielten lediglich Trinkwasser mit zugesetztem Süßstoff. Die Mäuse wurden ab einem Alter von 16 Wochen behandelt und es wurde eine Überlebensstudie durchgeführt. (A) In der kontrollbehandelten Gruppe lag das mittlere Überlebensalter bei 28 Wochen. Der Anteil von Mäusen mit einem makroskopisch erkennbaren PCa lag bei 50\%. In der VPA-behandelten Gruppe lag das mittlere Überlebensalter bei 39 Wochen und es wies lediglich eines der vier untersuchten Tiere ein makroskopisch erkennbares PCa auf (25\%). (B) Das durchschnittliche Verhältnis von Urogenitaltraktgewicht zu Gesamtgewicht war in beiden untersuchten Gruppen vergleichbar hoch (0,09 vs. 0,1$)$. 


\section{Diskussion}

\subsection{Zusammenfassung}

In dieser Arbeit sollte der Einfluss des Phytoöstrogens Tectorigenin sowie des Histondeacetylase-Inhibitors (HDI) Valproinsäure (VPA) auf das Prostatakarzinom (PCa) untersucht werden. Hierfür wurden neben etablierten humanen PCa-Zellen vorwiegend die primären TRAMP-PCa-Zellen 2E verwendet.

Das Phytoöstrogen Tectorigenin wird aus dem Gesamtextrakt aus Belamcanda chinensis isoliert. Es wurde zunächst die Wirksamkeit von zwei unterschiedlichen Gesamtextrakten aus Belamcanda chinensis (Extrakt $\mathrm{R}$ und O) in PCa-Zellen getestet. Sowohl in den humanen LNCaP-Zellen als auch in den murinen 2E-Zellen konnte eine Inhibition der Zellproliferation als auch eine Veränderung der Genexpression ausgewählter Kandidatengene detektiert werden. Zusätzlich wurde nach der Behandlung mit dem Gesamtextrakt R eine verstärkte zytoplasmatische Vesikelbildung beobachtet.

Anschließend wurde anhand der Expression von ausgewählten Kandidatengenen das Tectorigenin der Firma Shenzhen für weitere Analysen ausgewählt. Diese Analysen beinhalteten sowohl eine Microarray-Analyse als auch in vivo-Studien. In der Microarray-Analyse konnten einige differentiell exprimierte Gene nach der Behandlung der humanen LNCaP-Zellen mit Tectorigenin identifiziert werden, diese waren z.B. der IGF-IR (insulin-like growth factor I receptor), PSA (prostate specific antigen) und einige weitere Androgen-induzierte Gene. In den in vivo-Studien in TRAMP-Mäusen konnte eine langsamere Progression des PCa nach Behandlung mit Tectorigenin der Firma Girindus gezeigt werden. Ein Einfluss auf die Tumorinitiation war nicht zu detektieren. In den in vivo-Studien an subkutanen LNCaP-Tumoren im Nacktmaus-Modell konnte sowohl ein vermindertes Tumorgewicht als auch eine verminderte Tumorgröße nach der Behandlung der Mäuse mit Tectorigenin der Firma Shenzhen gezeigt werden.

Im zweiten Teil dieser Arbeit wurde die Wirkung des HDI VPA auf PCa-Zellen untersucht. Funktionell konnte eine erhöhte Acetylierung des Histons 3 an Lysin 9 sowie eine Verringerung der Zellproliferation, -migration und -invasion nach der Behandlung der primären PCa-Zellen 2E mit VPA gezeigt werden. Molekular konnten einige differentielle Genexpressionen nach der Behandlung der 2E-Zellen mit VPA detektiert werden. Es konnte z.B. eine Abnahme der Androgenrezeptor-Expression, eine Zunahme der Expression des proapoptotischen Proteins Bim sowie eine Verringerung der Expression von Foxo1 und Gsk3 $\beta$ gezeigt werden. Den Zellzyklus betreffend wurde eine erhöhte Cdkn1a- sowie $\mathrm{pRb}$-Expression und eine verringerte Cdk4-Expression nach VPA-Behandlung detektiert. Als Stellvertreter für die Angiogenese wurden Vegfa und Hif1 $\alpha$ untersucht. Es konnte hierbei 
eine verminderte Vegfa-Expression sowie eine verstärkte Hif1a-Expression nach Behandlung der primären PCa-Zellen 2E mit VPA demonstriert werden.

Des Weiteren wurden Kandidatengene aus einer Microarray-Analyse aus Witt (2009) untersucht. Es konnte für alle sieben untersuchten Kandidatengene die differentielle Genexpression nach der Behandlung der 2E-Zellen mit VPA sowohl konzentrations- als auch zeitabhängig mittels qRT-PCR bestätigt werden. Für die verstärkt exprimierten Gene konnte ein Zusammenhang mit einer erhöhten Acetylierung des Promotorbereichs der jeweiligen Gene nach VPA-Behandlung dargestellt werden.

Das Kandidatengen Cyclin D2 wurde für weiterführende Untersuchungen ausgewählt und es konnte gezeigt werden, dass es als einziges Mitglied der D-Typ-Cycline nach VPA-Behandlung verstärkt exprimiert vorlag. Die passagenabhängige, leicht erhöhte Basalexpression von Cyclin D2 in den primären PCa-Zellen 2E hatte keinen Einfluss auf die Re-Expression nach VPA-Behandlung der Zellen. Diese Re-Expression konnte auch durch die Behandlung mit anderen HDIs hervorgerufen werden. Das in vitro inaktive Amid von VPA, Valpromid, hingegen übte keinen Effekt auf die Cyclin D2-Expression in den PCa-Zellen 2E aus. Untersuchungen zum Einfluss der Methylierung des Cyclin D2-Gens auf die Re-Expression zeigten, dass eine allgemeine De-Methylierung durch den DNA-Methyltransferase-Inhibitor 5-aza-2'-deoxycytidine (5aza2) die Expression von Cyclin D2 nicht in dem Maße beeinflusste, wie eine Behandlung der 2E-Zellen mit VPA. Die anschließende methylierungsspezifische Sequenzierung einer CpG-Insel im Promotorbereich des Cyclin D2-Gens zeigte keine Änderung des Methylierungsstatus nach Behandlung der 2E-Zellen mit VPA.

Die Untersuchung der PCa-Zelllinien PC-3, DU145 und LNCaP nach VPA-Behandlung zeigte ebenfalls, wie bei den primären PCa-Zellen 2E, eine Re-Expression von Cyclin D2 sowie eine Inhibition der Proliferation. Die Analyse von nicht-malignen Zelllinien zeigte hingegen, dass die im Allgemeinen hohe Basalexpression von Cyclin D2 durch VPA nicht verändert wird und auch der Effekt auf die Zellproliferation nur moderat vorhanden war. Die VPA-Behandlung von kolorektalen Zelllinien mit VPA wies keine einheitliche Regulation der Cyclin D2-Expression sowie der Zellproliferation auf. Die Verringerung der Cyclin D2-Expression mittels siRNA in den murinen Fibroblastenzellen NIH/3T3 führte zu einem Anstieg der Zellproliferation.

Bei der immunhistochemischen Analyse von humanen PCa-Gewebeschnitten konnte keine Expression von Cyclin D2 im PCa-Gewebe nachgewiesen werden. In gesundem Prostatagewebe hingegen wurde Cyclin D2 in den proliferierenden Zellen exprimiert. Im Gegensatz dazu wurde Cyclin D1 im PCa-Gewebe stärker exprimiert als im gesunden Prostatagewebe. 
Schließlich wurden in vivo-Studien an TRAMP-Mäusen mit VPA-Gabe über das Trinkwasser durchgeführt. Es wurden drei verschiedene Versuchsgruppen untersucht. In der Überlebensstudie, welche VPA präventiv ab einem Alter von sechs Wochen erhielt, konnte ein höheres Überlebensalter, ein geringerer Tumoranteil sowie ein geringeres Tumorgewicht verzeichnet werden. Nach präventiver Gabe von VPA ab einem Alter von sechs Wochen bis zu einem Alter von 30 Wochen konnte kein Unterschied zwischen der VPA- und der Kontrollgruppe detektiert werden. In der Überlebensstudie nach therapeutischer Gabe von VPA ab einem Alter von 16 Wochen konnte ein höheres Überlebensalter und ein geringerer Tumoranteil, jedoch kein Unterschied im Tumorgewicht gezeigt werden. Da die in vivoStudien bisher noch nicht abgeschlossen sind, sind die hier genannten Daten nur als vorläufig anzusehen.

\subsection{Das Phytoöstrogen Tectorigenin}

\subsubsection{Auswahl einer geeigneten Substanz für weitere Analysen}

In dieser Arbeit wurde zunächst die Wirksamkeit von zwei Gesamtextrakten aus Belamcanda chinensis sowie von Tectorigenin insgesamt fünf verschiedener Hersteller in den primären PCa-Zellen 2E und den humanen PCa-Zellen LNCaP getestet. Es sollte das Tectorigenin eines Herstellers für weiterführende Untersuchungen ausgewählt werden. Dieses Vorgehen wurde gewählt, da es in vorherigen Arbeiten deutliche Diskrepanzen in den Effekten von Tectorigenin unterschiedlicher Hersteller gab (Witt, 2009). Sowohl der Gesamtextrakt aus Belamcanda chinensis als auch das Phytoöstrogen Tectorigenin wurden bereits durch andere Arbeitsgruppen im PCa untersucht. Die Ergebnisse wurden in insgesamt fünf Veröffentlichungen dargestellt (siehe Tabelle 4.1). Für die Untersuchungen zur Wirksamkeit der verschiedenen Substanzen in dieser Arbeit wurden aus der Literatur bekannte Effekte und Zielgene von Belamcanda chinensis bzw. Tectorigenin in LNCaP ausgewählt (vgl. Tabelle 4.1 gelbe Markierungen). 
Tabelle 4.1.: Übersicht zu ausgewählten, bereits bekannten Regulationen durch die Behandlung von PCa-Zellen mit dem Gesamtextrakt aus Belamcanda chinensis bzw. dem Phytoöstrogen Tectorigenin.

Falls nicht anders angegeben wurden die Substanzen von der Firma Bionorica bezogen. Gelb markiert sind die Faktoren bzw. Zielgene, die in dieser Arbeit untersucht wurden. TG: Tectorigenin

\begin{tabular}{|c|c|c|}
\hline & Analyse von & Effekte durch die Behandlung \\
\hline \multirow{8}{*}{ 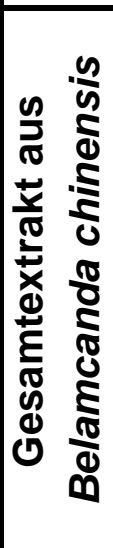 } & Proliferation & $\begin{array}{l}\text { verminderte Zellzahl in LNCaP und PC-3 (Morrissey et al., 2004); } \\
\text { Verringerung der Proliferation in LNCaP, kein Effekt in PC-3 (Thelen et al., } \\
\text { 2005; Thelen et al., 2007) }\end{array}$ \\
\hline & IGF-IR & Verringerung der Expression in LNCaP (Thelen et al., 2005) \\
\hline & AR & Verringerung der Expression in LNCaP (Thelen et al., 2007) \\
\hline & PSA & Verringerung der Expression und Sekretion in LNCaP (Thelen et al., 2007) \\
\hline & PDEF & Verringerung der Expression in LNCaP und PC-3 (Thelen et al., 2007) \\
\hline & ER $\beta$ & Verstärkte Expression in LNCaP, kein Effekt in PC-3 (Thelen et al., 2007) \\
\hline & NKX3.1 & Verringerung der Expression in LNCaP (Thelen et al., 2007) \\
\hline & in vivo & $\begin{array}{l}\text { Geringeres Tumorvolumen und langsamerer Verlauf (Thelen et al., 2005; } \\
\text { Thelen et al., 2006) }\end{array}$ \\
\hline \multirow{15}{*}{ 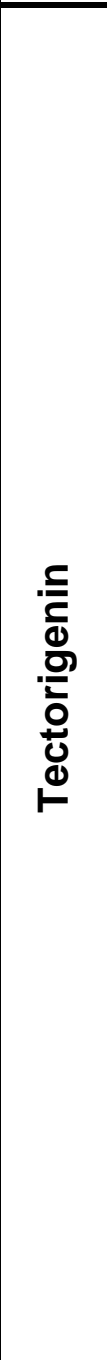 } & Proliferation & $\begin{array}{l}\text { verringerte Zellzahl in LNCaP und PC-3 (bis 100 } \mu \mathrm{M}) \text {, kein Effekt auf } \\
\left.\text { Proliferation in } \mathrm{H}^{3} \text {-Proliferationstest (bis } 50 \mu \mathrm{M}\right)(\text { Morrissey et al., 2004); } \\
\text { verringerte Proliferation in LNCaP }(100 \mu \mathrm{M}) \text {, mittels MTT-Assay } \\
\text { nachgewiesen (Thelen et al., 2005; Thelen et al., 2006; Stettner et al., 2007) }\end{array}$ \\
\hline & Zellzyklus & $\begin{array}{l}\text { Erhöhung von Zellen in der G1-Phase und Verringerung von Zellen in der } \\
\text { S-Phase (LNCaP und PC-3 mit 100 } \mathrm{MM} \text { ) (Morrissey et al., 2004) }\end{array}$ \\
\hline & p21 & $\begin{array}{l}\text { Verstärkte Expression in PC-3 }(100 \mu \mathrm{M}) \text {, kein Effekt in LNCaP (Morrissey et } \\
\text { al., 2004) }\end{array}$ \\
\hline & $\mathrm{p} 27$ & $\begin{array}{l}\text { Verstärkte Expression in LNCaP }(100 \mu M) \text {, kein Effekt in PC-3 (Morrissey et } \\
\text { al., 2004) }\end{array}$ \\
\hline & Apoptose & kein Effekt in LNCaP und PC-3 bis 100 MM (Morrissey et al., 2004) \\
\hline & IGF-IR & $\begin{array}{l}\text { Verringerung der Expression in LNCaP }(100 \mu \mathrm{M}) \text { (Thelen et al., 2005; } \\
\text { Thelen et al., 2006) }\end{array}$ \\
\hline & AR & $\begin{array}{l}\text { Verringerung der Expression in LNCaP }(100 \mu \mathrm{M})(\text { Thelen et al., 2005; } \\
\text { Thelen et al., 2006) }\end{array}$ \\
\hline & PSA & $\begin{array}{l}\text { Verringerung der Expression und Sekretion in LNCaP }(100 \mu \mathrm{M}) \text { (Thelen et } \\
\text { al., 2005; Thelen et al., 2006) }\end{array}$ \\
\hline & PDEF & $\begin{array}{l}\text { Verringerung der Expression in LNCaP }(100 \mu \mathrm{M})(\text { Thelen et al., 2005) und } \\
\text { PC-3 }(100 \mu \mathrm{M})(\text { Thelen et al., 2006; Stettner et al., 2007) }\end{array}$ \\
\hline & $\mathrm{DD}^{\mathrm{PCA} 3}$ & Verringerung der Expression in LNCaP $(100 \mu \mathrm{M})($ Thelen et al., 2005) \\
\hline & TIMP-3 & $\begin{array}{l}\text { Verstärkte Expression in LNCaP }(100 \mu \mathrm{M}) \text { (Thelen et al., 2005; Thelen et al., } \\
\text { 2006) }\end{array}$ \\
\hline & hTERT & $\begin{array}{l}\text { Verringerung der Expression und Aktivität in LNCaP }(100 \mu \mathrm{M}) \text { (Thelen et al., } \\
\text { 2005; Thelen et al., 2006) }\end{array}$ \\
\hline & NKX3.1 & kein Effekt in LNCaP (Thelen et al., 2005) \\
\hline & $\mathrm{ER \alpha}$ & Verringerung der Expression in LNCaP (TG Girindus) (Stettner et al., 2007) \\
\hline & $\mathrm{ER} \beta$ & 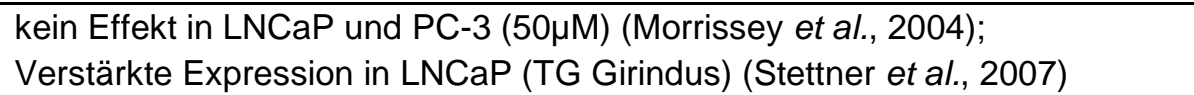 \\
\hline
\end{tabular}

Zudem wurden das IGFBP-3 sowie der Tumorsuppressor PTEN in die Analysen aufgenommen, um den IGF-IR-Signalweg umfassender zu untersuchen. Hierbei konnten einige differentielle Expressionen der Kandidatengene nach Behandlung der PCa-Zellen mit 
den beiden Gesamtextrakten bzw. Tectorigenin verschiedener Hersteller detektiert werden. Zunächst soll hier allerdings ein Überblick über die untersuchten Signalwege gegeben werden, um anschließend die Ergebnisse detaillierter zu diskutieren. In Abbildung 4.1 sind die untersuchten Signalwege dargestellt. Mit Pfeilen wurde die jeweilige Hypothese zur Genexpression nach Behandlung der PCa-Zellen mit den beiden Gesamtextrakten bzw. Tectorigenin bildlich dargestellt.

Der IGF-IR-Signalweg ist in vielen Tumorentitäten und auch dem $\mathrm{PCa}$ ein wichtiger Ansatzpunkt für Therapiemöglichkeiten (Abb. 4.1A). Im gesunden Gewebe regulieren IGF-Bindeproteine (IGFBP) das Plasmalevel des IGF-IR-Liganden IGF-I. Im Prostatakarzinom wurde eine Verringerung der IFGBP-3-Expression sowie ein erhöhtes Plasmalevel von IGF1 beschrieben (Chan et al., 2002). Zudem ist eine erhöhte Expression des IGF-IR bekannt (Cardillo et al., 2003). Der Signalweg ist folglich im PCa deutlich aktiver als im gesunden Prostatagewebe, was schließlich zu erhöhter Proliferation, dem Überleben der PCa-Zellen und verstärkter Metastasenbildung führt. Die Signalweiterleitung vom IGF-IR erfolgt entweder über den MAPK-Weg oder den PI3K-Weg. Letzterer kann durch das Tumorsuppressorprotein PTEN inhibiert werden. Allerdings liegt PTEN im PCa häufig deletiert vor und ist somit inaktiviert (Wang et al., 2003).

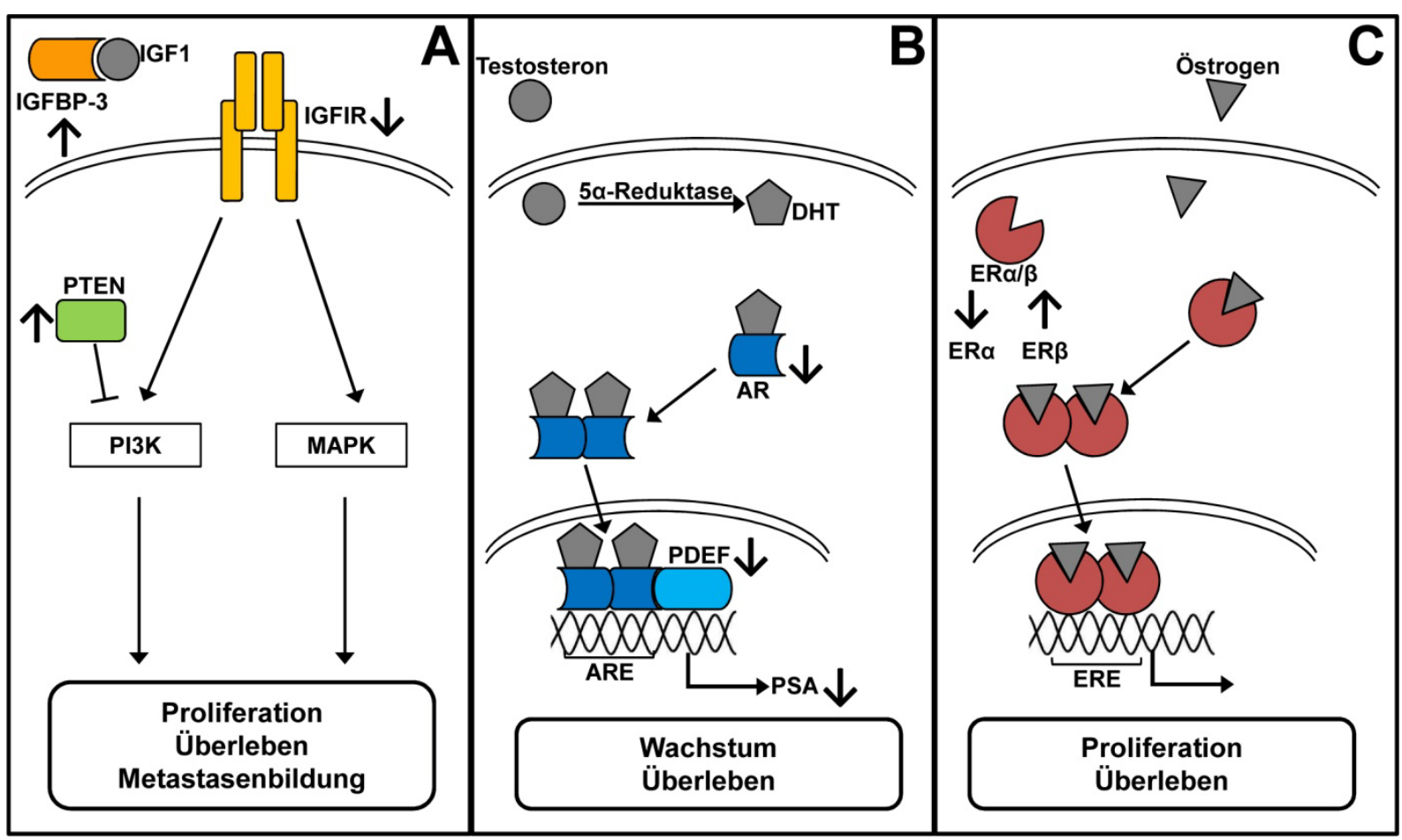

Abbildung 4.1: Übersicht über die untersuchten Signalwege. Die in dieser Arbeit analysierten Kandidatengene sind farblich markiert. Die Pfeile stellen die erwartete Genexpression nach der Behandlung von PCa-Zellen mit dem Gesamtextrakt aus Belamcanda chinensis bzw. dem daraus isolierten Tectorigenin dar. $\downarrow$ verminderte Expression; $\uparrow$ verstärkte Expression

(A) Der insulin-like growth factor I receptor (IGF-IR)-Signalweg. Extrazellulär steuern die IGF-Bindeproteine (hier dargestellt das IGFBP-3) die Verfügbarkeit des Liganden IGF-I. Der Transmembranrezeptor IGF-IR leitet die 
Signale intrazellulär entweder über den Phosphoinositid-3-Kinase (PI3K)-Weg oder den mitogen-activated protein kinase (MAPK)-Weg weiter (vgl. Sachdev und Yee, 2007). Der Tumorsuppressor PTEN (Phosphatase and Tensin homolog) kann die Signalweiterleitung über den PI3K-Signalweg inhibieren (vgl. Zhang und Yu, 2010).

(B) Der Androgenrezeptor-Signalweg (AR-Signalweg). Testosteron passiert die Zellmembran und wird intrazellulär durch die 5a-Reduktase zu Dihydrotestosteron (DHT) synthetisiert, welches an den AR bindet. Dieser Komplex bildet mit einem weiteren AR-DHT-Komplex ein Homodimer, welches in den Zellkern transloziert. Dort bindet es seinen Kofaktor, prostate derived Ets transcription factor (PDEF). Dieser Komplex bindet an die sog. androgen response elements (ARE) der DNA und initiiert die Transkription von Zielgenen, wie dem prostatespecific antigen (PSA) (vgl. Feldman und Feldman, 2001; Thelen et al., 2006).

(C) Der Östrogenrezeptor-Signalweg (ER-Signalweg). Dargestellt ist der klassische ER-Signalweg. Östrogen passiert die Zellmembran und bindet intrazellular an den ERa oder ERß. Dieser Komplex bildet ein Homodimer mit einem zweiten ER-Östrogen-Komplex. Das ER-Homodimer transloziert in den Zellkern, wo es an sog. estrogen-response elements (ERE) bindet und dadurch die Transkription von Zielgenen initiiert (vgl. Le Romancer et al., 2011; Tiano und Mauvais-Jarvis, 2012).

Zusätzlich zum IGF-IR- wurden auch Komponenten des Androgenrezeptor- und des Östrogenrezeptor-Signalwegs (AR- und ER-Signalwegs) untersucht. Der AR-Signalweg und der klassische ER-Signalweg sind in Abbildung 4.1B und $C$ dargestellt. Sie haben einen sehr ähnlichen Verlauf. Das Hormon (Testosteron bzw. Östrogen) passiert zunächst die Zellmembran. Testosteron wird durch die 5a-Reduktase zu Dihydrotestosteron (DHT) umgewandelt. Das Östrogen bleibt unmodifiziert. Schließlich binden die Hormone an ihren jeweiligen Rezeptor und es folgt eine Homodimer-Bildung mit einem weiteren HormonRezeptor-Komplex. Dieses Homodimer kann nun im Nukleus an die DNA binden. Im Falle des AR-Homodimers zusammen mit dem Kofaktor PDEF (prostate derived Ets transcription factor) am androgen response element (ARE) und im Falle des ER-Homodimers an das sog. estrogen response element (ERE). Dadurch wird die Transkription bestimmter Zielgene initiiert, z.B. PSA durch den AR (Feldman und Feldman, 2001; Thelen et al., 2006; Le Romancer et al., 2011; Tiano und Mauvais-Jarvis, 2012).

Die Rolle des AR im PCa wird kontrovers diskutiert. Festzuhalten ist jedoch, dass viele Möglichkeiten der Deregulation des AR beschrieben sind, wie z.B. Genamplifikation, verstärkte Sensitivität des Rezeptors sowie androgenunabhängige Aktivierung (zusammengefasst in Feldman und Feldman, 2001 und Knudsen und Penning, 2010). Auch die Rolle der beiden Östrogenrezeptoren $\alpha$ und $\beta$ im PCa ist nicht endgültig geklärt. Allgemein anerkannt ist, dass der Verlust der ER $\beta$-Expression mit der Tumorprogression einher geht und dass der ERa verstärkt exprimiert wird (zusammengefasst in Carruba, 2007; Chen et al., 2008).

In dieser Arbeit sollten anhand der ausgewählten Kandidatengene der drei Signalwege verschiedene Substanzen auf ihre Wirksamkeit im PCa untersucht werden. Dies wurde zunächst in den primären PCa-Zellen 2E durchgeführt. Aus den Daten der Literatur wurde vor allem eine Inhibition der IGF-IR-Expression erwartet. Die Ergebnisse der 
Untersuchungen dieser Arbeit sowie die in der Literatur beschriebenen Effekte sind in Tabelle 4.2 zusammengefasst. Die Inhibition der IGF-IR-Expression wurde durch die Behandlung der primären PCa-Zellen 2E mit beiden Gesamtextrakten aus Belamcanda chinensis erreicht. Es konnte bis auf die verstärkte Inhibition der Proliferation kein Unterschied in der Wirkung der beiden Gesamtextrakte auf die PCa-Zellen beobachtet werden. Auch das aus dem Gesamtextrakt $\mathrm{O}$ isolierte Tectorigenin der Firma Orgentis führte zu einer Abnahme der IGF-IR-Expression sowie einer Zunahme der ERß-Expression in den 2E-Zellen. Diese Aufreinigung wurde lediglich aufgrund der zu niedrigen verfügbaren Mengen aus den weiteren Untersuchungen ausgeschlossen. Das Tectorigenin der Firma PhytoLab wurde ausgeschlossen, da es weder eine Verringerung der IGF-IR-Expression noch eine Steigerung der ERß-Expression in den primären PCa-Zellen 2E bewirkte.

Tabelle 4.2: Zusammenfassung der Ergebnisse zu den zwei verschiedenen Gesamtextrakten aus Belamcanda chinensis ( $R$ und 0 ) sowie von Tectorigenin (TG) der Firma PhytoLab und Orgentis in den primären PCa-Zellen 2E.

Dargestellt ist das durchschnittliche Ergebnis aus qRT-PCR-, Western Blot- sowie ggf. ImmunfluoreszenzAnalysen. Die erste Spalte fasst die Ergebnisse aus der Literatur in humanen PCa-Zellen LNCaP zusammen (vgl. Tabelle 4.1).

\begin{tabular}{|c|l|c|c|c|c|}
\hline Literatur & Effekt / Gen & Extrakt R & Extrakt O & TG PhytoLab & TG Orgentis \\
\hline- & Proliferation & - & -- & n.a. & n.a. \\
\hline- & IGF-IR & - & - & 0 & - \\
\hline- & AR & - & - & n.a. & n.a. \\
\hline n.a. & PTEN & 0 & 0 & n.a. & n.a. \\
\hline- & ERa & - & n.a. & n.a. & n.a. \\
\hline+ & ER $\beta$ & + & n.a. & 0 & + \\
\hline
\end{tabular}

\begin{tabular}{|c|}
\hline- \\
\hline-- \\
\hline+ \\
\hline 0 \\
\hline n.a. \\
\hline
\end{tabular}

verminderte Expression

stark verminderte Expression

erhöhte Expression

keine Expressionsänderung

nicht analysiert

Für weitere Untersuchungen wurden die humanen PCa-Zellen LNCaP verwendet. Diese Zellen wurden bereits in der Literatur als PCa-Zellen für eine Behandlung mit dem Gesamtextrakt aus Belamcanda chinensis sowie dem Phytoöstrogen Tectorigenin verwendet und waren daher besonders geeignet für die Untersuchung der Wirksamkeit verschiedener Aufreinigungen aus Belamcanda chinensis. Die Ergebnisse der Analysen sind in Tabelle 4.3 zusammengefasst. Auch in den humanen PCa-Zellen LNCaP konnte kaum ein Unterschied in der Wirksamkeit der beiden untersuchten Gesamtextrakte aus Belamcanda chinensis nachgewiesen werden, beide riefen die in der Literatur beschriebenen Effekte hervor. Des Weiteren wurde das Tectorigenin der Firma Biopurify, welches bereits in Witt (2009) verwendet wurde, das Tectorigenin der Firma Girindus, welches das einzige chemisch 
hergestellte Tectorigenin ist und auch bereits in Witt (2009) verwendet wurde, sowie das Tectorigenin der Firma Shenzhen, welches direkt aus China bezogen wurde, untersucht. Die besten Ergebnisse konnten hier für das Tectorigenin der Firma Shenzhen gezeigt werden, da es sowohl eine starke Reduktion der IGF-IR-Expression als auch eine starke Inhibition der PSA-Expression in den PCa-Zellen LNCaP bewirkte. Es konnte zwar keine direkte Änderung der AR-Expression gezeigt werden, aber die starke Inhibition der PSA-Expression lässt auf eine Inhibition des AR-Signalwegs schließen. Für weitere Analysen wurde daher das Tectorigenin der Firma Shenzhen ausgewählt.

Tabelle 4.3: Zusammenfassung der Ergebnisse zu den zwei verschiedenen Gesamtextrakten aus Belamcanda chinensis ( $R$ und $O$ ) sowie von Tectorigenin (TG) der Firmen Biopurify, Girindus und Shenzhen in den humanen PCa-Zellen LNCaP.

Dargestellt ist das durchschnittliche Ergebnis aus qRT-PCR- und ggf. Western Blot-Analysen. Die erste Spalte fasst die Ergebnisse aus der Literatur in humanen PCa-Zellen LNCaP zusammen (vgl. Tabelle 4.1).

\begin{tabular}{|c|l|l|l|c|c|c|}
\hline Literatur & Effekt I Gen & $\begin{array}{l}\text { Extrakt } \\
\text { R }\end{array}$ & $\begin{array}{l}\text { Extrakt } \\
\mathbf{O}\end{array}$ & $\begin{array}{l}\text { TG } \\
\text { Biopurify }\end{array}$ & $\begin{array}{l}\text { TG } \\
\text { Girindus }\end{array}$ & $\begin{array}{l}\text { TG } \\
\text { Shenzhen }\end{array}$ \\
\hline- & Proliferation & - & -- & n.a. & n.a. & n.a. \\
\hline- & IGF-IR & -- & -- & - & - & -- \\
\hline n.a. & IGF-BP-3 & ++ & + & 0 & 0 & 0 \\
\hline- & AR & - & - & 0 & 0 & 0 \\
\hline-- & PDEF & -- & -- & n.a. & n.a. & n.a. \\
\hline-- & PSA & -- & -- & - & -- & -- \\
\hline
\end{tabular}

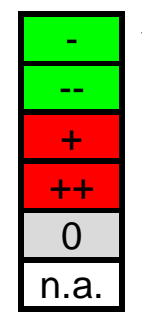

verminderte Expression

stark verminderte Expression

erhöhte Expression

stark erhöhte Expression

keine Expressionsänderung

nicht analysiert

Ein Grund für die unterschiedliche Wirksamkeit der untersuchten Substanzen konnte in dieser Arbeit nicht ermittelt werden. Es liegt allerdings die Vermutung nahe, dass es sich um unterschiedliche Reinheitsgrade in den Aufreinigungen von Tectorigenin handelt. Auch das Aufreinigungsverfahren war für die untersuchten Substanzen unterschiedlich. Eine Klärung dieser Frage kann daher nur eine chemische Analyse der Substanzen liefern.

\subsubsection{Vesikelbildung nach Behandlung mit dem Gesamtextrakt aus Belamcanda chinensis}

Bei den Analysen der Immunfluoreszenz-Färbungen an den mit dem Gesamtextrakt R aus Belamcanda chinensis behandelten primären PCa-Zellen $2 \mathrm{E}$ fiel eine verstärkte Vesikelbildung auf (vgl. Abb. 3.9). Es konnte bisher nicht geklärt werden, wodurch diese Vesikel entstehen. Es könnte sich um endozytotische Vesikel handeln. Bei der Endozytose 
unterscheidet man verschiedene Formen (Abb. 4.2). Eine Form ist die Phagozytose, bei der feste Partikel in die Zelle aufgenommen werden. Da in den Fluoreszenz-Aufnahmen keine Partikel zu erkennen waren, ist die Phagozytose auszuschließen. Es scheint lediglich Flüssigkeit aufgenommen zu werden. Diese Form der Endozytose wird Pinozytose genannt. Sie ist durch einen einfachen Test nachzuweisen: in das Medium der Zellen wird ein Farbstoff gegeben (Lucifer yellow). Wird dieser in die Vesikel aufgenommen, handelt es sich um Pinozytose (Overmeyer et al., 2008). Eine Form der Pinozytose, die Makropinozytose, wurde durch Overmeyer et al. (2008) als Apoptose-Mechanismus identifiziert. Sie nannten diesen Mechanismus demgemäß Methuosis (von griechisch methuo: Trinken bis zur Vergiftung) und konnten inn in Zusammenhang mit der Aktivierung von Ras in Glioblastom-Zellen stellen. Die Makropinozytose kann in dieser Arbeit zwar aufgrund der Größe der Vesikel ausgeschlossen werden, allerdings ist nicht auszuschließen, dass auch die beobachteten kleineren Vesikel in der hohen Anzahl zu Apoptose führen. Es könnte sich folglich um Clathrin- oder Caveolin-abhängige oder -unabhängige Endozytose handeln. Diese Möglichkeiten sollten durch Färbungen mit den entsprechenden Markern untersucht werden.

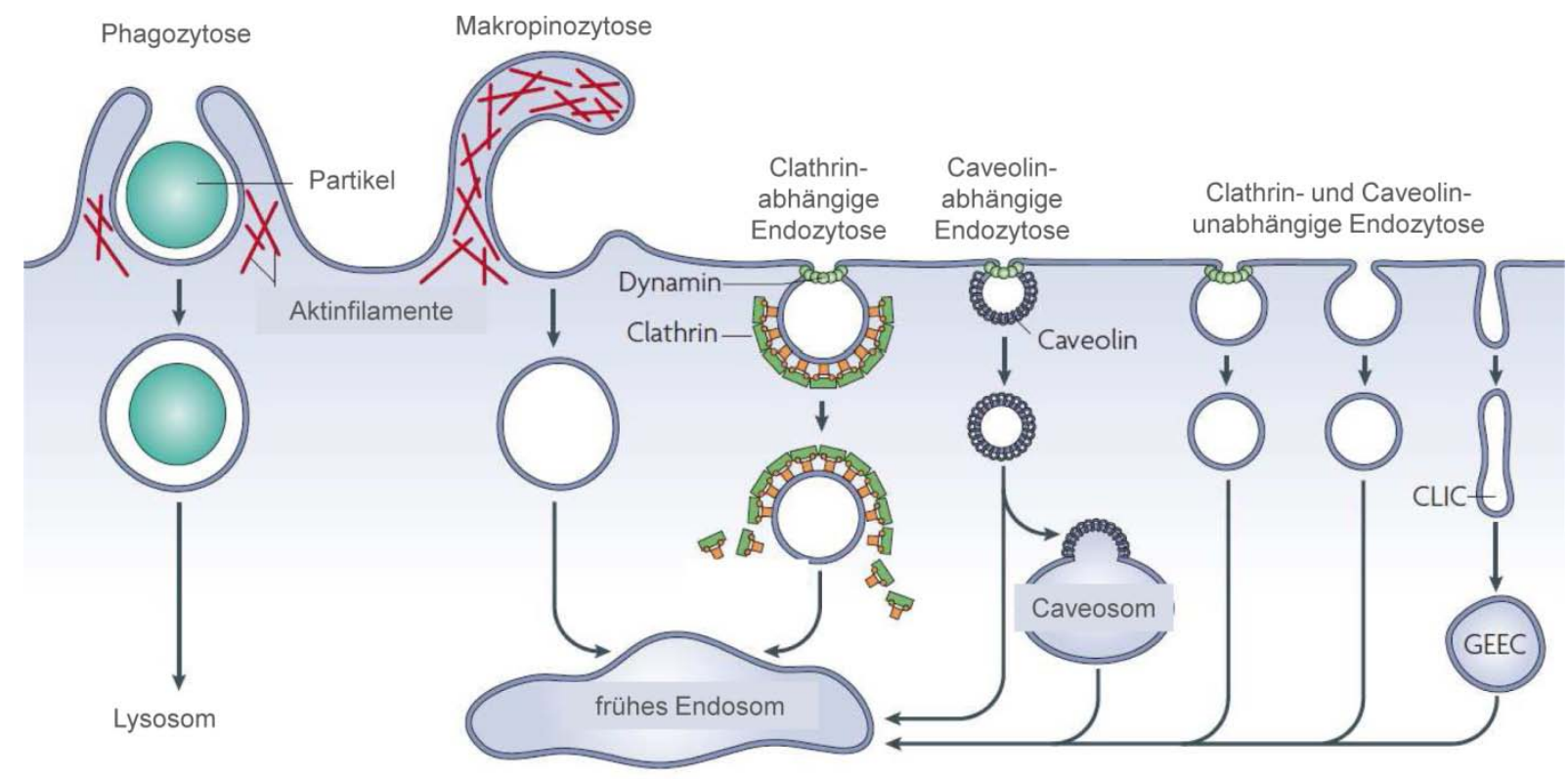

\section{Abbildung 4.2: Überblick über die Endozytose.}

Große Partikel werden über die Phagozytose in die Zelle aufgenommen. Flüssigkeitsaufnahme in die Zelle, die Pinozytose, kann über verschiedene Mechanismen erfolgen: die Makropinozytose, Clathrin- und Caveolinabhängige sowie Clathrin- und Caveolin-unabhängige Wege. Sowohl bei der Phagozytose als auch bei der Makropinozytose entstehen große Vesikel und die Bildung dieser ist Aktin-vermittelt. Bei allen anderen Formen der Endozytose entstehen nur kleine Vesikel. CLIC: clathrin- and dynamin-indipendent carriers, GEEC: glycosol phosphatidylinositol-anchored protein enriched early endosomal compartiment (modifiziert nach Mayor und Pagano, 2007). 
Auch die Möglichkeit der Autophagozytose als Grund für die Vesikelentstehung nach Behandlung der Zellen mit dem Gesamtextrakt $\mathrm{R}$ aus Belamcanda chinensis sollte berücksichtigt werden. Die Autophagozytose wird von Zellen normalerweise zur Nährstoffgewinnung durchgeführt, es werden unnötige Bestandteile der Zelle lysiert und anschließend wiederverwertet. Autophagosomen haben im Gegensatz zu Endosomen eine Doppelmembran. Als Marker für die Autophagozytose kann LC3II (microtuble-associated protein light chain 3, Form II) verwendet werden (Overmeyer et al., 2008). Es gibt eine Form der Autophagozytose, die zum Zelltod führt, die sog. autophagische Apoptose. Unterscheiden lassen sich die beiden Prozesse durch die Proteine Atg5 und Atg6, die während der normalen Autophagozytose gering exprimiert werden und in der autophagischen Apoptose verstärkt exprimiert werden (zusammengefasst in Tsujimoto und Shimizu, 2005). Zusammenfassend lässt sich schlussfolgern, dass die Vesikelbildung in den mit dem Gesamtextrakt aus Belamcanda chinensis behandelten Zellen funktionell im Zusammenhang mit Apoptose stehen kann. Der genaue Mechanismus sollte durch entsprechende Färbungen identifiziert werden. Die Induktion der Apoptose konnte bisher in PCa-Zellen nur für das Phytoöstrogen Tectorigenin durch eine Arbeitsgruppe ausgeschlossen werden (Morrissey et al., 2004). Für eine Behandlung von PCa-Zellen mit dem Gesamtextrakt aus Belamcanda chinensis liegen keine Untersuchungen vor.

\subsubsection{Tectorigenin als potentielles Mittel in der Prävention und Therapie des Prostatakarzinoms}

Tectorigenin wurde bereits erfolgreich bei in vitro-Studien zum PCa verwendet (vgl. Tabelle 4.1). In den in vitro-Analysen aus der Literatur wurde eine begrenzte Anzahl von allgemein anerkannten Kandidatengenen für das PCa untersucht. Anhand dieser Daten von bekannten Effekten einer Tectorigenin-Behandlung von PCa-Zellen auf die Expression bestimmter Kandidatengene wurde in der vorliegenden Arbeit das Tectorigenin der Firma Shenzhen für weitere Analysen an den humanen PCa-Zellen LNCaP ausgewählt. Das Wirkungsspektrum von Tectorigenin im PCa konnte durch diese Analysen nicht vollständig erfasst werden. Als Phytoöstrogen wäre eine primäre Wirkung über die Östrogenrezeptoren zu vermuten. Um diese Fragestellung zu beantworten, wurde in dieser Arbeit eine Microarray-Analyse an mit dem zuvor getesteten Tectorigenin der Firma Shenzhen behandelten LNCaP-Zellen durchgeführt. Es wurden hier nicht die primären PCa-Zellen 2E verwendet, da die Daten aus der Literatur an den humanen LNCaP-Zellen erhoben wurden und eine in Witt (2009) durchgeführte Microarray-Analyse mit Tectorigenin-behandelten 2E-Zellen wenig informativ war. In der Analyse der vorliegenden Arbeit konnten einige differentiell exprimierte Gene identifiziert werden. Zum Beispiel wurde der IGF-IR und KLK3 (PSA) nach der Behandlung der LNCaP-Zellen mit Tectorigenin vermindert exprimiert. 
Interessanterweise konnte aber weder eine signifikante differentielle Expression des $A R$, des $E R \alpha$ und ER $\beta$ sowie von PDEF, PTEN und dem IGF-BP-3 detektiert werden. Die identifizierten differentiell exprimierten Kandidatengene nach Behandlung der LNCaP-Zellen mit Tectorigenin sind in Tabelle 4.4 mit der Beschreibung des jeweiligen bekannten Zusammenhangs mit humaner (Prostata-)Karzinomentwicklung dargestellt.

Tabelle 4.4: Übersicht der Kandidatengene, die in der Microarray-Analyse nach Behandlung der humanen PCa-Zellen LNCaP mit 50 MM Tectorigenin (Firma Shenzhen für 24h) differentiell exprimiert wurden.

Dargestellt sind die Top10 vermindert exprimierten Gene und die Top24 verstärkt exprimierten Gene. Die Zahl der dargestellten verstärkt exprimierten Gene wurde erhöht, da in dieser Gruppe 16 olfaktorische Rezeptoren identifiziert wurden, für die kein Zusammenhang mit Karzinomentstehung bekannt ist. Rote Zahlen zeigen eine Abnahme, grüne Zahlen eine Zunahme der Genexpression an. FC, fold change.

\begin{tabular}{|c|c|c|c|}
\hline Gensymbol & Genname & $\begin{array}{l}\text { logFC } \\
\text { TG vs. } \\
\text { DMSO }\end{array}$ & $\begin{array}{l}\text { Zusammenhang mit humaner (Prostata-) } \\
\text { Karzinomentwicklung }\end{array}$ \\
\hline PMEPA1 & $\begin{array}{l}\text { prostate transmembrane } \\
\text { protein, androgen induced } \\
1\end{array}$ & $-1,57$ & $\begin{array}{l}\text { verstärkte Expression im PCa, } \\
\text { Herunterregulierung inhibiert Proliferation über } \\
\text { p21, Überexpression verstärkt die Proliferation } \\
\text { in PC-3 (Liu et al., 2011) }\end{array}$ \\
\hline TRPM8 & $\begin{array}{l}\text { transient receptor } \\
\text { potential cation channel, } \\
\text { subfamily M, member } 8\end{array}$ & $-1,52$ & $\begin{array}{l}\text { überexprimiert im PCa (Tsavaler et al., 2001), } \\
\text { Überexpression im PC-3-Xenograft führt zur } \\
\text { Progression der Proliferation und Angiogenese } \\
\text { (Zhu et al., 2011) }\end{array}$ \\
\hline KLK2 & $\begin{array}{l}\text { kallikrein-related } \\
\text { peptidase } 2\end{array}$ & $-1,50$ & $\begin{array}{l}\text { erhöhte Werte bei Patienten mit PCa (Nam et } \\
\text { al., 2000), verschiedene genetische Varianten } \\
\text { sind mit erhöhtem Risiko für das PCa assoziiert } \\
\text { (Nam et al., 2006) }\end{array}$ \\
\hline KLK3 (PSA) & $\begin{array}{l}\text { kallikrein-related } \\
\text { peptidase } 3\end{array}$ & $-1,39$ & $\begin{array}{l}\text { erhöhte Level von PSA wurden bei Patienten } \\
\text { mit PCa gezeigt, die Rolle als Marker für das } \\
\text { PCa wurde allerdings in Frage gestellt (Stamey } \\
\text { et al., 1987), das PSA-screening wird heute } \\
\text { noch durchgeführt, aber auch angezweifelt } \\
\text { (Heijnsdijk et al., 2012) }\end{array}$ \\
\hline TMEFF2 & $\begin{array}{l}\text { transmembrane protein } \\
\text { with EGF-like and two } \\
\text { follistatin-like domains } 2\end{array}$ & $-1,21$ & $\begin{array}{l}\text { Androgen-reguliertes Gen, kann die } \\
\text { Proliferation von PCa-Zellen inhibieren (Gery et } \\
\text { al., 2002), stärker in Androgen-abhängigen als } \\
\text { in Androgen-unabhängigen Zellen exprimiert } \\
\text { (Chen et al., 2006b) }\end{array}$ \\
\hline INPP4B & $\begin{array}{l}\text { inositol polyphosphate-4- } \\
\text { phosphatase, type II, } \\
\text { 105kDa }\end{array}$ & $-1,17$ & $\begin{array}{l}\text { Tumorsuppressorgen, AR-aktiviert, Verminderte } \\
\text { Expression führt zu verstärkter Proliferation von } \\
\text { PCa-Zellen, schwache Expression in primären } \\
\text { PCa-Tumoren (Hodgson et al., 2011) }\end{array}$ \\
\hline GREB1 & $\begin{array}{l}\text { growth regulation by } \\
\text { estrogen in breast cancer } \\
1\end{array}$ & $-1,16$ & $\begin{array}{l}\text { Androgen-abhängige Expression, bei } \\
\text { verringerter Expression Wachstumshemmung } \\
\text { von PCa-Zellen, Expression in PCa-Patienten } \\
\text { (Rae et al., 2006), potentieller Marker für das } \\
\text { PCa (Antunes et al., 2012) }\end{array}$ \\
\hline HGD & $\begin{array}{l}\text { homogentisate 1,2- } \\
\text { dioxygenase }\end{array}$ & $-1,15$ & kein Zusammenhang bekannt \\
\hline
\end{tabular}




\begin{tabular}{|c|c|c|c|}
\hline $\mathrm{ABCC} 4$ & $\begin{array}{l}\text { ATP-binding cassette, } \\
\text { sub-family C } \\
\text { (CFTR/MRP), member } 4\end{array}$ & $-1,13$ & $\begin{array}{l}\text { verstärkt exprimiert in PCa, androgenabhängige } \\
\text { Regulation, vermindert exprimiert nach } \\
\text { Androgenentzug (Ho et al., 2008) }\end{array}$ \\
\hline RBM24 & $\begin{array}{l}\text { RNA binding motif protein } \\
24\end{array}$ & $-1,10$ & kein Zusammenhang bekannt \\
\hline OR10K1 & $\begin{array}{l}\text { olfactory receptor, family } \\
10, \text { subfamily } \mathrm{K}, \text { member } \\
1\end{array}$ & 0,60 & \multirow{4}{*}{$\begin{array}{l}\text { Kein Zusammenhang bekannt } \\
\text { andere olfaktorische Rezeptoren: } \\
\text { OR51E2 inhibiert die Proliferation von } \\
\text { PCa-Zellen (Neuhaus et al., 2009) } \\
\text { PSGR2 ist im PCa verstärkt exprimiert (Weng et } \\
\text { al., 2006) } \\
\text { PSGR wird als neuer Marker für das PCa } \\
\text { vorgeschlagen (Rigau et al., 2010) }\end{array}$} \\
\hline OR7E24 & $\begin{array}{l}\text { olfactory receptor, family } \\
7 \text {, subfamily E, member } \\
24\end{array}$ & 0,60 & \\
\hline OR9Q2 & $\begin{array}{l}\text { olfactory receptor, family } \\
9, \text { subfamily Q, member } 2\end{array}$ & 0,60 & \\
\hline OR51B4 & $\begin{array}{l}\text { olfactory receptor, family } \\
51 \text {, subfamily } B \text {, member } \\
4\end{array}$ & 0,61 & \\
\hline KRTAP4-11 & $\begin{array}{l}\text { keratin associated protein } \\
4-11\end{array}$ & 0,61 & Kein Zusammenhang bekannt \\
\hline SNORD80 & $\begin{array}{l}\text { small nucleolar RNA, C/D } \\
\text { box } 80\end{array}$ & 0,63 & Kein Zusammenhang bekannt \\
\hline REX01L1 & $\begin{array}{l}\text { REX1, RNA exonuclease } \\
1 \text { homolog (S. cerevisiae)- } \\
\text { like } 1\end{array}$ & 0,63 & Kein Zusammenhang bekannt \\
\hline OR4M1 & $\begin{array}{l}\text { olfactory receptor, family } \\
4 \text {, subfamily } \mathrm{M}, \text { member } 1\end{array}$ & 0,63 & \multirow{6}{*}{$\begin{array}{l}\text { Kein Zusammenhang bekannt } \\
\text { andere olfaktorische Rezeptoren siehe oben }\end{array}$} \\
\hline OR6C3 & $\begin{array}{l}\text { olfactory receptor, family } \\
6, \text { subfamily C, member } 3\end{array}$ & 0,63 & \\
\hline OR7E5P & $\begin{array}{l}\text { olfactory receptor, family } \\
7, \text { subfamily E, member } 5 \\
\text { pseudogene }\end{array}$ & 0,65 & \\
\hline OR4C13 & $\begin{array}{l}\text { olfactory receptor, family } \\
4 \text {, subfamily } C \text {, member } \\
13\end{array}$ & 0,65 & \\
\hline OR1F2P & $\begin{array}{l}\text { olfactory receptor, family } \\
1 \text {, subfamily } F, \text { member } 2\end{array}$ & 0,65 & \\
\hline OR4Q3 & $\begin{array}{l}\text { olfactory receptor, family } \\
4, \text { subfamily } Q, \text { member } 3\end{array}$ & 0,67 & \\
\hline SPTLC3 & $\begin{array}{l}\text { serine } \\
\text { palmitoyltransferase, long } \\
\text { chain base subunit } 3\end{array}$ & 0,70 & Kein Zusammenhang bekannt \\
\hline NHEDC1 & $\begin{array}{l}\mathrm{Na}+/ \mathrm{H}+\text { exchanger } \\
\text { domain containing } 1\end{array}$ & 0,72 & Kein Zusammenhang bekannt \\
\hline OR51A4 & $\begin{array}{l}\text { olfactory receptor, family } \\
51 \text {, subfamily } A \text {, member } \\
4\end{array}$ & 0,75 & \multirow{4}{*}{$\begin{array}{l}\text { Kein Zusammenhang bekannt } \\
\text { andere olfaktorische Rezeptoren siehe oben }\end{array}$} \\
\hline OR1C1 & $\begin{array}{l}\text { olfactory receptor, family } \\
1 \text {, subfamily } C \text {, member } 1\end{array}$ & 0,76 & \\
\hline OR1D2 & $\begin{array}{l}\text { olfactory receptor, family } \\
1 \text {, subfamily } \mathrm{D}, \text { member } 2\end{array}$ & 0,78 & \\
\hline OR2J3 & $\begin{array}{l}\text { olfactory receptor, family } \\
2 \text {, subfamily } \mathrm{J} \text {, member } 3\end{array}$ & 0,87 & \\
\hline
\end{tabular}




\begin{tabular}{|l|l|l|l|}
\hline OR4K2 & $\begin{array}{l}\text { olfactory receptor, family } \\
\text { 4, subfamily K, member 2 }\end{array}$ & 0,93 & \multirow{2}{*}{} \\
\cline { 1 - 2 } OR2L8 & $\begin{array}{l}\text { olfactory receptor, family } \\
\text { 2, subfamily L, member 8 }\end{array}$ & 1,03 & \\
\hline FOS & $\begin{array}{l}\text { FBJ murine osteosarcoma } \\
\text { viral oncogene homolog }\end{array}$ & 1,08 & überexprimiert im PCa (Merz et al., 1994) \\
\hline EGR1 & early growth response 1 & 1,08 & $\begin{array}{l}\text { EGR1 vermittelt Apoptose, allerdings ist es } \\
\text { auch für die Progression der Proliferation } \\
\text { zuständig und EGR1 wird eine Rolle bei der } \\
\text { PCa-Progression zugeschrieben (Gitenay und } \\
\text { Baron, 2009) }\end{array}$ \\
\hline SPDYE7P & $\begin{array}{l}\text { Speedy homolog E7 } \\
\text { (Xenopus laevis), } \\
\text { pseudogene }\end{array}$ & 1,14 & Kein Zusammenhang bekannt \\
\hline
\end{tabular}

Die Kandidatengene, bei denen nach der Behandlung von LNCaP-Zellen mit Tectorigenin eine verstärkte Expression detektiert wurde, weisen größtenteils keinen bekannten Zusammenhang mit Tumorinitiation und -progression auf. Lediglich das FOS-Proto-Onkogen sowie der EGR1 sind beschrieben. Das FOS-Proto-Onkogen wurde überexprimiert im PCa nachgewiesen (Merz et al., 1994). EGR1 wird zum einen eine Rolle bei der PCa-Progression und der verstärkten Proliferation zugeschrieben, zum anderen vermittelt EGR1 allerdings auch Apoptose (Gitenay und Baron, 2009). Die detektierte verstärkte Expression könnte Folge eines Rettungsmechanismus der Tumorzellen sein. Da Tectorigenin die PCa-Zellproliferation hemmt (Thelen et al., 2005; Thelen et al., 2006; Stettner et al., 2007), werden positive Regulatoren der Proliferation verstärkt exprimiert, um die Zellproliferation wieder zu erhöhen. EGR1 könnte allerdings auch in Folge einer Induktion von Apoptose verstärkt exprimiert vorliegen. Es konnte zwar bislang keine Induktion von Apoptose nach der Behandlung mit Tectorigenin festgestellt werden (Morrissey et al., 2004), allerdings könnte dies auch experimentelle Gründe haben.

Einen interessanten Kandidaten stellt das GREB1-Gen dar, da dieses Gen auch in einer Studie nach Behandlung von Nrf2-Mäusen mit einem Gemisch aus verschiedenen Soja-Isoflavonen (unter anderem Genistein und Daidzein) im gesunden Prostatagewebe der Mäuse vermindert exprimiert vorlag (Barve et al., 2008). Der Effekt auf die GREB1-Expression in der Prostata scheint folglich ein allgemein durch die Behandlung mit Isoflavonen hervorgerufener Effekt zu sein.

INPP4B ist das einzige Kandidatengen, welches vermindert exprimiert detektiert wurde und nicht die chemotherapeutische Wirkung von Tectorigenin im PCa unterstreicht. INPP4B ist ein Tumorsuppressorgen, welches bei verminderter Expression zu verstärkter Proliferation von PCa-Zellen führt (Hodgson et al., 2011). Es stellt allerdings auch ein Androgen-aktiviertes Gen dar, was der Grund für die verminderte Expression nach der Behandlung der PCa-Zellen mit Tectorigenin sein könnte. 
Die Expression der Kandidatengene, die in der Microarray-Analyse verstärkt exprimiert detektiert wurden, ist überwiegend Androgen-abhängig. Der AR selbst ist allerdings nicht unter den Kandidatengenen, dafür aber das AR-Zielgen KLK3 (PSA), dessen Expression durch den AR gesteuert wird (vgl. Abb. 4.1B). Es ist folglich davon auszugehen, dass die Aktivität des AR nach der Behandlung der PCa-Zellen LNCaP mit dem Phytoöstrogen Tectorigenin vermindert vorliegt. Die zugrunde liegenden molekularen Mechanismen sind allerdings unbekannt und müssen daher aufgeklärt werden.

Die hohe Anzahl von Androgen-abhängigen differentiell exprimierten Genen lässt auf die mögliche Funktion von Tectorigenin als Anti-Androgen schließen. Zur detaillierteren Untersuchung dieser Frage wurden die Kandidatengene der in dieser Arbeit durchgeführten Microarray-Analyse mit einer Studie zu Androgen-induzierten Genen verglichen (Waltering et al., 2009). In der Studie von Waltering et al. wurden ebenfalls LNCaP-Zellen verwendet. Diese wurden mit verschiedenen Konzentrationen von Dihydrotestosteron (DHT) für vier bzw. 24 Stunden behandelt. In der anschließenden Microarray-Analyse konnten zahlreiche Androgen-induzierte Gene identifiziert werden (Waltering et al., 2009). Der Vergleich der in Waltering et al. identifizierten verstärkt exprimierten Gene (sowohl nach vier als auch nach 24 Stunden DHT-Behandlung der LNCaP-Zellen) zeigte eine hoch signifikante inverse Korrelation mit den vermindert exprimierten Kandidatengenen aus dieser Arbeit (für 24 Stunden mit Tectorigenin behandelte LNCaP-Zellen). Der p-Wert lag bei dem Vergleich beider Zeitpunkte jeweils bei $p<10^{-10}$. Die übereinstimmenden Kandidatengene aus beiden Untersuchungen sind in Tabelle 4.5 aufgeführt. Der Vergleich der bei Waltering et al. vermindert exprimierten Gene mit den verstärkt exprimierten Genen aus dieser Arbeit hingegen wies keine signifikante Korrelation auf. 
Tabelle 4.5: Inverse Korrelation der durch die Behandlung mit Tectorigenin vermindert exprimierten Gene im Vergleich mit Androgen-induzierten Genen aus der Literatur (Waltering et al., 2009).

Es wurden die vermindert exprimierten Kandidatengene nach der Tectorigenin-Behandlung der LNCaP-Zellen aus der Microarray-Analyse dieser Arbeit mit den verstärkt exprimierten Kandidatengenen einer Studie verglichen, in der LNCaP-Zellen mit verschiedenen Konzentrationen von Dihydrotestosteron (DHT) für vier und 24 Stunden behandelt wurden. Die dargestellte inverse Korrelation der beiden Gensets ist hoch signifikant $\left(p<10^{-10}\right)$. FC, fold change.

\begin{tabular}{|c|c|c|c|c|c|}
\hline $\begin{array}{l}\text { Gen- } \\
\text { symbol }\end{array}$ & Genname & $\begin{array}{l}\text { logFC } \\
\text { TG vS. } \\
\text { DMSO }\end{array}$ & $\begin{array}{l}\text { 10nM } \\
\text { DHT }\end{array}$ & $\begin{array}{l}\text { 100nM } \\
\text { DHT }\end{array}$ & $\begin{array}{l}\text { DHT- } \\
\text { Behandlung } \\
\text { (Std.) }\end{array}$ \\
\hline \multirow{2}{*}{ KLK2 } & \multirow{2}{*}{ kallikrein-related peptidase 2} & \multirow{2}{*}{$-1,50$} & 2,592 & 3,080 & 4 \\
\hline & & & 1,209 & 2,204 & 24 \\
\hline \multirow[b]{2}{*}{ KLK3 } & \multirow[b]{2}{*}{ kallikrein-related peptidase 3} & \multirow[b]{2}{*}{$-1,39$} & 2,071 & 2,973 & 4 \\
\hline & & & $\begin{array}{l}2,553 \\
1,985\end{array}$ & $\begin{array}{l}4,188 \\
2,634\end{array}$ & 24 \\
\hline \multirow{2}{*}{$\begin{array}{l}\text { PMEPA1 } \\
\text { (TMEPAI) }\end{array}$} & \multirow{2}{*}{$\begin{array}{l}\text { prostate transmembrane protein, } \\
\text { androgen induced } 1\end{array}$} & \multirow{2}{*}{$-1,57$} & $\begin{array}{l}2,197 \\
3,526 \\
\end{array}$ & $\begin{array}{l}2,631 \\
3,973 \\
\end{array}$ & 4 \\
\hline & & & $\begin{array}{l}1,600 \\
1,929 \\
\end{array}$ & $\begin{array}{l}2,728 \\
3,989 \\
\end{array}$ & 24 \\
\hline TMEFF2 & $\begin{array}{l}\text { transmembrane protein with } \\
\text { EGF-like and two follistatin-like } \\
\text { domains } 2\end{array}$ & $-1,21$ & 2,000 & 2,638 & 24 \\
\hline \multirow{2}{*}{ KCNN2 } & \multirow{2}{*}{$\begin{array}{l}\text { potassium intermediate/small } \\
\text { conductance calcium-activated } \\
\text { channel, subfamily N, member } 2\end{array}$} & \multirow{2}{*}{$-1,10$} & $\begin{array}{l}2,324 \\
2,032 \\
\end{array}$ & $\begin{array}{l}2,586 \\
2,393 \\
\end{array}$ & 4 \\
\hline & & & 2,192 & 3,590 & 24 \\
\hline DTL & denticleless homolog (Drosophila) & $-0,85$ & 1,963 & 2,611 & 24 \\
\hline FKBP5 & FK506 binding protein 5 & $-0,86$ & 1,803 & 2,229 & 4 \\
\hline \multirow{2}{*}{ TMPRSS2 } & \multirow{2}{*}{ transmembrane protease, serine 2} & \multirow{2}{*}{$-1,00$} & 4,844 & 6,090 & 4 \\
\hline & & & 1,358 & 2,847 & 24 \\
\hline UHRF1 & $\begin{array}{l}\text { ubiquitin-like with PHD and ring } \\
\text { finger domains } 1\end{array}$ & $-1,08$ & 2,633 & 3,623 & 24 \\
\hline CENPN & centromere protein $\mathrm{N}$ & $-0,73$ & 2,045 & 3,903 & 24 \\
\hline \multirow{2}{*}{ ZBTB16 } & \multirow{2}{*}{$\begin{array}{l}\text { zinc finger and BTB domain } \\
\text { containing } 16\end{array}$} & \multirow{2}{*}{$-0,79$} & 6,005 & 6,737 & 4 \\
\hline & & & 1,374 & 2,000 & 24 \\
\hline \multirow{2}{*}{ C19orf48 } & \multirow{2}{*}{$\begin{array}{l}\text { chromosome } 19 \text { open reading } \\
\text { frame } 48\end{array}$} & \multirow[t]{2}{*}{$-0,91$} & $\begin{array}{l}1,876 \\
2,217 \\
\end{array}$ & $\begin{array}{l}2,065 \\
2,325 \\
\end{array}$ & 4 \\
\hline & & & 1,237 & 2,108 & 24 \\
\hline ATAD2 & $\begin{array}{l}\text { ATPase family, AAA domain } \\
\text { containing } 2\end{array}$ & $-0,61$ & 3,009 & 3,023 & 24 \\
\hline AADAT & aminoadipate aminotransferase & $-0,61$ & 2,319 & 2,856 & 24 \\
\hline CDCA7 & cell division cycle associated 7 & $-0,69$ & 1,917 & 2,658 & 24 \\
\hline CDCA5 & cell division cycle associated 5 & $-0,74$ & 2,936 & 3,326 & 24 \\
\hline MCM4 & $\begin{array}{l}\text { minichromosome maintenance } \\
\text { complex component } 4\end{array}$ & $-0,73$ & 2,362 & 2,930 & 24 \\
\hline MCM5 & $\begin{array}{l}\text { minichromosome maintenance } \\
\text { complex component } 5\end{array}$ & $-0,83$ & 1,659 & 2,037 & 24 \\
\hline CDC25A & $\begin{array}{l}\text { cell division cycle } 45 \text { homolog } \\
\text { (S. cerevisiae) }\end{array}$ & $-0,79$ & 1,714 & 2,137 & 24 \\
\hline MCM7 & $\begin{array}{l}\text { minichromosome maintenance } \\
\text { complex component } 7\end{array}$ & $-0,70$ & 1,704 & 2,154 & 24 \\
\hline
\end{tabular}


In einer weiteren Studie wurde mit Anti-Androgenen behandeltes PCa-Patientenmaterial mittels Microarray-Analyse untersucht (Lehmusvaara et al., 2012). Es wurde in dieser Studie ebenfalls eine Verminderung der PSA-, PMEPA1-, TMEFF2-, KCNN2-, FKBP5-, TMPRSS2und C19orf48-Expression nach Behandlung der Patienten mit dem Anti-Androgen Bicalutamid beschrieben. Diese Regulationen stimmen mit denen in dieser Arbeit gezeigten Genexpressionen überein und unterstützen somit die Theorie, dass Tectorigenin im PCa als Anti-Androgen wirkt.

Die Microarray-Daten der mit Tectorigenin behandelten LNCaP-Zellen wurden weiterhin anhand der sog. Gene Ontology Informationen auf verstärkt repräsentierte biologische Funktionen, zelluläre Komponenten sowie molekulare Funktionen untersucht. Für die identifizierten verstärkt exprimierten Gene wurden einige interessante Gruppen identifiziert (siehe Anhang, Tabelle 7.1). Vor allem bei den biologischen Prozessen konnte eine verstärkte Aktivierung diverser Toll-like Rezeptor-Signalwege (TLR-Signalwege) detektiert werden. Dies deutet darauf hin, dass die Behandlung der PCa-Zellen LNCaP mit Tectorigenin das angeborene Immunsystem aktiviert, was zu der traditionellen Verwendung von Tectorigenin bei entzündlichen Erkrankungen passt. Der Aktivierung von TLR werden auch chemotherapeutische Wirkungen bei der Therapie von Karzinomen zugesprochen, so werden z.B. TLR-aktivierende Medikamente bei der Behandlung von Cervix-, Magen- sowie Plattenepithelkarzinomen der Mundhöhle verwendet. Allerdings wurde auch gezeigt, dass die Behandlung von Mammakarzinomzellen mit dem Liganden der TLR zu verstärkter Angiogenese, Migration und Invasion und die Stimulation der TLR im Kolonkarzinom zu verstärkter Proliferation und verminderter Apoptose führte (zusammengefasst in RakoffNahoum und Medzhitov, 2009). Patienten mit einem Polymorphismus des TLR 4 wurde eine erhöhte Suszeptibilität für ein $\mathrm{PCa}$ zugeschrieben. Dies konnte allerdings noch nicht hinreichend bestätigt werden (Kutikhin und Yuzhalin, 2012). Im Hinblick auf differentielle Expression von TLR im PCa liegt lediglich eine Studie vor, in der in PCa-Patientengewebe von Patienten mit einem biochemischem Rezidiv (PSA-Level höher als 0,2ng/ml nach radikaler Prostatektomie mit anschließend steigendem PSA-Level) eine erhöhte Expression des TLR3, TLR4 und TLR9 beobachtet wurde (González-Reyes et al., 2011). Es ist demnach noch nicht eindeutig geklärt, welchen Effekt eine verstärkte Aktivierung von TLR-Signalwegen im PCa ausübt.

Es wurden zudem die häufig auftretenden biologischen Prozesse bei den im Microarray als verringert exprimiert detektierten Gene analysiert. Dabei konnten 42 Prozesse als hoch signifikant und signifikant verringert gezeigt werden (siehe Anhang, Tabelle 7.2). Die Mehrheit der Prozesse ist beteiligt an Zellteilung sowie dem Zellzyklus. Dieses Ergebnis unterstreicht die bereits in der Literatur beschriebene Proliferationshemmung der Behandlung von PCa-Zellen mit Tectorigenin (Thelen et al., 2005; Thelen et al., 2006; 
Stettner et al., 2007) und bestätigt die Wirksamkeit des ausgewählten Tectorigenins der Firma Shenzhen.

Die Analyse der hauptsächlich vertretenen zellulären Kompartimente bei den vermindert exprimierten Genen nach Behandlung der LNCaP-Zellen mit Tectorigenin bestätigt die hemmende Wirkung von Tectorigenin auf die Zellteilung, da z.B. das Replisom, der Nukleus und die nukleare Replikationsgabel unter den signifikant vertretenen zellulären Kompartimenten sind (siehe Anhang, Tabelle 7.3).

Schließlich konnte auch die Analyse der hauptsächlich detektierten molekularen Funktionen bei den nach Behandlung der PCa-Zellen LNCaP mit Tectorigenin vermindert exprimierten Gene die vorher bereits beschriebenen Ergebnisse bestätigen (siehe Anhang, Tabelle 7.4). Es konnte z.B. vermehrt die DNA-Primase-Aktivität und die Helikase-Aktivität detektiert werden. Beide Enzyme sind wichtige Faktoren für die Replikation. Auch die DNA-gerichtete DNA-Polymerase-Aktivität sowie die Nukeotidyltransferase-Aktivität waren in dieser Analyse signifikant häufig vertreten.

Zusammenfassend lassen die Ergebnisse der Genontologie-Analyse darauf schließen, dass eine Behandlung mit Tectorigenin die Aktivierung des Immunsystems initiiert und gleichzeitig die Proliferation der Zellen durch eine Hemmung der Replikation der DNA sowie der Progression des Zellzyklus inhibiert.

Weitere Hinweise auf Tectorigenin als mögliches Mittel in der Therapie des PCa haben die in vivo-Studien in dieser Arbeit geliefert. Phytoöstrogene im Allgemeinen haben bereits vielversprechende Ergebnisse bei der Behandlung des $\mathrm{PCa}$ in vivo gezeigt. Vor allem das Phytoöstrogen Genistein, welches Tectorigenin strukturell sehr ähnlich ist, wurde intensiv auf seine Wirkung im PCa untersucht. Die Analysen in der Literatur wurden vermehrt im TRAMP-Modell durchgeführt. Auch im Rahmen dieser Arbeit wurden in Zusammenarbeit mit der Urologie und der Pathologie der Universitätsmedizin Göttingen Studien zur Wirksamkeit von Tectorigenin im TRAMP-Modell durchgeführt. In diesen Studien wurde das chemisch hergestellte Tectorigenin der Firma Girindus verwendet. Da in diesen Studien zwar erste Hinweise auf die Wirksamkeit von Tectorigenin im PCa erlangt werden konnten, jedoch der Anteil der Mäuse vor allem mit einer prostatischen intraepithelialen Neoplasie (PIN) sowie mit einem wenig differenzierten PCa (PDC) unerwartet hoch vorlag, wurde im Rahmen dieser Arbeit von der Verwendung des TRAMP-Modells für die in vivo-Versuche abgesehen und statt dessen das LNCaP-Xenograft-Modell verwendet. Die primären TRAMP-PCa-Zellen 2E tolerieren eine deutlich höhere Dosis von Tectorigenin und benötigen diese auch, um dieselben Effekte auf verschiedene Genexpressionen zu zeigen wie LNCaP-Zellen mit einer deutlich geringeren Konzentration. Daher hätte im TRAMP-Modell wahrscheinlich eine deutlich höhere Konzentration von Tectorigenin Verwendung gefunden, was dazugeführt hätte, dass die Vergleichbarkeit mit Studien aus der Literatur nicht mehr gegeben gewesen 
wäre. Das LNCaP-Xenograft-Modell fand bereits in der Literatur Verwendung bei der Untersuchung der Wirksamkeit des Gesamtextraktes aus Belamcanda chinensis. Es konnte hierbei sowohl ein geringeres Tumorvolumen als auch ein langsamerer Verlauf der Tumorprogression gezeigt werden (Thelen et al., 2005; Thelen et al., 2006).

Ein weiterer Punkt für die Verwendung des LNCaP-Xenograft-Modells anstelle des TRAMP-Modells wurde sowohl in der oben genannten Studie zu Tectorigenin im TRAMP-Modell als auch in zahlreichen Veröffentlichungen zu Untersuchungen zur Wirksamkeit von Genistein im TRAMP-Modell gezeigt. Die Tumorinitiation scheint durch die Behandlung mit den beiden Phytoöstrogenen nicht beeinflusst zu werden, da der Anteil an Mäusen mit einer PIN im Vergleich zu kontrollbehandelten Mäusen nicht verändert ist (El Touny und Banerjee, 2007). Allein die Tumorprogression wurde sowohl in der oben genannten Studie zu Tectorigenin-behandelten Mäusen sowie auch in einigen Studien zu mit Genistein behandelten TRAMP-Mäusen als verringert detektiert (Mentor-Marcel et al., 2001; El Touny und Banerjee, 2007). Da folglich nur die Tumorprogression und nicht die -initiation untersucht werden sollte, stellt das LNCaP-Xenograft-Modell ein geeignetes Modell dar. Die Verwendung dieses Modells ermöglicht zudem die Übertragung der Erkenntnisse aus den in vitro-Daten auf die in vivo-Studien und umgekehrt. Dies wäre bei der Verwendung des TRAMP-Modells problematisch gewesen.

Es konnte schließlich in den Analysen zur Wirkung von Tectorigenin der Firma Shenzhen im LNCaP-Xenograft-Modell gezeigt werden, dass sowohl das Tumorvolumen als auch das Tumorgewicht in den mit Tectorigenin behandelten Mäusen deutlich geringer war als in kontrollbehandelten Mäusen mit sojafreiem Futter. Dies könnte vor allem durch die beschriebene verminderte Proliferation von PCa-Zellen nach der Behandlung mit Tectorigenin begründet sein (Thelen et al., 2005; Thelen et al., 2006; Stettner et al., 2007). Die molekularen Mechanismen konnten in dieser Arbeit nicht untersucht werden, sollen aber Gegenstand folgender Untersuchungen sein.

Ob Tectorigenin als Mittel gegen das PCa eingesetzt werden sollte, kann durch die Studien dieser Arbeit noch nicht vollständig geklärt werden. Es gibt einige Untersuchungen einer Phytoöstrogen-Behandlung bei Patienten mit PCa. In diesen Studien konnten nicht immer chemotherapeutische Effekte nachgewiesen werden (zusammengefasst in Perabo et al., 2009 und Özten-Kandas und Bosland, 2011). Allerdings haben in der vorliegenden Arbeit sowohl die in vitro- als auch die in vivo-Analysen vielversprechende Resultate bezüglich einer chemotherapeutischen Wirksamkeit von Tectorigenin geliefert, aber auch viele Fragen aufgeworfen. Hierbei ist vor allem die Wirkung auf den AR-Signalweg zu nennen. In dieser Arbeit konnte ein deutlicher Effekt auf Androgen-induzierte Gene gezeigt werden, allerdings wurde die AR-Expression nicht durch die Behandlung mit Tectorigenin verändert. Es muss folglich anhand von weiterführenden Studien der zugrunde liegende Mechanismus dieses 
Effekts auf den AR-Signalweg und weitere Signalwege geklärt werden, bevor Tectorigenin als Mittel zur Therapie des PCa eingesetzt werden kann.

\subsection{Der Histondeacetylase-Inhibitor Valproinsäure}

In dieser Arbeit wurde der Effekt des Histondeacetylase-Inhibitors (HDI) Valproinsäure (VPA) auf PCa-Zellen untersucht. VPA findet bereits seit vielen Jahrzehnten Verwendung als Antikonvulsivum. Erste Untersuchungen zur Wirksamkeit von VPA in hämatologischen Tumorerkrankungen wurden bereits Mitte der achtziger Jahre durchgeführt (Regan, 1985; Fischkoff und Walter, 1984). Dass VPA ein HDI ist, wurde durch zwei Arbeiten am Anfang dieses Jahrtausends belegt (Göttlicher et al., 2001; Phiel et al., 2001). Die Histonacetylasen (HDACs) werden in vier Klassen unterteilt. Genauere Analysen zur Funktion von VPA zeigten, dass vorwiegend die HDACs der Klasse I sowie Ila gehemmt werden (Gurvich et al., 2004). Die Funktion der HDACs besteht in der Acetylierung der Histone. Die Acetylierung und Deacetylierung der Histone wird durch das Gleichgewicht zwischen den HDACs und den Histonacetyltransferasen (HATs) bestimmt. Durch die von VPA ausgeübte Inhibierung der HDACs sind nur noch die HATs aktiv, weshalb sich durch die Behandlung von Zellen mit dem HDI VPA das Gleichgewicht zwischen deacetyliertem und acetyliertem Chromatin auf die Seite des acetylierten Chromatins verschiebt und damit im Allgemeinen eine Genexpression ermöglicht wird.

VPA wurde nicht nur bei hämatologischen Tumorerkrankungen untersucht. Es gibt auch bereits in zahlreichen Studien Ergebnisse zur Wirksamkeit im PCa. Im Rahmen dieser Arbeit liegt der Schwerpunkt allerdings auf der Verwendung von primären PCa-Zellen des TRAMP-Modells. Auf diese Weise ist es möglich die in vitro erlangten Erkenntnisse auf die in vivo-Daten aus dem TRAMP-Maus-Modell zu übertragen und zu verifizieren.

\subsubsection{Einfluss von Valproinsäure auf Proliferation, Migration und Invasion von Prostatakarzinomzellen}

Wie bereits im oberen Abschnitt beschrieben, hemmt VPA die HDACs, was in einer verstärkten Acetylierung der Histone resultiert. Als Positivkontrolle für eine erfolgreiche Behandlung mit VPA wurde in dieser Arbeit die Acetylierung von Histon 3 an Lysin 9 untersucht. Es konnte sowohl in den primären PCa-Zellen $2 \mathrm{E}$ als auch in den etablierten, humanen PCa-Zellen PC-3 eine verstärkte Acetylierung dieses Histons detektiert werden (Witt et al., 2013), was auf eine effektive Inhibierung der HDACs mit den verwendeten Konzentrationen von VPA schließen lässt.

Die Auswirkung auf die Proliferation durch eine Behandlung mit VPA in Karzinomzellen im Allgemeinen und in PCa-Zellen im Speziellen wurde bereits durch einige Arbeitsgruppen 
untersucht. In verschiedenen humanen PCa-Zellen (LNCaP, PC-3, DU145) und auch in den dazugehörigen Xenograft-Modellen wurde eine Inhibition der Proliferation gezeigt (Xia et al., 2006; Annicotte et al., 2006; Angelucci et al., 2006; Shabbeer et al., 2007; Gao et al., 2007; Stettner et al., 2007; Angelucci et al., 2008; lacopino et al., 2008; Kortenhorst et al., 2009; Chou et al., 2011; Sidana et al., 2012). In einer Studie konnte die Proliferationsinhibition für DU145-Zellen nicht bestätigt werden, allerdings wurde hier eine sehr geringe VPAKonzentration (0,75mM) verwendet (Annicotte et al., 2006). Durch Xia et al. (2006) konnte später gezeigt werden, dass 1mM VPA die Proliferation der DU145-Zellen nur mäßig hemmt, die Behandlung mit 5mM VPA hingegen hemmt die Proliferation von DU145-Zellen vergleichbar zu PC-3- und LNCaP-Zellen. Im Rahmen der vorliegenden Arbeit konnte eine sowohl zeit- als auch konzentrationsabhängige Inhibition der Zellproliferation sowohl in 2E- als auch in PC-3-Zellen gezeigt werden (Witt et al., 2013). Dies unterstreicht die Funktionalität der verwendeten primären PCa-Zellen als Modellsystem für das PCa in den nachfolgenden Versuchen.

Im Rahmen dieser Arbeit sollte geprüft werden, ob auch in dem verwendeten Zellmodell der primären PCa-Zellen 2E eine Inhibierung der Migrations- und Invasionsfähigkeit nach Behandlung mit VPA vorliegt. Dies sollte vor allem in Hinblick auf folgende in vivo-Versuche untersucht werden. Es konnte gezeigt werden, dass eine VPA-Konzentration von 5mM sowohl die Migration als auch die Invasion der primären PCa-Zellen 2E effektiv inhibierte (Witt et al., 2013), was das chemotherapeutische Potential von VPA vor allem für späte Phasen des PCa (organüberschreitend) unterstreicht.

Die hier erzielten Ergebnisse werden von einer Reihe von Studien unterstützt. Es wurde gezeigt, dass in PC-3-, LNCaP- und DU145-PCa-Zellen nach Behandlung mit VPA die Zelladhäsion vermindert ist. Ebenfalls konnte zusätzlich eine Inhibition der Migration der PC-3-Zellen nach VPA-Behandlung gezeigt werden (Wedel et al., 2011d; Wedel et al., 2011c; Hudak et al., 2012). VPA inhibiert dabei die Zellmigration in PCa-Zellen über die Überexpression von E-Cadherin (Zhang et al., 2011).

Die Inhibition der Invasion von PCa-Zellen durch eine VPA-Behandlung ist dagegen ein kontrovers diskutiertes Gebiet. Zwei Arbeiten aus der Arbeitsgruppe von Prof. Dr. R. Blaheta zeigen eine Inhibition der Invasion für PC-3-Zellen nach der Behandlung mit VPA (Wedel et al., 2011c; Hudak et al., 2012). Für PC-3-Zellen konnte zusätzlich zu der in vitro gezeigten Inhibition auch die Inhibition der Invasion in vivo nach der Behandlung mit VPA nachgewiesen werden (Annicotte et al., 2006). Hingegen konnte in einer weiteren Studie kein Effekt auf die Invasion der PCa-Zellen DU145, PC-3 und LNCaP durch die Behandlung mit VPA (1,2mM und 5mM) nach bis zu 72 Stunden beobachtet werden (Chen et al., 2006a). Auch Annicotte et al. (2006) konnten in vitro keine Inhibition der Invasion für LNCaP-Zellen nach Behandlung mit VPA zeigen. Allerdings wurde in dieser Studie für die Behandlung der 
LNCaP-Zellen eine sehr geringe Konzentration von VPA $(0,375 \mathrm{mM})$ verwendet. Im Rahmen der vorliegenden Arbeit konnte die Inhibierung der Invasion durch eine VPA-Behandlung in den primären PCa-Zellen 2E bestätigt werden (Witt et al., 2013). Es ist folglich zu prüfen, was zu den unterschiedlichen Ergebnissen zur Invasion der PCa-Zellen nach VPABehandlung führt. Möglich wären z.B. methodische Modifikationen in der Untersuchung sowie Unterschiede in den verwendeten PCa-Zellen, die durch eine individuelle Kultivierung bedingt sein könnten.

\subsubsection{Molekulare Effekte von Valproinsäure auf Signalwege in Prostatakarzinomzellen}

Für die Behandlung von PCa-Zellen mit VPA konnten bereits zahlreiche Effekte auf die Expression von verschiedenen Genen aus den unterschiedlichsten Signalwegen gezeigt werden (zusammengefasst in Michaelis et al., 2007). Es sollten in dieser Arbeit zunächst die Expression von Kandidatengenen einiger ausgewählter Signalwege untersucht werden. Zusätzlich sollten differentiell exprimierte Gene aus einer vorherigen Microarray-Analyse eingehender untersucht werden (Witt, 2009).

\subsubsection{Der Einfluss von Valproinsäure auf den Androgenrezeptor-Signalweg}

Die Analyse des AR ist für eine Untersuchung im PCa unerlässlich. Der AR spielt eine entscheidende Rolle bei der Progression des PCa (zusammengefasst in Knudsen und Penning, 2010). Daher besteht ein großes Interesse, Therapien zu identifizieren, die die Expression oder die Aktivität des AR beeinflussen. Im Rahmen der vorliegenden Arbeit wurde daher die Expression des AR mittels qRT-PCR- sowie Immunfluoreszenz-Analyse in den primären PCa-Zellen 2E nach VPA-Behandlung untersucht. Es konnte sowohl eine konzentrations- als auch zeitabhängige Verringerung der AR-Expression demonstriert werden. Dies unterstreicht die chemotherapeutische Wirkung von VPA in PCa-Zellen, da eine verminderte AR-Expression mit der Abnahme von Proliferation und geringerem Überleben assoziiert ist (vgl. Abb. 4.1A) und der AR ein wesentliches Therapieziel des kastrationsresistenten PCa darstellt (zusammengefasst in Knudsen und Penning, 2010).

Die Wirkung von VPA auf die AR-Expression im PCa wurde von einigen Arbeitsgruppen untersucht, dabei konnte jedoch kein eindeutiger Effekt nachgewiesen werden. Einige Studien zeigten einen Anstieg der AR-Expression nach VPA-Behandlung von PCa-Zellen (Xia et al., 2006; lacopino et al., 2008), andere Analysen zeigten eine Verringerung der AR-Expression (Xia et al., 2006; Valentini et al., 2007). Teilweise wurden innerhalb einer Studie unterschiedliche Expressionslevel des AR nach VPA-Behandlung in Abhängigkeit mit der Behandlungsdauer detektiert (Xia et al., 2006; Iacopino et al., 2008). Es sollte daher in weiterführenden Analysen geprüft werden, ob eine Abhängigkeit zwischen VPA-Behandlungsdauer und der AR-Expression besteht. 


\subsubsection{Der Einfluss von Valproinsäure auf die Apoptose}

Durch die Behandlung von PCa-Zellen mit VPA wird Apoptose induziert. Dies konnte bereits von einigen Arbeitsgruppen in verschiedenen humanen PCa-Zellen (PC-3, DU145, LNCaP und VCaP) sowie zwei Xenograft-Modellen (PC-3, DU145) sowohl mittels eines TUNEL-Assays als auch mittels Durchflusszytometrie demonstriert werden (Annicotte et al., 2006; Angelucci et al., 2006; Xia et al., 2006; Gao et al., 2007; Shabbeer et al., 2007; Fortson et al., 2011). Eine Arbeitsgruppe konnte die Induktion der Apoptose zusätzlich konzentrations- und zeitabhängig zeigen (Angelucci et al., 2006).

Die zugrunde liegenden molekularen Mechanismen der Apoptose-Induktion nach VPA-Behandlung sind noch nicht hinreichend geklärt. Grundsätzlich könnte es sich um intrinsische oder extrinsische Apoptose handeln. Die intrinsische Apoptose wird hauptsächlich durch Stimuli in der Zelle ausgelöst. Eine vereinfachte Übersicht über die Mechanismen der intrinsischen Apoptose ist in Abbildung 4.3 dargestellt. In der gesunden Zelle sind die sog. BH3-only-Proteine (hier repräsentiert durch Bim, BCL-2 interacting mediator of cell death) am Zytoskelett assoziiert. In der apoptotischen Zelle werden diese Proteine freigesetzt und inhibieren die Aktivität von Bcl-2. Bax und Bak bilden Homo-Oligomere in der äußeren Mitochondrienmembran und bilden so Poren, durch die sowohl Zytochrom c als auch inhibitorische Faktoren in das Zytoplasma gelangen. Die inhibitorischen Faktoren Omi und Diablo hemmen dort die Aktivität der Apoptose-verhindernden Proteine (IAP, inhibitor of apoptosis protein). Zytochrom c, die aktivierte Caspase 9 sowie Apaf-1 bilden zusammen das Apoptosom, welches anschließend die Caspase 3 aktiviert und so über die Caspase-Kaskade zur Apoptose der Zelle führt (Adams, 2003). 


\section{gesunde Zelle}

\section{apoptotische Zelle}

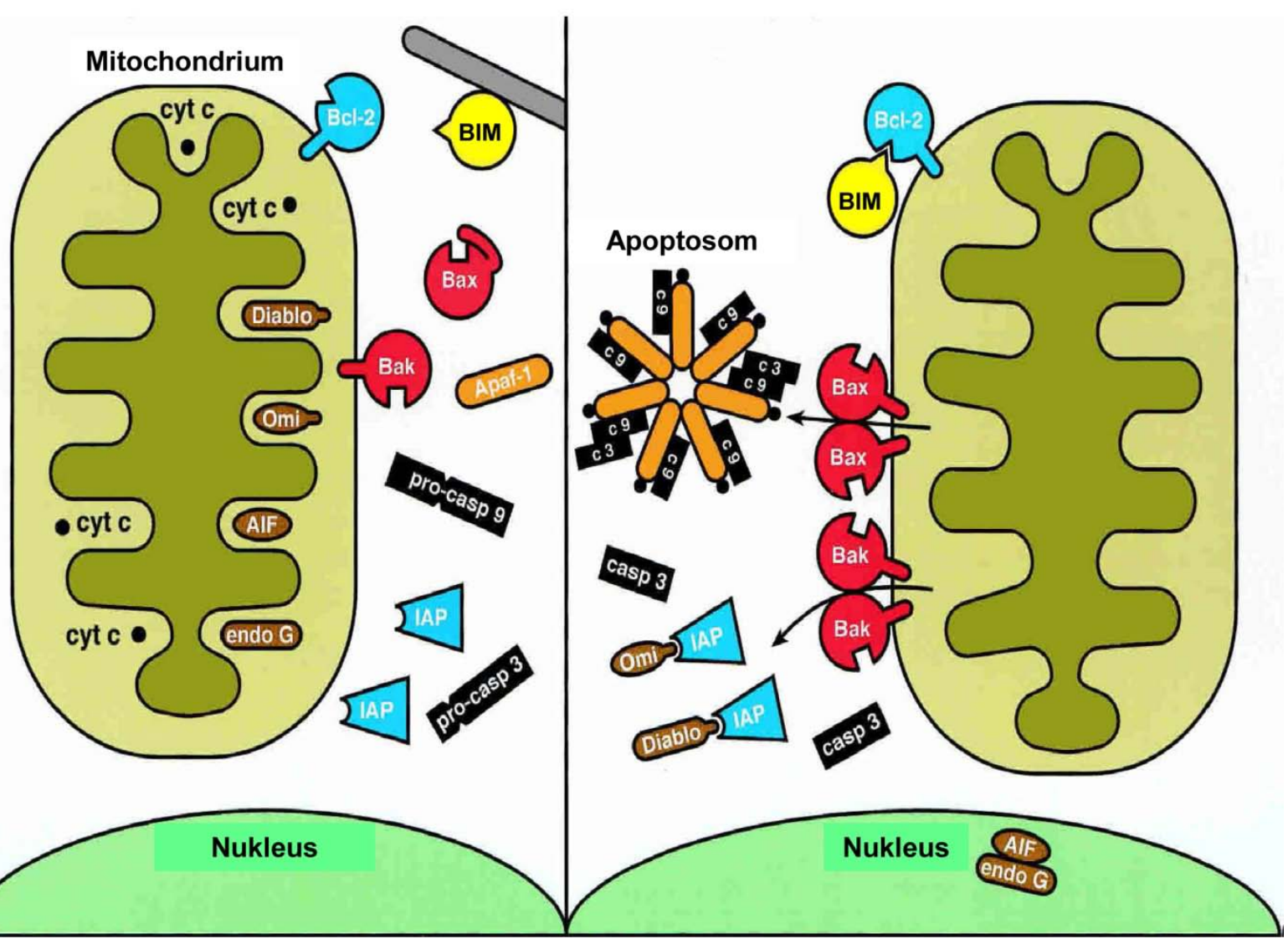

Abbildung 4.3: Übersicht über die Mechanismen der intrinsischen Apoptose-Aktivierung.

In der gesunden Zelle sind BH3-only-Proteine mit dem Zytoskelett assoziiert (hier repräsentiert durch Bim). Nach dem apoptotischen Stimulus werden sie zum Mitochondrium transloziert und hemmen dort die Aktivität von Bcl-2. Die proapoptotischen Proteine Bax und Bak bilden nach dem apoptotischen Stimulus Homo-Oligomere an der äußeren Mitochondrienmembran und bilden so Poren, durch die sowohl Zytochrom c als auch die inhibitorischen Faktoren in das Zytoplasma gelangen. Die inhibitorischen Faktoren blockieren anschließend die Funktion der IAPs (inhibitor of apoptosis protein). Zytochrom c, die aktive, gespaltene Caspase 9 sowie Apaf-1 bilden in der apoptotischen Zelle das Apoptosom, welches anschließend die Caspase 3 aktiviert (modifiziert nach Adams, 2003).

Die extrinsische Apoptose ist Rezeptor-vermittelt. Sie ist folglich eine Reaktion auf externe Stimuli. Beide Wege der Apoptose sind eng miteinander gekoppelt (Abb. 4.4). Bindet ein Ligand an den sog. Todesrezeptor, so wird über ein Adapterprotein das Signal an die Procaspase 8 weitergegeben. In sog. Typ II-Zellen liegen nach diesem Stimulus geringe Mengen von aktivierter Caspase 8 vor. Als Reaktion darauf wird durch die aktivierte Caspase 8 das proapoptotische Protein Bid in tBid gespalten, welches dann über die Rekrutierung von Bax den intrinsischen Weg der Apoptose aktiviert. Werden große Mengen an gespaltener Caspase 8 produziert (in sog. Typ I-Zellen), so wird direkt die Caspase 3 und die folgende Caspase-Kaskade aktiviert, was schließlich zur Apoptose der Zelle führt (Jesenberger und Jentsch, 2002). Es ist demnach festzuhalten, dass die Aktivierung von Caspase 9 spezifisch für den intrinsischen Weg der Apoptose ist, die Aktivierung von 
Caspase 8 spezifisch für den extrinsischen Weg der Apoptose und die Aktivierung von

Caspase 3 übergreifend für beide Wege der Apoptose.

extrinsischer Stimulus

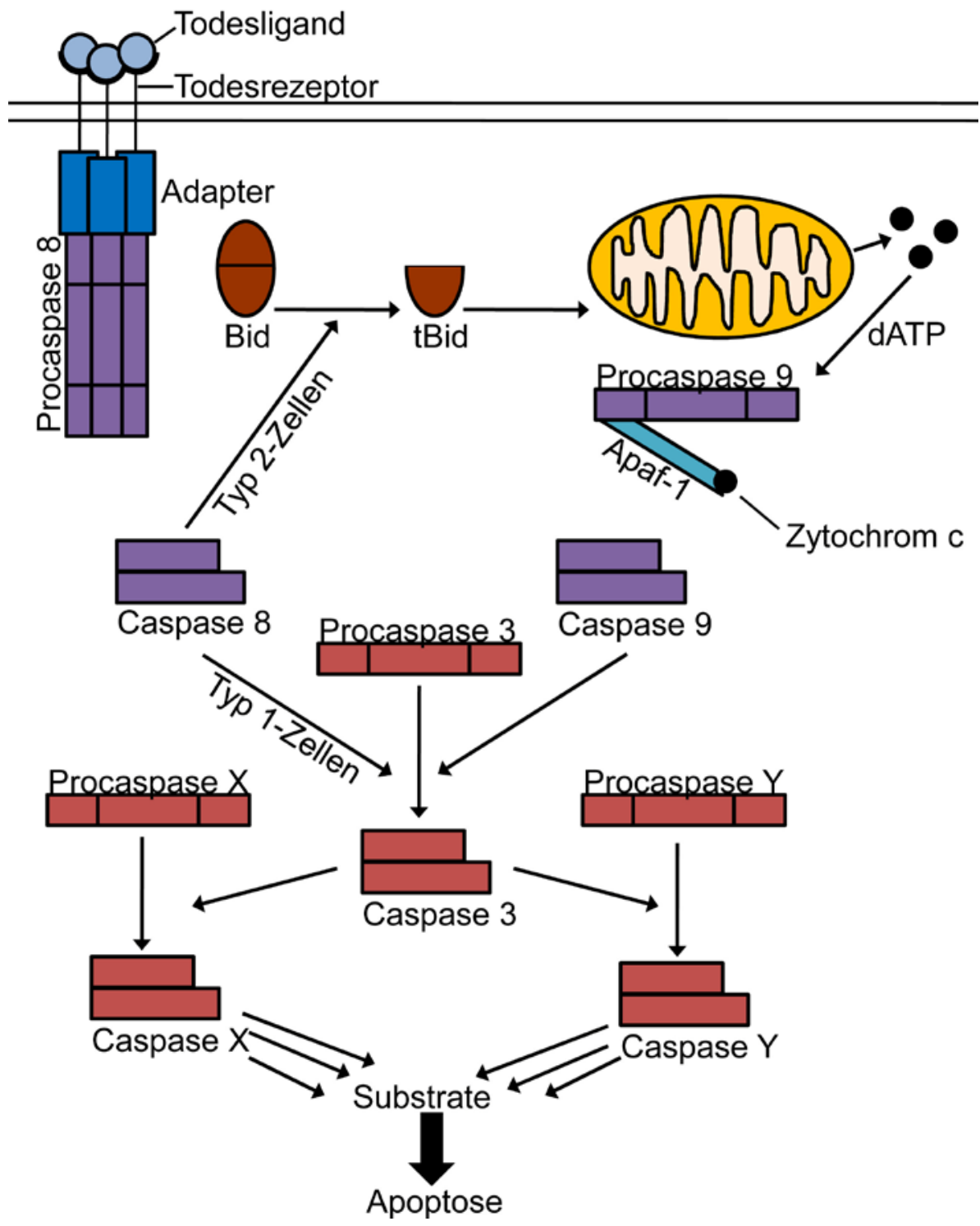

Abbildung 4.4: Überblick über die extrinsische und intrinsische Apoptose.

Bei der extrinsischen Apoptose wird das Signal durch die Bindung eines Todesliganden an einen Todesrezeptor (z.B. TNF-Rezeptor 1 oder Fas/CD95) über ein Adaptermolekül an die Procaspase 8 weitergegeben. In Typ I-Zellen, in denen nur geringe Mengen an aktivierter Caspase 8 vorliegen, wird das proapoptotische Protein Bid durch die Caspase 8 in tBid gespalten. Dies aktiviert schließlich die intrinsische Apoptose über die Rekrutierung von Bax. In Typ II-Zellen, in denen große Mengen an aktivierter Caspase 8 vorliegen, wird direkt die Apoptose über die Aktivierung von Caspase 3 und der folgenden Caspase-Kaskade initiiert. Die intrinsische Apoptose wird, wie bereits in Abbildung 4.3 ausführlich dargestellt, über Caspase 9 vermittelt (modifiziert nach Jesenberger und Jentsch, 2002). 
Es ist festzuhalten, dass VPA in PCa-Zellen Apoptose vermittelt, jedoch über welchen Weg, ob extrinsischer oder intrinsischer, ist noch unklar. Die im Rahmen dieser Arbeit identifizierten Mechanismen sowie die in der Literatur beschriebenen Mechanismen nach VPA-Behandlung von PCa-Zellen sind in Abbildung 4.5 schematisch zusammengefasst und werden im Folgenden beschrieben.

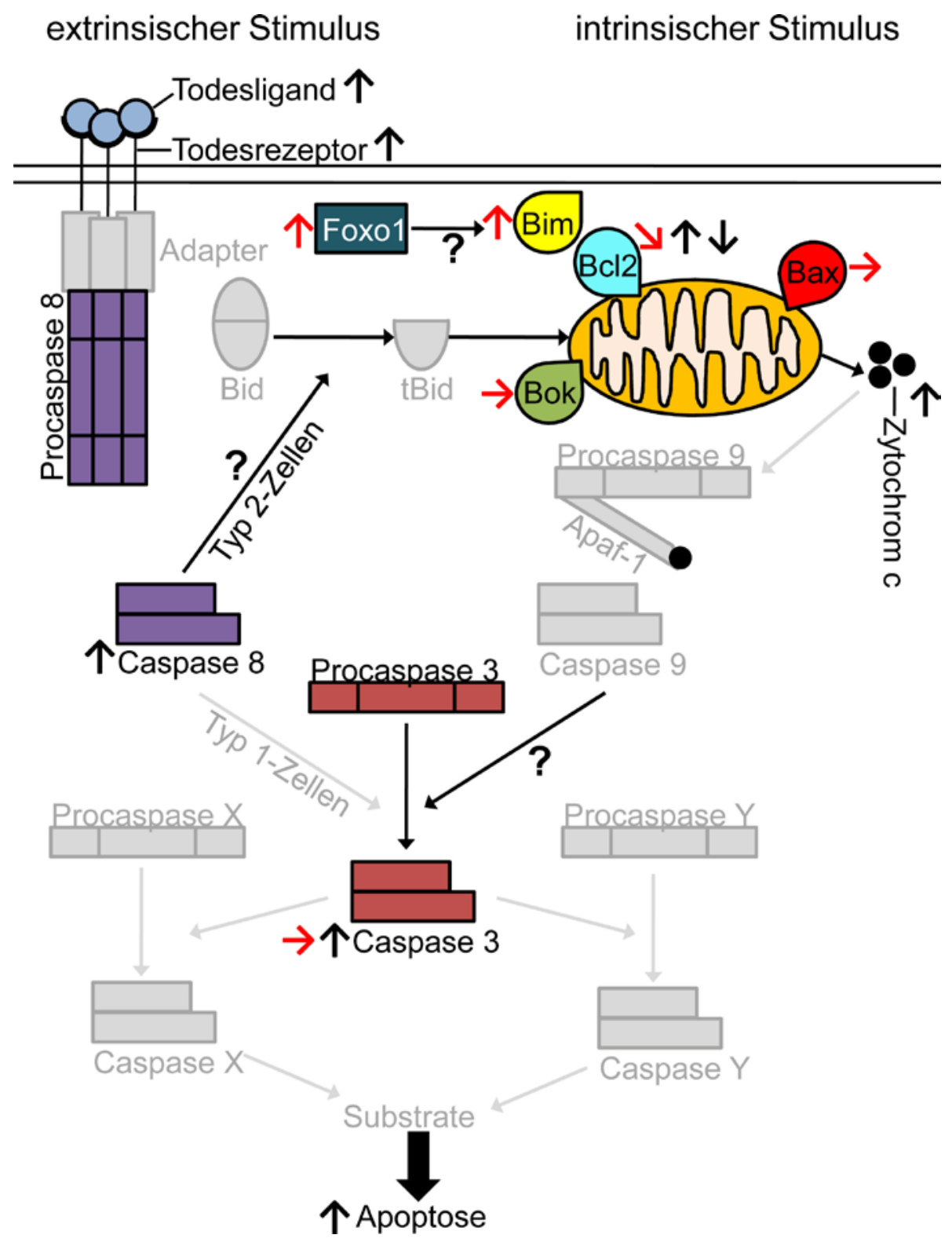

Abbildung 4.5: Übersicht über die in dieser Arbeit gezeigten Regulationen sowie der in der Literatur beschriebenen Mechanismen nach VPA-Behandlung von PCa-Zellen.

In Studien aus der Literatur konnte nach VPA-Behandlung von humanen PCa-Zellen eine Induktion von Apoptose gezeigt werden, mechanistisch konnte eine verstärkte Aktivierung der beiden Caspasen 9 und 3, eine erhöhte Zytochrom c-Freisetzung sowie eine verstärkte Expression des Todesliganden und -rezeptors detektiert werden (Annicotte et al., 2006; Angelucci et al., 2006; Xia et al., 2006; Gao et al., 2007; Shabbeer et al., 2007; Thelen et al., 2004; Fortson et al., 2011). Die Ergebnisse zur Expression des anti-apoptotischen Proteins Bcl-2 nach VPA-Behandlung sind widersprüchlich, es konnte in vitro eine verstärkte Expression in PCa-Zellen und in vivo eine verminderte Expression von Bcl-2 im PC3-Xenograft-Modell gezeigt werden (Angelucci et al., 2006; 
Angelucci et al., 2008). In der vorliegenden Arbeit konnte eine leichte Verminderung der Expression von Bcl-2 nach VPA-Behandlung der primären PCa-Zellen 2E detektiert werden. Zudem konnte eine konzentrations- und zeitabhängige verstärkte Expression des pro-apoptotischen Proteins Bim durch eine VPA-Behandlung gezeigt werden. Es konnte die Hypothese aufgestellt werden, dass diese verstärkte Expression von Bim nach VPABehandlung der PCa-Zellen 2E durch eine verstärkte Expression von Foxo1 begründet sein könnte. Es konnte allerdings kein Einfluss von VPA auf die Expression der pro-apoptotischen Proteine Bax und Bok und die Aktivierung der Caspase 3 in den primären PCa-Zellen 2E detektiert werden.

Die Effekte der VPA-Behandlung von PCa-Zellen sind wie folgt dargestellt: $\searrow$ leicht verminderte Expression, $\uparrow$ verstärkte Expression/Aktivierung, $\rightarrow$ kein Effekt, $\downarrow$ verminderte Expression, schwarze Pfeile symbolisieren hierbei Ergebnisse aus der Literatur, rote Pfeile symbolisieren Ergebnisse aus der vorliegenden Arbeit (modifiziert und erweitert nach Jesenberger und Jentsch, 2002).

Nach der Studie von Angelucci et al. (2006) könnte es sich um extrinsische Apoptose in Typ II-Zellen handeln, da sie eine verstärkte Expression eines Todesrezeptors und auch seines Liganden, eine verstärkte Aktivierung von Caspase 8, aber auch eine Zytochrom c Freisetzung detektierten. Diese Ergebnisse konnten in einer weiteren Studie zwar nicht bestätigt werden, da keine Aktivierung der Caspase 8 nach Behandlung von PCa-Zellen mit VPA detektiert wurde (Xia et al., 2006), allerdings ist es möglich, dass die geringe Aktivierung von Caspase 8, wie sie in Typ II-Zellen üblich ist, aus methodischen Gründen nicht detektiert wurde.

Eine Aktivierung der für beide Wege der Apoptose übergreifend wirkende Caspase 3 nach Behandlung von PCa-Zellen (LNCaP-, PC-3- und DU145-Zellen) mit VPA wurde bereits durch einige Arbeitsgruppen beschrieben (Thelen et al., 2004; Xia et al., 2006; Angelucci et al., 2006). Im Rahmen der vorliegenden Arbeit konnte die Aktivierung von Caspase 3 nach Behandlung mit VPA nicht gezeigt werden. Es ist davon auszugehen, dass dies aus methodischen Gründen nicht gezeigt werden konnte.

In weiteren Untersuchungen zu den Proteinen des intrinsischen Wegs der Apoptose konnte für die Expression der beiden pro-apoptotischen Proteine Bax und Bok keine Änderung nachgewiesen werden. Für das anti-apoptotische Protein Bcl-2 konnte nach 24 Stunden VPA-Behandlung eine verminderte Expression detektiert werden, die nach 72 Stunden Behandlung jedoch nicht mehr nachzuweisen war. Auch die Daten aus der Literatur zur Expression von Bcl-2 nach VPA-Behandlung von PCa-Zellen sind widersprüchlich. Während in vitro in LNCaP, DU145 und PC-3-Zellen eine Verringerung der Expression detektiert wurde, konnte in einem PC-3-Xenograft-Modell eine verstärkte Expression von Bcl-2 nach VPA-Behandlung gezeigt werden (Angelucci et al., 2006; Angelucci et al., 2008). Dieser Unterschied wurde damit erklärt, dass die Zellen, die im Xenograft-Modell Bcl-2 verstärkt exprimieren resistent gegen eine VPA-Behandlung sein könnten. Es sollte in zukünftigen Untersuchungen mit einbezogen werden, dass bei der intrinsischen Apoptose diese Proteine hauptsächlich eine Translokation durchführen. 
Im Rahmen der vorliegenden Arbeit konnte allerdings gezeigt werden, dass in den primären PCa-Zellen 2E die Expression des proapoptotischen Proteins Bim sowohl konzentrations- als auch zeitabhängig nach Behandlung mit VPA stark ansteigt. Eine verstärkte Expression von Bim wurde bereits nach der Behandlung von Karzinomzellen verschiedenster Entitäten mit anderen HDIs beschrieben (Zhao et al., 2005; Gillespie et al., 2006; Inoue et al., 2007; Yang et al., 2009; Richter-Larrea et al., 2010; Yamaguchi et al., 2010; Stauber et al., 2012), jedoch ist die vorliegende Arbeit die einzige bekannte Studie, die eine verstärkte Expression von Bim nach VPA-Behandlung von PCa-Zellen zeigte. Die molekularen Mechanismen, die zu dieser Überexpression führen könnten, sollten hier weiter untersucht werden. Es wurde beschrieben, dass Zellen durch die Phosphorylierung von Bim durch aktiviertes Erk und Akt den Abbau von Bim durch Ubiquitin-vermittelte Degradierung initiieren (Qi et al., 2005; Akiyama et al., 2009). Auch in der vorliegenden Arbeit konnte eine verstärkte Aktivierung von Erk und Akt nach der Behandlung der primären PCa-Zellen 2E mit VPA nachgewiesen werden (Daten nicht gezeigt). Dies lässt darauf schließen, dass möglicherweise in PCa-Zellen nach der VPA-Behandlung ein Rettungsmechanismus einsetzt, welcher die Apoptose inhibieren soll. Es konnte allerdings in der vorliegenden Arbeit gezeigt werden, dass die Proteinexpression von Bim in den PCa-Zellen 2E nach VPA-Behandlung mit der Zeit sogar noch zunimmt. Diese Beobachtung spricht dafür, dass der Abbau von Bim in den PCa-Zellen 2E nicht erfolgreich stattfindet und somit Apoptose induziert wird. Die Regulation der Expression von Bim ist in humanen Lungenkarzinomzellen über den Transkriptionsfaktor Foxo1 vermittelt (Yang et al., 2009). Daher wurde im Rahmen der vorliegenden Arbeit ebenfalls die Expression von Foxo1 untersucht und es konnte gezeigt werden, dass die Foxo1-Expression nach der Behandlung der primären PCa-Zellen 2E mit VPA verstärkt wird. Der Anstieg der Foxo1-Expression könnte folglich den zugrunde liegenden Mechanismus darstellen, durch den die erhöhte Expression von Bim in den PCa-Zellen 2E nach der Behandlung mit VPA vermittelt wird.

\subsubsection{Der Einfluss von Valproinsäure auf den Zellzyklus}

Einige Arbeitsgruppen haben eine Analyse des Zellzyklus nach VPA-Behandlung von PCa-Zellen durchgeführt. Hierbei wurde in den untersuchten humanen PCa-Zellen (LNCaP, PC-3, DU145) vorwiegend ein Arrest der Zellen in der G1-Phase nach VPA-Behandlung detektiert (Annicotte et al., 2006; Angelucci et al., 2006; Angelucci et al., 2008; Chou et al., 2011; Hudak et al., 2012). In einigen Arbeiten konnte jedoch auch ein Arrest in der G2-Phase in den PCa-Zellen PC-3 nach Behandlung mit VPA demonstriert werden (Angelucci et al., 2006; Shabbeer et al., 2007). Eine Analyse des Zellzyklus nach Behandlung mit VPA wurde im Rahmen dieser Arbeit in den primären PCa-Zellen 2E durchgeführt (Daten nicht gezeigt). Es konnte kein eindeutiges Ergebnis nachgewiesen werden, da die Zellen innerhalb der 
Untersuchungen schwankende Zellzyklusprofile aufwiesen. Es konnte allerdings in einigen Versuchen ein Hinweis auf verstärkte Apoptose (sub G1-Phase) nach VPA-Behandlung detektiert werden. Aufgrund der Daten aus der Literatur ist nach der Behandlung mit VPA von einem Arrest der PCa-Zellen in der G1-Phase auszugehen.

Die Inhibition des Zellzyklus ist ein wichtiger chemotherapeutischer Effekt der VPA-Behandlung, da die Regulation des Zellzyklus in Tumorzellen häufig nicht intakt ist (Sherr, 1996). Der Zellzyklus ist in die vier Phasen G1, S, G2 und M sowie die G0-Ruhephase unterteilt. Der Übergang der Zelle von einer in die nächste Phase wird streng kontrolliert (Abb. 4.6). Dabei spielen die Cycline eine bedeutende Rolle. Sie dienen als Kofaktoren für die Cyclin-abhängigen Kinasen (CDKs, cyclin dependent kinases). Die spezifischen Komplexe aus Cyclinen und CDKs aktivieren Familienmitglieder der Retinoblastoma-Familie, die daraufhin nicht mehr die Transkription hemmen und den Übergang in die nächste Phase des Zellzyklus ermöglichen. Reguliert wird dies zum einen über die Expression der Cycline und CDKs, aber auch über die Expression von CDK-Inhibitoren (z.B. p16, p21 und p27) (Voorzanger-Rousselot und Garnero, 2007). In Tumorzellen können zahlreiche dieser Regulationsmechanismen gestört vorliegen. Wesentliche Ziele für eine Deregulation sind hierbei unter anderem die Expression der D-Typ-Cycline und ihrer dazugehörigen CDKs (Musgrove et al., 2011). 


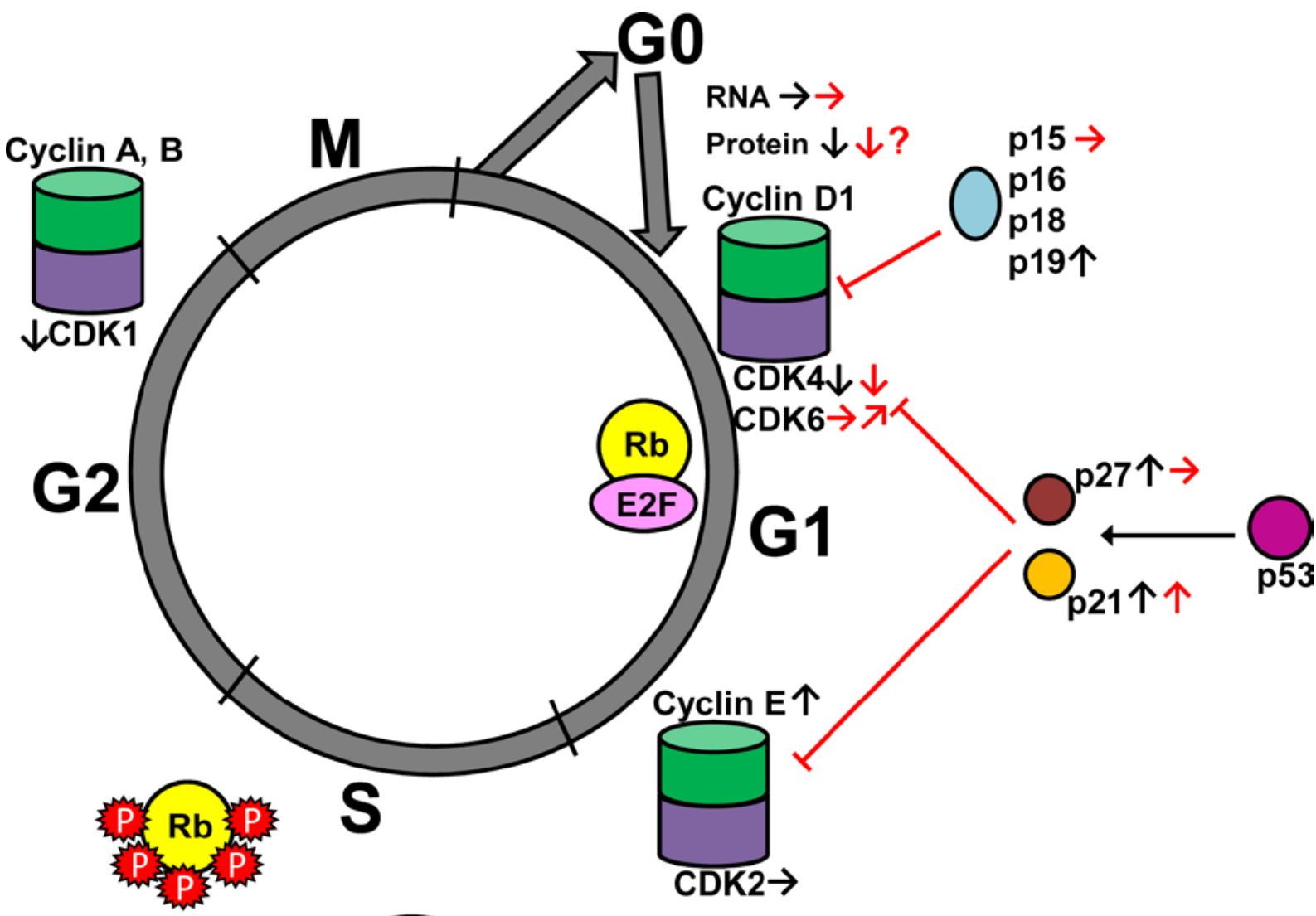

\section{E2F}

Abbildung 4.6: Übersicht über den Zellzyklus und dessen Regulation nach VPA-Behandlung von PCa-Zellen.

Dargestellt ist die allgemeine Regulation des Zellzyklus, lange rote Striche symbolisieren eine Inhibition, lange schwarze Pfeile symbolisieren eine Aktivierung. Dargestellt sind zusätzlich die aus der Literatur bekannten Regulationen durch eine VPA-Behandlung von humanen PCa-Zellen (schwarze kurze Pfeile) sowie die im Rahmen der vorliegenden Arbeit detektierten Regulationen durch eine VPA-Behandlung der primären PCa-Zellen 2E (rote kurze Pfeile). Hierbei bedeutet $\rightarrow$ kein Effekt $\downarrow$ verminderte Expression 个verstärkte Expression 7 leicht erhöhte Expression nach VPA-Behandlung von PCa-Zellen (Ergebnisse zusammengefasst aus Annicotte et al., 2006; Angelucci et al., 2006; Angelucci et al., 2008; Chou et al., 2011; Hudak et al., 2012; Shabbeer et al., 2007; Xia et al., 2006; Gao et al., 2007; Wedel et al., 2011d; Wedel et al., 2011a).

Der Zellzyklus ist in vier aktive Phasen unterteilt (G1, S, G2 und M) sowie die G0-Ruhephase. Der Übergang der Zellen ist durch verschiedene Mechanismen reguliert. So wird z.B. die Expression der spezifischen Cycline und der CDKs (cyclin dependent kinase) im Verlauf des Zellzyklus reguliert. Auch die Expression der CDK-Inhibitoren (z.B. p16, p27 und p21) ist streng kontrolliert (modifiziert nach Voorzanger-Rousselot und Garnero, 2007).

In der Literatur ist nach der VPA-Behandlung von PCa-Zellen vor allem ein G1-Arrest beschrieben. Dies wurde mechanistisch mit einer verminderten Cyclin D1-Expression auf Proteinebene, einer erhöhten Expression von p19, p27 und p21 sowie einer verminderten Expression von CDK4 verknüpft. Zusätzlich wurde auch eine verstärkte Expression von Cyclin E nach VPA-Behandlung von PCa-Zellen gezeigt, die Expression von CDK2 lag hingegen unverändert vor. In einigen Arbeiten wurde auch ein G2-Arrest beschrieben, dies geht mit der Beobachtung einher, dass nach VPA-Behandlung von PCa-Zellen CDK1 vermindert exprimiert wurde.

Im Rahmen der vorliegenden Arbeit konnte kein Effekt auf die Expression von p15, p27 sowie die Cyclin D1-mRNA durch eine VPA-Behandlung der primären PCa-Zellen 2E gezeigt werden. Die Expression von p21 lag hingegen erhöht vor, sowie die CDK6-Expression zeitabhängig leicht erhöht vorlag. Die Expression von 
Cdk4 wurde durch die Behandlung der PCa-Zellen 2E mit VPA vermindert (modifiziert und erweitert nach Molecular Staging, 2011).

Die bisher beschriebenen Effekte von VPA in PCa-Zellen auf Proteine des Zellzyklus sind passend zu dem häufig detektierten G1-Arrest der Zellen nach VPA-Behandlung. So konnte von einigen Arbeitsgruppen eine verstärkte Expression des CDK-Inhibitors p21 in humanen PCa-Zellen (LNCaP, PC-3, DU145) nach VPA-Behandlung detektiert werden (Xia et al., 2006; Annicotte et al., 2006; Gao et al., 2007; Shabbeer et al., 2007; Chou et al., 2011; Wedel et al., 2011d; Wedel et al., 2011a; Hudak et al., 2012). Auch eine verstärkte Expression von p19 und p27 wurde in verschiedenen PCa-Zellen nach VPA-Behandlung nachgewiesen (Annicotte et al., 2006; Wedel et al., 2011d; Wedel et al., 2011a; Hudak et al., 2012), was den inhibitorischen Effekt auf die Zellproliferation durch VPA unterstreicht.

Im Rahmen der vorliegenden Arbeit konnte keine Expressionsänderung des CDK4-Inhibitors p15 sowie von p27 nach VPA-Behandlung der primären PCa-Zellen 2E gezeigt werden, jedoch eine verstärkte Expression von p21 und der p21-aktivierten Kinase Pak, was die Vermutung unterstützt, dass auch in den primären PCa-Zellen 2E nach VPA-Behandlung ein G1-Arrest eintritt.

Zudem konnte im Rahmen dieser Arbeit bei der Untersuchung G1-spezifischer Proteine gezeigt werden, dass die VPA-Behandlung der primären PCa-Zellen zu einer Abnahme der Cdk4-Expression führt und eine kurze Behandlungszeit der Zellen (24 Stunden) keine Änderung der Cdk6-Expression bewirkt, allerdings nach einer längeren Behandlungszeit (72 Stunden) die Expression von Cdk6 leicht ansteigt. In den vorhandenen Studien aus der Literatur wurde lediglich die CDK4-Expression nach VPA-Behandlung der humanen PCa-Zellen LNCaP und DU145 untersucht. Es konnte eine verminderte Expression von CDK4 demonstriert werden (Wedel et al., 2011d; Hudak et al., 2012).

Bei der Untersuchung von Proteinen, die spezifisch für andere Phasen des Zellzyklus sind, konnten durch die verminderte Expression von CDK1 Hinweise auf eine Inhibition in Richtung der M-Phase gezeigt werden (Wedel et al., 2011a; Wedel et al., 2011d; Hudak et al., 2012). Cyclin E, welches spezifisch für den Übergang von der späten G1-Phase in die S-Phase ist, wurde verstärkt exprimiert nach VPA-Behandlung von PCa-Zellen detektiert. Da allerdings die dazugehörige Kinase, CDK2, unverändert vorlag (Wedel et al., 2011a; Wedel et al., 2011d; Hudak et al., 2012), liegt die Vermutung nahe, dass es sich hierbei um einen weiteren Rettungsmechanismus der Zelle handelt, um den Zellzyklus voranzutreiben. Es ist also weiterhin von einem G1-Arrest der Zellen nach VPA-Behandlung auszugehen.

Hinsichtlich des G1-spezifischen Cyclins wird häufig nur allgemein von Cyclin D gesprochen, obwohl Cyclin D1 untersucht wurde. Im Rahmen der vorliegenden Arbeit konnte gezeigt werden, dass substanzielle Unterschiede in der Funktion der Familienmitglieder der D-Typ Cycline im PCa vorhanden sind. Es wird hier daher zunächst auf die Expression von 
Cyclin D1 nach VPA-Behandlung von PCa-Zellen eingegangen, die Ergebnisse zum Kandidatengen Cyclin D2 werden im Kapitel 4.3.3 eingehend diskutiert. In verschiedenen Studien konnte gezeigt werden, dass die Expression von Cyclin D1 nach kurzer Behandlung von PCa-Zellen mit VPA unverändert vorlag (Wedel et al., 2011d), jedoch nach fünf Tagen Behandlung von DU145- und PC-3-Zellen anstieg (Wedel et al., 2011a). In einer weiteren Studie konnte demonstriert werden, dass die Expression von Cyclin D1 nach der Behandlung von PCa-Zellen mit VPA auf RNA-Ebene unverändert vorlag, jedoch auf Proteinebene vermindert war (Annicotte et al., 2006; Chou et al., 2011). Im Rahmen der vorliegenden Arbeit konnte die Analyse der Cyclin D1-Expression nur auf RNA-Ebene vorgenommen werden, da kein geeigneter Maus-spezifischer Antikörper zur Verfügung stand. Hierbei konnte in allen untersuchten Zelllinien ( $\mathrm{PCa}$, nicht-maligne Zellen und Kolonkarzinom) nach VPA-Behandlung keine signifikante Änderung der Cyclin D1-Expression detektiert werden (Witt et al., 2013). Die Möglichkeit, der durch Annnicotte et al. beschriebenen post-translationalen Regulierung der Cyclin D1-Expression (Annicotte et al., 2006) sollte jedoch in zukünftigen Arbeiten berücksichtigt werden. In der vorliegenden Arbeit konnten allerdings zwei Mechanismen identifiziert werden, die für eine post-translationale Inhibition von Cyclin D1 nach VPA-Behandlung der primären PCa-Zellen 2E sprechen. Zum einen konnte gezeigt werden, dass HIF1 $\alpha$ nach VPA-Behandlung verstärkt exprimiert wird. Es konnte durch Wen et al. (2010) nachgewiesen werden, dass HIF1a die Cyclin D1-Expression negativ reguliert. Zudem ist das Cyclin D1-Level in der Zelle

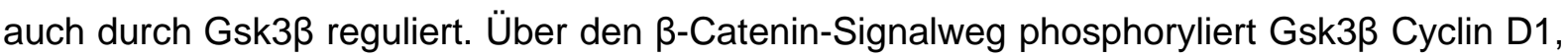
welches anschließend degradiert wird (zusammengefasst in Takahashi-Yanaga und Sasaguri, 2008). Auch die Expression von Gsk3 $\beta$ liegt in den primären PCa-Zellen 2E nach der Behandlung mit VPA verstärkt vor und könnte somit die post-translationale Degradierung von Cyclin D1 initiieren. Ein weiteres Ergebnis dieser Arbeit spricht für einen Abbau von Cyclin D1. Es konnte gezeigt werden, dass das Retinoblostoma-Protein (Rb-Protein) lediglich nach 24 Stunden Behandlung der primären PCa-Zellen 2E deutlich phosphoryliert vorlag. Nach 72 Stunden konnte nur noch eine moderate Aktivierung nachgewiesen werden. In der G1-Phase des Zellzyklus bindet das Rb-Protein an den Transkriptionsfaktor E2F und inhibiert damit die Expression der Zielgene. Der Komplex aus Cyclin D1 und CDK4 aktiviert das $\mathrm{Rb}$-Protein durch Phosphorylierung und dadurch wird die Expression einiger spezifischer Gene, z.B. Cyclin E, ermöglicht. Der Komplex aus Cyclin E und CDK2 phosphoryliert das $\mathrm{Rb}$-Protein an weiteren Stellen und bewirkt damit die Freisetzung von E2F, so dass eine Aktivierung der Transkription von E2F-Zielgenen stattfindet (Takahashi-Yanaga und Sasaguri, 2008). Die verringerte Aktivierung des Rb-Proteins nach der VPA-Behandlung der primären $\mathrm{PCa}-Z$ ellen 2E für 72 Stunden spricht also sowohl für eine post-translationale Degradierung von Cyclin D1 als auch für einen einsetzenden G1-Arrest im Allgemeinen. 
Ein weiteres Kandidatengen aus Witt (2009) ist in diesem Zusammenhang interessant: die Ubiquitin carboxyl-terminale Hydrolase 1 (Uchl1). Sie wurde als neuer Tumorsuppressor in PCa-Zellen beschrieben (Ummanni et al., 2011). Im Rahmen der vorliegenden Arbeit konnte eine verstärkte Expression von Uchl1 nach der Behandlung der primären PCa-Zellen 2E sowohl konzentrations- als auch zeitabhängig gezeigt werden (Witt et al., 2013). Die Daten aus der Studie von Ummanni et al. (2011) belegen, dass in Uchl1-positiven LNCaP-Zellen die Expression von Cyclin D1 auf RNA-Ebene nur moderat, jedoch auf Proteinebene deutlich reduziert vorliegt. Zudem zeigten LNCaP-Zellen eine Proliferations-Inhibierung nach Uchl1Überexpression (Ummanni et al., 2011). Diese Überexpression von Uchl1 wurde im Rahmen der vorliegenden Arbeit durch die Behandlung der PCa-Zellen 2E mit VPA hervorgerufen und auch in unseren Untersuchungen wurde eine Inhibition der Proliferation der PCa-Zellen 2E vermutlich durch einen Arrest der Zellen in der G1-Phase gezeigt (Witt et al., 2013). Zusammenfassend ist die Hypothese zur post-translationalen Degradierung von Cyclin D1 und dem G1-Arrest nach Behandlung von PCa-Zellen mit VPA in Abbildung 4.7 graphisch dargestellt.

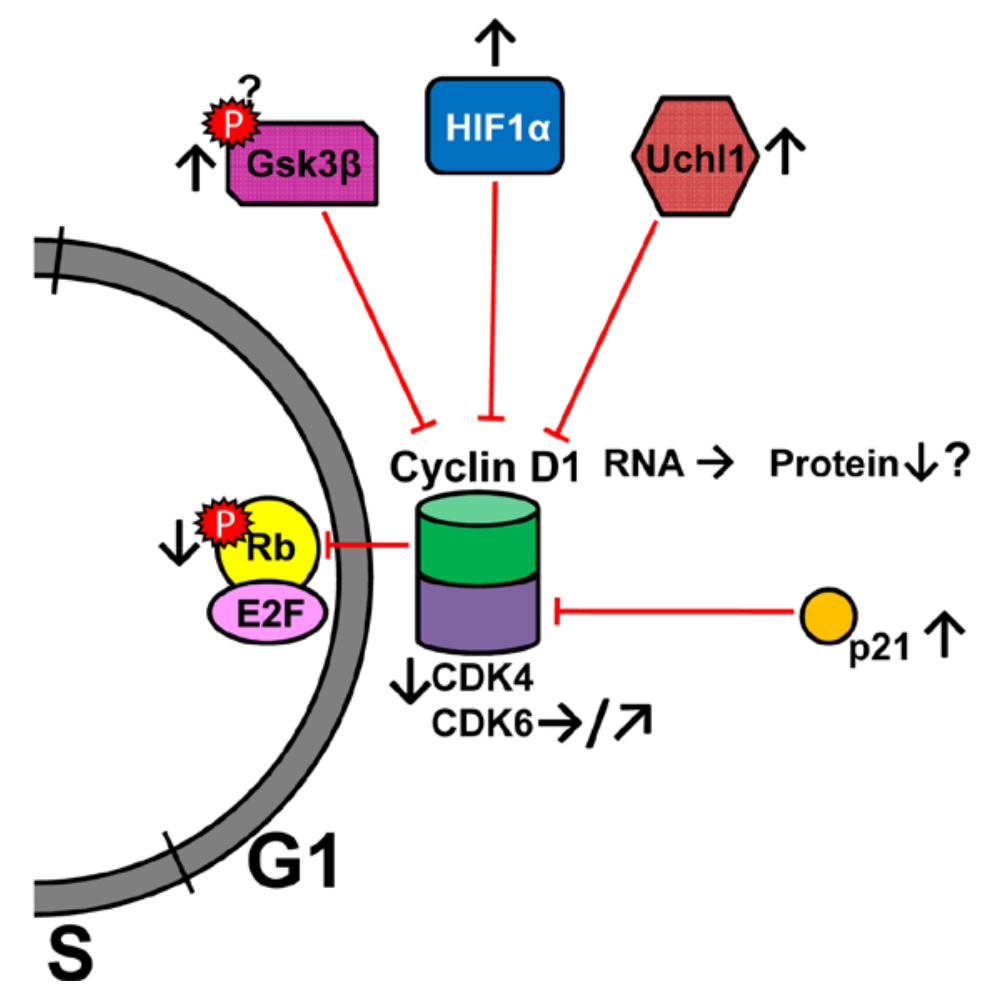

Abbildung 4.7: Hypothese zur post-translationalen Degradierung von Cyclin D1 und Arrest in der G1-Phase nach VPA-Behandlung von PCa-Zellen.

Im Rahmen der vorliegenden Arbeit konnte gezeigt werden, dass Cyclin D1 auf RNA-Ebene nach VPA-Behandlung der PCa-Zellen 2E unverändert vorlag. Die Ergebnisse dieser Arbeit deuten allerdings auf eine post-translationale Degradierung von Cyclin D1 hin. So wurde eine verstärkte Expression von Gsk3 $\beta$, HIF1 $\alpha$ sowie Uchl1 detektiert. Diese drei Proteine sind an dem Abbau des Cyclin D1-Proteins beteiligt. Auch die verminderte Aktivierung von $\mathrm{pRb}$ weist sowohl auf eine verminderte Expression von Cyclin D1 hin, als auch auf 
einen G1-Arrest im Allgemeinen. Dies wird unterstützt durch die erhöhte Expression von p21 und die verminderte Expression von CDK4.

Die Pfeile symbolisieren die Expression nach VPA-Behandlung der primären PCa-Zellen 2E: $\uparrow$ verstärkte Expression, $\boldsymbol{\lambda}$ leicht erhöhte Expression, $\downarrow$ verminderte Expression, $\rightarrow$ keine Expressionsänderung. Rote Striche zeigen eine Inhibition an (modifiziert und erweitert nach Molecular Staging , 2011).

In Zusammenhang mit einer allgemeinen Inhibition der Proliferation von PCa-Zellen steht auch ein weiteres im Rahmen der vorliegenden Arbeit identifiziertes Kandidatengen: der Leukemia inhibitory factor (Lif). Es wurde gezeigt, dass die Expression von Lif in den primären PCa-Zellen 2E nach der Behandlung mit VPA sowohl konzentrations- als auch zeitabhängig deutlich reduziert vorlag (Witt et al., 2013). Dies könnte möglicherweise ein weiterer molekularer Mechanismus der Proliferationsinhibition der PCa-Zellen 2E sein, da in der Literatur beschrieben ist, dass humane DU145-PCa-Zellen ein hohes Basallevel von LIF exprimieren. Wird LIF in diesen PCa-Zellen durch einen Antikörper blockiert, so wird die Proliferation der Zellen inhibiert (Kellokumpu-Lehtinen et al., 1996).

\subsubsection{Der Einfluss von Valproinsäure auf die Angiogenese}

Die Effekte der VPA-Behandlung auf die Angiogenese sind noch weitestgehend unerforscht. In einer Studie konnte eine Hemmung der Angiogenese durch VPA in PC-3-Xenograft-Modellen, allerdings nicht in DU145-Xenograft-Modellen über das Trinkwasser (0,4\% w/v) mittels Blutgefäß-Dichte-Messung nach Färbung mit CD31 gezeigt werden (Shabbeer et al., 2007). In einer weiteren Studie konnte gezeigt werden, dass die Expression von VEGF nach VPA-Behandlung von PC-3-Xenograften vermindert vorlag (Gao et al., 2007). Dies wurde im Rahmen dieser Arbeit aufgegriffen und es konnte auch in den primären PCa-Zellen eine leichte Verringerung der Vegf-Expression gezeigt werden, sowie eine verstärkte Hif1a-Expression. Die Expression von Vegf wird unter hypoxischen Bedingungen von HIF1a induziert, hierfür sind allerdings noch weitere Faktoren notwendig (Banerjee et al., 2007). Unter normoxischen Bedingungen wird HIF1a post-translational über Ubiquitinierung degradiert (D'Andrea et al., 2010). Liegt allerdings viel Kupfer in der Zelle vor, so wird diese Ubiquitinierung verhindert und HIF1a kann wie unter Hypoxie-Bedingungen die Transkription von VEGF initiieren (Martin et al., 2005). Ceruloplasmin ist das Haupt-Kupfertransport-Protein in der Zelle und die Transkription von Ceruloplasmin wird wiederum durch hohe Kupferkonzentrationen und HIF1a initiiert (Martin et al., 2005). Es wurde gezeigt, dass das Plasmalevel von Ceruloplasmin bei Patienten mit PCa signifikant erhöht vorliegt (Nayak et al., 2003). Es wird sogar als neuer Marker für das PCa angesehen (Fotiou K., 2007). In Witt (2009) konnte Ceruloplasmin als differentiell exprimiertes Gen nach der Behandlung der primären PCa-Zellen 2E mit VPA identifiziert werden (Witt et al., 2013). Im Rahmen dieser Arbeit konnte die verminderte Expression von Ceruloplasmin nach 
VPA-Behandlung sowohl konzentrations- als auch zeitabhängig in den PCa-Zellen 2E gezeigt werden (Witt et al., 2013). Es ist demnach anzunehmen, dass in den mit VPAbehandelten PCa-Zellen durch die herunterregulierte Expression von Ceruloplasmin die Kupferkonzentration vermindert ist und somit HIF1a zwar auf RNA-Ebene verstärkt exprimiert wird, in der Zelle allerdings post-translational schnell durch Ubiquitinierung degradiert wird (Abb. 4.8). Daher kann HIF1a nicht die Expression von VEGF beeinflussen und VEGF liegt in VPA-behandelten PCa-Zellen vermindert vor im Vergleich zu kontrollbehandelten Zellen. Dieser Zustand führt möglicherweise zur Inhibition der Angiogenese nach VPA-Behandlung von PCa-Zellen.

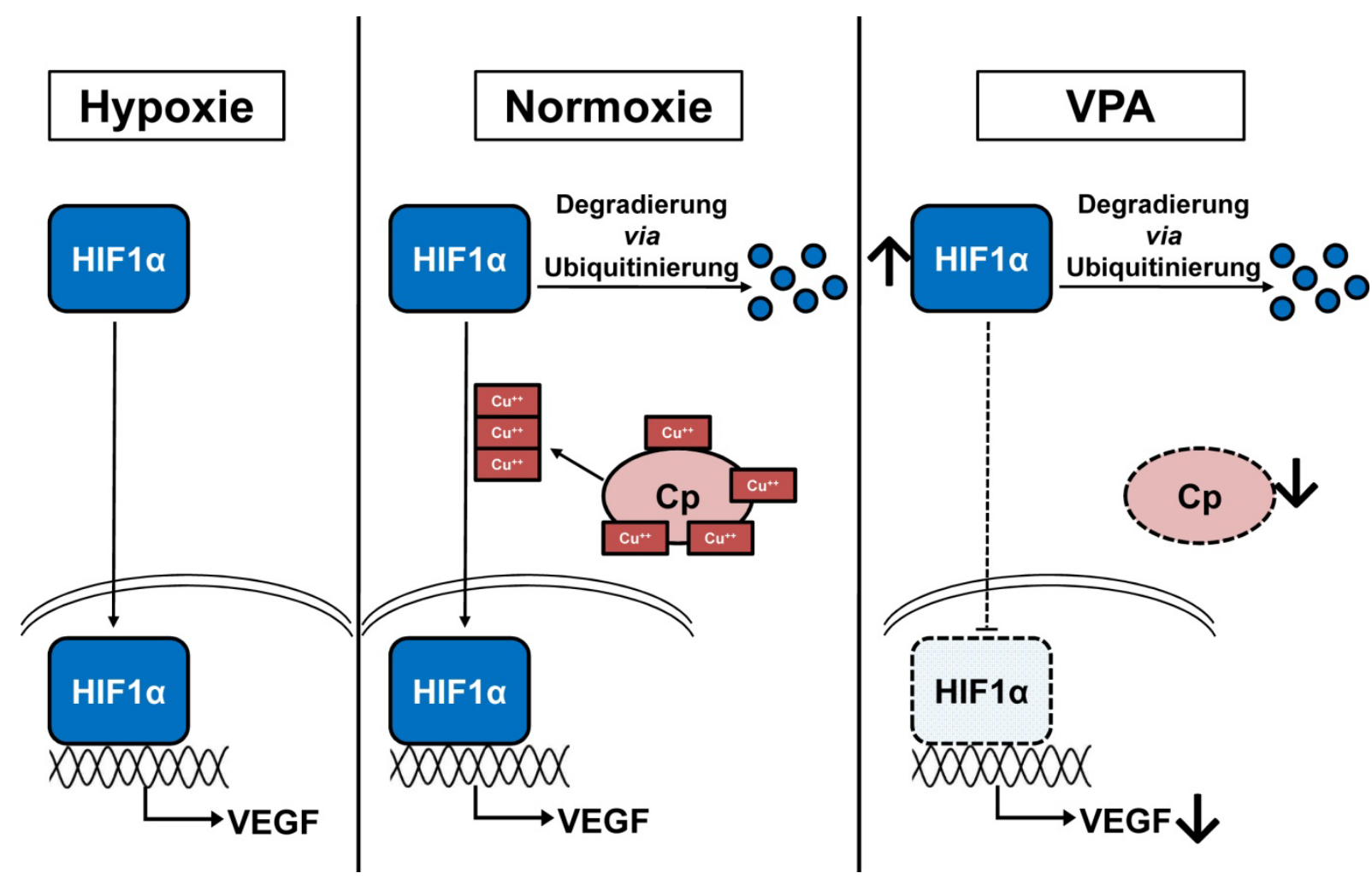

Abbildung 4.8: Vereinfachte Übersicht über die transkriptionelle Regulation von VEGF sowie der in dieser Arbeit generierten Hypothese zur Wirkung von VPA.

Unter Hypoxie-Bedingungen gelangt HIF1 $\alpha$ in den Zellkern und induziert dort zusammen mit weiteren Faktoren (nicht dargestellt) die Expression von VEGF. Unter Normoxie-Bedingungen wird HIF1a über die Ubiquitinierung degradiert. Liegt in der Zelle allerdings viel Kupfer vor, so kann HIF1 $\alpha$ wie unter Hypoxie-Bedingungen in den Zellkern gelangen und dort die Transkription von VEGF initiieren. Kupfer wird in der Zelle durch Ceruloplasmin transportiert (vgl. D'Andrea et al., 2010).

Im Rahmen der vorliegenden Arbeit konnte gezeigt werden, dass nach der Behandlung der primären PCa-Zellen 2E mit VPA eine verminderte Expression von VEGF vorliegt, allerdings auch eine erhöhte mRNA-Expression von HIF1 $\alpha$. Dies führt zu der Hypothese, dass trotz erhöhter HIF1a-mRNA-Expression durch VPA das vorhandene HIF1a-Protein degradiert wird, da die Kupferkonzentration in der Zelle durch die verminderte Expression von Ceruloplasmin niedrig ist. In Folge dessen wird die Expression von VEGF inhibiert.

Die Pfeile symbolisieren die Expression nach VPA-Behandlung der primären PCa-Zellen 2E: 个 verstärkte Expression, $\downarrow$ verminderte Expression (vereinfacht nach D'Andrea et al., 2010). 
Ein weiterer Angiogenese-assoziierter Faktor konnte in der Analyse in Witt (2009) identifiziert werden: Cxcl15. Cxcl15 ist bislang nur in der Maus beschrieben. Es gehört zur Familie der CXC-Chemokine. In dieser Familie haben einige Mitglieder, so auch Cxcl15, ein ELR(Glu-Leu-Arg-)Motiv. ELR-positive CXC-Chemokine können effektiv Angiogenese aktivieren (Strieter et al., 1995) und das Plasmalevel dieser Chemokine ist bei Patienten mit multiplem Myelom erhöht (Pappa et al., 2011). Es konnte gezeigt werden, dass Cxcl15 nach der Behandlung der primären PCa-Zellen 2E mit VPA sowohl konzentrations- als auch zeitabhängig vermindert exprimiert wird (Witt et al., 2013). Dies lässt zusätzlich zu den oben genannten Mechanismen auf eine Inhibition der Angiogenese in den primären PCa-Zellen 2E schließen, deren molekulare Mechanismen in der verminderten Expression von VEGF, Ceruloplasmin sowie Cxcl15 liegen.

\subsubsection{Der Einfluss von Valproinsäure auf epigenetische Mechanismen}

Bei der Untersuchung der Wirkung eines Histondeacetyase-Inhibitors ist das Einbeziehen von epigenetischen Mechanismen unerlässlich. VPA inhibiert die HDACs der Klasse I und Ila (Phiel et al., 2001; Gurvich et al., 2004). Im Rahmen dieser Arbeit wurde daher untersucht, ob die Expression von Kandidatengenen aufgrund des Acetylierungszustandes im Promotorbereich des Gens verändert ist. Es wurden alle in der Microarray-Analyse aus Witt (2009) identifizierten und im Rahmen dieser Arbeit bestätigten Kandidatengene daraufhin untersucht. Die Inhibierung der HDAC-Aktivität führt zu einer verstärkten Acetylierung der Histone, damit zu einer gelockerten Chromatinstruktur und folglich zur Genexpression. Dem entsprechend konnte für keines der Kandidatengene, welche nach der VPA-Behandlung der primären PCa-Zellen 2E vermindert exprimiert vorlag, eine signifikante Änderung der Acetylierung im Promotorbereich detektiert werden (Witt et al., 2013). Allerdings wiesen alle verstärkt exprimierten Gene Ptprn, Uchl1 und Ccnd2 (nach VPA-Behandlung der PCa-Zellen 2E) eine verstärkte Acetylierung im jeweiligen Promotorbereich des Gens auf (Witt et al., 2013). Dies lässt auf einen direkten Mechanismus über die Inhibierung der HDAC durch VPA auf die Genexpression dieser Kandidaten schließen.

Für das Kandidatengen Cyclin D2 wurde dies noch ausführlicher untersucht, indem die Möglichkeit einer veränderten Methylierung im Promotorbereich des Gens mit einbezogen wurde. Es konnte bereits gezeigt werden, dass die Methylierung einiger Gene durch die Behandlung von PCa-Zellen mit HDIs vermutlich durch verminderte Expression der DNA-Methyltransferase 1 verändert vorliegt (Sarkar et al., 2011). Um zu prüfen, ob auch eine Hypomethylierung im Promotorbereich zur verstärkten Expression von Cyclin D2 führt, wurden die PCa-Zellen 2E, PC-3 und DU145 mit dem DNA-Methyltransferase-Inhibitor 5-aza-2'deoxycytidine (5aza2) behandelt. Der DNA-Methyltransferase-Inhibitor 5aza2 führt 
zu einer allgemeinen Hypomethylierung der DNA und somit zur Genexpression (zusammengefasst in Christman, 2002). Als Positivkontrolle einer erfolgreichen 5aza2-Behandlung wurde hier zunächst die Expression von Clusterin untersucht. In der Literatur wurde eine Überexpression von Clusterin nach Behandlung von TRAMP-PCa-Zellen mit 5 aza2 sowie dem HDI Trichostatin A bereits beschrieben (Rauhala et al., 2008). Im Rahmen der vorliegenden Arbeit konnte die verstärkte Expression von Clusterin sowohl durch die Behandlung der PCa-Zellen mit 5aza2 als auch durch VPA bestätigt werden.

Daten aus der Literatur zeigen ebenfalls, dass die Cyclin D2-Expression nach Behandlung von humanen PCa-Zellen mit 5aza2 aktiviert wird. Henrique et al. (2006) konnten nachweisen, dass die Behandlung von PCa-Zellen (LNCaP, DU145 und PC-3) mit 5aza2 nur in LNCaP-Zellen zu einer verstärkten Expression von Cyclin D2 führte. Es konnte im Rahmen dieser Arbeit gezeigt werden, dass die Behandlung aller drei untersuchten PCa-Zellen (2E, PC-3 und DU145) mit 5aza2 die Cyclin D2-Expression nicht in dem Maße induziert, wie es durch VPA hervorgerufen wird. In der methylierungsspezifischen Sequenzierung einer CpG-Insel im Promotorbereich des Cyclin D2-Gens nach VPA-Behandlung der primären PCa-Zellen 2E konnte dieses Ergebnis bestätigt werden. Der untersuchte Promotorbereich des Cyclin D2-Gens lag in den primären PCa-Zellen 2E bereits unmethyliert vor, was sich nach der Behandlung mit VPA nicht änderte.

Zusammenfassend lässt sich sagen, dass die Acetylierung im Promotorbereich der Zielgene nach der Behandlung mit VPA die entscheidende Rolle für die Aktivierung der Genexpression spielt und die Methylierung dabei einen eher untergeordneten Mechanismus darstellt.

\subsubsection{Cyclin D2 als Kandidatengen für die Wirksamkeit von Valproinsäure}

\subsubsection{Die Familie der D-Typ Cycline}

Cyclin D2 gehört zur Familie der D-Typ Cycline. Zu dieser Familie gehören auch das bereits im Kapitel 4.3.2.3 zum Zellzyklus beschriebene Cyclin D1 sowie Cyclin D3. In der Literatur wird häufig allgemein von Cyclin D geschrieben, es gibt allerdings entscheidende Unterschiede in Struktur und Funktion innerhalb dieser Familie. Abbildung 4.9 zeigt die Struktur der drei D-Typ Cycline mit der jeweiligen prozentualen Übereinstimmung in den Domänen im Vergleich zu Cyclin D1. Allein Cyclin D1 besitzt ein LLXXXL-Motiv, welches die Bindung zu bestimmten Transkriptionsfaktoren ermöglicht. Die größte Homologie zwischen den drei Cyclinen ist in der sogenannten Cyclin-Box zu finden, die die Interaktion mit CDK4 und CDK6 vermittelt. Das Rb-Interaktion-vermittelnde LXCXE-Motiv ist in allen drei Cyclinen konserviert. Das Threonin am C-Terminus der drei Proteine kann phosphoryliert werden und 
damit wird die Ubiquitin-vermittelte Degradation initiiert (zusammengefasst in Musgrove et al., 2011).

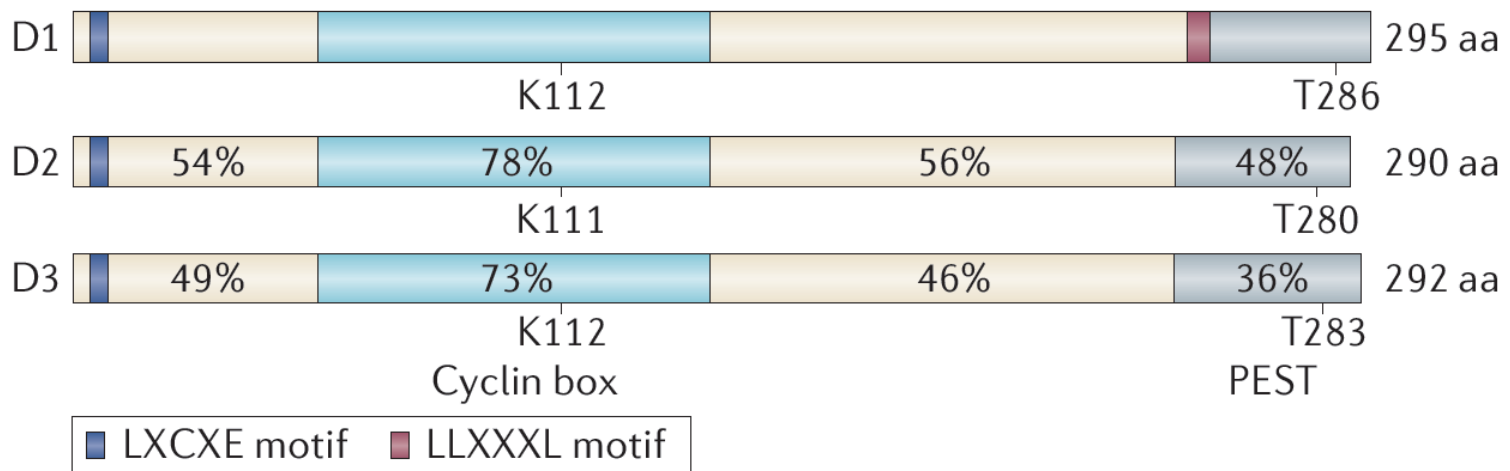

Abbildung 4.9: Proteindomänen der drei D-Typ Cycline.

Die Prozentangaben bezeichnen die jeweilige Übereinstimmung mit der Sequenz von Cyclin D1. Das LXCXE-Motiv ist in allen drei D-Typ Cyclinen konserviert, es ermöglicht die Interaktion mit dem Rb-Protein. In hellblau unterlegt ist die Cyclin Box, die die Interaktion mit den CDKs und den CDK-Inhibitoren ermöglicht. In dunkelblau unterlegt ist die PEST-Domäne, welche spezifisch ist für Proteine, die einen hohen Umsatz haben. In dieser Domäne liegt ein Threonin, welches bei Phosphorylierung die Ubiquitin-vermittelte Degradierung initiiert. Die Phosphorylierung des Threonins 286 von Cyclin D1 vermittelt auch den Transport von Cyclin D1 in den Nukleus. Cyclin D1 besitzt als einziges Familienmitglied ein Leucin-reiches Motiv (LLXXXL-Motiv), welches wichtig ist für die Bindung von Transkriptionsfaktoren (modifiziert nach Musgrove et al., 2011).

Neben den strukturellen Unterschieden gibt es auch zahlreiche funktionelle Spezialisierungen innerhalb der D-Typ Cycline. So können z.B. Cyclin D2 und D3, aber nicht Cyclin D1 zusätzlich zu ihren bekannten Bindungspartnern CDK4 und CDK6 auch die CDK2 binden (Ewen et al., 1993). Die Expression der D-Typ Cycline unterscheidet sich bereits in der frühen Embryonalentwicklung sowohl zeitlich als auch gewebespezifisch (Wianny et al., 1998). So sind Z.B. Zellen, die aus dem Epiblasten und Trophoblasten stammen ausschließlich positiv für eine Cyclin D3-Expression. Der Epiblast selbst exprimiert jedoch noch kein Cyclin D3 (Wianny et al., 1998). Trotz der spezifischen Expressionen aller drei D-Typ Cycline, scheinen sie sich gegenseitig substituieren zu können. Dies zeigen Untersuchungen an knockout-Mäusen für jedes einzelne D-Typ Cyclin. Mäuse ohne die Expression nur eines D-Typ Cyclins sind alle lebensfähig. Sie zeigen allerdings sehr unterschiedliche Phänotypen. Cyclin D1-knockout-Mäuse zeigten z.B. eine gestörte Proliferation des Brustepithels während der Schwangerschaft, während weibliche Cyclin D2-knockout-Mäuse steril waren aufgrund einer Proliferationsinhibition der ovarialen Granulosazellen. Cyclin D3-knockout-Mäuse zeigten eine gestörte Entwicklung unreifer T-Lymphozyten. Auch die Prädisposition für verschiedene Krebsentitäten war unterschiedlich in den verschiedenen knockout-Modellen. Die Abwesenheit der Cyclin D1-Expression erzeugte eine Resistenz gegen durch Ras und Neu erzeugten Brustkrebs, die Abwesenheit 
von Cyclin D2 verminderte die Anfälligkeit für Keimdrüsenkarzinome und das Fehlen der Cyclin D3-Expression verminderte die Suszeptibilität gegenüber dem Haut-Papillom und Myc-induzierten Tumoren der Mundschleimhaut (alle Daten zu Cyclin DEinzel-knockout-Mäusen zusammengefasst in Kozar und Sicinski, 2005). Offensichtlich haben die unterschiedlichen D-Typ Cycline also einige spezialisierte und einige allgemeine Funktionen, die von jedem Cyclin D übernommen werden können. Die Studie der Cyclin D-null-Mäuse brachte weitere interessante neue Erkenntnisse. Wenn alle drei D-Typ Cycline fehlen, entwickelt sich ein Embryo, der bis zum embryonalen Tag 13,5 (E13,5) phänotypisch nicht von den Kontrollmäusen zu unterscheiden ist (Kozar et al., 2004). Bis zu diesem Tag haben sich bereits viele Organe vollständig entwickelt. Die Cyclin-D-null-Mäuse starben alle vor dem E17,5 durch Missbildung des Herzens und daraus resultierender Anämie (Kozar et al., 2004). Diese Studie zeigt eindeutig, dass eine Progression des Zellzyklus auch ohne D-Typ Cycline möglich ist. Andererseits wirft sie auch die Frage auf, warum D-Typ Cycline ab dem oben genannten Zeitpunkt nicht mehr entbehrlich sind. Es wurde bereits gezeigt, dass D-Typ Cycline einige CDK-unabhängige Funktionen ausüben. So kann z.B. Cyclin D1 die Expression der Östrogenrezeptoren und des Androgenrezeptors direkt beeinflussen (zusammengefasst in Fu et al., 2004). Die Untersuchung der D-Typ Cycline stellt folglich ein interessantes, weil noch nicht weit verstandenes Forschungsfeld dar und wurde daher für diese Arbeit ausgewählt.

\subsubsection{Ist Cyclin D2 ein Onkogen oder ein Tumorsuppressorgen?}

Cyclin D2 wurde als Kandidatengen für weitere Untersuchungen ausgewählt. Es wurde in der Microarray-Analyse in Witt (2009) nach Behandlung der PCa-Zellen 2E mit VPA als verstärkt exprimiert nachgewiesen im Vergleich zu kontrollbehandelten Zellen (Witt et al., 2013). Diese Expression konnte im Rahmen dieser Arbeit sowohl zeit- als auch konzentrationsabhängig bestätigt werden (Witt et al., 2013). Zunächst scheint die verstärkte Expression eines Cyclins keine chemotherapeutisch erwünschte Wirkung zu sein. Die Expression von Cyclin D2 ist allerdings in verschiedenen Tumorentitäten unterschiedlich zu bewerten. In Ovarial-, Kolon- sowie Magenkarzinomen ist Cyclin D2 verstärkt exprimiert (Dhillon et al., 2004; Mermelshtein et al., 2005; Takano et al., 2000), wohingegen die Cyclin D2-Expression in Mamma-, Lungen-, Pankreaskarzinom, aber auch in einigen Magenkarzinomen herunterreguliert ist (Evron et al., 2001; Fischer et al., 2002; Virmani et al., 2003; Matsubayashi et al., 2003; Yu et al., 2003). Im Rahmen der vorliegenden Arbeit konnte gezeigt werden, dass in allen untersuchten PCa-Zellen keine Expression von Cyclin D2 detektiert werden konnte (Witt et al., 2013). In den untersuchten nicht-malignen Zelllinien hingegen konnte eine starke Cyclin D2-Expression detektiert werden (Witt et al., 2013). Die im Rahmen dieser Arbeit untersuchten kolorektalen Karzinomzellen wiesen unterschiedliche 
Basalexpressionen von Cyclin D2 auf (Witt et al., 2013). Wie bereits oben beschrieben, ist Cyclin D2 bei Patienten mit einem Kolonkarzinom häufig überexprimiert (Mermelshtein et al., 2005). Zudem ist eine verstärkte Cyclin D2-Expression im Kolonkarzinom mit einem fortgeschrittenen Erkrankungsbild assoziiert und die Deletion von Cyclin D2 in Apcdefizienten-Mäusen verhindert die Entwicklung eines Kolonkarzinoms, was in dieser Tumorentität auf die Rolle von Cyclin D2 als Onkogen schließen lässt (Mermelshtein et al., 2005; Cole et al., 2010).

Im PCa wurde die Expression von Cyclin D2 ebenfalls untersucht. Bereits 2003 konnte durch Padar et al. gezeigt werden, dass in PCa-Patienten in Abhängigkeit vom Schweregrad des Tumors der Cyclin D2-Promotor verstärkt hypermethyliert und damit inaktiv vorliegt. In einer weiteren Studie konnte dies bestätigt werden und die Hypermethylierung des Cyclin D2Promotors mit einer schnelleren Tumorprogression assoziiert werden (Rosenbaum et al., 2005). Durch Henrique et al. (2006) konnte dies in einer Patientengruppe und auch in einigen PCa-Zelllinien gezeigt werden und die Hypermethylierung des Cyclin D2-Promotors in einen Zusammenhang mit einer Verringerung der Genexpression gebracht werden. In diesen Studien wurden Analysen auf DNA- und RNA-Ebene aus PCa-Patientengewebe durchgeführt. Im Rahmen der vorliegenden Arbeit wurden erstmals immunhistochemische Färbungen mit einem Cyclin D2-spezifischen Antikörper an humanen Gewebeschnitten angefertigt. Dadurch konnte die Aussage von Padar, Rosenbaum und Henrique auch auf Proteinebene bestätigt werden und dahingehend ausgeweitet werden, dass tatsächlich nur die PCa-Zellen keine Cyclin D2-Expression zeigten. Zellen im interstitiellen Raum sowie Zellen aus dem umgebenden gesunden Gewebe hingegen zeigten eine Cyclin D2Expression (Witt et al., 2013). Zusätzlich wurden Cyclin D1-spezifische Färbungen durchgeführt. So konnte gezeigt werden, dass Cyclin D1 im PCa-Gewebe verstärkt exprimiert wird (Witt et al., 2013). Die Ergebnisse aus den oben genannten Analysen führen zur Hypothese, dass Cyclin D1 im PCa als Onkogen, Cyclin D2 jedoch als Tumorsuppressor wirken könnte.

\subsubsection{Valproinsäure induziert die Re-Expression von Cyclin D2}

Zur Untermauerung der Theorie, dass Cyclin D2 im PCa als Tumorsuppressor wirkt, wurden zunächst weitere Studien zur VPA-induzierten Cyclin D2-Re-Expression durchgeführt. Es konnte gezeigt werden, dass sich nur die Expression von Cyclin D2 nach der Behandlung der primären PCa-Zellen 2E mit VPA erhöhte, die Expression von Cyclin D1 und Cyclin D3 blieb jeweils unverändert (Witt et al., 2013). Hierbei ist anzumerken, dass die Expression von Cyclin D1 lediglich auf RNA-Ebene untersucht werden konnte und, wie bereits im Kapitel 4.3.2.3 zum Zellzyklus beschrieben wurde, eine post-translationale Degradierung von Cyclin D1 vermutet wird. 
Der Zusammenhang einer Cyclin D2-Überexpression und einer Proliferationshemmung wurde schon 1998 in primären und etablierten Fibroblasten-Zelllinien beschrieben (Meyyappan et al., 1998). Diese Arbeitsgruppe konnte zeigen, dass eine Inhibition der Zellproliferation sowohl nach Kontaktinhibition als auch Serumentzug mit einer verstärkten Expression von Cyclin D2 und einem G1-Arrest einhergeht. Zudem demonstrierten diese Arbeiten, dass durch eine hohe Passagenzahl der Zellen die Cyclin D2-Expression steigt und die Proliferationsrate abnimmt (Meyyappan et al., 1998). Im Rahmen der vorliegenden Arbeit wurde untersucht, ob dieses Phänomen auch in den primären PCa-Zellen 2E detektiert werden kann. Es konnte gezeigt werden, dass die Expression von Cyclin D2 in den 2E-Zellen ebenfalls passagenabhängig ansteigt. Ein Zusammenhang zwischen einer endogen verstärkten Cyclin D2-Expression in hohen Zell-Passagen und der Proliferation der Zellen konnte allerdings nicht beobachtet werden (Daten nicht gezeigt). Die höchste untersuchte Passagenzahl in der vorliegenden Arbeit lag bei Passage 35, diese Anzahl wurde in Meyyappan et al. (1998) durchschnittlich als niedrige Passage bezeichnet, die hohen Passagenzahlen lagen dort zwischen 44 und 81. Es ist also nicht auszuschließen, dass eine Kultivierung der 2E-Zellen bis zu deutlich höheren Passagen das Cyclin D2-Level noch weiter ansteigen lässt und dann auch ein Effekt auf die Proliferation zu detektieren wäre. Das Expressionslevel war selbst in der höchsten hier untersuchten Passage der primären PCa-Zellen nicht vergleichbar mit der Cyclin D2-Expression nach Behandlung mit VPA. Daher konnte auch nach VPA-Behandlung kein passagenabhängiger Effekt auf die Re-Expression von Cyclin D2 beobachtet werden.

Ein funktioneller Zusammenhang zwischen der Cyclin D2-Expression und der Expression eines weiteren nach VPA-Behandlung der primären PCa-Zellen 2E verstärkt exprimierten Gens, Ptprn, konnte in Insulinom-Zellen gezeigt werden (Mziaut et al., 2008). In dieser Arbeit konnte ein direkter Zusammenhang zwischen der Expression von Ptprn, Cyclin D2 und den beiden Transkriptionsfaktoren STAT 3 und STAT5 mit der Proliferation der Zellen nachgewiesen werden (Mziaut et al., 2008). Im PCa wurde ein solcher Zusammenhang bisher noch nicht beschrieben.

Die Proliferationsinhibition nach Cyclin D2-Überexpression mittels Transfektion mit einem Expressionsvektor konnte bereits in den PCa-Zellen LNCaP gezeigt werden (Kobayashi et al., 2009). Daher wurde im Rahmen der vorliegenden Arbeit von einer Überexpression von Cyclin D2 in den primären PCa-Zellen 2E abgesehen und zunächst der Mechanismus der Re-Expression von Cyclin D2 nach VPA-Behandlung eingehender untersucht. 


\subsubsection{Ist die Re-Expression von Cyclin D2 in den Prostatakarzinomzellen 2E Valproinsäure-spezifisch?}

Im Rahmen der vorliegenden Arbeit konnte gezeigt werden, dass der Cyclin D2-Promotor nach der Behandlung mit VPA verstärkt acetyliert vorliegt (Witt et al., 2013). Um zu prüfen, ob die Re-Expression von Cyclin D2 ein spezifischer Effekt durch eine VPA-Behandlung ist oder dies auch nach der Behandlung mit anderen HDIs vorliegt, wurden die primären PCaZellen 2E mit verschiedenen HDIs behandelt. Ein Überblick über die verwendeten HDIs ist in Tabelle 4.5 dargestellt. Die Kriterien zur Auswahl waren sowohl die Struktur, die klinische Etablierung sowie die Spezifität für die verschiedenen HDAC-Klassen. Die HDIs Trichostatin A (TSA) und Suberoylanilide hydroxamic acid (SAHA) wurden neben VPA als weitere etablierte HDIs ausgewählt. Apicidin ist ein neuer HDI mit komplexer Struktur und hemmt als einziger untersuchter HDI neben den HDACs der Klasse I auch die HDACs der Klasse III. Natriumbutyrat (NaB) ist VPA sowohl in der Struktur als auch in der inhibierten HDAC-Klasse ähnlich (zusammengefasst in Bolden et al., 2006). Valpromid (VPM) ist das in vitro inaktive Amid von VPA und wurde als Negativkontrolle mitgeführt.

Tabelle 4.6: Übersicht zu den verwendeten Histondeacetylase-Inhibitoren.

Es sind sowohl die Stukturformel, als auch das Auswahlkriterium sowie die jeweilige Histondeacetylase-KlasseSpezifität (nach Bolden et al., 2006) aufgeführt.

\begin{tabular}{|c|c|c|c|}
\hline HDI & Struktur & Auswahlkriterium & $\begin{array}{c}\text { HDAC- } \\
\text { Klasse- } \\
\text { Spezifität }\end{array}$ \\
\hline Valproinsäue (VPA) & & Etablierter HDI & I, Ila \\
\hline $\begin{array}{c}\text { Trichostatin A } \\
\text { (TSA) }\end{array}$ & & Etablierter HDI & I, II, IV \\
\hline Apicidin & & $\begin{array}{c}\text { Neuer HDI, komplexe } \\
\text { Struktur }\end{array}$ & I, III \\
\hline $\begin{array}{c}\text { Suberoylanilide } \\
\text { hydroxamic acid } \\
\text { (SAHA) }\end{array}$ & & Etablierter HDI & I, II, IV \\
\hline $\begin{array}{l}\text { Natriumbutyrat } \\
\qquad(\mathrm{NaB})\end{array}$ & & $\begin{array}{c}\text { Kurzkettige Fettsäure, } \\
\text { Ähnlichkeit zu VPA }\end{array}$ & I, Ila \\
\hline Valpromid (VPM) & & Negativkontrolle & $\begin{array}{c}\text { Keine } \\
\text { HDI- } \\
\text { Aktivität in } \\
\text { vitro }\end{array}$ \\
\hline
\end{tabular}


Die Behandlung der primären PCa-Zellen 2E mit allen untersuchten HDIs führte zu einer Re-Expression von Cyclin D2 (Witt et al., 2013). Dagegen zeigte die Behandlung mit VPM keine Wirkung auf die Cyclin D2-Expression (Witt et al., 2013). Das einzige bekannte gemeinsame Merkmal aller untersuchten HDIs ist die Inhibition der HDACs der Klasse I. Es ist demnach davon auszugehen, dass die Re-Expression von Cyclin D2 in den 2E-Zellen durch die Inhibierung der HDACs der Klasse I vermittelt wird. Die Proteine der HDAC-Klasse I sind als einzige ausschließlich im Nukleus lokalisiert und können so direkten Einfluss auf die Genexpression nehmen (zusammengefasst in Marks und Xu, 2009). Zusammenfassend lässt sich sagen, dass die Re-Expression von Cyclin D2 in den PCa-Zellen 2E HDI- und nicht allein VPA-spezifisch induzierbar ist.

\subsubsection{Ist die Re-Expression von Cyclin D2 nach Valproinsäure-Behandlung Zelltyp-spezifisch?}

Die Rolle von Cyclin D2 im PCa wurde bereits weiter oben im Text beschrieben. Es wird vermutet, dass Cyclin D2 im PCa die Rolle eines Tumorsuppressors vertritt. Dies geht einher mit der Tatsache, dass alle im Rahmen dieser Arbeit untersuchten PCa-Zelllinien eine niedrige Basalexpression von Cyclin D2 aufwiesen. Nach der Behandlung mit VPA konnte eine Re-Expression von Cyclin D2 detektiert werden und die Proliferation wurde effektiv gehemmt (Witt et al., 2013). Studien zur Inhibition der Proliferation durch VPA im PCa sind bereits zahlreich vorhanden (vgl. Kapitel 4.3.1 über die funktionellen Effekte von VPA). Es sind allerdings keine Arbeiten bekannt, die einen Zusammenhang zwischen der Proliferationsinhibition durch VPA mit der Re-Expression von Cyclin D2 aufzeigen.

Untersuchungen zu einer VPA-Behandlung von nicht-malignen Zellen wurden bislang kaum durchgeführt. In einer Studie konnte gezeigt werden, dass die Behandlung von Hautfibroblasten mit VPA im Gegensatz zu anderen HDIs nicht zu einer Verringerung der Reparatur von Doppelstrangbrüchen führt, allerdings trotzdem wie alle untersuchten HDIs eine Sensibilisierung der Zellen gegenüber einer Bestrahlungstherapie vermittelt (Purrucker et al., 2010). Zur Rolle von Cyclin D2 in Fibroblastenzellen ist bislang lediglich bekannt, dass ein durch Kontaktinhibition hervorgerufener Proliferationsarrest mit einer verstärkten Expression von Cyclin D2 einher geht (Meyyappan et al., 1998; Fang et al., 2002). Im Rahmen der vorliegenden Arbeit konnte gezeigt werden, dass alle nicht-malignen Zellen eine starke Basalexpression von Cyclin D2 aufwiesen (für MRC5-Zellen konnte dies in der Western Blot-Analyse nicht bestätigt werden; Witt et al., 2013). Diese Basalexpression wurde in der überwiegenden Zahl der untersuchten nicht-malignen Zelllinien durch die VPABehandlung nicht verändert und gleichzeitig wurde auch die Proliferation kaum beeinflusst (Witt et al., 2013). Für die weitere Analyse des Zusammenhangs von Cyclin D2 mit der Inhibition der Proliferation von Zellen wurde in den embryonalen Fibroblastenzellen NIH/3T3 
die Cyclin D2-Expression mittels siRNA verringert (Witt et al., 2013). Anschließende Proliferationsassays zeigten, dass die Fibroblastenzellen durch die Verminderung der Cyclin D2-Expression stärker proliferierten (Witt et al., 2013). Zusammenfassend konnte durch die hohe Basalexpression von Cyclin D2 in nicht-malignen Zellen kein Effekt durch VPA auf die Cyclin D2-Expression ausgeübt werden und daher auch keine Inhibition der Proliferation gezeigt werden. Der gegenteilige Ansatz durch Verringerung der Cyclin D2-Expression zeigte einen klaren Zusammenhang zwischen der niedrigen Cyclin D2-Expression und einer erhöhten Proliferation.

Des Weiteren wurde im Rahmen dieser Arbeit der Einfluss von VPA auf Kolonkarzinomzellen analysiert. Wie bereits in Kapitel 4.3.3.2 beschrieben ist Cyclin D2 bei Patienten mit einem Kolonkarzinom häufig überexprimiert (Mermelshtein et al., 2005). Aufgrund dieser Beobachtung und weiterer Studien aus der Literatur ist Cyclin D2 bei dieser Tumorentität wahrscheinlich als Onkogen zu bezeichnen (Cole et al., 2010). In den Untersuchungen im Rahmen der vorliegenden Arbeit wurden zunächst Kolonkarzinomzellinien ermittelt, die unterschiedliche Basalexpressionen von Cyclin D2 aufwiesen. Dies waren DLD-1- und SW620-Zellen mit niedriger, Caco-2-Zellen mit hoher und SW480-Zellen mit Zelldichte-induzierbarer Cyclin D2-Expression. SW480-Zellen wurden zudem ausgewählt, da sie eine sehr hohe Basalexpression von Cyclin D1 im Vergleich zu den anderen untersuchten Zellinien aufwiesen. In der Literatur konnte bereits eine Inhibition der Proliferation in SW480-Zellen durch die Behandlung mit VPA gezeigt werden (Venkataramani et al., 2010). Dies konnte im Rahmen der vorliegenden Arbeit bestätigt werden (Witt et al., 2013). Es konnte bei der Untersuchung der Kolonkarzinomzellen allerdings kein Zusammenhang zwischen Cyclin D2-Expression und Proliferation detektiert werden (Witt et al., 2013), was auf eine gewebespezifische Rolle von Cyclin D2 schließen lässt, die unabhängig von der Regulation der Proliferation ist.

Im Mammakarzinom ist ein Verlust der Expression von Cyclin D2 bekannt (Evron et al., 2001; Fischer et al., 2002). Es konnte im Rahmen dieser Arbeit auch in den Mammakarzinomzellen MDA-MB-231 eine Re-Expression von Cyclin D2 nach der Behandlung mit VPA detektiert werden (Daten nicht gezeigt). Durch Jawaid et al. (2010) konnte eine Inhibition der Proliferation in diesen Zellen sowie den Mammakarzinomzellen MCF7 nach der Behandlung mit VPA gezeigt werden. Die Untersuchung der Cyclin D2Expression nach Behandlung der MCF7-Zellen wird Gegenstand zukünftiger Forschungen sein.

Auch die Untersuchung des sehr aggressiven Pankreaskarzinoms wäre ein interessantes Feld. Die Cyclin D2-Expression bei Patienten wurde als vermindert berichtet (Matsubayashi et al., 2003) und die Behandlung von Pankreaskarzinomzellen mit VPA resultierte in der Inhibition der Proliferation (Jones et al., 2008b; Venkataramani et al., 2010). Diese Daten aus 
der Literatur stimmen mit den vorliegenden Daten zum PCa überein. Es wird daher für das Pankreaskarzinom ein ähnlicher Cyclin D2-vermittelter Mechanismus der Wirkung von VPA auf die Proliferation vermutet, wie er in der vorliegenden Arbeit für das PCa gezeigt werden konnte.

Schlussfolgernd lässt sich sagen, dass VPA in den Untersuchungen dieser Arbeit krebszellspezifisch eine Re-Expression von Cyclin D2 (bei bekanntem Verlust der Expression für die Tumorentität) bewirkte, die in der Inhibition der Proliferation resultierte (Witt et al., 2013). Hierbei ist das Basallevel von Cyclin D2 entscheidend für die Wirkung von VPA. Daher ist davon auszugehen, dass VPA in der Therapie des PCa wenig Nebeneffekte auf gesundes Gewebe hätte, da nicht-maligne Zellen in unseren Untersuchungen bereits eine hohe Basalexpression von Cyclin D2 aufwiesen und durch die VPA-Behandlung nur geringfügig in ihrer Proliferation gehemmt wurden (Witt et al., 2013). Eine graphische Zusammenfassung dieser Hypothese zeigt Abbildung 4.10.

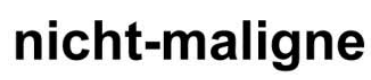

Zelle

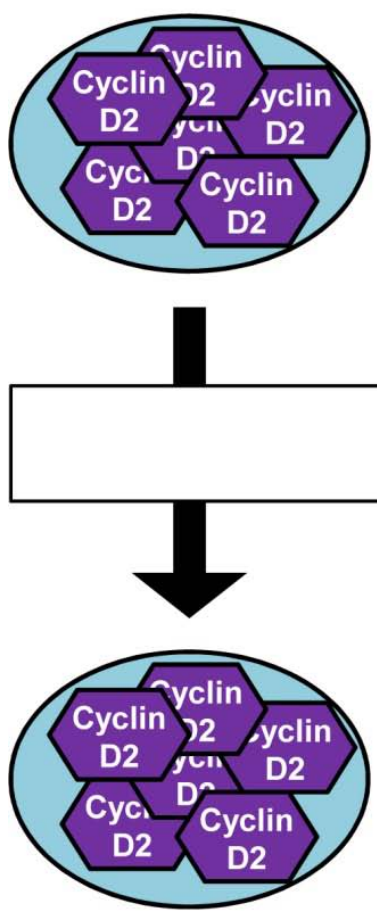

Proliferation $\rightarrow$
ProstatakarzinomZelle

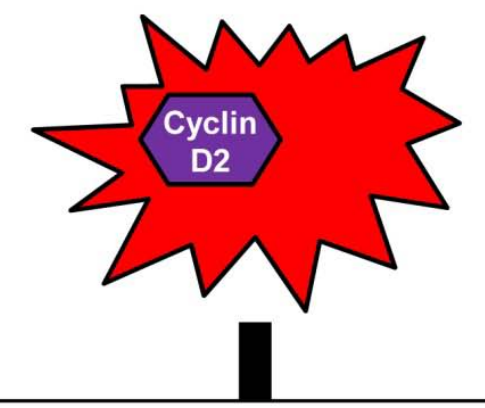

Valproinsäure

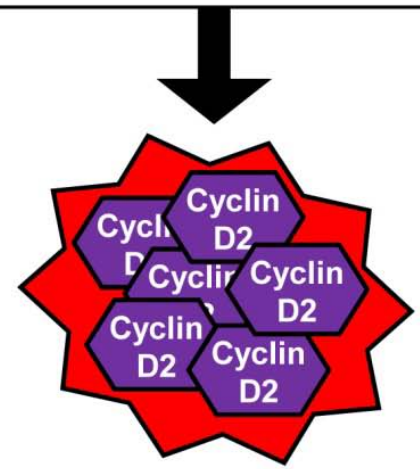

Proliferation $\downarrow$
KolonkarzinomZelle
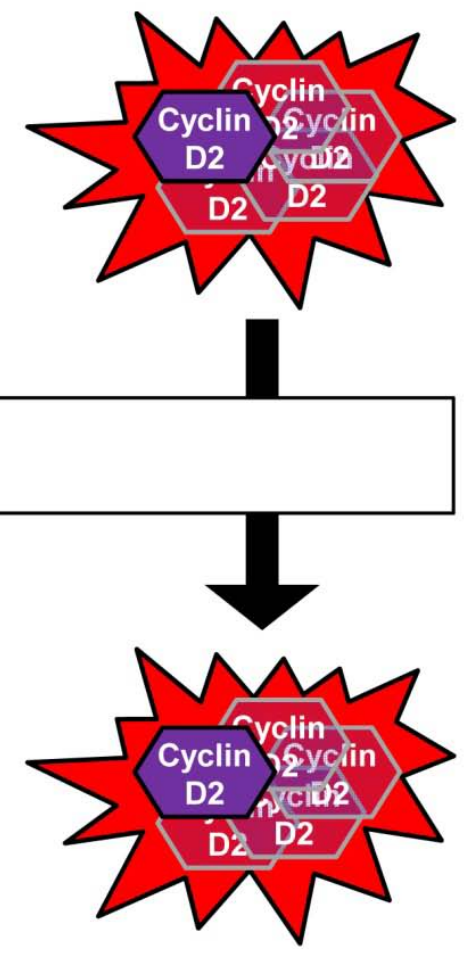

Proliferation $\downarrow \rightarrow$ ?

Abbildung 4.10: Hypothese zum Zusammenhang der Cyclin D2-Expression und der Proliferation von Zellen verschiedener Herkunft.

In nicht-malignen Zellen ist die Basalexpression von Cyclin D2 hoch, die VPA-Behandlung dieser nicht-malignen Zellen beeinflusst die Cyclin D2-Expression nicht und damit auch nicht die Proliferation der Zellen. In PCa-Zellen hingegen ist die Basalexpression von Cyclin D2 niedrig, eine Behandlung mit VPA bewirkt in PCa-Zellen eine Anhebung der Cyclin D2-Expression auf ein physiologisches Level, welches vergleichbar mit nicht-malignen Zellen ist. Damit einher geht eine Inhibition der Proliferation von VPA-behandelten PCa-Zellen. In 
Kolonkarzinomzellen hingegen ist die Cyclin D2-Basalexpression sehr unterschiedlich. Folglich konnte keine eindeutige Regulation der Cyclin D2-Expression und Proliferationsinhibition nach VPA-Behandlung der Kolonkarzinomzellen gezeigt werden.

\subsubsection{Valproinsäure als potentielles Mittel für die Therapie des Prostatakarzinoms}

\subsubsection{In vivo-Experimente}

Für die Untersuchung eines möglichen Präparates für die Therapie sind in vivo-Versuche unerlässlich. Für die Wirksamkeit einer VPA-Behandlung im PCa wurden bereits einige Analysen in verschiedenen Xenograft-Modellen durchgeführt. Shabbeer et al. (2007) führten in diesem Zusammenhang wichtige Grundlagenstudien zur Halbwertszeit von VPA im Blut durch. Sie konnten im Nacktmaus-Modell zeigen, dass eine Einzelinjektion von 300mg VPA pro Kilogramm Körpergewicht eine Halbwertszeit von 60 Minuten aufwies. Eine Behandlung über das Trinkwasser mit 0,4\% w/v VPA resultierte in einem konstanten Plasmalevel von 0,4mM VPA (Shabbeer et al., 2007). Der überwiegende Teil der Studien führte eine VPABehandlung von Mäusen daher über das Trinkwasser durch. Lediglich in den CWR-22-PCaXenografts wurde nach täglicher Injektion von 200mg VPA pro Kilogramm Körpergewicht nach 30 Tagen ein reduziertes Tumorvolumen detektiert (Hudak et al., 2012). In PC-3Xenografts konnte nach vier Wochen VPA-Injektion mit 150mg pro Kilogramm Körpergewicht keine Änderung des Tumorgewichts und -volumens, der Proliferation sowie der p21Expression detektiert werden (Annicotte et al., 2006). Mit einer höheren Dosis (300mg/kg Körpergewicht) wurde allerdings eine verminderte Invasivität beobachtet (Annicotte et al., 2006).

Die Studien zur Behandlung mit VPA über das Trinkwasser sind deutlicher. Es wurden Xenograft-Modelle mit verschiedenen PCa-Zellen untersucht, diese waren PC-3-, DU145-, LNCaP- und C4-2-Zellen. In allen untersuchten Modellen konnte ein geringeres Tumorvolumen nach Behandlung mit 0,4\% w/v VPA nach ca. einem Monat Behandlung nachgewiesen werden (Xia et al., 2006; Shabbeer et al., 2007; Gao et al., 2007; Angelucci et al., 2008). Im Rahmen der vorliegenden Arbeit sollten 2E-Zellen im Xenograft-Modell untersucht werden. Es konnte allerdings kein reproduzierbares Tumorwachstum nach subkutaner Injektion von Nacktmäusen mit 2E-Zellen erreicht werden (Daten nicht gezeigt). Aufgrund der zahlreich vorhandenen Veröffentlichungen zu der Wirkung von VPA im PCa-Xenograft-Modell sollten parallel die Effekte von VPA im TRAMP-Modell untersucht werden. Hierfür wurden zunächst in Zusammenarbeit mit den Abteilungen Urologie und Pathologie der Universitätsmedizin Göttingen in vivo-Versuche durchgeführt. Die behandelten TRAMP-Mäuse wurden mit dem VPA-enthaltenden Medikament Orfiril ${ }^{\circledR}$ über das Trinkwasser gefüttert. Es konnten keine eindeutigen chemopräventiven Effekte von VPA in Form von Orfiril ${ }^{\circledR}$ auf die Tumorprogression bei den TRAMP-Mäusen detektiert werden 
(Daten nicht gezeigt). Bei den Untersuchungen zur Expression konnte in den Orfiril $^{\circledR}$-behandelten Tumoren eine verstärkte Expression des AR, des ER $\beta$ sowie von Cyclin D2 detektiert werden (Daten nicht gezeigt). Es konnten hier also erste molekulare Ansatzpunkte zur Wirksamkeit von VPA in vivo identifiziert werden, jedoch war das Ergebnis zur Tumorprogression nicht wie erwartet.

Orfiril $^{\circledR}$ enthält eine Mischung von Süßstoffen, die nicht näher deklariert ist. Es konnte folglich nicht ausgeschlossen werden, dass die Gabe dieser Süßstoffe die Tumorprogression fördert, da keine geeignete Kontrollgruppe vorlag. Ohne Süßungsmittel hat VPA einen bitteren Geschmack und wird von den Mäusen nicht toleriert. Daher wurde im Rahmen der vorliegenden Arbeit eine weitere Studie zur Wirkung von VPA durchgeführt in der sowohl die kontrollbehandelten als auch die VPA-behandelten TRAMP-Mäuse eine definierte Menge Süßstoff zu sich nahmen. Diese Untersuchungen wurden in drei Gruppen eingeteilt: eine präventive und eine therapeutische Überlebensstudie sowie eine präventive Progressionsstudie (vgl. Tabelle 4.6). Diese Studien konnten im Rahmen der vorliegenden Arbeit noch nicht abgeschlossen werden. Daher sind die hier präsentierten Ergebnisse lediglich als vorläufig anzusehen.

Es wurden zwei generelle, unerwartete Effekte beobachtet. Zum einen wurden im Verlauf der Versuche in den TRAMP-Mäusen zahlreiche Samenblasentumore (SB-Tumore) makroskopisch detektiert. Dies ist ein für das TRAMP-Modell bekannter Effekt (Tani et al., 2005; Yeh et al., 2009). Es wurden jedoch in den Experimenten im Rahmen dieser Arbeit die SB-Tumore in der Mehrheit der Fälle nicht gleichzeitig mit einem PCa beobachtet. Lediglich bei drei Tieren der Kontrollgruppe von sechs bis 30 Wochen wurde ein gleichzeitiges Auftreten eines $\mathrm{PCa}$ mit einem SB-Tumor detektiert. Diese Ergebnisse bedürfen allerdings zunächst noch einer histopathologischen Auswertung.

Ein weiterer unerwünschter Nebeneffekt in den Untersuchungen war, dass sich nicht bei 100\% der Mäuse ein PCa entwickelte. Laut der Literatur entwickelt sich bei TRAMP-Mäusen ein aggressives PCa nach etwa 30 Wochen (Mentor-Marcel et al., 2001). Dies konnte hier und in früheren Arbeiten unserer Arbeitsgruppe nicht bestätigt werden.

Im Allgemeinen weisen die Untersuchungen zur Wirkung von VPA allerdings darauf hin, dass VPA vor allem in späten Phasen der Tumorprogression wirkt. In der Gruppe, die präventiv VPA bis zu einem Alter von 30 Wochen erhielt, konnte bislang kein Unterschied zur Kontrollgruppe gezeigt werden. In der Überlebensstudie nach präventiver Gabe von VPA konnten hingegen deutlich weniger $\mathrm{PCa}$ im Vergleich zu kontrollbehandelten Mäusen makroskopisch detektiert werden. Zusätzlich überlebten die VPA-behandelten Mäuse einen längeren Zeitraum. Die Überlebensstudie nach therapeutischer Gabe von VPA ist mit jeweils vier Mäusen pro Gruppe noch nicht auswertbar. Allerdings zeichnet sich auch hier eine Tendenz zu längerem Überleben sowie geringerer Tumoranzahl bei den VPA-behandelten 
Mäusen ab. Zusammengefasst deuten diese Ergebnisse auf eine effektive Wirkung von VPA in späten Phasen der PCa-Entwicklung hin, die allerdings noch histopathologisch und durch höhere Mauszahlen abgesichert werden muss.

Tabelle 4.7: Überblick über die bis zum Zeitpunkt dieser Arbeit vorhandenen Daten aus den TRAMP-Maus-Experimenten mit VPA-Gabe über das Trinkwasser.

Der Anteil an Prostatakarzinomen (PCa) und Samenblasentumoren (SB-Tumoren) wurde makroskopisch ermittelt. $\varnothing$, durchschnittlich.

\begin{tabular}{|l|c|c|c|c|c|c|}
\hline & \multicolumn{2}{|c|}{$\begin{array}{c}\text { ab sechs Wochen } \\
\text { Überlebens-studie }\end{array}$} & \multicolumn{2}{c|}{$\begin{array}{c}\text { ab sechs } \\
\text { Wochen bis 30 } \\
\text { Wochen }\end{array}$} & \multicolumn{2}{c|}{$\begin{array}{c}\text { ab 16 Wochen } \\
\text { Überlebens- } \\
\text { studie }\end{array}$} \\
\cline { 2 - 7 } & Kontrolle & VPA & Kontrolle & VPA & Kontrolle & VPA \\
\hline $\begin{array}{l}\text { Anzahl untersuchter } \\
\text { Mäuse }\end{array}$ & 10 & 13 & 9 & 9 & 4 & 4 \\
\hline $\begin{array}{l}\boldsymbol{\emptyset} \text { Überlebensalter in } \\
\text { Wochen }\end{array}$ & 31 & 37 & 30 & 30 & 28 & 39 \\
\hline Anteil an PCa & $6 / 10$ & $3 / 13$ & $1 / 9$ & $\begin{array}{c}1 / 9 \\
11 \%\end{array}$ & $\begin{array}{c}2 / 4 \\
50 \%\end{array}$ & $\begin{array}{c}1 / 4 \\
25 \%\end{array}$ \\
\hline $\begin{array}{l}\text { Anteil an SB- } \\
\text { Tumoren }\end{array}$ & $7 / 10$ & $9 / 13$ & $5 / 9$ & $3 / 9$ & $2 / 4$ & $3 / 4$ \\
\hline $\begin{array}{l}\text { Urogenitaltrakt (g) I } \\
\text { Gesamtgewicht (g) }\end{array}$ & $70 \%$ & $69 \%$ & $55 \%$ & $33 \%$ & $50 \%$ & $75 \%$ \\
\hline
\end{tabular}

\subsubsection{Klinische Studien zur Valproinsäure-Behandlung von Tumorerkrankungen}

Für die Behandlung von hämatogischen Krebserkrankungen mit VPA gibt es bereits eine Reihe von klinischen Studien. VPA wird hierbei häufig zusammen mit der All-trans-Retinsäure verwendet und es ist überwiegend ein gutes Ansprechen der Patienten auf diese Kombinationstherapie zu verzeichnen (zusammengefasst in Kuendgen und Gattermann, 2007 und Wagner et al., 2010).

Klinische Studien für die Verwendung von VPA als Medikament bei soliden Tumorerkrankungen sind bereits bis zu Phase 3-Studien vorangeschritten. Vor allem Studien zur Kombinationsbehandlung von VPA mit Mitteln, die eine Hypomethylierung bewirken, wurden durchgeführt. Für das nicht-kleinzellige Lungenkarzinom wurde erst kürzlich gezeigt, dass eine Behandlung mit VPA in Kombination mit dem DNA-Methyltransferase-Inhibitor 5-aza-2'-deoxycytidine ein vielversprechender Ansatz sein könnte, da eine Stabilisierung der Erkrankung sowie die Verbesserung von Blutparametern erreicht werden konnte (Phase 1-Studie) (Chu et al., 2012). Weitere Phase 1- und Phase 2-Studien wurden an Patienten mit Mammakarzinom (Arce et al., 2006; Candelaria et al., 2007), Glioblastom (Weller et al., 2011), Melanom (Rocca et al., 2009), Cervix-, Ovarial-, Lungen-, und Testiskarzinom (Candelaria et al., 2007) durchgeführt und konnten (teilweise in Kombination 
mit Chemo- oder Radiotherapie) im Allgemeinen ein gutes Ansprechen auf die VPABehandlung zeigen. Für das Cervix-Karzinom wurde bereits eine Phase 3-Studie durchgeführt, welche eine Verlangsamung der Tumorprogression nach Behandlung mit VPA in Kombination mit Zytostatika zeigen konnte (Coronel et al., 2011).

Zwei Studien haben sich mit der Wirksamkeit von VPA auf verschiedene solide Tumore beschäftigt. Munster et al. (2009) führten eine Studie an Mammakarzinom- und MelanomPatienten und Patienten mit weiteren soliden Tumoren, unter anderem Lungen-, Cervix-, Pankreas- und Prostatakarzinom, durch. Sie konnten bei der Kombinationstherapie von VPA mit dem Zytostatikum Epirubicin ein gutes Ansprechen auf die Therapie mit einer Abnahme der Tumorgröße verzeichnen. Dies konnte vor allem bei Patienten mit einem Mamma-, Cervix-, Pankreas- oder Prostatakarzinom gezeigt werden (Munster et al., 2009). Die Anzahl an untersuchten Patienten war in dieser Studie allerdings sehr klein, es wurden z.B. lediglich zehn Patienten mit einem Mammakarzinom und nur zwei Patienten mit einem PCa untersucht. In einer weiteren Studie zur Wirkung von VPA in Kombination mit dem DNA-Methyltransferase-Inhibitor 5-aza-2'-deoxycytidine auf verschiedene solide Tumore konnte bei einem von zwei untersuchten PCa-Patienten im fortgeschrittenen Stadium eine Stabilisierung der Erkrankung über einen Untersuchungszeitraum von sechs Monaten gezeigt werden (Braiteh et al., 2008).

Es liegt lediglich eine Veröffentlichung zu einer Phase 2-Studie an zehn Patienten mit einem kastrationsresistenten PCa vor. In dieser Studie konnten aufgrund von schlechter Toleranz im Vergleich zu anderen Studien nur geringe Mengen an VPA verabreicht werden, die zu einem Plasmalevel von VPA führten, welches deutlich unter dem der anderen Studien lag. Die Behandlungsdauer lag zwischen sieben und 633 Tagen. Das PSA-Level der Patienten lag zwischen 5,5 und $731,6 \mathrm{ng} / \mathrm{ml}$ (Sharma et al., 2008). Ein Patient verstarb im Laufe der Studie aufgrund der Progression des PCa, zwei Patienten zeigten ein vermindertes PSALevel und keine Tumorprogression, wobei das PSA-Level invers mit dem VPA-Level im Blut korrelierte (29 Tage bzw. 632 Tage Behandlung). Die durchschnittliche Acetylierung des Histons 3 veränderte sich kaum über einen Zeitraum von 28 Tagen (Sharma et al., 2008). Diese Studie zeigt, dass selbst eine sehr geringe Dosis von VPA bereits zu einer Verbesserung des Krankheitsbildes führen kann. In folgenden Studien sollten VPA-Dosen verabreicht werden, die zu einer nachweisbaren Acetylierung der Histone führen und ein höheres Plasmalevel von VPA erreichen. Die Dosis wurde in der Studie von Sharma et al. (2008) aufgrund der Nebenwirkungen von VPA nicht erhöht. Es handelte sich hierbei hauptsächlich um neurologische Nebenwirkungen des Grades 1-2. Dies waren z.B. Somnolenz, Schwindel und Tremor. Diese Nebenwirkungen wurden auch bei höheren Dosen von VPA im gleichen Schweregrad beschrieben (zusammengefasst in Dueñas-González et al., 2008 und Wagner et al., 2010). 


\subsubsection{Tumorrisiko bei Patienten mit Valproinsäure-behandelter Epilepsie}

Der Zusammenhang zwischen Tumorinitiation und der Therapie mit Histondeacetylase-Inhibitoren wie VPA aufgrund einer Epilepsieerkrankung konnte lange Zeit nicht hinreichend gezeigt werden. In einer dänischen Studie wurde kein Zusammenhang zwischen einer Behandlung mit VPA und dem Tumorrisiko detektiert (Hallas et al., 2009). In einer britischen Studie wurde gezeigt, dass in der untersuchten VPA-Gruppe im Vergleich zu einer Kontrollgruppe das Risiko an einem Kolonkarzinom zu erkranken signifikant höher ist und das Risiko an einem Prostatakarzinom zu erkranken einen Trend in Richtung erhöhtem Risiko aufwies (Singh et al., 2012). Für das Mammakarzinom konnte hingegen ein Trend in Richtung eines verminderten Risikos gezeigt werden (Singh et al., 2012). Beim PCa ist ein entscheidender Risikofaktor das Alter. In der Studie von Singh et al. (2012) wurden jedoch nur Teilnehmer in einem Alter zwischen 13 und 52 Jahren untersucht. Das mittlere Erkrankungsalter beim PCa liegt (in Deutschland) jedoch bei ca. 70 Jahren (RKI und GEKID, 2012).

In einer deutschen Studie wurden VPA-behandelte Epilepsie-Patienten und Kontrollpersonen altersabhängig verglichen (Stettner et al., 2012). Es konnte gezeigt werden, dass das PSA-Level der Kontrollpersonen altersabhängig steigt, wohingegen das PSA-Level der VPA-behandelten Patienten konstant bleibt zwischen 40- und 80jährigen Patienten. In dieser Studie wurden zudem Patienten, die eine Therapie mit anderen HDIs erhielten, untersucht. VPA zeigte hierbei den stärksten Effekt auf das PSA-Level der Patienten im Vergleich zu anderen HDIs (Stettner et al., 2012).

\subsubsection{Fazit: Ist Valproinsäure ein potentielles Mittel für die Therapie des Prostatakarzinoms?}

Für die Verwendung des HDIs VPA in der Therapie des PCa sprechen viele Punkte. Zum einen die oben genannte Studie von Stettner et al. (2012), die zeigen konnte, dass das PSA-Level altersabhängig bei VPA-behandelten Epilepsie-Patienten niedriger ist als bei einer Kontrollgruppe. Der Anstieg des PSA-Levels ist als Marker für das PCa weit verbreitet (Stettner et al., 2012). Die klinischen Studien zur VPA-Behandlung von Patienten mit PCa sind jedoch nicht informativ. In den vorliegenden Studien wurden insgesamt nur 14 Patienten untersucht (Braiteh et al., 2008; Sharma et al., 2008; Munster et al., 2009). Diese Studien zur Wirksamkeit von VPA im PCa sollten weiter ausgedehnt werden, auch in Kombination mit einer Dosisfindungsstudie.

Die Ergebnisse aus den in vitro- und in vivo-Experimenten der vorliegenden Arbeit sowie aus den aus der Literatur bekannten Studien sprechen ausnahmslos für eine Verwendung von VPA als Mittel gegen das PCa. Die Inhibierung der Proliferation, Migration und Invasion der PCa-Zellen sind dabei die entscheidenden Aspekte. Auch in zahlreichen weiteren in vivo- 
Studien in Maus-Modellen konnte die chemotherapeutische Wirkung von VPA im PCa demonstriert werden. Im Rahmen der vorliegenden Arbeit gibt es sogar Hinweise darauf, dass VPA vor allem in späteren Stadien des PCa wirksam ist. Bei Patienten mit einem PCa gibt es in diesen Stadien bislang lediglich palliative Therapie-Ansätze.

Bei den molekularen Mechanismen zur Wirkung von VPA in PCa-Zellen ist im Rahmen der vorliegenden Arbeit vor allem das Kandidatengen Cyclin D2 identifiziert und eingehender untersucht worden. Es ist bekannt, dass Cyclin D2 bei PCa-Patienten vermindert exprimiert vorliegt (Henrique et al., 2006). Im Rahmen der vorliegenden Arbeit konnte gezeigt werden, dass durch eine VPA-Behandlung von PCa-Zellen Cyclin D2 re-exprimiert wird (Witt et al., 2013). Es konnte zusätzlich demonstriert werden, dass es sich nicht um eine generelle Überexpression von Cyclin D2 in jedem Zelltyp handelt, sondern lediglich das Cyclin D2Expressionslevel von einem pathologischen Verlust auf ein physiologisches Level angehoben wird (Witt et al., 2013). Bei der Behandlung von Patienten mit einem PCa könnte es folglich möglich sein, den Therapieerfolg anhand des Cyclin D2-Levels in den Tumorzellen vor der Therapie zu prognostizieren.

Zusammenfassend lässt sich sagen, dass VPA ein hohes Potential als Mittel gegen das humane PCa hat, da es auf epigenetischem Level wirkt. Damit bringt VPA das Expressionslevel von deregulierten Zielgenen, wie z.B. Cyclin D2, lediglich wieder auf ein physiologisches Level.

\subsection{Perspektiven}

\subsubsection{Das Phytoöstrogen Tectorigenin}

Bei den Untersuchungen zum Gesamtextrakt aus Belamcanda chinensis sowie dem daraus gewonnenen Tectorigenin konnte bereits in Witt (2009) eine starke Abweichung der Wirksamkeit der verschiedenen Tectorigenin-Aufreinigungen in PCa-Zellen demonstriert werden. Dies konnte im Rahmen dieser Arbeit auch für weitere Tectorigenin-Aufreinigungen gezeigt werden. Es sollte folglich eine chemische Analyse der verschiedenen Substanzen erfolgen, welche Klarheit über den tatsächlichen Gehalt an Tectorigenin sowie möglicher Verunreinigungen bringt. In dieser Arbeit wurde anhand von ausgewählten Kandidatengenen eine bestimmte Tectorigenin-Aufreinigung für weitere Analysen ausgewählt. Dieses Vorgehen sollte in Zukunft beibehalten werden, da es sich bei Tectorigenin um ein Naturprodukt handelt und daher immer von Schwankungen in verschiedenen Chargen auszugehen ist. Als nützliche Marker für die Wirksamkeit von Tectorigenin haben sich vor allem der IGF-IR und PSA, welche beide vermindert vorliegen sollten, sowie das IGFBP-3, welches verstärkt exprimiert vorliegen sollte nach der Behandlung von PCa-Zellen mit 
Tectorigenin, herausgestellt. So wäre gewährleistet, dass ein Qualitätsstandard auch für neue Chargen des Produkts eingehalten werden kann.

Ein interessanter Effekt der mit dem Gesamtextrakt $\mathrm{R}$ aus Belamcanda chinensis behandelten primären PCa-Zellen 2E konnte im Rahmen dieser Arbeit identifiziert werden: nach der Behandlung waren die Zellen angefüllt mit zytoplasmatischen Vesikeln. Es sollte untersucht werden, ob es sich bei diesem Effekt um Endozytose oder Autophagozytose handelt. Dies kann durch Färbungen von spezifischen Marker-Proteinen durchgeführt werden (vgl. Kapitel 4.2.2). Auch sollte getestet werden, ob dieser Effekt lediglich durch den Gesamtextrakt aus Belamcanda chinensis auftritt oder auch durch eine Behandlung mit Tectorigenin. Zudem sollte die Entstehung und die weitere Progression der Vesikel untersucht werden. Die im Rahmen dieser Arbeit gezeigten Färbungen wurden nach 24 Stunden Behandlung mit dem Gesamtextrakt aus Belamcanda chinensis angefertigt, es wäre interessant einen zeitlichen Verlauf der Vesikelentstehung und -progression darzustellen.

Des Weiteren sollte geklärt werden, warum die primären, murinen PCa-Zellen 2E bei einer z.T. achtfach höheren Dosis von Tectorigenin erst vergleichbare Ergebnisse auf die Modulation von Genexpressionen zeigten wie die humanen PCa-Zellen LNCaP. Die primären 2E-Zellen wurden aus dem transgenen TRAMP-Maus-Modell generiert. Diese Tumorzellen aus dem transgenen Modell könnten spezifische Mutationen aufweisen, die die Wirksamkeit von Tectorigenin in niedrigen Dosen beeinflussen. Die Identifizierung dieser Mutationen würde nicht nur die Unterschiede der benötigten Konzentrationen von Tectorigenin in den verwendeten Zell-Modellen erklären sondern zudem interessante Einblicke in die Wirkungsweise von Tectorigenin geben.

Einige Hinweise auf die Wirkungsweise konnte die im Rahmen dieser Arbeit durchgeführte Microarray-Analyse liefern. Hierbei wurden zahlreiche interessante Kandidatengene identifiziert, die in folgenden Studien zunächst bestätigt und anschließend näher analysiert werden sollten, z.B. durch Überexpressions- oder siRNA-Studien. Es wurden vermehrt Gene detektiert, welche eine Inhibition des Zellzyklus und der Replikation hervorrufen. Diese sollten einen Schwerpunkt der nachfolgenden Untersuchungen darstellen, da eine Inhibition der Proliferation nach Behandlung von PCa-Zellen mit Tectorigenin zwar bereits beschrieben ist, die zugrunde liegenden molekularen Mechanismen allerdings weitestgehend ungeklärt sind.

Ein zweiter Schwerpunkt der Microarray-bezogenen Untersuchungen sollte die Analyse von Tectorigenin als mögliches Anti-Androgen im PCa darstellen. Es konnte gezeigt werden, dass eine signifikant hohe Anzahl an Genen aus der Microarray-Analyse Androgen-reguliert ist. Allerdings konnte eine Veränderung der AR-Expression in PCa-Zellen nach TectorigeninBehandlung selbst nicht demonstriert werden. Zum einen könnte lediglich die Aktivität des 
AR vermindert sein. Dies könnte durch Luciferase-Assays sowie ImmunfluoreszenzFärbungen zur Lokalisation des AR überprüft werden. Es besteht die Möglichkeit, dass der AR nach der Behandlung mit Tectorigenin zwar in unveränderter Menge vorliegt, allerdings nicht mehr im Kern lokalisiert ist und daher die Expression der Zielgene nicht mehr beeinflussen kann. Zum anderen könnte auch die Aktivität der $5 \alpha$-Reduktase durch die Behandlung der PCa-Zellen mit Tectorigenin vermindert sein. Dies konnte bereits für die in grünem Tee enthaltenen Katechine in einem Ratten-Modell gezeigt werden (Liao und Hiipakka, 1995). Diese Inhibition könnte durch Ermittlung des Umsatzes von Testosteron in Dihydrotestosteron untersucht werden. Eine Inhibition der Aktivität beider Komponenten, des AR sowie der 5a-Reduktase, würde die beobachtete Inhibition von AR-Zielgenen nach Behandlung mit Tectorigenin erklären und sollte somit Gegenstand zukünftiger Untersuchungen sein.

Schließlich sollte weiterhin untersucht werden, warum Tectorigenin als Phytoöstrogen in den Analysen im Rahmen dieser Arbeit keinen Einfluss auf die Expression der beiden Östrogenrezeptoren $\alpha$ und $\beta$ ausübte. Auch hier wäre eine Inhibierung der Aktivität möglich, daher sollte zunächst die Expression von Zielgenen der beiden Östrogenrezeptoren untersucht werden. Sind diese differentiell exprimiert, so sollten Aktivitätsstudien der Östrogenrezeptoren folgen. Falls bei diesen Studien ein Einfluss von Tectorigenin auf die Aktivität der Östrogenrezeptoren bestätigt werden kann, so könnten Studien zur Wirksamkeit von Tectorigenin in ERa- bzw. ERß-defizienten TRAMP-Mäusen folgen. Ähnliche Analysen wurden kürzlich in einer Studie zur Wirkungsweise des Isoflavons Genistein durchgeführt (Slusarz et al., 2012). Diese Untersuchungen zeigten, dass in beiden ER-knockout-TRAMP-Modellen die Wirkung von Genistein vermindert ist im Vergleich zu ER-Wildtyp-TRAMP-Mäusen. Dies weist auf einen eindeutigen Wirkungsmechanismus von Genistein über die Östrogenrezeptoren hin, der für das Isoflavon Tectorigenin auch möglich wäre.

\subsubsection{Der Histondeacetylase-Inhibitor Valproinsäure}

Die Wirkung des Histondeacetylase-Inhibitors VPA wurde bereits von einigen Arbeitsgruppen im PCa untersucht. Im Rahmen der vorliegenden Arbeit konnten einige weitere Mechanismen von VPA identifiziert werden, die die Wirksamkeit von VPA für die Therapie des PCa unterstreichen. Diese Ergebnisse bieten zahlreiche Ansatzpunkte für weiterführende Analysen. Zunächst sollten einige globalere Analysen durchgeführt werden. Im Rahmen dieser Arbeit wurde bereits eine Sequenzierung nach Chromatinimmunopräzipitation (ChIP-Seq) durchgeführt. Die Ergebnisse dieser Analyse liegen allerdings noch nicht vor. Es wurde mit einem Antikörper gegen acetyliertes Histon 3 an Lysin 9 präzipitierte DNA aus 2E-Zellen, die mit und ohne VPA kultiviert wurden, 
sequenziert. Diese Analyse wird einen Einblick geben, welche Gene aus der in Witt (2009) durchgeführten Microarray-Analyse direkt durch eine Änderung des Acetylierungszustandes des Gens durch VPA reguliert werden. Zudem können durch diese Analyse weitere Kandidatengene für nachfolgende Untersuchungen identifiziert werden.

Ein weiterer umfassender Ansatz wäre die Durchführung von Aktivierungsassays nach der Behandlung von PCa-Zellen mit VPA. Es konnten in dieser Arbeit zahlreiche differentiell exprimierte Gene nach der Behandlung der primären PCa-Zellen 2E identifiziert werden. Um allerdings einen Überblick über Regulationen vor allem im Zellzyklus zu erhalten, muss auch der Phosphorylierungszustand der Proteine untersucht werden. Hierbei könnte auch die Regulation der Cyclin D1-Expression untersucht werden. Es wurde die Hypothese aufgestellt, dass Cyclin D1 nach der Behandlung mit VPA zwar auf RNA-Ebene unverändert exprimiert vorliegt, allerdings auf Proteinebene durch Interaktionen mit Gsk3 $\beta$, Hif1 $\alpha$ und Uchl1 post-translational degradiert werden könnte. Diese Interaktionen sind vorwiegend durch Phosphorylierungen reguliert, daher sollten die Studien der Phosphorylierung von Proteinen Gegenstand zukünftiger Forschungen sein.

Generell sollten die aufgestellten Hypothesen $\mathrm{zu}$ den Zusammenhängen der Genregulationen in Apoptose, Angiogenese sowie dem Zellzyklus in folgenden Arbeiten untersucht werden. Hierbei wäre z.B. interessant, die HIF1a- sowie VEGF-Expression nach Behandlung von VPA unter Hypoxiebedingungen zu untersuchen, da die beschriebene Hypothese bezüglich des Zusammenhangs mit der verminderten Ceruloplasmin-Expression lediglich unter Normoxiebedingungen Bestand hat.

Der größte Teil der weiterführenden Untersuchungen sollte sich allerdings mit Cyclin D2 beschäftigen. Es konnte in dieser Arbeit eine spezifische Rolle von Cyclin D2 im PCa bestätigt werden. Daher sollten zunächst Grundlagenforschungen zu Cyclin D2 im PCa abseits der VPA-Behandlung durchgeführt werden. Ein wichtiger Punkt hierbei ist die Identifikation von direkten Interaktionspartnern von Cyclin D2. Dies könnte beispielsweise durch ein Yeast-two-Hybrid-Experiment geschehen. Auch die Möglichkeit, dass Cyclin D2 als Transkriptionsfaktor agiert, sollte untersucht werden. Diese Funktion konnte für Cyclin D1 bereits gezeigt werden (zusammengefasst in Musgrove et al., 2011). Hierfür könnte mit einem Antikörper gegen Cyclin D2 präzipitierte DNA mittels Sequenzierung untersucht werden.

Auch weitere siRNA-Studien sollten durchgeführt werden. Es konnte im Rahmen dieser Arbeit gezeigt werden, dass die murinen Fibroblastenzellen NIH/3T3 nach Verminderung der Cyclin D2-Expression verstärkt proliferieren. Es wäre interessant zu untersuchen, ob diese Zellen weitere Tumorzell-spezifische Eigenschaften erlangen. In diese Untersuchungen könnten die im Institut vorhandenen Prostata-Stromazellen mit einbezogen werden, da diese Zellen PCa-Zellen am ähnlichsten sind. Es sollten Analysen zur Proliferation, Migration und 
Invasion nach Verringerung der Cyclin D2-Expression durchgeführt werden. Auch Überexpressionsstudien könnten neue Erkenntnisse zur Rolle von Cyclin D2 im PCa liefern. Eine Überexpression von Cyclin D2 in PCa-Zellen sollte, vergleichbar mit dem Effekt durch VPA, zu einer Verringerung der Zellproliferation führen. Dies konnte in den humanen PCa-Zellen LNCaP bereits gezeigt werden (Kobayashi et al., 2009). Es wäre interessant zu prüfen, ob eine Überexpression von Cyclin D2 in weiteren PCa-Zelllinien den identischen Effekt ausübt und zudem noch weitere funktionelle Effekte wie z.B. auf die Migration und Invasion der PCa-Zellen hat.

Diese Überexpressionsstudien könnten zudem weitere Erkenntnisse zur Wirkung von VPA aufzeigen. Eine Überexpression von Cyclin D2 in PCa-Zellen mit anschließender VPA-Behandlung sollte, nach den in dieser Arbeit gezeigten Ergebnissen, zu keiner zusätzlichen Inhibition der Proliferation im Vergleich zu unbehandelten Cyclin D2überexprimierenden $\mathrm{PCa}$-Zellen führen. Ein Ansatz hierzu stellte die Kultivierung der primären PCa-Zellen 2E bis zu hohen Passagen dar. Dieser Ansatz könnte weiter verfolgt werden, da eventuell die Passagenanzahl und damit die Cyclin D2-Expression nicht hoch genug war um den VPA-Effekt zu kompensieren. Dieses Vorgehen hat den Vorteil, dass es sich um eine endogene Überexpression handelt, d.h. im Gegensatz zur exogenen Überexpression wird hier nur Cyclin D2 mit natürlicher Funktion untersucht.

Interessant wäre zudem die Untersuchung der PCa-Zellproliferation nach Inhibierung von Cyclin D2 und anschließender VPA-Behandlung. Es ist allerdings kein spezifischer Inhibitor für Cyclin D2 bekannt und die Inhibition weiterer D-Typ Cycline würde das Ergebnis verfälschen. Die Verringerung der Cyclin D2-Expression mittels siRNA in den primären PCaZellen 2E war im Rahmen dieser Arbeit nicht ausreichend, um die starke Re-Expression von Cyclin D2 nach VPA-Behandlung zu inhibieren.

Die bereits oben erwähnte ChIP-Seq-Analyse an mit einem Antikörper gegen Cyclin D2 präzipitierter DNA wäre auch für die Identifizierung des Einflusses von Cyclin D2 auf die Wirkung von VPA im PCa nützlich. Es könnten hierbei spezifisch durch die Re-Expression von Cyclin D2 nach VPA-Behandlung von PCa-Zellen beeinflusste Gene identifiziert werden. Dies wäre hilfreich, um den Stellenwert von Cyclin D2 bei der Therapie des PCa einordnen zu können.

Im Rahmen dieser Arbeit konnte gezeigt werden, dass die Re-Expression von Cyclin D2 nicht allein nach der Behandlung der primären PCa-Zellen 2E mit VPA, sondern auch nach der Behandlung mit weiteren HDIs detektiert wurde. Alle untersuchten HDIs hemmen die Histondeacetylasen der Klasse I. Es wäre daher nützlich zu prüfen, ob ein HDI, der die Histondeacetylasen der Klasse I nicht hemmt, keine Wirkung auf die Expression von Cyclin D2 in PCa-Zellen ausübt. Hierfür könnte beispielsweise Tubacin verwendet werden, ein HDI mit ausschließlicher Spezifität für die Histondeacetylase 6 (Klasse Ilb) oder auch 
MC1568, ein Klasse Ilb-spezifischer HDI (Haggarty et al., 2003; Mai et al., 2005). Sollte sich durch diese Untersuchungen ein ausschließlicher Effekt auf die Cyclin D2-Expression durch HDIs spezifisch für Histondeacetylasen der Klasse I bestätigen lassen, so könnten weitere Studien folgen, bei denen mittels siRNA die Expression der verschiedenen Histondeacetylasen der Klasse I verringert wird. Kann hierbei eine spezifische Histondeacetylase ermittelt werden, die die Acetylierung des Cyclin D2-Gens bewirkt, könnte die Aktivität dieser spezifischen Histondeacetylase bei PCa-Patienten untersucht werden und damit ein neues Feld für zukünftige Therapiemöglichkeiten des PCa eröffnet werden. Es ist jedoch davon auszugehen, dass die Inhibierung nur einer spezifischen Histondeacetylase nicht das volle Spektrum der durch eine VPA-Behandlung von PCa-Zellen beobachteten Wirkung erzielt. Allerdings könnten wichtige Hinweise zur malignen Aktivität verschiedener Histondeacetylasen in verschiedenen Tumorentitäten erlangt werden.

Im Rahmen dieser Arbeit konnte bereits gezeigt werden, dass eine VPA-Behandlung verschiedener nicht-maligner und maligner Zelllinien unterschiedliche Ergebnisse brachte. Gegenstand zukünftiger Forschungen sollen daher vor allem Untersuchungen einer VPA-Behandlung von Mammakarzinom- sowie Pankreaskarzinom-Zelllinien sein. In diesen beiden Tumorentitäten ist sowohl ein Verlust der Cyclin D2-Expression beschrieben als auch eine Proliferationsinhibition durch VPA. Es wäre daher interessant zu prüfen, ob diese Inhibition der Proliferation nach VPA-Behandlung mit einer Re-Expression von Cyclin D2 einhergeht.

Ein wichtiges Feld weiterer Studien werden die im Rahmen dieser Arbeit begonnenen Fütterungsversuche mit VPA über das Trinkwasser darstellen. Erste Hinweise auf eine chemotherapeutische Wirkung von VPA im TRAMP-Modell konnten hier bereits beschrieben werden. Es sollten allerdings genaue histopathologische Studien zum Tumorstadium sowie der Metastasierung durchgeführt werden. Auch eine Untersuchung zur Blutgefäßdichte als Marker für die Angiogenese sollte in die Studien mit eingeschlossen werden. Zudem sollten sowohl an Gewebeschnitten als auch an RNA und Proteinen, die aus den Geweben gewonnen wurden, Untersuchungen zur Expression ausgewählter Kandidatengene aus dieser Arbeit durchgeführt werden. Vor allem die Expression von Cyclin D2 sollte vor und nach der VPA-Behandlung geprüft werden. Sollte hierbei gezeigt werden können, dass die Cyclin D2-Expression, vergleichbar mit der Situation im humanen Prostatakarzinom, in den PCa-Zellen der kontrollbehandelten Tiere vermindert vorliegt, so sollten weitere in vivo-Versuche zur möglichen Rolle von Cyclin D2 als Tumorsuppressor im PCa folgen. Hierbei wäre vor allem interessant, die Tumorentwicklung bei TRAMP-Mäusen, die mit transgenen Cyclin D2-Mäusen, die Cyclin D2 spezifisch in der Prostata überexprimieren, verpaart wurden, zu beobachten. Sollte Cyclin D2 im PCa einen Tumorsuppressor 
darstellen, so sollten sich bei diesen Cyclin D2-TRAMP-Mäusen weniger PCa entwickeln als bei reinen TRAMP-Mäusen. 


\section{Zusammenfassung}

In dieser Arbeit sollte jeweils der Einfluss des Phytoöstrogens Tectorigenin und des Histondeacetylase-Inhibitors (HDI) Valproinsäure (VPA) auf PCa-Zellen untersucht werden. Hierfür wurden vorwiegend die primären TRAMP-PCa-Zellen 2E verwendet. Es wurde in den PCa-Zellen 2E regelmäßig die für das TRAMP-Modell spezifische Expression des SV40 large $T$ Antigens überprüft und nur Zellen für die Untersuchungen verwendet, die eine nahezu 100\%ige Expression des SV40 large T Antigens aufwiesen (Witt et al., 2013).

\subsection{Das Phytoöstrogen Tectorigenin}

Das Phytoöstrogen Tectorigenin stammt aus dem Gesamtextrakt von Belamcanda chinensis. In dieser Arbeit wurden zunächst zwei verschiedene Gesamtextrakte ( $R$ und $O$ ) untersucht, um zu prüfen, ob sich durch beide Extrakte die aus der Literatur bekannten Effekte einer Gesamtextrakt-Behandlung in den etablierten, humanen PCa-Zellen LNCaP sowie den primären, murinen PCa-Zellen 2E hervorrufen lassen. Für beide Gesamtextrakte konnte eine Inhibition der Proliferation sowohl bei den 2E-Zellen als auch den LNCaP-Zellen nachgewiesen werden. Bei der Analyse von Immunfluoreszenz-Färbungen wurde eine starke Bildung von zytoplasmatischen Vesikeln in den mit dem Gesamtextrakt $\mathrm{R}$ behandelten Zellen beobachtet, was vermutlich auf die Induktion von Apoptose in den Zellen hinweist. Die Analyse der Genexpression von einigen ausgewählten Kandidatengenen (AR, PSA, PDEF, IGF-IR, IGF-BP-3, PTEN sowie ESR1 und ESR2) ${ }^{2}$ zeigte eine Änderung der Expression nach der Behandlung mit beiden Gesamtextrakten aus Belamcanda chinensis sowohl in den primären PCa-Zellen 2E als auch in den humanen PCa-Zellen LNCaP. Diese Kandidatengene wurden im Folgenden nach der Behandlung beider PCa-Zelllinien mit Tectorigenin verschiedener Hersteller untersucht. Es konnte nicht bei allen untersuchten Substanzen die durch die Gesamtextrakte gezeigten Expressionsänderungen bestätigt werden. In den humanen PCa-Zellen LNCaP konnte nach der Behandlung mit dem Tectorigenin der Firma Shenzhen eine Abnahme der IGF-IR- sowie der PSA-Expression gezeigt werden. Daher wurde das Tectorigenin der Firma Shenzhen für weiterführende Versuche ausgewählt. Mittels einer Microarray-Analyse nach Behandlung der LNCaP-Zellen mit dem Tectorigenin der Firma Shenzhen konnten zahlreiche differentiell exprimierte Gene identifiziert werden, unter anderem auch die bereits bestätigten Gene IGF-IR und KLK3 (PSA). Bei der weiterführenden Analyse der Daten konnte gezeigt werden, dass die durch

\footnotetext{
${ }^{2}$ AR: Androgenrezeptor; PSA: prostate specific antigen; PDEF: prostate-derived Ets transcription factor; IGF-IR: insulin-like growth factor-I receptor; IGF-BP-3: insulin-like growth factor binding protein 3; PTEN: phosphatase and tensin homolog; ESR1: estrogen receptor 1 (auch ER $\alpha$ ); ESR2: estrogen receptor 2 (auch ER $\beta$ )
} 
die Behandlung von LNCaP-Zellen mit Tectorigenin vermindert exprimierten Gene hoch signifikant invers korrelieren mit den Androgen-induzierten Kandidatengenen einer Studie aus der Literatur (Waltering et al., 2009). Es konnte so die Hypothese aufgestellt werden, dass Tectorigenin im PCa als Anti-Androgen wirkt. In der Literatur ist eine Inhibition der Proliferation von PCa-Zellen nach Behandlung mit Tectorigenin beschrieben (Thelen et al., 2005; Thelen et al., 2006; Stettner et al., 2007). Dies konnte im Rahmen der vorliegenden Arbeit durch die Analyse der vorwiegend differentiell regulierten biologischen Prozesse, molekularen Funktionen und zellulären Komponenten mit einer eindeutigen Hemmung von Genen, die die Replikation und den Zellzyklus steigern, assoziiert werden.

In anschließenden in vivo-Versuchen an TRAMP-Mäusen, welche Tectorigenin-haltiges Futter der Firma Girindus erhielten, konnten erste Hinweise auf eine inhibitorische Wirkung von Tectorigenin auf die Tumorprogression gezeigt werden. An subkutanen LNCaP-Tumoren im Nacktmaus-Modell führte eine Behandlung der Mäuse mit Tectorigenin der Firma Shenzhen über das Futter sowohl zu einem reduzierten Tumorgewicht als auch zu einer verminderten Tumorgröße im Vergleich zu kontrollbehandelten Tieren.

Zusammengefasst konnten im Rahmen dieser Arbeit vor allem in vivo eindeutige chemotherapeutische Effekte von Tectorigenin im PCa gezeigt werden. Zudem konnten einige neue, interessante, differentiell exprimierte Kandidatengene nach der TectorigeninBehandlung von PCa-Zellen identifiziert werden, mit Hilfe derer die Hypothese aufgestellt wurde, dass Tectorigenin im PCa als Anti-Androgen wirkt.

\subsection{Der Histondeacetylase-Inhibitor Valproinsäure}

Zunächst wurde die Wirksamkeit der Valproinsäure-Behandlung (VPA-Behandlung) in den primären PCa-Zellen 2E geprüft. Es konnte funktionell eine verstärkte Acetylierung des Histons 3 an Lysin 9 sowie eine Inhibition der Proliferation, der Migration und der Invasion im Vergleich zu kontrollbehandelten Zellen nachgewiesen werden (Witt et al., 2013).

In den nachfolgenden Analysen wurden einige für die Therapie des PCa wichtige Faktoren und Signalwege auf molekularer Ebene untersucht. Der Androgenrezeptor-Signalweg ist hierbei ein wichtiger Ansatzpunkt. Es konnte im Rahmen dieser Arbeit eine verminderte Expression des Androgenrezeptors nach Behandlung der primären PCa-Zellen 2E mit VPA demonstriert werden. Bei den Analysen zur Apoptose konnte erstmalig eine erhöhte Expression des proapoptotischen Faktors Bim nach der Behandlung von PCa-Zellen mit VPA gezeigt werden. Es ist bekannt, dass in Lungenkarzinomzellen die Expression von Bim durch den Transkriptionsfaktor Foxo1 reguliert wird (Yang et al., 2009). Es konnte im Rahmen der vorliegenden Arbeit ein Anstieg der Foxo1-Expression nach VPA-Behandlung der 2E-Zellen detektiert werden, dies könnte daher der zu Grunde liegende Mechanismus der Überexpression von Bim nach VPA-Behandlung in PCa-Zellen sein. 
Die Angiogenese ist ein weiterer wichtiger Ansatzpunkt, vor allem in der Therapie des fortgeschrittenen PCa. In den Analysen der vorliegenden Arbeit konnte eine verstärkte mRNA-Expression von Hif1a sowie eine verminderte mRNA-Expression von Vegfa und Ceruloplasmin nach VPA-Behandlung der primären PCa-Zellen 2E gezeigt werden (Witt et al., 2013). Unter normoxischen Bedingungen kann Hif1a nur bei hoher Kupferkonzentration im Zytoplasma in den Zellkern gelangen und dort die Expression von Vegfa beeinflussen. Das Vorhandensein von Kupfer in der Zelle wird in der Zelle hauptsächlich durch Ceruloplasmin reguliert. Es konnte daher die Hypothese aufgestellt werden, dass nach VPABehandlung von PCa-Zellen durch die verminderte Expression von Ceruloplasmin nur geringe Mengen von Kupfer in der Zelle vorliegen, Hif1a daher post-translational über Ubiquitinierung abgebaut wird und folglich die Expression von Vegfa vermindert vorliegt und schließlich die Angiogenese gehemmt wird.

Die Inhibition der Proliferation von PCa-Zellen nach VPA-Behandlung wurde im Rahmen der vorliegenden Arbeit sowie in zahlreichen Arbeiten aus der Literatur bereits beschrieben (vgl. Kapitel 4.3.1). Hierbei ist in der Literatur ein G1-Arrest von PCa-Zellen nach VPA-Behandlung gezeigt worden. Vermutlich liegt auch in den primären PCa-Zellen 2E nach VPA-Behandlung ein G1-Arrest vor, da die Expression von Cdkn1a (p21) erhöht ist, die Expression von Cdk4 hingegen vermindert. Lediglich die Aktivierung von $\mathrm{pRb}$ war leicht erhöht und die mRNA-Expression von Cyclin D1 lag nach der VPA-Behandlung der 2E-Zellen unverändert vor (Witt et al., 2013). Die verminderte Expression von Gsk3 $\beta$ sowie die verstärkte Expression von Hif1 $\alpha$ und Uchl1 nach der VPA-Behandlung der 2E-Zellen lieferten allerdings Hinweise auf einen post-translationalen Abbau von Cyclin D1.

Weitere Expressionsstudien wurden an ausgewählten Kandidatengenen aus einer Microarray-Analyse aus Witt (2009) von mit VPA behandelten primären PCa-Zellen 2E durchgeführt (Witt et al., 2013). Die differentielle Expression der Kandidatengene aus der Microarray-Analyse konnte für alle sieben untersuchten Kandidatengene bestätigt und zusätzlich eine sowohl zeit- als auch konzentrationsabhängige Änderung der Expression gezeigt werden (Witt et al., 2013). Mechanistisch ging die Erhöhung der Expression der Kandidatengene Uchl1, Ptprn und Ccnd2 nach VPA-Behandlung der PCa-Zellen 2E mit einer Erhöhung der Acetylierung im Promotorbereich der Gene einher (Witt et al., 2013).

Das Kandidatengen Ccnd2 wurde für weiterführende Analysen ausgewählt. Die Expressionsanalyse aller Mitglieder der Cyclin D-Familie (Cyclin D1, Cyclin D2 und Cyclin D3) ergab, dass nur Cyclin D2 zeit- und konzentrationsabhängig durch VPA-Behandlung verstärkt exprimiert wurde (Witt et al., 2013). Es sollte nun geprüft werden, ob diese ReExpression aufgrund der HDI-Aktivität von VPA zu beobachten war. Nach Behandlung der primären PCa-Zellen 2E mit den HDIs Trichostatin A (TSA), Suberoylanilide hydroxamic acid (SAHA), Natriumbutyrat (NaB) und Apicidin wurde eine Re-Expression von Cyclin D2 gezeigt 
(Witt et al., 2013). Die Behandlung mit Valpromid, dem in vitro inaktiven Amid von VPA, hingegen hatte keinen Effekt auf die Expression von Cyclin D2 (Witt et al., 2013). Da alle untersuchten HDIs Histondeacetylasen der Klasse I hemmen, ist davon auszugehen, dass die Re-Expression von Cyclin D2 über diese Klasse der Histondeacetylasen vermittelt wird. In der Literatur ist beschrieben, dass durch die Behandlung von PCa-Zellen mit HDIs auch die Methylierung einiger Gene durch eine verminderte Expression der DNA-Methyltransferase 1 beeinflusst werden kann (Sarkar et al., 2011). Daher wurde zunächst analysiert, ob eine allgemeine De-Methylierung des Genoms durch den DNA-Methyltransferase-Inhibitor 5-Aza-2'-deoxycytidine (5aza2) eine Re-Expression von Cyclin D2 hervorrufen kann. In keiner der drei untersuchten PCa-Zelllinien (2E, PC-3, DU145) wurde nach der Behandlung mit 5aza2 eine vergleichbare Re-Expression von Cyclin D2 beobachtet, wie nach der Behandlung der PCa-Zellen mit VPA. Weiterführend konnte mittels Bisulfit-Sequenzierung gezeigt werden, dass im Promotorbereich des Cyclin D2-Gens eine CpG-Insel bereits unmethyliert vorlag und die Behandlung mit VPA keine Veränderung des Methylierungszustandes zur Folge hatte. Es ist demnach anzunehmen, dass die erhöhte Acetylierung des Promotorbereichs durch die VPA-Behandlung der zugrunde liegende Mechanismus bei der Re-Expression von Cyclin D2 in PCa-Zellen ist und die Methylierung lediglich eine untergeordnete Rolle spielt.

Die Funktion von Cyclin D2 in der Tumorentstehung und -progression wird in der Literatur kontrovers diskutiert (vgl. Kapitel 4.3.3.2). Um zu prüfen, ob es sich bei der Re-Expression von Cyclin D2 nach der Behandlung mit VPA um einen zellspezifischen Effekt in PCa-Zellen handelt, wurden weitere Zelllinien in die Untersuchung einbezogen. Alle untersuchten PCa-Zelllinien (LNCaP, DU145 und PC-3) wiesen eine niedrige Basalexpression von Cyclin D2 auf, die durch VPA anstieg und mit einer Inhibition der Zellproliferation assoziiert war (Witt et al., 2013). In den untersuchten nicht-malignen Zelllinien wurde durchschnittlich eine hohe Basalexpression von Cyclin D2 detektiert, die durch die VPA-Behandlung in der Mehrzahl der untersuchten Zelllinien nicht verändert wurde. Im Allgemeinen wurde auch keine deutliche Inhibition der Zellproliferation durch die Behandlung mit VPA hervorgerufen (Witt et al., 2013). Des Weiteren wurden für die Untersuchung kolorektale Karzinomzellen mit unterschiedlicher Basalexpression von Cyclin D2 ausgewählt. In diesen Zellen konnte keine klare Assoziation zwischen Basalexpression, Re-Expression von Cyclin D2 und der Inhibition der Proliferation festgestellt werden (Witt et al., 2013), was auf eine andere Rolle von Cyclin D2 im kolorektalen Karzinom im Gegensatz zum PCa und in nicht-malignen Zellen schließen lässt.

Zur Bedeutung von Cyclin D2 bei der Proliferation wurden zusätzlich siRNA-Studien durchgeführt. Eine Herunterregulierung der Expression von Cyclin D2 mittels siRNA nach VPA-Behandlung konnte in den primären PCa-Zellen 2E nicht aufrecht erhalten werden, 
weshalb eine andere Herangehensweise ausgewählt wurde. Die murinen Fibroblastenzellen $\mathrm{NIH} / 3 \mathrm{~T} 3$ wiesen in den vorhergehenden Untersuchungen eine hohe Basalexpression von Cyclin D2 auf. Daher wurde die Expression in diesen Zellen mittels siRNA verringert und der anschließende Proliferationsassay konnte zeigen, dass die Proliferation nach erfolgreicher Verminderung der Cyclin D2-Expression verstärkt war (Witt et al., 2013).

Bei der immunhistochemischen Untersuchung von Patienten-Gewebeschnitten konnte eine verringerte Expression von Cyclin D2 im PCa-Gewebe im Vergleich zum gesunden Prostatagewebe gezeigt werden (Witt et al., 2013). Im Gegensatz dazu lag die Expression von Cyclin D1 im PCa-Gewebe verstärkt exprimiert vor im Vergleich zum gesunden Prostatagewebe (Witt et al., 2013). Zusammen mit den vorherigen Ergebnissen lassen diese Resultate darauf schließen, dass Cyclin D2 im PCa möglicherweise als Tumorsuppressor wirkt und nicht wie bisher beschrieben als Onkogen.

Bisherige Studien analysierten die Wirksamkeit einer VPA-Behandlung für die Therapie des PCa zumeist in Xenograft-Modellen. Im Rahmen der vorliegenden Arbeit wurde das TRAMP-Maus-Modell für diese Untersuchungen herangezogen, bei dem sich durch die Überexpression des Onkogens SV40 t/T ein PCa in den männlichen Mäusen entwickelt. Alle Mäuse erhielten $0,4 \%$ w/v VPA über das Trinkwasser. Es wurden insgesamt drei Versuchsgruppen mit jeweiliger Kontrollgruppe untersucht: zwei präventive Ansätze mit VPA-Gabe ab sechs Wochen, einer davon als Überlebensstudie, einer terminiert auf ein Alter von 30 Wochen, sowie ein therapeutischer Ansatz mit VPA-Gabe ab einem Alter von 16 Wochen als Überlebensstudie. Die Versuche konnten noch nicht abgeschlossen werden. Daher sind die hier gezeigten Ergebnisse nur als vorläufig anzusehen. In der präventiven Überlebensstudie (VPA-Gabe ab einem Alter von sechs Wochen) konnte ein durchschnittlich höheres Überlebensalter mit einer verzögerten Progression sowie ein durchschnittlich geringeres Tumorgewicht in einer verringerten Tumorinitiation nach der Behandlung der Mäuse mit VPA gezeigt werden ( $(\mathrm{VPA})=13, \mathrm{n}($ Kontrolle $)=10)$. In der kontrollbehandelten Gruppe wiesen 60\% der Mäuse ein makroskopisch sichtbares PCa auf, in der VPA-behandelten Gruppe lediglich 23\%. In der nach 30 Wochen terminierten präventiven Studie (VPA-Gabe im Alter von sechs bis 30 Wochen) konnte nach 30 Wochen kein Unterschied im Verhältnis von Urogenitaltraktgewicht zu Gesamtgewicht detektiert werden, allerdings erreichten auch nicht alle untersuchten Mäuse ein Alter von 30 Wochen $(n(V P A)=9, n($ Kontrolle)=9). In den kontrollbehandelten Mäusen musste eine Maus nach 25 Wochen abgetötet werden, in der VPA-behandelten Gruppe eine Maus mit 28 Wochen. Der Anteil der Mäuse mit einem makroskopisch sichtbaren PCa lag in beiden Gruppen bei 11\%. In der therapeutischen Überlebensstudie (VPA-Gabe ab einem Alter von 16 Wochen) konnten in der Kontroll- sowie der VPA-Gruppe bisher lediglich jeweils vier Mäuse untersucht werden. Das mittlere Überlebensalter war in der VPA-behandelten Gruppe deutlich höher als 
in der Kontrollgruppe, wobei das durchschnittliche Verhältnis von Urogenitaltraktgewicht zu Gesamtgewicht vergleichbar in beiden Gruppen war.

Zusammenfassend konnten im Rahmen der vorliegenden Arbeit zahlreiche chemotherapeutisch wirksame Effekte einer VPA-Behandlung von PCa-Zellen gezeigt werden. Zusätzlich wurden einige interessante molekulare Mechanismen, z.B. die Re-Expression von Cyclin D2 als Tumorsuppressor im PCa, identifiziert, die einen Einsatz von VPA als Mittel gegen das PCa unterstützen. 


\section{Literaturverzeichnis}

Adams, J. M. (2003): Ways of dying: multiple pathways to apoptosis. Genes \& Development 17 (20), S. 2481-2495.

Akiyama, T.; Dass, C. R.; Choong, P. F.M (2009): Bim-targeted cancer therapy: A link between drug action and underlying molecular changes. Molecular Cancer Therapeutics 8 (12), S. 3173-3180.

Angelucci, A.; Muzi, P.; Cristiano, L.; Millimaggi, D.; Cimini, A.-M.; Dolo, V.; Miano, R.; Vicentini, C.; Cerù, M. P.; Bologna, M. (2008): Neuroendocrine transdifferentiation induced by VPA is mediated by PPARy activation and confers resistance to antiblastic therapy in prostate carcinoma. Prostate 68 (6), S. 588-598.

Angelucci, A.; Valentini, A.; Millimaggi, D.; Gravina, G. L.; Miano, R.; Dolo, V.; Vicentini, C.; Bologna, M.; Federici, G.; Bernardini, S. (2006): Valproic acid induces apoptosis in prostate carcinoma cell lines by activation of multiple death pathways. Anti-Cancer Drugs 17 (10), S. 1141-1150.

Annicotte, J.-S; lankova, I.; Miard, S.; Fritz, V.; Sarruf, D.; Abella, A.; Berthe, M.-L; Noel, D.; Pillon, A.; Iborra, F.; Dubus, P.; Maudelonde, T.; Culine, S.; Fajas, L. (2006): Peroxisome Proliferator-Activated Receptor Regulates E-Cadherin Expression and Inhibits Growth and Invasion of Prostate Cancer. Molecular and Cellular Biology 26 (20), S. 7561-7574.

Antunes, A. A.; Leite, K. R.; Reis, S. T.; Sousa-Canavez, J. M.; Camara-Lopes, L. H.; Dall'oglio, M. F.; Srougi, M. (2012): GREB1 tissue expression is associated with organconfined prostate cancer. Urol Oncol 30 (1), S. 16-20.

Arce, C.; Pérez-Plasencia, C.; González-Fierro, A.; La Cruz-Hernández, E. de; RevillaVázquez, A.; Chávez-Blanco, A.; Trejo-Becerril, C.; Pérez-Cárdenas, E.; Taja-Chayeb, L.; Bargallo, E.; Villarreal, P.; Ramírez, T.; Vela, T.; Candelaria, M.; Camargo, M. F.; Robles, E.; Dueñas-González, A. (2006): A Proof-Of-Principle Study of Epigenetic Therapy Added to Neoadjuvant Doxorubicin Cyclophosphamide for Locally Advanced Breast Cancer. PLoS ONE 1 (1), S. e98.

Baker, M. (2010): Epigenome: mapping in motion. Nat Meth 7 (3), S. 181-186.

Banerjee, S.; Dowsett, M.; Ashworth, A.; Martin, L.-A. (2007): Mechanisms of Disease: angiogenesis and the management of breast cancer. Nat Clin Prac Oncol 4 (9), S. 536550.

Barve, A.; Khor, T. O.; Nair, S.; Lin, W.; Yu, S.; Jain, M. R.; Chan, J. Y.; Kong, A. N. (2008): Pharmacogenomic profile of soy isoflavone concentrate in the prostate of Nrf2 deficient and wild-type mice. J Pharm Sci 97 (10), S. 4528-4545.

Bialer, M.; Rubinstein, A.; Dubrovsky, J.; Raz, I.; Abramsky, O. (1985): A comparative pharmacokinetic study of valpromide and valproic acid after intravenous administration in humans. International Journal of Pharmaceutics 23 (1), S. 25-33.

Blaheta, R. A.; Michaelis, M.; Driever, P. H.; Cinatl, J. Jr. (2005): Evolving anticancer drug valproic acid: Insights into the mechanism and clinical studies. Med. Res. Rev 25 (4), S. 383-397.

Blaheta, R. A.; Nau, H.; Michaelis, M.; Cinatl, J. Jr (2002): Valproate and valproateanalogues: potent tools to fight against cancer. Curr Med Chem 9 (15), S. 1417-1433.

Bolden, J. E.; Peart, M. J.; Johnstone, R. W. (2006): Anticancer activities of histone deacetylase inhibitors. Nat Rev Drug Discov 5 (9), S. 769-784. 
Bradford, M.M. (1976): A rapid and sensitive method for the quantitation of microgram quantities of protein utilizing the principle of protein-dye binding. Anal Biochem 72: 24854.

Braiteh, F.; Soriano, A. O.; Garcia-Manero, G.; Hong, D.; Johnson, M. M.; Silva, L. de P.; Yang, H.; Alexander, S.; Wolff, J.; Kurzrock, R. (2008): Phase I Study of Epigenetic Modulation with 5-Azacytidine and Valproic Acid in Patients with Advanced Cancers. Clinical Cancer Research 14 (19), S. 6296-6301.

Brinkmann, H.; Dahler, A. L.; Popa, C.; Serewko, M. M.; Parsons, P. G.; Gabrielli, B. G.; Burgess, A. J.; Saunders, N. A. (2001): Histone hyperacetylation induced by histone deacetylase inhibitors is not sufficient to cause growth inhibition in human dermal fibroblasts. J Biol Chem 276 (25), S. 22491-22499.

Byler, T. K.; Leocadio, D.; Shapiro, O.; Bratslavsky, G.; Stodgell, C. J.; Wood, R. W.; Messing, E. M.; Reeder, J. E. (2012): Valproic Acid Decreases Urothelial Cancer Cell Proliferation and Induces Thrombospondin-1 Expression. BMC Urol 12 (1), S. 21.

Candelaria, M.; Gallardo-Rincon, D.; Arce, C.; Cetina, L.; Aguilar-Ponce, J. L.; Arrieta, O.; González-Fierro, A.; Chávez-Blanco, A.; La Cruz-Hernández, E. de; Camargo, M. F.; Trejo-Becerril, C.; Pérez-Cárdenas, E.; Pérez-Plasencia, C.; Taja-Chayeb, L.; WegmanOstrosky, T.; Revilla-Vázquez, A.; Dueñas-González, A. (2007): A phase II study of epigenetic therapy with hydralazine and magnesium valproate to overcome chemotherapy resistance in refractory solid tumors. Ann Oncol 18 (9), S. 1529-1538.

Cardillo, M. R.; Monti, S.; Di Silverio, F.; Gentile, V.; Sciarra, F.; Toscano, V. (2003): Insulinlike growth factor (IGF)-I, IGF-II and IGF type I receptor (IGFR-I) expression in prostatic cancer. Anticancer Res 23 (5A), S. 3825-3835.

Carruba, G. (2007): Estrogen and prostate cancer: an eclipsed truth in an androgendominated scenario. J Cell Biochem 102 (4), S. 899-911.

Chan, J. M.; Stampfer, M.J.; Ma, J.; Gann, P.; Gaziano, J.M., Pollak, M.; Giovannucci, E. (2002): Insulin-Like Growth Factor-I (IGF-I) and IGF Binding Protein-3 as Predictors of Advanced-Stage Prostate Cancer. CancerSpectrum Knowledge Environment 94 (14), S. 1099-1106.

Chateauvieux, S.; Morceau, F.; Dicato, M.; Diederich, M. (2010): Molecular and Therapeutic Potential and Toxicity of Valproic Acid. Journal of Biomedicine and Biotechnology 2010, S. 1-19.

Chen, C.-L; Sung, J.; Cohen, M.; Chowdhury, W. H.; Sachs, M. D.; Li, Y.; Lakshmanan, Y.; Yung, B. Y. M.; Lupold, S. E.; Rodriguez, R. (2006a): Valproic Acid Inhibits Invasiveness in Bladder Cancer but Not in Prostate Cancer Cells. Journal of Pharmacology and Experimental Therapeutics 319 (2), S. 533-542.

Chen, G. G.; Zeng, Q.; Tse, G. M. K. (2008): Estrogen and its receptors in cancer. Med Res Rev 28 (6), S. 954-974.

Chen, Q.; Watson, J. T.; Marengo, S. R.; Decker, K. S.; Coleman, I.; Nelson, P. S.; Sikes, R. A. (2006b): Gene expression in the LNCaP human prostate cancer progression model: progression associated expression in vitro corresponds to expression changes associated with prostate cancer progression in vivo. Cancer Lett 244 (2), S. 274-288.

Chou, Y.-W.; Chaturvedi, N. K.; Ouyang, S.; Lin, F.-F.; Kaushik, D.; Wang, J.; Kim, I.; Lin, M.-F. (2011): Histone deacetylase inhibitor valproic acid suppresses the growth and increases the androgen responsiveness of prostate cancer cells. Cancer Letters 311 (2), S. $177-186$.

Christman, Judith K. (2002): 5-Azacytidine and 5-aza-2'-deoxycytidine as inhibitors of DNA methylation: mechanistic studies and their implications for cancer therapy. Oncogene 21 (35), S. 5483-5495. 
Chu, B. F.; Karpenko, M. J.; Liu, Z.; Aimiuwu, J.; Villalona-Calero, M. A.; Chan, K. K. .; Grever, M. R.; Otterson, G. A. (2012): Phase I study of 5-aza-2'-deoxycytidine in combination with valproic acid in non-small-cell lung cancer. Cancer Chemother Pharmacol.

Cole, A. M.; Myant, K.; Reed, K. R.; Ridgway, R. A.; Athineos, D.; van den Brink, G. R.; Muncan, V.; Clevers, H.; Clarke, A. R.; Sicinski, P.; Sansom, O. J. (2010): Cyclin D2Cyclin-Dependent Kinase 4/6 Is Required for Efficient Proliferation and Tumorigenesis following Apc Loss. Cancer Research 70 (20), S. 8149-8158.

Coronel, J.; Cetina, L.; Pacheco, I.; Trejo-Becerril, C.; González-Fierro, A.; La CruzHernández, E. de; Pérez-Cárdenas, E.; Taja-Chayeb, L.; Arias-Bofill, D.; Candelaria, M.; Vidal, S.; Dueñas-González, A. (2011): A double-blind, placebo-controlled, randomized phase III trial of chemotherapy plus epigenetic therapy with hydralazine valproate for advanced cervical cancer. Preliminary results. Med Oncol 28 Suppl 1, S. S540-6.

Costa, Vera L.; Henrique, Rui; Jeronimo, Carmen (2007): Epigenetic markers for molecular detection of prostate cancer. Dis Markers 23 (1-2), S. 31-41.

D'Andrea, L. D.; Romanelli, A.; Di Stasi, R.; Pedone, C. (2010): Bioinorganic aspects of angiogenesis. Dalton Trans. 39 (33), S. 7625.

Davis, J. N.; Singh, B.; Bhuiyan, M.; Sarkar, F. H. (1998): Genistein-induced upregulation of p21 WAF1, downregulation of cyclin $\mathrm{B}$, and induction of apoptosis in prostate cancer cells. Nutrition and Cancer 32 (3), S. 123-131.

Death, A. K.; McGrath, K. C. Y.; Handelsman, D. J. (2005): Valproate is an anti-androgen and anti-progestin. Steroids 70 (14), S. 946-953.

Dhillon, V. S.; Shahid, M.; Husain, S. A. (2004): CpG methylation of the FHIT, FANCF, cyclin-D2, BRCA2 and RUNX3 genes in Granulosa cell tumors (GCTs) of ovarian origin. Mol Cancer 3, S. 33.

Dokmanovic, M.; Clarke, C.; Marks, P. A. (2007): Histone Deacetylase Inhibitors: Overview and Perspectives. Molecular Cancer Research 5 (10), S. 981-989.

Dueñas-González, A.; Candelaria, M.; Perez-Plascencia, C.; Pérez-Cárdenas, E.; La CruzHernández, E. de; Herrera, L. A. (2008): Valproic acid as epigenetic cancer drug: preclinical, clinical and transcriptional effects on solid tumors. Cancer Treat Rev 34 (3), S. 206-222.

Dunn, J. E. (1975): Cancer epidemiology in populations of the United States--with emphasis on Hawaii and California--and Japan. Cancer Res 35 (11 Pt. 2), S. 3240-3245.

El Touny, L. H.; Banerjee, P. P. (2007): Akt GSK-3 pathway as a target in genistein-induced inhibition of TRAMP prostate cancer progression toward a poorly differentiated phenotype. Carcinogenesis 28 (8), S. 1710-1717.

Enders, P., Fiebrand, H.-J.; Zacharias, J.-P.; Doehn, C.; Hakenberg, O.; Höcht, S.; Weißbach, L. (2009): Prostatakrebs II - Lokal fortgeschrittenes und metastasiertes Prostatakarzinom. Berlin.

Evron, E.; Umbricht, C. B.; Korz, D.; Raman, V.; Loeb, D. M.; Niranjan, B.; Buluwela, L.; Weitzman, S. A.; Marks, J.; Sukumar, S. (2001): Loss of Cyclin D2 Expression in the Majority of Breast Cancers Is Associated with Promoter Hypermethylation. Cancer Research 61 (6), S. 2782-2787.

Ewen, M. E.; Sluss, H. K.; Sherr, C. J.; Matsushime, H.; Kato, J.-Y.; Livingston, D. M. (1993): Functional interactions of the retinoblastoma protein with mammalian D-type cyclins. Cell 73 (3), S. 487-497.

Fang, M.-Z.; Lee, M.-H.; Lee, Y.-S.; Kim, Y.-C.; Lee, B.-M.; Cho, M.-H. (2002): Low expression of cyclin D2 in G2/M-arrested and transformed proliferating Balb/3T3 cells. J Vet Med Sci 64 (3), S. 201-205. 
Feldman, B. J.; Feldman, D. (2001): The development of androgen-independent prostate cancer. Nat Rev Cancer 1 (1), S. 34-45.

Fischer, H.; Chen, J.; Skoog, L.; Lindblom, A. (2002): Cyclin D2 expression in familial and sporadic breast cancer. Oncology reports 9 (6).

Fischkoff, S. A.; Walter, E. Jr. (1984): Induction of neutrophilic differentiation of human promyelocytic leukemic cells by branched-chain carboxylic acid anticonvulsant drugs. $J$ Biol Response Mod 3 (2), S. 132-137.

Fortson, W. S.; Kayarthodi, S.; Fujimura, Y.; Xu, H.; Matthews, R.; Grizzle, W. E; Rao, V. N.; Bhat, G. K.; Reddy, E. S. (2011): Histone deacetylase inhibitors, valproic acid and trichostatin-A induce apoptosis and affect acetylation status of p53 in ERG-positive prostate cancer cells. Int J Oncol 39 (1), S. 111-119.

Fortunati, N.; Bertino, S.; Costantino, L.; Bosco, O.; Vercellinatto, I.; Catalano, M. G.; Boccuzzi, G. (2008): Valproic acid is a selective antiproliferative agent in estrogensensitive breast cancer cells. Cancer Lett 259 (2), S. 156-164.

Fotiou, K.; Vaiopoulos, G.; Lilakos, K.; Giannopoulos, A.; Mandalenaki, K.; Marinos, G.; Koritsiadis, G.; Sourdis, J.; Konstantinidou, E.; Konstantopoulos, K. (2007) Serum ceruloplasmin as a marker in prostate cancer. Minerva Urol Nefrol, 59 (4), S. 407-411.

Fukutake, M.; Takahashi, M.; Ishida, K.; Kawamura, H.; Sugimura, T.; Wakabayashi, K. (1996): Quantification of genistein and genistin in soybeans and soybean products. Food and Chemical Toxicology 34 (5), S. 457-461.

Fu, M.; Wang, C.; Li, Z.; Sakamaki, T.; Pestell, R.G. (2004): Minireview: Cyclin D1: Normal and Abnormal Functions. Endocrinology 145 (12), S. 5439-5447.

Gan, C. P.; Hamid, S.; Hor, S. Y.; Zain, R. B.; Ismail, S. M.; Wan Mustafa, W. M.; Teo, S. H.; Saunders, N.; Cheong, S. C. (2012): Valproic acid: growth inhibition of head and neck cancer by induction of terminal differentiation and senescence. Head Neck 34 (3), S. 344-353.

Gao, D.; Xia, Q.; Lv, J.; Zhang, H. (2007): Chronic administration of valproic acid inhibits PC3 cell growth by suppressing tumor angiogenesis in vivo. International Journal of Urology 14 (9), S. 838-845.

Gery, S.; Sawyers, C. L.; Agus, D. B.; Said, J. W.; Koeffler, H. P. (2002): TMEFF2 is an androgen-regulated gene exhibiting antiproliferative effects in prostate cancer cells. Oncogene 21 (31), S. 4739-4746.

Gillespie, S.; Borrow, J.; Zhang, X. D.; Hersey, P. (2006): Bim plays a crucial role in synergistic induction of apoptosis by the histone deacetylase inhibitor SBHA and TRAIL in melanoma cells. Apoptosis 11 (12), S. 2251-2265.

Gillet, N.; Florins, A.; Boxus, M.; Burteau, C.; Nigro, A.; Vandermeers, F.; Balon, H.; Bouzar, A. B.; Defoiche, J.; Burny A.; Reichert, M.; Kettmann, R.; Willems, L. (2007): Mechanisms of leukemogenesis induced by bovine leukemia virus: prospects for novel anti-retroviral therapies in human. Retrovirology 4 (1), S. 18.

Gitenay, D.; Baron, V. T. (2009): Is EGR1 a potential target for prostate cancer therapy? Future Oncol 5 (7), S. 993-1003.

González-Reyes, S.; Fernández, J. M.; González, L. O.; Aguirre, A.; Suárez, A.; González, J. M., Escaff, S.; Vizoso, F.J. (2011): Study of TLR3, TLR4, and TLR9 in prostate carcinomas and their association with biochemical recurrence. Cancer Immunol Immunother 60 (2), S. 217-226.

Göttlicher, M.; Minucci, S.; Zhu, S.; Krämer, O. H.; Schimpf, A.; Giavara, S.; Sleeman, J. P., Lo Coco, F.; Nervi, C.; Pelicci, P. G.; Heinzel, T. (2001): Valproic acid defines a novel class of HDAC inhibitors inducing differentiation of transformed cells. The EMBO Journal 20 (24), S. 6969-6978. 
Greenberg, N. M.; DeMayo, F.; Finegold M. J.; Medina, D.; Tilley W. D.; Aspinall, J. O.; Cunha, G. R.; Donjacour, A. A.; Matusik, R. J.; Rosen, J. M. (1995): Prostate cancer in a transgenic mouse. Proc Natl Acad Sci U S A. 92 (8), S. 3439-3443.

Gurvich, N.; Tsygankova, O. M.; Meinkoth, J. L.; Klein, P. S. (2004): Histone Deacetylase Is a Target of Valproic Acid-Mediated Cellular Differentiation. Cancer Research 64 (3), S. 1079-1086.

Haenszel, W.; Kurihara, M. (1968): Studies of Japanese migrants. I. Mortality from cancer and other diseases among Japanese in the United States. J Natl Cancer Inst 40 (1), S. 43-68.

Haggarty, S. J.; Koeller, K. M.; Wong, J. C.; Grozinger, C. M.; Schreiber, S. L. (2003): Domain-selective small-molecule inhibitor of histone deacetylase 6 (HDAC6)-mediated tubulin deacetylation. Proc Natl Acad Sci U S A 100 (8), S. 4389-4394.

Hallas, J.; Friis, S.; Bjerrum, L.; Støvring, H.; Narverud, S. F.; Heyerdahl, T.; Grønbaek, K.; Andersen, M. (2009): Cancer Risk in Long-term Users of Valproate: A Population-Based Case-Control Study. Cancer Epidemiology Biomarkers \& Prevention 18 (6), S. 17141719.

Hanahan, D. (1983): Studies on transformation of Escherichia coli with plasmids. J Mol Biol 166 (4), S. 557-580.

Hardenberg, S. von (2010): Charakterisierung von Leupaxin und seiner Interaktionspartner in Karzinomzellen. Dissertation. Universität Göttingen, Göttingen. Institut für Humangenetik.

Heijnsdijk, E. A. M.; Wever, E. M.; Auvinen, A.; Hugosson, J.; Ciatto, S.; Nelen, V.; Kwiatkowski, M.; Villers, A.; Páez, A.; Moss, S. M.; Zappa, M.; Tammela, T. L.; Mäkinen, T.; Carlsson, S.; Korfage, I. J.; Essink-Bot, M. L.; Otto, S. J.; Draisma, G.; Bangma, C. H.; Roobol, M. J.; Schröder, F. H.; de Koning, H. J. (2012): Quality-of-life effects of prostate-specific antigen screening. N Engl J Med 367 (7), S. 595-605.

Henrique, R.; Costa, V. L.; Cerveira, N.; Carvalho, A. L.; Hoque, M. O.; Ribeiro, F. R.; Oliveira, J.; Teixeira, M. R.; Sidransky, D, Jerónimo, C. (2006): Hypermethylation of Cyclin D2 is associated with loss of mRNA expression and tumor development in prostate cancer. J Mol Med 84 (11), S. 911-918.

Hodgson, M. C.; Shao, L.-J.; Frolov, A.; Li, R.; Peterson, L. E.; Ayala, G.; Ittmann, M. M.; Weigel, N. L.; Agoulnik, I. U. (2011): Decreased expression and androgen regulation of the tumor suppressor gene INPP4B in prostate cancer. Cancer Res 71 (2), S. 572-582.

Ho, L. L.; Kench, J. G.; Handelsman, D. J.; Scheffer, G. L.; Stricker, P. D.; Grygiel, J. G.; Sutherland, R. L.; Henshall, S. M.; Allen, J. D.; Horvath, L. G (2008): Androgen regulation of multidrug resistance-associated protein 4 (MRP4/ABCC4) in prostate cancer. Prostate 68 (13), S. 1421-1429.

Hubaux, R.; Vandermeers, F.; Crisanti, M. C.; Kapoor, V.; Burny, A.; Mascaux, C.; Albelda, S. M.; Willems, L. (2010): Preclinical evidence for a beneficial impact of valproate on the response of small cell lung cancer to first-line chemotherapy. Eur J Cancer 46 (9), S. 1724-1734.

Huber, J. (2000): Phytoöstrogene und SERMs, Alternativen zur klassischen Hormontherapie? Therapeutische Umschau 57 (10), S. 651-654.

Hudak, L.; Tezeeh, P.; Wedel, S.; Makarevic, J.; Juengel, E.; Tsaur, I.; Bartsch, G.; Wiesner, C.; Haferkamp, A.; Blaheta, R. A (2012): Low dosed interferon alpha augments the antitumor potential of histone deacetylase inhibition on prostate cancer cell growth and invasion. Prostate 72 (16), S. 1719-1735. 
Iacopino, F.; Urbano, R.; Graziani, G.; Muzi, A.; Navarra, P.; Sica, G. (2008): Valproic acid activity in androgen-sensitive and -insensitive human prostate cancer cells. International Journal of Oncology 32 (6), S. 1293-1303.

Inoue, S.; Riley, J.; Gant, T. W.; Dyer, M. J.; Cohen, G. M. (2007): Apoptosis induced by histone deacetylase inhibitors in leukemic cells is mediated by Bim and Noxa. Leukemia 21 (8), S. 1773-1782.

Jawaid, K.; Crane, S. R.; Nowers, J. L.; Lacey, M.; Whitehead, S. A. (2010): Long-term genistein treatment of MCF-7 cells decreases acetylated histone 3 expression and alters growth responses to mitogens and histone deacetylase inhibitors. J Steroid Biochem Mol Biol 120 (4-5), S. 164-171.

Jesenberger, V.; Jentsch, S. (2002): Deadly encounter: ubiquitin meets apoptosis. Nat. Rev. Mol. Cell Biol. 3 (2), S. 112-121.

Jones, J.; Bentas, W.; Blaheta, R. A.; Makarevic, J.; Hudak, L.; Wedel, S.; Probst, M.; Jonas, D.; Juengel, E. (2008a): Modulation of adhesion and growth of colon and pancreatic cancer cells by the histone deacetylase inhibitor valproic acid. Int J Mol Med 22 (3), S. 293-299.

Jones, J.; Bentas, W.; Blaheta, R. A.; Makarevic, J.; Hudak, L.; Wedel, S.; Probst, M.; Jonas, D.; Juengel, E. (2008b): Modulation of adhesion and growth of colon and pancreatic cancer cells by the histone deacetylase inhibitor valproic acid. Int J Mol Med 22 (3), S. 293-299.

Jones, J.; Juengel, E.; Mickuckyte, A.; Hudak, L.; Wedel, S.; Jonas, D.; Blaheta, R. A. (2009): The histone deacetylase inhibitor valproic acid alters growth properties of renal cell carcinoma in vitro and in vivo. J Cell Mol Med 13 (8B), S. 2376-2385.

Jung, S. H.; Lee, Y. S.; Lee, S.; Lim, S. S.; Kim, Y. S.; Ohuchi, K.; Shin, K. H. (2003): Antiangiogenic and anti-tumor activities of isoflavonoids from the rhizomes of Belamcanda chinensis. Planta Med 69 (7), S. 617-622.

Kellokumpu-Lehtinen, P.; Talpaz, M.; Harris, D.; Van, Q.; Kurzrock, R.; Estrov, Z. (1996): Leukemia-inhibitory factor stimulates breast, kidney and prostate cancer cell proliferation by paracrine and autocrine pathways. Int J Cancer 66 (4), S. 515-519.

Kilpeläinen, T. P.; Tammela, T. L.; Roobol, M.; Hugosson, J.; Ciatto, S.; Nelen, V.; Moss, S.; Määttänen, L.; Auvinen, A. (2011): False-positive screening results in the European randomized study of screening for prostate cancer. European Journal of Cancer 47 (18), S. 2698-2705.

Knudsen, K. E.; Penning, T. M. (2010): Partners in crime: deregulation of AR activity and androgen synthesis in prostate cancer. Trends in Endocrinology \& Metabolism 21 (5), S. 315-324.

Kobayashi, T.; Nakamura, E.; Shimizu, Y.; Terada, N.; Maeno, A.; Kobori, G.; Kamba, T; Kamoto, T.; Ogawa, O.; Inoue, T. (2009): Restoration of cyclin D2 has an inhibitory potential on the proliferation of LNCaP cells. Biochemical and Biophysical Research Communications 387 (1), S. 196-201.

Kortenhorst, M. S.; Zahurak, M.; Shabbeer, S.; Kachhap, S.; Galloway, N.; Parmigiani, G.; Verheul, H. M.; Carducci, M. A. (2008): A Multiple-Loop, Double-Cube Microarray Design Applied to Prostate Cancer Cell Lines with Variable Sensitivity to Histone Deacetylase Inhibitors. Clinical Cancer Research 14 (21), S. 6886-6894.

Kortenhorst, M. S.; Isharwal, S.; van Diest, P. J.; Chowdhury, W. H.; Marlow, C.; Carducci, M. A.; Rodriguez, R.; Veltri, R. W. (2009): Valproic acid causes dose- and timedependent changes in nuclear structure in prostate cancer cells in vitro and in vivo. $\mathrm{Mol}$ Cancer Ther 8 (4), S. 802-808. 
Kozar, K.; Ciemerych, M. A.; Rebel, V. I.; Shigematsu, H.; Zagozdzon, A.; Sicinska, E.; Geng, Y.; Yu, Q.; Bhattacharya, S. (2004): Mouse Development and Cell Proliferation in the Absence of D-Cyclins. Cell 118 (4), S. 477-491.

Kozar, K.; Sicinski, P. (2005): Cell cycle progression without cyclin D-CDK4 and cyclin DCDK6 complexes. Cell Cycle 4 (3), S. 388-391.

Kuendgen, A.; Gattermann, N. (2007): Valproic acid for the treatment of myeloid malignancies. Cancer 110 (5), S. 943-954.

Kutikhin, A. G.; Yuzhalin, A. E. (2012): Are Toll-like receptor gene polymorphisms associated with prostate cancer? Cancer Manag Res 4, S. 23-29.

Le Romancer, M.; Poulard, C.; Cohen, P.; Sentis, S.; Renoir, J.-M; Corbo, L. (2011): Cracking the Estrogen Receptor's Posttranslational Code in Breast Tumors. Endocrine Reviews 32 (5), S. 597-622.

Lehmusvaara, S.; Erkkilä, T.; Urbanucci, A.; Waltering, K.; Seppälä, J.; Larjo, A.; Tuominen, V. J.; Isola, J.; Kujala, P.; Lähdesmäki, H.; Kaipia, A.; Tammela, T. L.; Visakorpi, T. (2012): Chemical castration and anti-androgens induce differential gene expression in prostate cancer. J. Pathol. 227 (3), S. 336-345.

Liao, S.; Hiipakka, R. A. (1995): Selective inhibition of steroid 5 alpha-reductase isozymes by tea epicatechin-3-gallate and epigallocatechin-3-gallate. Biochem Biophys Res Commun 214 (3), S. 833-838.

Li, L.-C.; Dahiya, R. (2002): MethPrimer: designing primers for methylation PCRs. Bioinformatics 18 (11), S. 1427-1431.

Liu, R.; Zhou, Z.; Huang, J.; Chen, C. (2011): PMEPA1 promotes androgen receptornegative prostate cell proliferation through suppressing the Smad3/4-c-Myc-p21 Cip1 signaling pathway. J Pathol 223 (5), S. 683-694.

Liu, T.; Kuljaca, S.; Tee, A.; Marshall, G. M. (2006): Histone deacetylase inhibitors: multifunctional anticancer agents. Cancer Treat Rev 32 (3), S. 157-165.

Machado, M. C. C.; Bellodi-Privato, M.; Kubrusly, M. S.; Molan, N. A. T.; Tharcisio, T. Jr.; Oliveira, E. R. de; D'Albuquerque, L. A. C. (2011): Valproic acid inhibits human hepatocellular cancer cells growth in vitro and in vivo. J Exp Ther Oncol 9 (2), S. 85-92.

Mai, A.; Massa, S.; Pezzi, R.; Simeoni, S.; Rotili, D.; Nebbioso, A.; Scognamiglio, A.; Altucci, L.; Loidi, P.; Brosch, G. (2005): Class II (Ila)-selective histone deacetylase inhibitors. 1. Synthesis and biological evaluation of novel (aryloxopropenyl)pyrrolyl hydroxyamides. $J$ Med Chem 48 (9), S. 3344-3353.

Marks, P.A; Xu, W.-S (2009): Histone deacetylase inhibitors: Potential in cancer therapy. J. Cell. Biochem. 107 (4), S. 600-608.

Martin, F.; Linden, T.; Katschinski, D. M.; Oehme, F.; Flamme, I.; Mukhopadhyay, C.K.; Eckhardt, K.; Tröger, J.; Barth, S.; Camenisch, G.; Wenger, R. H. (2005): Copperdependent activation of hypoxia-inducible factor (HIF)-1: implications for ceruloplasmin regulation. Blood 105 (12), S. 4613-4619.

Matsubayashi, H.; Sato, N.; Fukushima, N.; Yeo, C. J.; Walter, K. M.; Brune, K.; Sahin, F.; Hruban, R. H.; Goggins, M. (2003): Methylation of Cyclin D2 Is Observed Frequently in Pancreatic Cancer but Is Also an Age-related Phenomenon in Gastrointestinal Tissues. Clinical Cancer Research 9 (4), S. 1446-1452.

Matsuda, T.; Saika, K. (2007): Comparison of Time Trends in Prostate Cancer Incidence (1973 1997) in East Asia, Europe and USA, from Cancer Incidence in Five Continents Vols IV VIII. Japanese Journal of Clinical Oncology 37 (7), S. 556-557.

Mayor, S.; Pagano, R. E. (2007): Pathways of clathrin-independent endocytosis. Nat Rev Mol Cell Biol 8 (8), S. 603-612. 
Mentor-Marcel, R.; Lamartiniere, C. A.; Eltoum, I. E.; Greenberg, N. M.; Elgavish, A. (2001): Genistein in the diet reduces the incidence of poorly differentiated prostatic adenocarcinoma in transgenic mice (TRAMP). Cancer Res 61 (18), S. 6777-6782.

Mermelshtein, A.; Gerson, A.; Walfisch, S.; Delgado, B.; Shechter-Maor, G.; Delgado, J.; Fich, A.; Gheber, L. (2005): Expression of D-type cyclins in colon cancer and in cell lines from colon carcinomas. Br J Cancer 93 (3), S. 338-345.

Merz, V. W.; Arnold, A. M.; Studer, U. E. (1994): Differential expression of transforming growth factor-beta 1 and beta 3 as well as c-fos mRNA in normal human prostate, benign prostatic hyperplasia and prostatic cancer. World J Urol 12 (2), S. 96-98.

Meyyappan, M.; Wong, H.; Hull, C.; Riabowol, K. T. (1998): Increased expression of cyclin D2 during multiple states of growth arrest in primary and established cells. Mol Cell Biol 18 (6), S. 3163-3172.

Michaelis, M.; Doerr, H. W.; Cinatl, J. Jr. (2007): Valproic acid as anti-cancer drug. Curr Pharm Des 13 (33), S. 3378-3393.

Milutinovic, S.; D'Alessio, A. C.; Detich, N.; Szyf, M. (2007): Valproate induces widespread epigenetic reprogramming which involves demethylation of specific genes. Carcinogenesis 28 (3), S. 560-571.

Molecular Staging (2011): Cancer as a Disease of the Cell Cycle. Online verfügbar unter http://www.molecularstaging.com/cancer-as-a-disease-of-the-cell-cycle.html, zuletzt geprüft am 18.12.2012.

Morrissey, C.; Bektic, J.; Spengler, B.; Galvin, D.; Christoffel, V.; Klocker, H. Fitzpatrick, J. M.; Watson, R. W. (2004): Phytoestrogens derived from Belamcanda chinensis have an antiproliferative effect on prostate cancer cells in vitro. J Urol 172 (6 Pt 1), S. 24262433.

Munster, P.; Marchion, D.; Bicaku, E.; Lacevic, M.; Kim, J.; Centeno, B.; Daud, A.; Neuger, A.; Minton, S.; Sullivan, D. (2009): Clinical and Biological Effects of Valproic Acid as a Histone Deacetylase Inhibitor on Tumor and Surrogate Tissues: Phase I/II Trial of Valproic acid and Epirubicin/FEC. Clinical Cancer Research 15 (7), S. 2488-2496.

Musgrove, E. A.; Caldon, C. E.; Barraclough, J.; Stone, A.; Sutherland, R. L. (2011): Cyclin D as a therapeutic target in cancer. Nat Rev Cancer 11 (8), S. 558-572.

Mziaut, H.; Kersting, S.; Knoch, K.-P; Fan, W.-H; Trajkovski, M.; Erdmann, K.; Bergert, H.; Ehehalt, F.; Saeger, H. D.; Solimena, M. (2008): ICA512 signaling enhances pancreatic -cell proliferation by regulating cyclins $D$ through STATs. Proceedings of the National Academy of Sciences 105 (2), S. 674-679.

Nam, R. K.; Diamandis, E. P.; Toi, A.; Trachtenberg, J.; Magklara, A.; Scorilas, A.; Papnastasiou, P. A.; Jewett, M. A.; Narod, S. A. (2000): Serum human glandular kallikrein-2 protease levels predict the presence of prostate cancer among men with elevated prostate-specific antigen. J Clin Oncol 18 (5), S. 1036-1042.

Nam, R. K.; Zhang, W. W.; Klotz, L. H.; Trachtenberg, J.; Jewett, M. A.; Sweet, J.; Toi, A.; Teahan, S.; Venkateswaran, V.; Sugar, L.; Loblaw, A.; Siminovitch, K.; Narod, S. A. (2006): Variants of the hK2 protein gene (KLK2) are associated with serum hK2 levels and predict the presence of prostate cancer at biopsy. Clin Cancer Res 12 (21), S. 6452-6458.

National Center for Biotechnology Information (2012a): PubChem Compound Database. CID=5757, http://pubchem.ncbi.nlm.nih.gov/summary/summary.cgi?cid=5757 (zuletzt geprüft am 20.12.2012).

National Center for Biotechnology Information (2012b): PubChem Compound Database. CID=5280961, http://pubchem.ncbi.nlm.nih.gov/summary/summary.cgi?cid=5280961 (zuletzt geprüft am 20.12.2012). 
National Center for Biotechnology Information (2012c): PubChem Compound Database. $\mathrm{CID}=5281811, \quad \mathrm{http}: / /$ pubchem.ncbi.nlm.nih.gov/summary/summary.cgi?cid=5281811 (zuletzt geprüft am 20.12.2012).

Nayak, S. B.; Bhat, V. R.; Upadhyay, D.; Udupa, S. L. (2003): Copper and ceruloplasmin status in serum of prostate and colon cancer patients. Indian J Physiol Pharmacol 47 (1), S. 108-110.

Neuhaus, E. M.; Zhang, W.; Gelis, L.; Deng, Y.; Noldus, J.; Hatt, H. (2009): Activation of an olfactory receptor inhibits proliferation of prostate cancer cells. J Biol Chem 284 (24), S. 16218-16225.

Onozawa, M.; Fukuda, K.; Ohtani, M.; Akaza, H.; Sugimura, T.; Wakabayashi, K. (1998): Effects of soybean isoflavones on cell growth and apoptosis of the human prostatic cancer cell line LNCaP. Jpn J Clin Oncol 28 (6), S. 360-363.

Overmeyer, J. H.; Kaul, A.; Johnson, E. E.; Maltese, W. A. (2008): Active ras triggers death in glioblastoma cells through hyperstimulation of macropinocytosis. Mol Cancer Res 6 (6), S. 965-977.

Ozawa, A.; Tanji, N.; Kikugawa, T.; Sasaki, T.; Yanagihara, Y.; Miura, N.; Yokoyama, M. (2010): Inhibition of bladder tumour growth by histone deacetylase inhibitor. BJU International 105 (8), S. 1181-1186.

Özten-Kandas, N.; Bosland, M. C. (2011): Chemoprevention of prostate cancer: Natural compounds, antiandrogens, and antioxidants - In vivo evidence. J Carcinog 10 (1), S. 27.

Padar, A.; Sathyanarayana, U. G.; Suzuki, M.; Maruyama, R.; Hsieh, J.-T.; Frenkel, E. P.; Minna, J. D.; Gazdar, A. F. (2003): Inactivation of Cyclin D2 Gene in Prostate Cancers by Aberrant Promoter Methylation. Clinical Cancer Research 9 (13), S. 4730-4734.

Pappa, C. A.; Tsirakis, G.; Kanellou, P.; Kaparou, M.; Stratinaki, M.; Xekalou, A.; Alegakis, A.; Boula, A.; Stathopoulos, E. N.; Alexandrakis, M. K. (2011): Monitoring serum levels ELR+ CXC chemokines and the relationship between microvessel density and angiogenic growth factors in multiple myeloma. Cytokine 56 (3), S. 616-620.

Perabo, F. G.; Löw, E. C.; Siener, R.; Ellinger, J.; Müller, S. C.; Bastian, P.J (2009): Eine kritische Bewertung der Phytotherapie des Prostatakarzinoms. Urologe 48 (3), S. 270283.

Peterson, G.; Barnes, S. (1993): Genistein and biochanin A inhibit the growth of human prostate cancer cells but not epidermal growth factor receptor tyrosine autophosphorylation. Prostate 22 (4), S. 335-345.

Phé, V.; Cussenot, O.; Rouprêt, M. (2010): Methylated genes as potential biomarkers in prostate cancer. BJU Int 105 (10), S. 1364-1370.

Phiel, C. J.; Zhang, F.; Huang, E.Y., Guenther, M. G.; Lazar, M. A.; Klein, P. S. (2001): Histone Deacetylase Is a Direct Target of Valproic Acid, a Potent Anticonvulsant, Mood Stabilizer, and Teratogen. Journal of Biological Chemistry 276 (39), S. 36734-36741.

Purrucker, J. C.; Fricke, A.; Ong, M. F.; Rübe, C.; Rübe, C. E.; Mahlknecht, U. (2010): HDAC inhibition radiosensitizes human normal tissue cells and reduces DNA DoubleStrand Break repair capacity. Oncol Rep 23 (1), S. 263-269.

Qi, X.-J; Wildey, G. M.; Howe, P. H. (2005): Evidence that Ser87 of BimEL is phosphorylated by Akt and regulates BimEL apoptotic function. Journal of Biological Chemistry 281 (2), S. 813-823.

Rae, J. M.; Johnson, M. D.; Cordero, K. E.; Scheys, J. O.; Larios, J. M.; Gottardis, M. M.; Pienta, K. J.; Lippman, M. E. (2006): GREB1 is a novel androgen-regulated gene required for prostate cancer growth. Prostate 66 (8), S. 886-894. 
Rakoff-Nahoum, S.; Medzhitov, R. (2009): Toll-like receptors and cancer. Nat Rev Cancer 9 (1), S. 57-63.

Rauhala, H. E.; Porkka, K. P.; Saramaki, O. R.; Tammela, T. L.; Visakorpi, T. (2008): Clusterin is epigenetically regulated in prostate cancer. Int J Cancer 123 (7), S. 16011609.

Regan, C. M. (1985): Therapeutic levels of sodium valproate inhibit mitotic indices in cells of neural origin. Brain Res 347 (2), S. 394-398.

Richter-Larrea, J. A.; Robles, E. F.; Fresquet, V.; Beltran, E.; Rullan, A. J.; Agirre, X.; Calasanz, M. J.; Panizo, C.; Richter, J. A.; Hernandez, J. M.; Roman-Gomez, J.; Prosper, F.; Martinez-Climent J. A. (2010): Reversion of epigenetically mediated BIM silencing overcomes chemoresistance in Burkitt lymphoma. Blood 116 (14), S. 25312542.

Rigau, M.; Morote, J.; Mir, M. C.; Ballesteros, C.; Ortega, I.; Sanchez, A., Colás, E.; Garcia, M.; Ruiz, A.; Abal, M.; Planas, J.; Reventós, J.; Doll, A. (2010): PSGR and PCA3 as biomarkers for the detection of prostate cancer in urine. Prostate 70 (16), S. 1760-1767.

Robert, E.; Guibaud, P. (1982): Maternal valproic acid and congenital neural tube defects. Lancet 2 (8304), S. 937.

Robert Koch-Institut (Hrsg.) (2007): Prostataerkrankungen. Berlin: Robert Koch-Institut (Gesundheitsberichterstattung des Bundes, Heft 36).

Robert Koch-Institut; Gesellschaft der epidemiologischen Krebsregister in Deutschland e.V. (Hrsg.) (2012): Krebs in Deutschland 2007/2008. 8. Auflage, Berlin: Robert Koch-Institut (Beiträge zur Gesundheitsberichterstattung des Bundes).

Rocca, A.; Minucci, S.; Tosti, G.; Croci, D.; Contegno, F.; Ballarini, M.; Nolè, F.; Munzone, E.; Salmaggi, A.; Goldhirsch, A.; Pelicci, P. G.; Testori, A. (2009): A phase I-II study of the histone deacetylase inhibitor valproic acid plus chemoimmunotherapy in patients with advanced melanoma. Br J Cancer 100 (1), S. 28-36.

Rohde, C.; Zhang, Y.; Reinhardt, R.; Jeltsch, A. (2010): BISMA - Fast and accurate bisulfite sequencing data analysis of individual clones from unique and repetitive sequences. BMC Bioinformatics 11 (1), S. 230.

Rosenbaum, E.; Hoque, M. O.; Cohen, Y.; Zahurak, M.; Eisenberger, M. A.; Epstein, J. I.; Partin, A. W.; Sidransky, D. (2005): Promoter Hypermethylation as an Independent Prognostic Factor for Relapse in Patients with Prostate Cancer Following Radical Prostatectomy. Clinical Cancer Research 11 (23), S. 8321-8325.

Sachdev, D.; Yee, D. (2007): Disrupting insulin-like growth factor signaling as a potential cancer therapy. Mol Cancer Ther 6 (1), S. 1-12.

Saiki, R. K.; Scharf, S.; Faloona, F.; Mullis, K. B.; Horn, G. T.; Erlich, H. A.; Arnheim, N. (1985): Enzymatic amplification of beta-globin genomic sequences and restriction site analysis for diagnosis of sickle cell anemia. Science 230 (4732), S. 1350-1354.

Sambrook, J.; Fritsch, E.F.; Maniatis, T. (1989): Molecular cloning: a laboratory manual. New York, USA, Cold Spring Habour.

Sami, S.; Hoti, N.; Xu, H.-M.; Shen, Z.; Huang, X. (2008): Valproic acid inhibits the growth of cervical cancer both in vitro and in vivo. J Biochem 144 (3), S. 357-362.

Sanger, F.; Coulson, A. R. (1975): A rapid method for determining sequences in DNA by primed synthesis with DNA polymerase. J Mol Biol 94 (3), S. 441-448.

Santibanez, J. F.; Navarro, A.; Martinez, J. (1997): Genistein inhibits proliferation and in vitro invasive potential of human prostatic cancer cell lines. Anticancer Res 17 (2A), S. 11991204. 
Sarkar, S.; Abujamra, A. L.; Loew, J. E.; Forman, L. W.; Perrine, S. P.; Faller, D. V. (2011): Histone Deacetylase Inhibitors Reverse CpG Methylation by Regulating DNMT1 through ERK Signaling. Anticancer Research 31 (9), S. 2723-2732.

Shabbeer, S.; Kortenhorst, M. S.; Kachhap, S.; Galloway, N.; Rodriguez, R.; Carducci, M. A. (2007): Multiple Molecular pathways explain the anti-proliferative effect of valproic acid on prostate cancer cells in vitro and in vivo. Prostate 67 (10), S. 1099-1110.

Sharma, S.; Symanowski, J.; Wong, B.; Dino, P.; Manno, P.; Vogelzang, N. (2008): A Phase II Clinical Trial of Oral Valproic Acid in Patients with Castration-Resistant Prostate Cancers Using an Intensive Biomarker Sampling Strategy. Transl Oncol 1 (3), S. 141147.

Sherr, C. J. (1996): Cancer Cell Cycles. Science 274 (5293), S. 1672-1677.

Sidana, A.; Wang, M.; Shabbeer, S.; Chowdhury, W. H.; Netto, G.; Lupold, S. E.; Carduccci, M.; Rodriguez, R. (2012): Mechanism of growth inhibition of prostate cancer xenografts by valproic acid. J Biomed Biotechnol 2012, S. 180363.

Singh, G.; Driever, P. H.; Sander, J. W. (2004): Cancer risk in people with epilepsy: the role of antiepileptic drugs. Brain 128 (1), S. 7-17.

Singh, G.; Bell, G. S.; Driever, P. H.; Sander, J. W. (2012): Cancer risk in people with epilepsy using valproate-sodium. Acta Neurologica Scandinavica 125 (4), S. 234-240.

Slusarz, A.; Jackson, G. A.; Day, J. K.; Shenouda, N. S.; Bogener, J. L.; Browning, J. D.; Fritsche, K. L.; MacDonald, R. S.; Besch-Williford, C. L.; Lubahn, D. B. (2012): Aggressive Prostate Cancer Is Prevented in ER KO Mice and Stimulated in ER KO TRAMP Mice. Endocrinology.

Stamey, T. A.; Yang, N.; Hay, A. R.; McNeal, J. E.; Freiha, F. S.; Redwine, E. (1987): Prostate-specific antigen as a serum marker for adenocarcinoma of the prostate. $N$ Engl J Med 317 (15), S. 909-916.

Stauber, R. H.; Knauer, S. K.; Habtemichael, N.; Bier, C.; Unruhe, B.; Weisheit, S.; Spange, S.; Nonnenmacher, F.; Fetz, V.; Ginter, T.; Reichardt, S.; Liebmann, C.; Schneider, G.; Krämer, O. H. (2012): A combination of a ribonucleotide reductase inhibitor and histone deacetylase inhibitors downregulates EGFR and triggers BIM-dependent apoptosis in head and neck cancer. Oncotarget 3 (1), S. 31-43.

Stettner, M.; Kaulfuß, S.; Burfeind, P.; Schweyer, S.; Strauss, A.; Ringert, R.-H; Thelen, P. (2007): The relevance of estrogen receptor-expression to the antiproliferative effects observed with histone deacetylase inhibitors and phytoestrogens in prostate cancer treatment. Molecular Cancer Therapeutics 6 (10), S. 2626-2633.

Stettner, M.; Kramer, G.; Strauss, A.; Kvitkina, T.; Ohle, S.; Kieseier, B. C.; Thelen, P. (2012): Long-term antiepileptic treatment with histone deacetylase inhibitors may reduce the risk of prostate cancer. Eur J Cancer Prev 21 (1), S. 55-64.

Strieter, R. M.; Polverini, P. J.; Kunkel, S.L.; Arenberg, D. A.; Burdick, M. D.; Kasper, J.; Dzuiba, J.; Van Damme, J.; Walz, A.; Marriott, D.; Chan, S.-Y; Roczniak, S.; Shanafelt, A. B (1995): The Functional Role of the ELR Motif in CXC Chemokine-mediated Angiogenesis. Journal of Biological Chemistry 270 (45), S. 27348-27357.

Takahashi-Yanaga, F.; Sasaguri, T. (2008): GSK-3 $\beta$ regulates cyclin D1 expression: A new target for chemotherapy. Cellular Signalling 20 (4), S. 581-589.

Takano, Y.; Kato, Y.; Diest, P. J. van; Masuda, M.; Mitomi, H.; Okayasu, I. (2000): Cyclin D2 overexpression and lack of p27 correlate positively and cyclin E inversely with a poor prognosis in gastric cancer cases. Am J Pathol 156 (2), S. 585-594.

Tani, Y.; Suttie, A.; Flake, G. P.; Nyska, A.; Maronpot, R. R. (2005): Epithelial-Stromal Tumor of the Seminal Vesicles in the Transgenic Adenocarcinoma Mouse Prostate Model. Veterinary Pathology 42 (3), S. 306-314. 
Thelen, P.; Seseke, F.; Ringert, R.-H.; Wuttke, W.; Seidlová-Wuttke, D. (2006): Pharmacological potential of phytoestrogens in the treatment of prostate cancer. Urologe A 45 (2), S. 195-6, 197-201.

Thelen, P.; Peter, T.; Hünermund, A.; Kaulfuß, S.; Seidlová-Wuttke, D.; Wuttke, W.; Ringert, R.-H.; Seseke, F. (2007): Phytoestrogens from Belamcanda chinensis regulate the expression of steroid receptors and related cofactors in LNCaP prostate cancer cells. BJU Int 100 (1), S. 199-203.

Thelen, P.; Scharf, J.-G.; Burfeind, P.; Hemmerlein, B.; Wuttke, W.; Spengler, B.; Christoffel, V.; Ringert, R.-H.; Seidlová-Wuttke, D. (2005): Tectorigenin and other phytochemicals extracted from leopard lily Belamcanda chinensis affect new and established targets for therapies in prostate cancer. Carcinogenesis 26 (8), S. 1360-1367.

Thelen, P.; Schweyer, S.; Hemmerlein, B.; Wuttke, W.; Seseke, F.; Ringert, R.-H. (2004): Expressional changes after histone deacetylase inhibition by valproic acid in LNCaP human prostate cancer cells. Int J Oncol 24 (1), S. 25-31.

Tiano, J. P.; Mauvais-Jarvis, F. (2012): Importance of oestrogen receptors to preserve functional $\beta$-cell mass in diabetes. Nat Rev Endocrinol.

Tominaga, S. (1985): Cancer incidence in Japanese in Japan, Hawaii, and western United States. Natl Cancer Inst Monogr 69, S. 83-92.

Tsavaler, L.; Shapero, M. H.; Morkowski, S.; Laus, R. (2001): Trp-p8, a novel prostatespecific gene, is up-regulated in prostate cancer and other malignancies and shares high homology with transient receptor potential calcium channel proteins. Cancer Res 61 (9), S. 3760-3769.

Tsujimoto, Y.; Shimizu, S. (2005): Another way to die: autophagic programmed cell death. Cell Death Differ 12 Suppl 2, S. 1528-1534.

Uhmann, A.; Niemann, H.; Lammering, B.; Henkel, C.; Hess, I.; Nitzki, F.; Fritsch, A.; Prüfer, N.; Rosenberger, A.; Dullin, C.; Schraepler, A.; Reifenberger, J.; Schweyer, S.; Pietsch, T.; Strutz, F.; Schulz-Schaeffer, W.; Hahn, H. (2011): Antitumoral effects of calcitriol in basal cell carcinomas involve inhibition of hedgehog signaling and induction of vitamin $D$ receptor signaling and differentiation. Mol Cancer Ther 10 (11), S. 2179-2188.

Ummanni, R.; Jost, E.; Braig, M.; Lohmann, F.; Mundt, F.; Barett, C.; Schlomm, T.; Sauter, G.; Senff, T.; Bokemeyer, C.; Sültmann, H.; Meyer-Schwesinger, C.; Brümmendorf, T. H.; Balabanov, S. (2011): Ubiquitin carboxyl-terminal hydrolase 1 (UCHL1) is a potential tumour suppressor in prostate cancer and is frequently silenced by promoter methylation. Mol Cancer 10 (1), S. 129.

Valentini, A.; Biancolella, M.; Amati, F.; Gravina, P.; Miano, R.; Chillemi, G.; Farcomeni, A.; Bueno, S.; Vespasiani, G.; Desideri, A.; Federici, G.; Novelli, G.; Bernardini, S. (2007): Valproic Acid Induces Neuroendocrine Differentiation and UGT2B7 Up-Regulation in Human Prostate Carcinoma Cell Line. Drug Metabolism and Disposition 35 (6), S. 968972.

Vallo, S.; Xi, W.; Hudak, L.; Juengel, E.; Tsaur, I.; Wiesner, C.; Haferkamp, A.; Blaheta, R. A. (2011): HDAC inhibition delays cell cycle progression of human bladder cancer cells in vitro. Anticancer Drugs 22 (10), S. 1002-1009.

Venkataramani, V.; Rossner, C.; Iffland, L.; Schweyer, S.; Tamboli, I. Y.; Walter, J.; Wirths, O.; Bayer, T. A. (2010): Histone Deacetylase Inhibitor Valproic Acid Inhibits Cancer Cell Proliferation via Down-regulation of the Alzheimer Amyloid Precursor Protein. Journal of Biological Chemistry 285 (14), S. 10678-10689.

Virmani, A.; Rathi, A.; Heda, S.; Sugio, K.; Lewis, C.; Tonk, V.; Takahashi, T.; Roth, J. A.; Minna, J. D.; Euhus, D. M.; Gazdar, A. F. (2003): Aberrant methylation of thecyclin D2 promoter in primary small cell, nonsmall cell lung and breast cancers. Int. J. Cancer 107 (3), S. 341-345. 
Vollmer, G.; Zierau, O. (2004): Was sind Phytoestrogene und Phyto-SERMs?: Pflanzeninhaltsstoffe mit Wirkung auf das Hormonsystem. Pharmazie in unserer Zeit 33 (5), S. 378-383.

Voorzanger-Rousselot, N.; Garnero, P. (2007): Biochemical markers in oncology. Part I: Molecular basis. Part II: Clinical uses. Cancer Treatment Reviews 33 (3), S. 230-283.

Wagner, J. M.; Bug, G.; Jung, M. (2010): Valproinsäure als Histon-Desacetylase-Hemmstoff. Neues Einsatzgebiet für einen altbekannten Arzneistoff. Pharmazie in unserer Zeit 39 (3), S. 197-203.

Waltering, K. K.; Helenius, M. A.; Sahu, B.; Manni, V.; Linja, M. J.; Janne, O. A.; Visakorpi, T. (2009): Increased Expression of Androgen Receptor Sensitizes Prostate Cancer Cells to Low Levels of Androgens. Cancer Research 69 (20), S. 8141-8149.

Wang, J.; Eltoum, I.-E.; Lamartiniere, C. A. (2004): Genistein alters growth factor signaling in transgenic prostate model (TRAMP). Mol Cell Endocrinol 219 (1-2), S. 171-180.

Wang, S.; Gao, J.; Lei, Q.; Rozengurt, N.; Pritchard, C.; Jiao, J.; Thomas, G. V.; Li, G.; RoyBurman, P.; Nelson, P. S.; Liu, X.; Wu, H. (2003): Prostate-specific deletion of the murine Pten tumor suppressor gene leads to metastatic prostate cancer. Cancer Cell 4 (3), S. 209-221.

Wedel, S.; Hudak, L.; Seibel, J.-M.; Juengel, E.; Oppermann, E.; Haferkamp, A.; Blaheta, R. A. (2011a): Critical analysis of simultaneous blockage of histone deacetylase and multiple receptor tyrosine kinase in the treatment of prostate cancer. Prostate 71 (7), S. 722-735.

Wedel, S.; Hudak, L.; Seibel, J.-M.; Juengel, E.; Tsaur, I.; Wiesner, C.; Haferkamp, A.; Blaheta, R. A. (2011b): Inhibitory effects of the HDAC inhibitor valproic acid on prostate cancer growth are enhanced by simultaneous application of the mTOR inhibitor RAD001. Life Sciences 88 (9-10), S. 418-424.

Wedel, S.; Hudak, L.; Seibel, J.-M.; Makarević, J.; Juengel, E.; Tsaur, I.; Wiesner, C.; Haferkamp, A.; Blaheta, R. A. (2011c): Impact of combined HDAC and mTOR inhibition on adhesion, migration and invasion of prostate cancer cells. Clin Exp Metastasis 28 (5), S. 479-491.

Wedel, S.; Hudak, L.; Seibel, J.-M.; Makarević, J.; Juengel, E.; Tsaur, I.; Waaga-Gasser, A.; Haferkamp, A.; Blaheta, R. A. (2011d): Molecular targeting of prostate cancer cells by a triple drug combination down-regulates integrin driven adhesion processes, delays cell cycle progression and interferes with the cdk-cyclin axis. BMC Cancer 11 (1), S. 375.

Weller, M.; Gorlia, T.; Cairncross, J. G.; van den Bent, M. J.; Mason, W.; Belanger, K.; Brandes, A. A.; Bogdahn, U.; Macdonald, D. R.; Forsyth, P.; Rossetti, A. O.; Lacombe, D.; Mirimanoff, R. O.; Vecht, C. J.; Strupp, R. (2011): Prolonged survival with valproic acid use in the EORTC/NCIC temozolomide trial for glioblastoma. Neurology 77 (12), S. 1156-1164.

Weng, J.; Wang, J.; Hu, X.; Wang, F.; Ittmann, M.; Liu, M. (2006): PSGR2, a novel G-protein coupled receptor, is overexpressed in human prostate cancer. Int J Cancer 118 (6), S. 1471-1480.

Wen, W.; Ding, J.; Sun, W.; Wu, K.; Ning, B.; Gong, W.; He, G.; Huang, S., Ding, X.; Yin, P.; Chen, L.; Liu, Q.; Xie, W.; Wang, H. (2010): Suppression of Cyclin D1 by HypoxiaInducible Factor-1 via Direct Mechanism Inhibits the Proliferation and 5-FluorouracilInduced Apoptosis of A549 Cells. Cancer Research 70 (5), S. 2010-2019.

Whittemore, A. S.; Wu, A. H.; Kolonel, L. N.; John, E. M.; Gallagher, R. P.; Howe, G. R.; West, D. W.; The, C. Z.; Stamey, T. (1995): Family History and Prostate Cancer Risk in Black, White, and Asian Men in the United States and Canada. American Journal of Epidemiology 141 (8), S. 732-740. 
Wianny, F.; Real, F. X.; Mummery, C. L.; van Rooijen, M.; Lahti, J.; Samarut, J.; Savatier, P. (1998): G1-phase regulators, cyclin D1, cyclin D2, and cyclin D3: up-regulation at gastrulation and dynamic expression during neurulation. Dev Dyn 212 (1), S. 49-62.

Witt, D. (2009): Der Einfluss des Phytoöstrogens Tectorigenin und des HistondeacetylaseInhibitors Valproinsäure auf Wachstumsfaktor regulierte Signalwege im Prostatakarzinom. Diplomarbeit. Universität Göttingen, Göttingen. Institut für Humangenetik.

Witt, D.; Burfeind, P.; Hardenberg, S. von; Opitz, L.; Salinas-Riester, G.; Bremmer, F.; Schweyer, S.; Thelen, P.; Neesen, J.; Kaulfuß, S. (2013): Valproic acid inhibits the proliferation of cancer cells by reexpressing cyclin D2. Carcinogenesis 34 (5), S. 11151124.

Wlodarczyk, B. J.; Palacios, A. M.; George, T. M.; Finnell, R. H. (2012): Antiepileptic drugs and pregnancy outcomes. Am. J. Med. Genet. 158 (8), S. 2071-2090.

Xia, Q.; Sung, J.; Chowdhury, W.; Chen, C.-I.; Höti, N.; Shabbeer, S.; Carducci, M.; Rodriguez, R. (2006): Chronic Administration of Valproic Acid Inhibits Prostate Cancer Cell Growth In vitro and In vivo. Cancer Research 66 (14), S. 7237-7244.

Yamaguchi, H.; Chen, C-T; Chou, C-K; Pal, A.; Bornmann, W.; Hortobagyi, G. N.; Hung, MC (2010): Adenovirus 5 E1A enhances histone deacetylase inhibitors-induced apoptosis through Egr-1-mediated Bim upregulation. Oncogene 29 (41), S. 5619-5629.

Yang, Y.; Zhao, Y.; Liao, W.; Yang, J.; Wu, L.; Zheng, Z.; Yu, Y.; Zhou, W.; Li, L.; Feng, J.; Wang, H.; Zhu, W. G. (2009): Acetylation of FoxO1 activates Bim expression to induce apoptosis in response to histone deacetylase inhibitor depsipeptide treatment. Neoplasia 11 (4), S. 313-324.

Yeh, I.-T.; Reddick, R. L.; Kumar, A. P. (2009): Malignancy arising in seminal vesicles in the transgenic adenocarcinoma of mouse prostate (TRAMP) model. Prostate 69 (7), S. 755-760.

Yu, J.; Leung, W. K.; Ebert, M. P. A.; Leong, R. W.; Tse, P. C.; Chan, M. W., Bai, A. H.; To, K. F., Malfertheiner, P.; Sung, J. J. (2003): Absence of cyclin D2 expression is associated with promoter hypermethylation in gastric cancer. $\mathrm{Br} J$ Cancer 88 (10), S. 1560-1565.

Zhang, L.; Wang, G.; Wang, L.; Song, C.; Wang, X.; Kang, J. (2011): Valproic acid inhibits prostate cancer cell migration by up-regulating E-cadherin expression. Pharmazie 66 (8), S. 614-618.

Zhang, S.; Yu, D. (2010): PI(3)King Apart PTEN's Role in Cancer. Clinical Cancer Research 16 (17), S. 4325-4330.

Zhao, Y.; Tan, J.; Zhuang, L.; Xia, J.; Liu, E. T.; Yu, Q. (2005): Inhibitors of histone deacetylases target the Rb-E2F1 pathway for apoptosis induction through activation of proapoptotic protein Bim. Proceedings of the National Academy of Sciences 102 (44), S. 16090-16095.

Zhou, J. R.; Gugger, E. T.; Tanaka, T.; Guo, Y.; Blackburn, G. L.; Clinton, S. K. (1999): Soybean phytochemicals inhibit the growth of transplantable human prostate carcinoma and tumor angiogenesis in mice. J Nutr 129 (9), S. 1628-1635.

Zhou, J.; Xie, G.; Yan, X. (2011): Encyclopedia of Traditional Chinese Medicines. Molecular Structures, Pharmacological Activities, Natural Sources and Applications. Vol. 5, Isolated Compounds T-Z, References, TCM Plants and Congeners. Berlin und Heidelberg: Springer.

Zhu, G.; Wang, X.; Yang, Z.; Cao, H.; Meng, Z.; Wang, Y.; Chen, D. (2011): Effects of TRPM8 on the proliferation and angiogenesis of prostate cancer PC-3 cells in vivo. Oncol Lett 2 (6), S. 1213-1217. 


\section{Anhang}

Tabelle 7.1: Gene Ontology (GO) enrichment Analyse der im Microarray als verstärkt exprimierten Gene nach Behandlung der PCa-Zellen LNCaP mit Tectorigenin.

Es wurde eine Analyse anhand der biologischen Prozesse, des zellulären Kompartiments sowie der molekularen

Funktion durchgeführt.

\begin{tabular}{|c|c|c|}
\hline \multicolumn{3}{|c|}{ Biologischer Prozess } \\
\hline GO Nummer & GO Bezeichnung & p-Wert \\
\hline GO:0050890 & cognition & $1.64063605839435 \mathrm{e}-05$ \\
\hline GO:0060395 & SMAD protein signal transduction & $2.33690049546289 \mathrm{e}-05$ \\
\hline GO:0071277 & cellular response to calcium ion & $5.83330198327541 \mathrm{e}-05$ \\
\hline GO:0009314 & response to radiation & $8.30718586469924 \mathrm{e}-05$ \\
\hline GO:0035666 & TRIF-dependent toll-like receptor signaling pathway & 0.000297863507681979 \\
\hline GO:0034130 & toll-like receptor 1 signaling pathway & 0.000308642190460564 \\
\hline GO:0034138 & toll-like receptor 3 signaling pathway & 0.00031961053081722 \\
\hline GO:0034134 & toll-like receptor 2 signaling pathway & 0.00034211579012287 \\
\hline GO:0007612 & learning & 0.000377293648030536 \\
\hline GO:0008063 & Toll signaling pathway & 0.000377293648030536 \\
\hline GO:0002755 & MyD88-dependent toll-like receptor signaling pathway & 0.000389397865177872 \\
\hline GO:0007610 & behavior & 0.00039278554575272 \\
\hline GO:0051591 & response to cAMP & 0.000401691050521946 \\
\hline GO:0045087 & innate immune response & 0.000432186165179228 \\
\hline GO:0034142 & toll-like receptor 4 signaling pathway & 0.00043970343176193 \\
\hline GO:0035026 & leading edge cell differentiation & 0.000510139012880995 \\
\hline GO:0072303 & $\begin{array}{l}\text { positive regulation of glomerular metanephric mesangial } \\
\text { cell proliferation }\end{array}$ & 0.000510139012880995 \\
\hline GO:0034097 & response to cytokine stimulus & 0.000541852678004004 \\
\hline GO:0071241 & cellular response to inorganic substance & 0.000671034762487342 \\
\hline GO:0045944 & $\begin{array}{l}\text { positive regulation of transcription from RNA polymerase II } \\
\text { promoter }\end{array}$ & 0.000705114491859759 \\
\hline GO:0007179 & $\begin{array}{l}\text { transforming growth factor beta receptor signaling } \\
\text { pathway }\end{array}$ & 0.00083995285232544 \\
\hline GO:0000302 & response to reactive oxygen species & 0.000857869410096453 \\
\hline GO:0002221 & pattern recognition receptor signaling pathway & 0.000875971894317519 \\
\hline GO:0002218 & activation of innate immune response & 0.000931393927617727 \\
\hline GO:0009612 & response to mechanical stimulus & 0.000931393927617727 \\
\hline \multicolumn{3}{|c|}{ Zelluläres Kompartiment } \\
\hline \multicolumn{3}{|c|}{ keine signifikanten Ergebnisse } \\
\hline \multicolumn{3}{|c|}{ Molekulare Funktion } \\
\hline GO Nummer & GO Bezeichnung & p-Wert \\
\hline GO:0003690 & double-stranded DNA binding & $2.34802802421708 \mathrm{e}-05$ \\
\hline GO:0070412 & R-SMAD binding & $3.95742378310645 \mathrm{e}-05$ \\
\hline GO:0044212 & transcription regulatory region DNA binding & 0.000226165218328636 \\
\hline GO:0001067 & regulatory region nucleic acid binding & 0.000250993940738668 \\
\hline
\end{tabular}


Tabelle 7.2: Gene Ontology (GO) enrichment Analyse der im Microarray als vermindert exprimierten Gene nach Behandlung der PCa-Zellen LNCaP mit Tectorigenin.

Es wurde eine Analyse anhand der biologischen Prozesse durchgeführt.

\begin{tabular}{|c|c|c|}
\hline \multicolumn{3}{|c|}{ biologischer Prozess } \\
\hline GO Nummer & GO Bezeichnung & p-Wert \\
\hline GO:0006260 & DNA replication & $1.64021203391333 \mathrm{e}-19$ \\
\hline GO:0006270 & DNA-dependent DNA replication initiation & $2.36967312145837 \mathrm{e}-19$ \\
\hline GO:0006271 & DNA strand elongation involved in DNA replication & $7.27340846428044 \mathrm{e}-18$ \\
\hline GO:0000084 & S phase of mitotic cell cycle & $1.50365871623451 \mathrm{e}-16$ \\
\hline GO:0051325 & interphase & $5.19602084956104 \mathrm{e}-16$ \\
\hline GO:0000278 & mitotic cell cycle & $6.69159357616397 \mathrm{e}-15$ \\
\hline GO:0000216 & M/G1 transition of mitotic cell cycle & $2.2708795271699 \mathrm{e}-14$ \\
\hline GO:0006310 & DNA recombination & $7.81689007127673 \mathrm{e}-12$ \\
\hline GO:0000075 & cell cycle checkpoint & $4.37249580402748 \mathrm{e}-08$ \\
\hline GO:0000722 & telomere maintenance via recombination & $4.82740841377779 \mathrm{e}-08$ \\
\hline GO:0032201 & telomere maintenance via semi-conservative replication & $4.82740841377779 \mathrm{e}-08$ \\
\hline GO:0000279 & M phase & $4.99193331045168 \mathrm{e}-08$ \\
\hline GO:0022402 & cell cycle process & $6.38623239123644 \mathrm{e}-08$ \\
\hline GO:0000082 & G1/S transition of mitotic cell cycle & $1.16515203392848 \mathrm{e}-07$ \\
\hline GO:0000724 & double-strand break repair via homologous recombination & $3.7291728239639 \mathrm{e}-07$ \\
\hline GO:0006269 & DNA replication, synthesis of RNA primer & $6.81565913688683 e-07$ \\
\hline GO:0000083 & $\begin{array}{l}\text { regulation of transcription involved in G1/S phase of } \\
\text { mitotic cell cycle }\end{array}$ & $6.85577691864259 \mathrm{e}-07$ \\
\hline GO:0007126 & meiosis & $8.93901365563715 \mathrm{e}-07$ \\
\hline GO:0051321 & meiotic cell cycle & $1.16091746237169 \mathrm{e}-06$ \\
\hline GO:0032200 & telomere organization & $3.27706547809896 \mathrm{e}-06$ \\
\hline GO:0051298 & centrosome duplication & $7.38319671620087 \mathrm{e}-06$ \\
\hline GO:0006281 & DNA repair & $8.67952241054388 \mathrm{e}-06$ \\
\hline GO:0006268 & DNA unwinding involved in replication & $1.33709063616724 \mathrm{e}-05$ \\
\hline GO:0045786 & negative regulation of cell cycle & $2.481250757266 \mathrm{e}-05$ \\
\hline GO:0031023 & microtubule organizing center organization & $2.86558088178116 \mathrm{e}-05$ \\
\hline GO:0000086 & G2/M transition of mitotic cell cycle & $5.73928077732067 \mathrm{e}-05$ \\
\hline GO:0046605 & regulation of centrosome cycle & $7.81908086043906 \mathrm{e}-05$ \\
\hline GO:2000615 & regulation of histone $\mathrm{H} 3-\mathrm{K} 9$ acetylation & $7.85705176089055 \mathrm{e}-05$ \\
\hline GO:0010564 & regulation of cell cycle process & $8.39116172282649 \mathrm{e}-05$ \\
\hline GO:0051052 & regulation of DNA metabolic process & 0.00016994214764078 \\
\hline GO:0060249 & anatomical structure homeostasis & 0.000213672701914291 \\
\hline GO:0010948 & negative regulation of cell cycle process & 0.000214040545883527 \\
\hline GO:0071103 & DNA conformation change & 0.00042049363463748 \\
\hline GO:0045143 & homologous chromosome segregation & 0.00046598805662265 \\
\hline GO:0032465 & regulation of cytokinesis & 0.000505122592331418 \\
\hline GO:0007067 & mitosis & 0.000559248656708588 \\
\hline GO:0007059 & chromosome segregation & 0.000663068402331694 \\
\hline GO:0048285 & organelle fission & 0.000757972799949165 \\
\hline GO:0046599 & regulation of centriole replication & 0.00077216105294905 \\
\hline GO:0090304 & nucleic acid metabolic process & 0.000805068684230789 \\
\hline GO:0007017 & microtubule-based process & 0.000902285917893461 \\
\hline
\end{tabular}


Tabelle 7.3: Gene Ontology (GO) enrichment Analyse der im Microarray als vermindert exprimierten Gene nach Behandlung der PCa-Zellen LNCaP mit Tectorigenin.

Es wurde eine Analyse anhand der zellulären Kompartimente durchgeführt.

\begin{tabular}{|l|l|l|}
\hline \multicolumn{2}{|l|}{ Zelluläres Kompartiment } & \\
\hline GO Nummer & GO Bezeichnung & p-Wert \\
\hline GO:0005658 & alpha DNA polymerase:primase complex & $5.32675291515529 \mathrm{e}-11$ \\
\hline GO:0000228 & nuclear chromosome & $9.17377740622162 \mathrm{e}-10$ \\
\hline GO:0042555 & MCM complex & $1.10291341887727 \mathrm{e}-09$ \\
\hline GO:0030894 & replisome & $4.01514799612527 \mathrm{e}-08$ \\
\hline GO:0005654 & nucleoplasm & $1.11723206931032 \mathrm{e}-07$ \\
\hline GO:0043596 & nuclear replication fork & $3.02822849882976 \mathrm{e}-07$ \\
\hline GO:0044427 & chromosomal part & $2.0298929523297 \mathrm{e}-06$ \\
\hline GO:0070013 & intracellular organelle lumen & $7.80656627431246 \mathrm{e}-06$ \\
\hline GO:0031974 & membrane-enclosed lumen & $1.91773316126566 \mathrm{e}-05$ \\
\hline GO:0043232 & intracellular non-membrane-bounded organelle & $4.51784309637028 \mathrm{e}-05$ \\
\hline GO:0005634 & nucleus & 0.000167403698000635 \\
\hline GO:0000793 & condensed chromosome & 0.000274094801450863 \\
\hline
\end{tabular}

Tabelle 7.4: Gene Ontology (GO) enrichment Analyse der im Microarray als vermindert exprimierten Gene nach Behandlung der PCa-Zellen LNCaP mit Tectorigenin.

Es wurde eine Analyse anhand der molekularen Funktionen durchgeführt.

\begin{tabular}{|l|l|l|}
\hline \multicolumn{2}{|l|}{ Molekulare Funktion } \\
\hline GO Nummer & GO Bezeichnung & p-Wert \\
\hline GO:0003896 & DNA primase activity & $7.30196057130055 \mathrm{e}-07$ \\
\hline GO:0004386 & helicase activity & $1.72648034979492 \mathrm{e}-05$ \\
\hline GO:0003824 & catalytic activity & $1.86328168822184 \mathrm{e}-05$ \\
\hline GO:0003697 & single-stranded DNA binding & $5.64716117795473 \mathrm{e}-05$ \\
\hline GO:0004003 & ATP-dependent DNA helicase activity & $9.56634946165955 \mathrm{e}-05$ \\
\hline GO:0016462 & pyrophosphatase activity & 0.000135432913765515 \\
\hline GO:0016817 & hydrolase activity, acting on acid anhydrides & 0.000147391421830604 \\
\hline GO:0003677 & DNA binding & 0.000289547309815331 \\
\hline GO:0003887 & DNA-directed DNA polymerase activity & 0.000307043604384306 \\
\hline GO:0016779 & nucleotidyltransferase activity & 0.000367615138433373 \\
\hline GO:0048256 & flap endonuclease activity & 0.000487663144247844 \\
\hline GO:0005524 & ATP binding & 0.000679108138550555 \\
\hline GO:0030554 & adenyl nucleotide binding & 0.000912079955455705 \\
\hline
\end{tabular}

